DEGRADATION OF THE VETERINARY

ANTIBIOTICS IN SWINE MANURE VIA

ANAEROBIC DIGESTION

A Dissertation

presented to

the Faculty of the Graduate School

at the University of Missouri-Columbia

In Partial Fulfillment

of the Requirements for the Degree

Doctor of Philosophy

by

Ali Hosseini Taleghani

Dr. Teng-Teeh Lim, Dissertation Supervisor

MAY 2021 
The undersigned, appointed by the dean of the Graduate School, have examined the dissertation entitled:

\section{DEGRADATION OF THE VETERINARY}

ANTIBIOTICS IN SWINE MANURE VIA

\section{ANAEROBIC DIGESTION}

presented by Ali Hosseini Taleghani,

a candidate for the degree of Doctor of Philosophy,

and hereby certify that, in their opinion, it is worthy of acceptance.

Dr. Teng-Teeh Lim

Dr. Chung-Ho Lin

Dr. Caixia Wan

Dr. David Brune 


\section{DEDICATION}

I dedicate this dissertation to my family and friends. A special feeling of gratitude to my loving parents, Aliakbar Hosseini Taleghani and Mehri Kianifar, whose words of encouragement and motivation for persistence ring in my ears.

My lovely sisters Dr. Nazila, Dr. Azadeh and brother Dr. Navid who have never left my side and are very special. Also, my brothers in-laws, Dr. Hamidreza Zarepour, Dr. Hamidreza Soleimanimehr and my sister in-law, Dr. Elahe Zabihi for their support and guidance. Wish the best for my awesome nieces and nephews, Anahita, Atrina, Selena and Ario.

And my dearest uncle, Dr. Mohsen Kianifar who is my role model of knowledge, humility, respect and showing me the true meaning of life, to be dedicated and nice to all people. He was the one who made me confident to pursue my Ph.D.

I also dedicate this dissertation to my many friends who have supported me throughout the process. I will always appreciate all they have done, especially Drs. Rouzbeh, Masoud, Sahab and Parvaneh for supporting me mentally all these years.

Finally, I would like to dedicate this work to all the people in this world who may benefit from the results of these projects. I really hope that my endeavor will result in less pain, disease and mortality and more happiness for this world. 


\section{ACKNOWLEDGEMENTS}

When I started my Ph.D. journey in 2016, I would have never imagined that not being able to see my parents and family, missing weddings, birthdays, and losing loved ones can be this challenging. As Coelho said, "Tell your heart that the fear of suffering is worse than the suffering itself", I just decided to be strong and keep on moving forward. You do not know how strong you are, until being strong is your only option. Throughout my hardest times, I have always trusted in God, "And will provide for him from where he never expected. Whoever relies on God-He will suffice him. God will accomplish His purpose. He has set a measure to all things."

Being a Ph.D. student in the United States and the University of Missouri was a wonderful opportunity for me. I have learned so much about kindness, generosity, and patience from the people living in Missouri. People surrounding me were so welcoming and amiable that I felt at home all these years, and I will never forget that.

I would like to express my sincere gratitude to my advisor, Dr. Teng Teeh Lim who trusted in my abilities and passion. He was a complete source of support, encouragement, and kindness that helped me persevere in my toughest moments. He was always giving me a positive vibe and with his generosity he neglected my shortcomings. I have learned so many precious skills, to be hardworking and dedicated, more organized and not being afraid of challenges. He supported me financially as well and I am so grateful for that. 
I am deeply indebted to my co-advisor, Dr. Chung-Ho Lin, for generously teaching and training me, giving me the chance to work in his lab. He was always willing to share his valuable experience, knowledge, and ideas to improve the quality of the research. Without his unwavering guidance and his laboratory support, and his team members including Phuc $\mathrm{H}$. Vo, Shu Yu Hsu, and Vu Danh, this achievement would not be possible.

I would like to express my deepest appreciation to my committee members who have guided me throughout my research all these years. Thank you so much, Dr. Caixia Wan and Dr. David Brune for being my committee members. Dr. Wan guided and taught me a lot during her class- Bioprocess Engineering, and answered willingly all my questions. I am so grateful to have Dr. Brune on my committee, his feedbacks and comments have helped me promote our research, giving me insights and support.

My office co-workers were among the best friends I have had and supported me a lot. Thanks so much, Joshua Brown, Haipeng Wang, Cuong Duong, Tim Canter, Meghan O’Brien, Liyuan Hou, and Gabriel Abdulai.

Besides, I had an amazing opportunity to work on a real farm to carry out an interesting project. I am so pleased to meet the farm manager, Mel Gerber and his family, Mary and Wally which became like my family here. We have lots of great memories and thanks again for welcoming us to your farm and provided us this substantial opportunity. I am also so lucky to be working on a joint project with the NCSU university team, Dr. John Classen and Alison Deviney, and the Waste 2 Green, LLC team, Dan, Jason, and Sheldon. 
I would like to acknowledge the contribution of Dr. Ericsson and his laboratory at the University of Missouri Metagenomics Center, which has helped me perform and complete the sequencing part of my research. 


\section{TABLE OF CONTENTS}

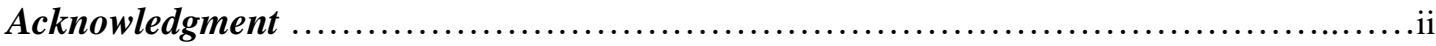

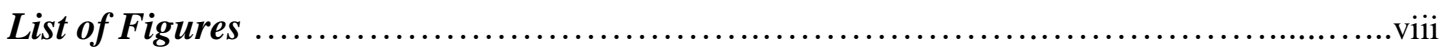

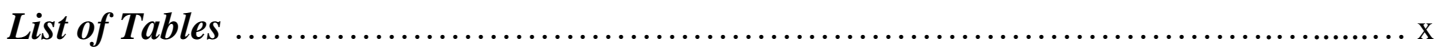

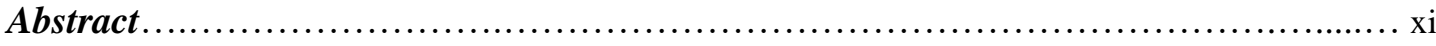

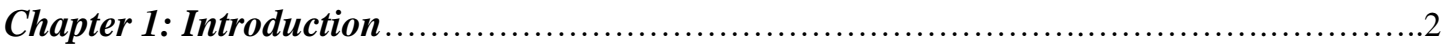

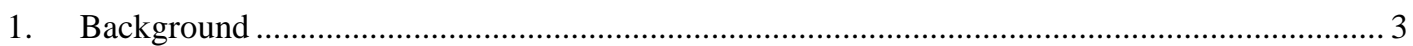

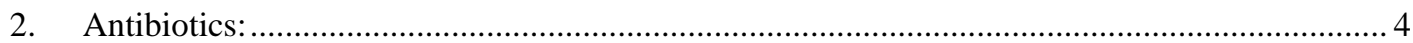

Chapter 2: Degradation of Veterinary Antibiotics in Swine Manure via Anaerobic

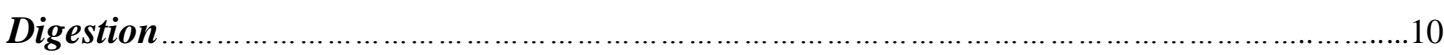

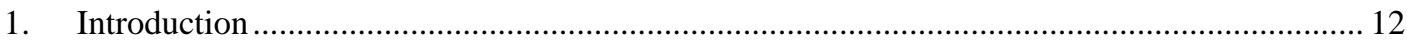

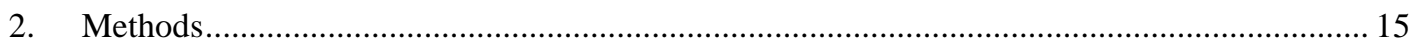

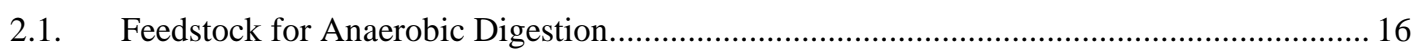

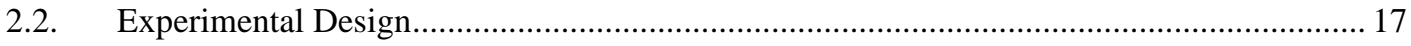

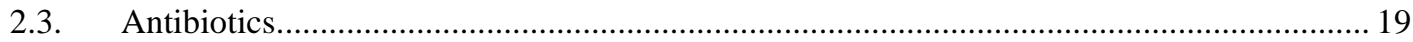

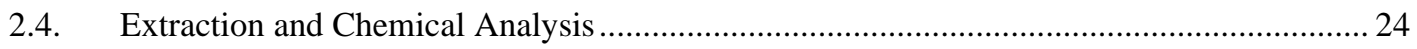

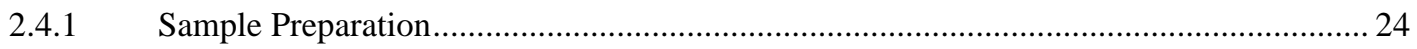

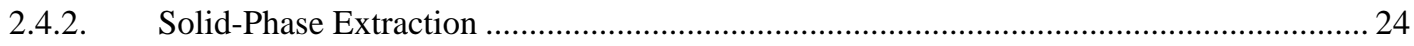

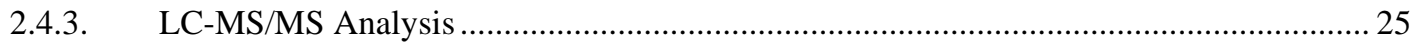

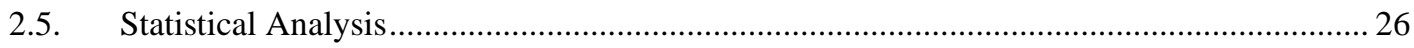

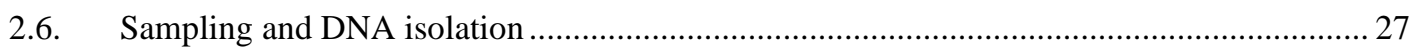

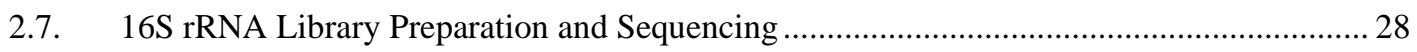

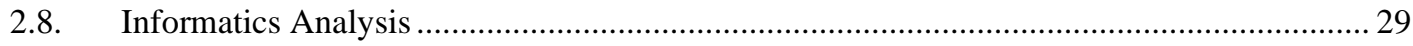

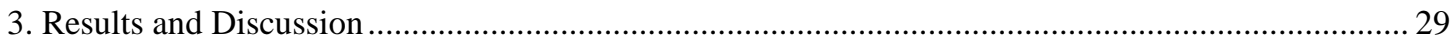

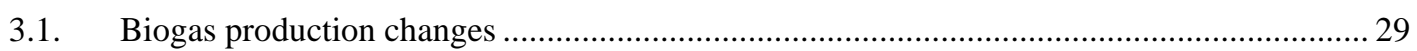

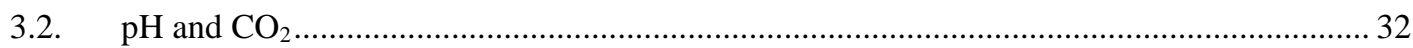

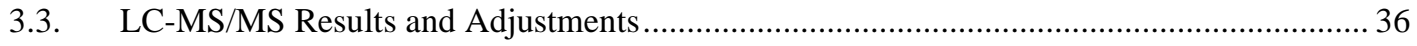

3.3.1. Relatively High Recovery of Enrofloxacin in the Water-only Samples.................................... 39

3.3.2. Very High Recovery of Tylosin in the Water-only Samples.................................................. 40

3.3.3. Consistent and Proportional LC-MS/MS Tylosin Results in the Digestate Samples................ 40

3.3.4. Consistent LC-MS/MS Tylosin Measurements in the Manure External Standards.................. 41 
3.3.5. Relatively Higher Recovery of CTC in the External Standard Samples, and Two Additional CTC Standards

3.3.6. Applying External Standard Correction Factors ......................................................... 43

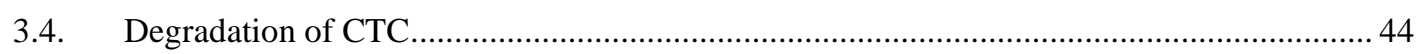

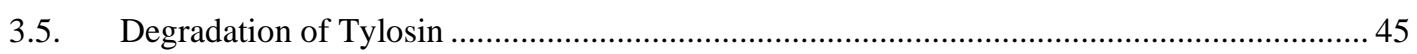

3.6. Effects of Having Two Types of VA in the Digestion and Water .................................... 46

3.7. Contrast Tylosin Reduction in Water and AD Reactors ............................................. 47

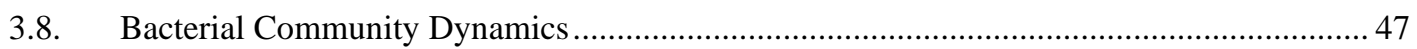

3.9. Statistical Analysis of the Effect of Different Treatments on Samples ...............................5 52

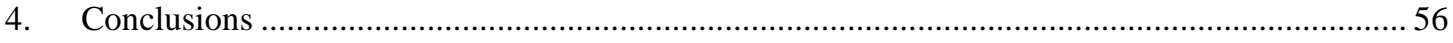

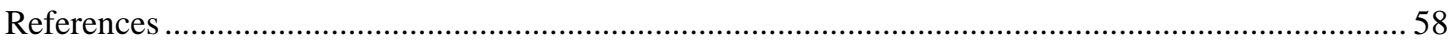

Chapter 3: Degradation of Sulfamethazine in Swine Manure via Anaerobic Digestion .......67

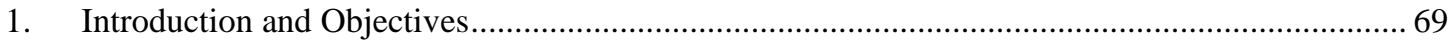

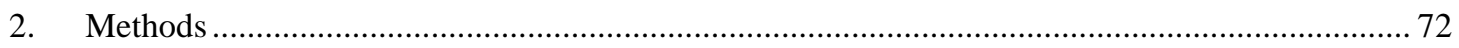

2.1. Feedstock for Anaerobic Digestion............................................................................ 73

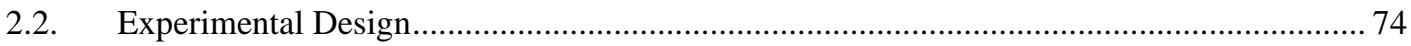

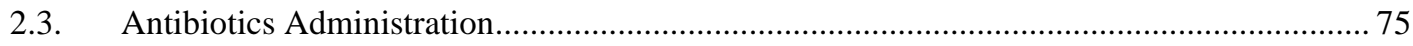

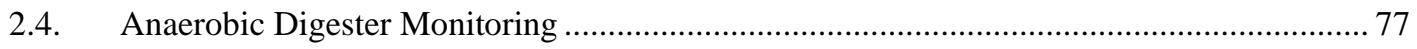

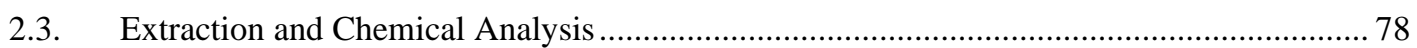

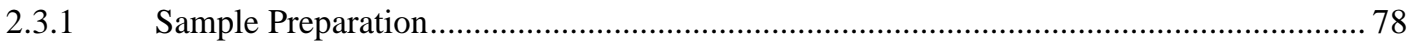

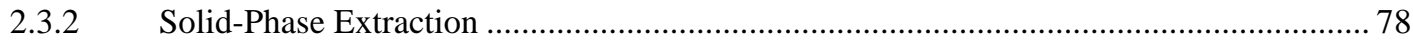

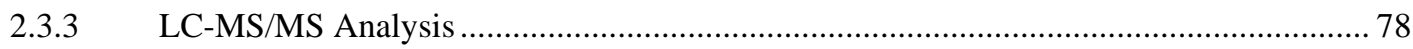

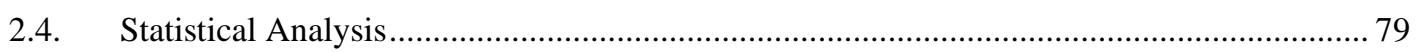

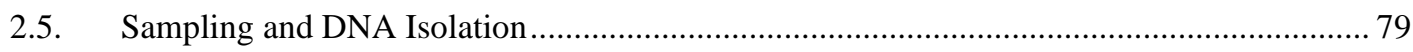

2.6. 16S rRNA Library Preparation and Sequencing ....................................................... 80

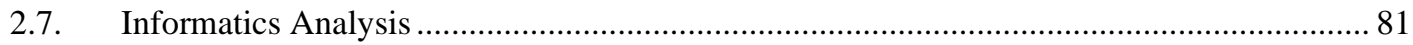

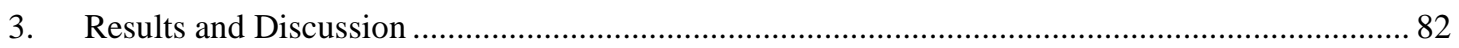

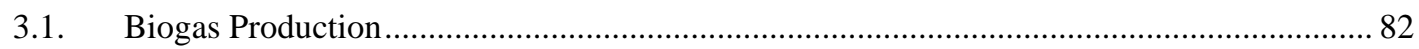

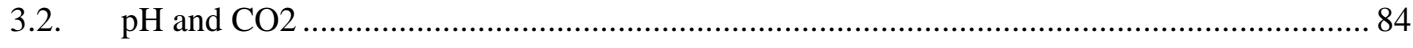

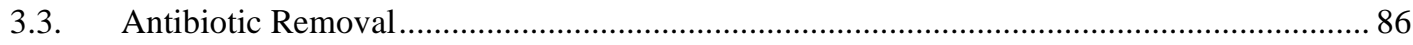

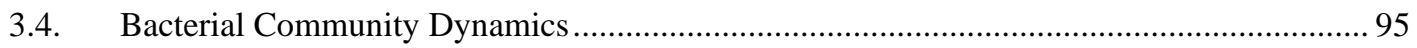

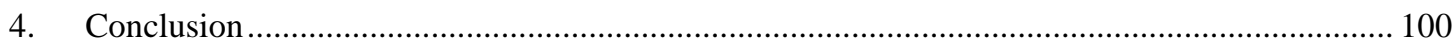

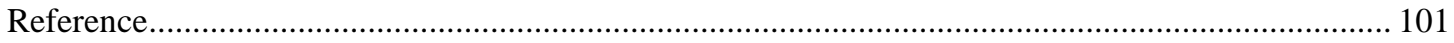


Appendix I: A Field Test of Acidifying Separated Liquid Manure, Set-up, Troubleshooting,

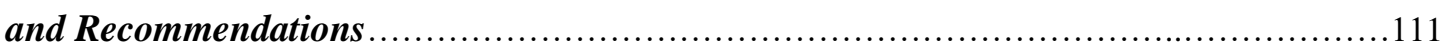

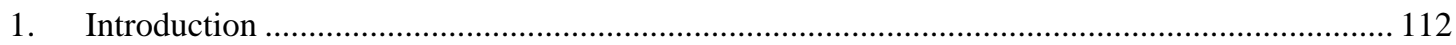

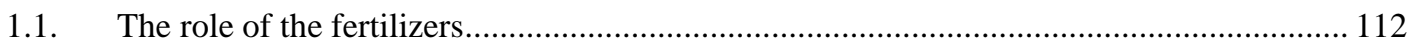

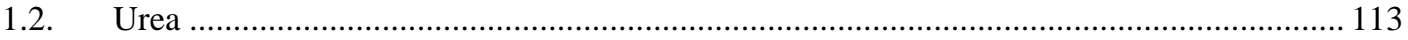

1.3. Ammonia volatilization and its adverse effect................................................................. 114

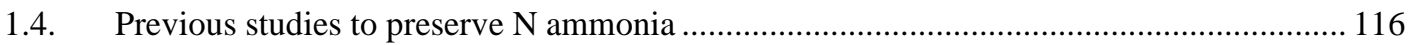

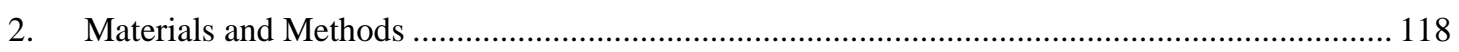

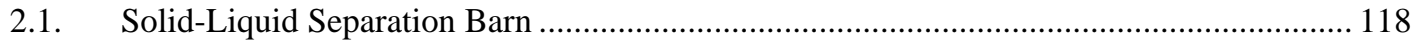

2.2. Equipment installation and initial modifications: ........................................................... 120

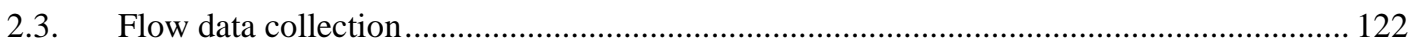

2.4. Acid and base addition set-up and laboratory tests ............................................................ 123

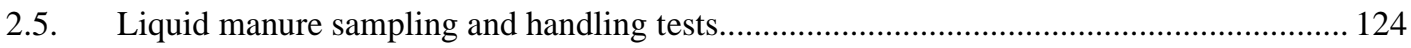

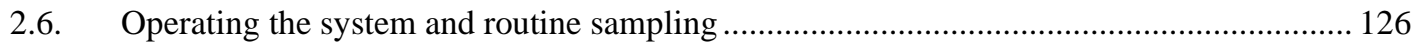

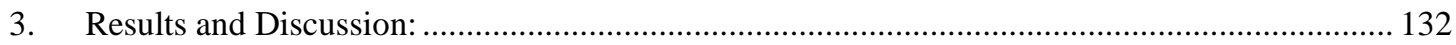

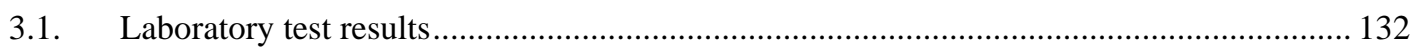

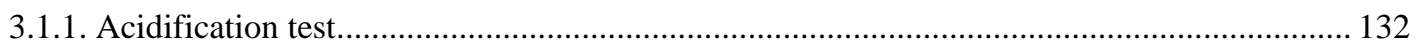

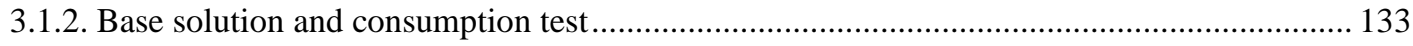

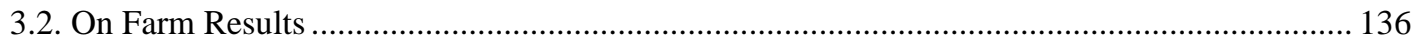

3.2.1. Acidification improvement, foaming, and pump malfunction ............................................... 137

3.2.2. Reservoir and pipes dimension to prevent debris collection and clogging ........................... 140

3.2.3. Autosampler and Doppler flowmeter issues ........................................................................... 143

3.2.4. Additional flexible solid discharge line and final pilot system setup .................................... 144

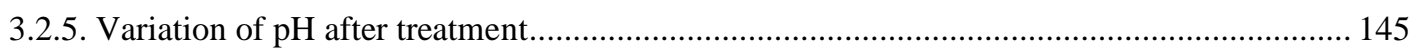

3.3. Comparisons of estimated liquid manure production and acid consumption ............................ 146

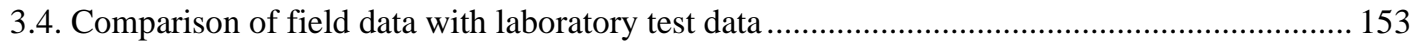

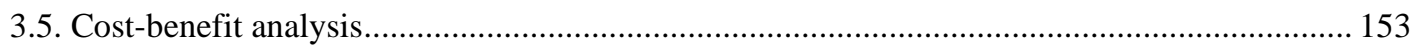

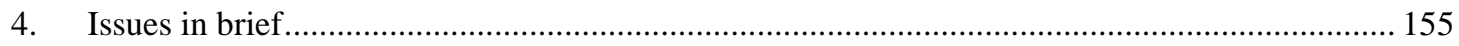

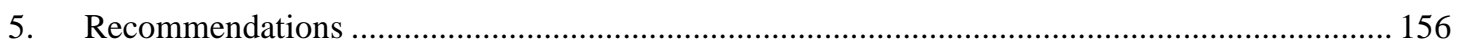

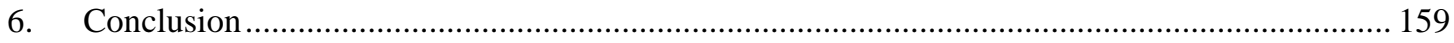

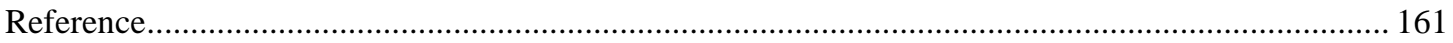

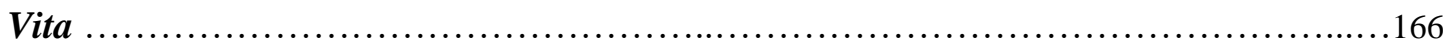




\section{LIST OF FIGURES}

Figure 1. The scheme of the reactors, tubes transferring biogas and the incubator.

Table 5. The ionization mode, retention times, and optimized precursor/product ions for analysis of the VAs by the developed LC-MS/MS method.

Figure 2. Biogas production in 2017-2018, a. \#1 low, \#2 medium, and \#3 high concentration, before and after adding CTC, $\boldsymbol{b}$. \#4 low, \#5 medium and \#6 high concentration, before and after adding both CTC and tylosin, and c. \#7 w, \#8 medium, and \#9 high concentration, before and after adding tylosin and the dotted box shows the administration period of the VAs.

Figure 3. Digestate $\mathrm{pH}$ levels for $\boldsymbol{a}$. before and after CTC spike, $\boldsymbol{b}$. before and after CTC plus tylosin spike, and c. before and after tylosin spike and the dotted box shows the administration period of the VAs......

Figure 4. The concentrations of $\mathrm{CO}_{2} \boldsymbol{a}$. before and after CTC spike, $\boldsymbol{b}$. before and after CTC plus tylosin spike, and c. before and after tylosin spike and the dotted box shows the administration period of the VAs

Figure 5. Digestate volatile solid (VS) concentrations before and after VA additions...........................36

Figure 6. Correlations of LC-MS/MS measured and spiked tylosin concentrations. 41

Figure 7. Left: concentrations of CTC, comparing calculated, measured, and corrected concentrations. Right: concentrations of tylosin, comparing calculated, measured, and corrected concentrations. ..... 44

Figure 8. Left: CTC concentration change with anaerobic digestion. Right: CTC concentration change with reactors filled with diluted water.

Figure 9. Left: Tylosin concentration changes with anaerobic digestion. Right: Tylosin concentration changes with reactors filled with diluted water.

Figure 10. The removal of tylosin in water and the anaerobic digestion $(A D)$ reactor.

Figure 11. Dendrogram of bacterial community based on Bray-Curtis similarities and Jaccard similarities.

Figure 12. The stacked bar chart at the best taxonomic resolution.

Figure 13. Heat map of treated samples using a hierarchical method (UPGMA) based on the 50 operational taxonomic units (OTUs) (rows) with the lowest $p$ values.

Figure 14. Box plots representing the relative abundance of 8 of the OTUs with the lowest $p$ values. .55

Figure 15. Random forest analysis of biomarkers based on MeanDecreaseAccuracy. 56

Figure 1. Left) The scheme of the reactors, tubes transferring biogas, and the incubator, Right) Solidphase extraction step.

Figure 2. Average biogas production, before and after the addition of SMZ .....................................83

Figure 3. Average $\mathrm{pH}$ of $A D$ reactors, before and after the addition of SMZ. .................................... 85

Figure 5. Isotope recovery rate in SMZ added samples and control samples with 100X dilution. .........89

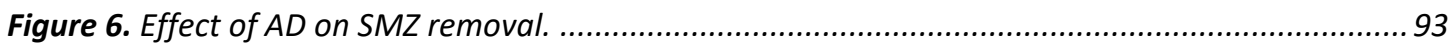


Figure 7. a) Evenness and b) amplicon sequence variant comparison with ANOVA test.

Figure 8. The stacked bar chart at the best taxonomic resolution comparing incubators 1 and 2.......96

Figure 9. Principal coordinate analysis plots using Bray-Curtis and Jaccard similarities for incubators 1 and 2 .

Figure 10. The stacked bar chart at the best taxonomic resolution comparing the effect of different VAs on bacterial dynamics.

Figure 11. Heat map of treated samples using a hierarchical method (UPGMA) based on the 50 ASVs (rows) with the lowest $p$ values. $R 1$ and $R 2$ refer to incubators 1 and 2, respectively. 99

Figure 1. Simplified barn plan, finishing rooms, liquid urine collection system, acidification equipment, February 19 (not to scale)

Figure 2. Cross-section plan of acidification pumps, tanks, and autosampler at the barn, February 19 (Not to scale) 121

Figure 4. Simplified sketch of the final urine acid treatment system, October 19 (Not to scale). 126

Figure 5. Comparison of the nitrogen concentrations of liquid manure samples collected from left and right-side trough over time (Adopted from A. Deviney et al., NCSU, 2019). ................................... 128

Figure 6. Acid citric addition $(\mathrm{ml})$ to the liquid manure and $\mathrm{pH}$ reduction rate.................................. 133

Figure 7. Baking soda addition to the tap water and well water and $\mathrm{pH}$ achieved........................... 135

Figure 8. Chemical calculation of baking soda molarity and $p H$............................................... 135

Figure 9. Neutralization of 1 liter of the treated liquid manure with baking soda solution................. 136

Figure 10. Flow meter probe location and solid manure collection system, March 19...................... 138

Figure 11. Sketch of the system with added recirculation line and flex line, May 19........................ 139

Figure 12. Recirculation line from acid tank to the trough, June 19. ............................................ 140

Figure 13. Foaming issue, left foaming happens in the acid tank; right foaming happens in the reservoir.

Figure 14. Self-aligning union and rubber couplings added to simply add an access to the system for cleaning.

Figure 15. Foaming deactivated the float switch, led to continuous pumping and excessive foaming (July 19), and installation of a filter screen (removed later)........................................................... 143

Figure 16. Manual settlement discharge line installed below the acid tank, June 19........................ 144

Figure 17. Final outline of the urine treatment system, June 19 (Not to scale). ............................... 145

Figure 18. Animal growth curve based on the percentage of nursing and finisher period. ................ 147

Figure 19. Weekly and biweekly feed consumption......................................................................... 148

Figure 20. Estimated swine manure production. ....................................................................... 148

Figure 22. Daily and hourly acid consumption vs. estimated volume. .......................................... 151

Figure 23. Flow rate measurements of the Doppler flow meter, for one day. ................................... 158

Figure 24. Daily flow rate readings of the Doppler flow meter, for three weeks in May and June 2019. 


\section{LIST OF TABLES}

Table1. Antimicrobial drugs approved for use in food-producing animals in the U.S., 2019................ 6

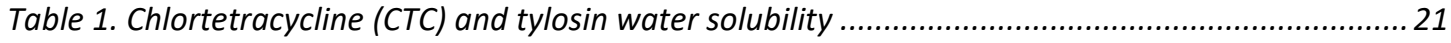

Table 2. Summary of antibiotics' prescription and concentrations added every two days. ................... 22

Table 3. Veterinary antibiotics (VAs) concentration spiked in each reactor...................................... 22

Table 4. Comparative table of methane content between data collected by Bacharach Fyrite Classic Combustion Analyzers and gas chromatography

Table 6. Samples, their content and comparison between their calculated, detected by LC-MS/MS and

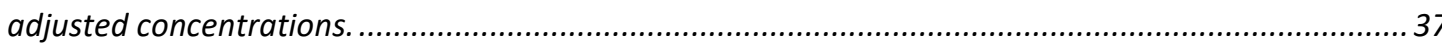

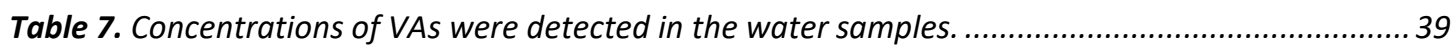

Table 8. Comparison of calculated VAs concentrations and LC-MS/MS detected levels...................... 40

Table 9. Concentrations of VAs were detected in the manure external standard samples.................. 42

Table 11. Percentages of different microorganisms with various treatment plans. ............................. 48

Table 1. Recommended dosage of SMZ administration by the manufacturer................................... 76

Table 2. Low, medium, and high concentrations of SMZ and water solubility check......................... 76

Table 3. SMZ removal and its effect on biogas production in the literature. .................................... 84

Table 4. Internal standard concentration and recovery rate verification. ..........................................8 87

Table 5. LCMS results of the recovery and removal of $10 X$ and $100 X$ sample dilution.........................87

Table 6. Second round of data verification with the modified protocol version. .................................9 90

Table 7. Third round of data verification with the modified protocol version.......................................99 92

Table 8. TS/VS, ammonia and alkalinity, biogas, and methane content produced based on VS destroyed results of the SMZ samples and control group. ...............................................................94

Table 1. Amounts of citric acid were added to $2 \mathrm{~L}$ of liquid manure, to reduce the $\mathrm{pH}$ from 7.0 to 4.5, mimicking the farm condition.

Table 2. Volume of citric acid required to reduce $2 \mathrm{~L}$ of the liquid manure $\mathrm{pH}$ to 5.5 and 4.5........... 133

Table 3. Baking soda molarity and achieved $\mathrm{pH}$ with tap and well water. ......................................... 134

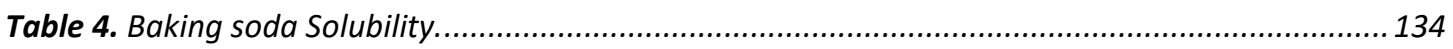

Table 5. Important timeline of the project, installation and modification..................................... 137

Table 6. Doppler flowmeter calibration. ........................................................................................ 144

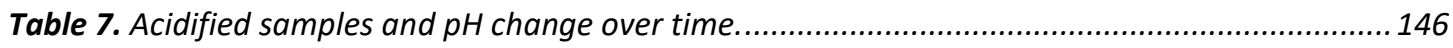

Table 8. Brown study liquid manure and solid manure estimations. .............................................. 149

Table 9. Ratio of acid consumption to the estimated liquid manure volume...................................... 152

Table 10. Simple cost-benefit analysis of the acidification of the liquid manure, for 1200-hd finishing barn.

Table 11. Total nitrogen and plant available nitrogen conversion factors based on MU guide G9186 


\title{
DEGRADATION OF THE VETERINARY ANTIBIOTICS IN SWINE MANURE VIA ANAEROBIC DIGESTION
}

Ali Hosseini Taleghani

\section{Dr. Teng-Teeh Lim, Dissertation Supervisor}

\begin{abstract}
Antimicrobial resistance is becoming an imminent danger for human health, in part because of excessive consumption of antibiotics in the animal industry. Laboratory-scale anaerobic digesters (ADs) were utilized to investigate the potential removal of veterinary antibiotics (VA) in swine manure. Nine laboratory ADs were kept at $39 \pm 2^{\circ} \mathrm{C}$ in incubators and were loaded every two days. The digesters had a working volume of $1.38 \mathrm{~L}$ (in a 1.89-L glass jar), with a hydraulic retention time (HRT) of 21 days and a loading rate of $1.0 \mathrm{~g}$-VS/L-day. Carbon dioxide concentration of the biogas and $\mathrm{pH}$ values of the digestate verifying digester performance were measured every four days and every week, respectively. The AD process allowed 2 HRT to stabilize before the addition of the VAs, of Chlortetracycline (CTC), Tylosin, and Sulfamethazine (SMZ). Tests were conducted to compare the effects of VAs on manure nutrients, volatile solid destruction, and biogas production. Concentrations of VA added to the manure samples were 263 to $298 \mathrm{mg} / \mathrm{L}$ of CTC, 88 to $263 \mathrm{mg} / \mathrm{L}$ of Tylosin, and 1042 to 1339 $\mathrm{mg} / \mathrm{L}$ of SMZ, respectively. Analysis of VA concentrations before and after the AD process was conducted to determine the VA degradation. The process of measuring the relatively low VA concentrations involves using solid-phase extraction and LC-MS-MS methodology. Further tests were performed in water under room temperature and digester temperature to approve the degradation of VAs. Amplicon sequencing analysis performed on each group using the 50
\end{abstract}


most frequent amplicon sequence variants (ASVs) showed significant discriminations between groups. A hierarchical method (UPGMA) was applied to obtain the major alteration in bacterial dynamics between treatments. The biomarkers' abundance can be employed to distinguish different antibiotics contamination. 
Chapter 1

Introduction 


\section{Background}

The world population is predicted to reach 11 billion in 2100 [1], so the agriculture and animal industries need to keep pace to provide food. In this regard, farmers are likely utilizing more veterinary antibiotics (VAs) to prevent, cure, and increase the growth rate of the animals. It is predicted that by 2030, VAs consumption will exceed 100,000 tons [2]. Considering that more than $60 \%$ of the VAs administered are being excreted to the environment since the animal body cannot absorb it all [3], it is a rising concern. The existence of VAs in the manure which is then used as crop fertilizer can impose adverse environmental impacts [4]-[7]. Antibiotic resistance genes (ARGs) are the consequence of overusing antibiotics [8], will cost $\$ 3.4$ trillion due to hospitalization, mortality, and exploring alternative methods by 2030 [9]. Since VAs are eliminating the non-resistant microorganisms, it will provide more promising opportunities for resistant ones to thrive.

Most excreted VAs are eventually stored within manure for a long-term (several months) and applied to the land as crop fertilizer. Thus manure can be addressed as one of the major reasons for antimicrobial resistance [10]. Most of the antibiotics being used are less biodegradable, with degradation extents varying between 4 and 27\% [11]. In the US, most animal farms are not equipped with wastewater treatment facilities, only some of them have rudimentary treatment units such as wetlands, lagoons, and some advanced anaerobic digesters [12]-[14].

There are various investigations on animal wastes fostering the emergence of the ARGs [15], [16]. There are new approaches to remove or reduce antibiotics, including activated carbon 
adsorption, membrane filtration, advanced oxidation processes [17]-[21], however, they require advanced technical supervision as well as high expenses. Anaerobic digesters can produce energy and waste stabilization as well as removing VAs and ARGs [22]-[26]. In contrast, composting [27] requires less monitoring, has a more stable working system and a generally higher removal rate for certain VAs, but consumes energy and occasionally has less capability to remove ARGs than AD.

In 2030, antibiotic resistance would cost $\$ 3.4$ trillion due to subsequent mortality and substitute treatment [9]. Therefore, according to this extensive use of antibiotics and their stability in the environment, seeking an efficient and financially feasible method is vital. Besides, limited findings are available about the threshold concentrations of different classes of antibiotics in manure that can be removed during the $\mathrm{AD}$ process and the interaction between anaerobic digesters and antibiotics.

\section{Importance and Popularity of Antibiotics:}

The first step to identify the most critical antibiotics in terms of their danger to the environment was examining the consumption rate and the market share of different antibiotic classes. Every animal antimicrobial manufacturer should report the volume of the drugs being sold or distributed in the U.S. to the FDA, annually. As a result of implementing the Guideline for Industry \#213 act, over-the-counter sales declined dramatically, from 8 million kilograms in 2016 to 271,280 kg in 2017 [28]. Despite all these restrictions, the US's total annual VAs consumption was 10,900 and 11,500 tons in 2017 and 2018, respectively [29]. 
Based on the 2019 FDA report, although the volume has decreased by 36\% from 2015 to 2019, it started to grow again from 2018 by 3\%, compared to 2019. Tetracycline which is the most used antimicrobial (more than 67\% of the total VAs used) increased by $4 \%$ from 2018 through 2019. The swine industry has the highest share of antimicrobial consumption in 2019, with more than $42 \%$.

Second, we had to distinguish the purposes, which are medically important and are being used as antibiotic treatments and preventions, and which are growthpromoting compounds. It would help us to separate part of drugs that are normally used for infection treatment.

Chemical half-lives of antibiotics and by-products of these antibiotics have raised the attention of evaluating their hazard to the environment. For instance, usually, as much as half-life extends, the antibiotics can be transported to numerous lieu like entering in run-off water, groundwater, soil, and finally plants before degradation.

Cost and administration periods always have a pivotal role in the popularity of a drug. Consumers are looking for their most cost-beneficial option, which can be effective and inexpensive at the same time. Therefore, if two different VAs have the same effect, farmers prefer to choose the one with a lower price. For this purpose, we gathered information about the drug family, the price per unit uses for the animal. Next, we dismissed antibiotics mostly used for small animals (dogs and cats), because they own a narrow share of antibiotics consumption in 2019 [30]. In conclusion, 
chlortetracycline from the tetracycline family, tylosin from macrolides, and sulfamethazine from sulfonamides were selected. Table1 shows the most popular antibiotics available in the US.

Table1. Antimicrobial drugs approved for use in food-producing animals in the U.S., 2019.

\begin{tabular}{|c|c|c|c|c|}
\hline Category & Antibiotic Name & $\begin{array}{l}\text { Drug } \\
\text { Class } \\
\end{array}$ & $\begin{array}{c}\text { Consumption } \\
\text { share } \\
\end{array}$ & Half-life \\
\hline Aminocoumarins & Novobiocin & $\begin{array}{c}\text { Not } \\
\text { Medically } \\
\text { Important }\end{array}$ & & ---- \\
\hline Aminoglycosides & $\begin{array}{c}\text { Dihydrostreptomycin } \\
\text { Gentamicin } \\
\text { Hygromycin B } \\
\text { Neomycin } \\
\text { Spectinomycin } \\
\end{array}$ & $\begin{array}{l}\text { Medically } \\
\text { Important }\end{array}$ & $3 \%$ & N.A. \\
\hline Amphenicols & Florfenicol & $\begin{array}{l}\text { Medically } \\
\text { Important }\end{array}$ & $<1 \%$ & 7.3 days \\
\hline Cephalosporins & $\begin{array}{c}\text { Ceftiofur } \\
\text { Cephapirin }\end{array}$ & $\begin{array}{l}\text { Medically } \\
\text { Important }\end{array}$ & $<1 \%$ & 10-50 days \\
\hline Diaminopyrimidines & Ormetoprim & $\begin{array}{l}\text { Medically } \\
\text { Important }\end{array}$ & For Dogs only & \\
\hline Fluoroquinolones & $\begin{array}{c}\text { Danofloxacin } \\
\text { Enrofloxacin }\end{array}$ & $\begin{array}{l}\text { Medically } \\
\text { Important }\end{array}$ & $<1 \%$ & $>50$ \\
\hline Glycolipids & Bambermycins & $\begin{array}{c}\text { Not } \\
\text { Medically } \\
\text { Important }\end{array}$ & & \\
\hline Ionophores & $\begin{array}{l}\text { Laidlomycin } \\
\text { Lasalocid } \\
\text { Monensin } \\
\text { Narasin } \\
\text { Salinomycin }\end{array}$ & $\begin{array}{l}\text { Not } \\
\text { Medically } \\
\text { Important }\end{array}$ & $37 \%$ & $\begin{array}{c}\text { Monensin <13 day, } \\
\text { Salinomycin } 0.6 \text { day } \\
\text { Narasin } 7 \text { day }\end{array}$ \\
\hline Lincosamides & $\begin{array}{l}\text { Lincomycin } \\
\text { Pirlimycin }\end{array}$ & $\begin{array}{l}\text { Medically } \\
\text { Important }\end{array}$ & $1 \%$ & \\
\hline Macrolides & $\begin{array}{c}\text { Erythromycin } \\
\text { Gamithromycin } \\
\text { Tildipirosin } \\
\text { Tilmicosin } \\
\text { Tulathromycin } \\
\text { Tylosin } \\
\text { Tylvalosin }\end{array}$ & $\begin{array}{l}\text { Medically } \\
\text { Important }\end{array}$ & $4 \%$ & $\begin{array}{c}\text { Erythromycin } 8 \text { days } \\
\text { Tylosin }<10, \\
\text { others } 10-50 \text { days }\end{array}$ \\
\hline Orthosomycins & Avilamycin & $\begin{array}{c}\text { Not } \\
\text { Medically } \\
\text { Important }\end{array}$ & & \\
\hline Penicillins & $\begin{array}{c}\text { Amoxicillin } \\
\text { Ampicillin } \\
\text { Cloxacillin } \\
\text { Penicillin } \\
\end{array}$ & $\begin{array}{l}\text { Medically } \\
\text { Important }\end{array}$ & $\begin{array}{c}6 \% \\
\text { For cats, dogs } \\
\text { and fishes }\end{array}$ & 10-50 days \\
\hline Pleuromutilins & Tiamulin & & & \\
\hline Polymyxins & Polymyxin & $\begin{array}{l}\text { Medically } \\
\text { Important }\end{array}$ & $\begin{array}{c}\text { Horse, Dog \& } \\
\text { cat }\end{array}$ & \\
\hline Polypeptides & Bacitracin & $\begin{array}{c}\text { Not } \\
\text { Medically } \\
\text { Important }\end{array}$ & & 12 days \\
\hline Quinoxalines & Carbadox & $\begin{array}{c}\text { Not } \\
\text { Medically } \\
\text { Important }\end{array}$ & & \\
\hline \multirow[t]{2}{*}{ Streptogramins } & Virginiamycin & $\begin{array}{l}\text { Medically } \\
\text { Important }\end{array}$ & & In silty sand $>87$ days \\
\hline & Sulfadimethoxine & & $3 \%$ & $>50$ \\
\hline
\end{tabular}




\begin{tabular}{|c|c|c|c|c|}
\hline $\begin{array}{c}\text { Sulfonamides } \\
\text { (Sulfas) }\end{array}$ & Sulfamethazine & $\begin{array}{l}\text { Medically } \\
\text { Important }\end{array}$ & & \\
\hline \multirow[t]{2}{*}{ Tetracyclines } & $\begin{array}{l}\text { Chlortetracycline } \\
\text { Oxytetracycline }\end{array}$ & \multirow[t]{2}{*}{$\begin{array}{l}\text { Medically } \\
\text { Important }\end{array}$} & \multirow[t]{2}{*}{$36 \%$} & CTC in Manure 37degree $=7$ days \\
\hline & Tetracycline & & & OTC $<5$ days \\
\hline
\end{tabular}

3. Objectives

This research was designed to investigate the i) biodegradation of chlortetracycline (CTC), tylosin, and sulfamethazine through anaerobic digestion, ii) possible disturbance in reactor performance, and iii) change in microbial population and their activity due to VAs in anaerobic digesters treating swine manure. In the literature, mostly batch reactors were used, while in actual farm conditions it is mostly a semi-continuously loaded reactor. Besides, the concentration of VAs explored was far from the real condition. Very few of them considered reactor performance as well as the removal of the antibiotic simultaneously. The innovation of this research is to mimic the actual farm condition with similar antibiotic concentrations applied by farmers, using relatively larger semi-continuous anaerobic digestion bioreactors over several months.

Chapter two reports degradations of CTC and tylosin in swine manure anaerobic digestions, with detailed methods and modifications employed, and potential interaction of the two antibiotics being treated at the same time. Chapter 3 investigates the degradation of sulfamethazine with more replications. In addition, amplicon sequencing of the digestate was carried out to characterize the bacterial dynamic alteration due to VAs addition. In chapter 4 we tried to compare and conclude the effects of treatment groups on biogas production, $\mathrm{pH}$ change and bacterial activity. Furthermore, biodegradation of VAs was reviewed to determine 
if the anaerobic digestion is efficient. Both Chapters two and three were submitted to a scientific journal for publication.

In appendix I, we included a field test report of acidifying separated liquid manure, documenting the set-up, troubleshooting, and recommendations. Our research group had an opportunity to collaborate with researchers from the North Carolina State University and a private industry. The main objective was to conduct a field test of acidifying separated liquid manure in a commercial farm, for better preserving the nitrogen contents in the liquid manure.

Urea, with relatively high $\mathrm{N}$ content $(46 \%)$, simplicity of application, and fair price is the most popular $\mathrm{N}$ fertilizer consumed globally. For liquid manure, to maximize the absorption of nutrients by crops, and to reduce negative environmental impacts, urine has to be stabilized. Acid addition to urine in order to decrease the $\mathrm{pH}$ showed a substantial effect on urease inhibition and reduced the ammonia loss during collection, storage, and application. An onfarm liquid manure acidification system was established at a commercial farm with a solidliquid separation system in Versailles, Missouri. The desired $\mathrm{pH}$ was achieved by utilizing a Programmable logic controller and a probe installed in the manure acidification tank. An autosampler was programmed to grab samples while acidification was targeted for $\mathrm{pH} 4.5$ and 5.5 .

Frequent clogging due to solids, foaming, pump malfunction, flowmeter clogging, general system failure due to settlements, and concrete acid corrosion were among the issues. 
Finally, a model was elaborated to estimate manure production and acid consumption for $\mathrm{pH}$ 5.5 and 4.5, which was verified with manual data recording at the farm. 


\section{Chapter 2}

Degradation of Veterinary Antibiotics in Swine Manure via Anaerobic Digestion 
Abstract: Antibiotic-resistant microorganisms are drawing a lot of attention due to their severe and irreversible consequences on human health. The animal industry is considered responsible in part because of the enormous volume of antibiotics used annually. In the current research, veterinary antibiotic (VA) degradation, finding the threshold of removal, and recognizing the joint effects of chlortetracycline (CTC) and Tylosin combination on the digestion process were studied. Laboratory scale anaerobic digesters were utilized to investigate the potential mitigation of VA in swine manure. The digesters had a working volume of 1.38 L (in a 1.89-L glass jar), with a hydraulic retention time (HRT) of 21 days and a loading rate of $1.0 \mathrm{~g}$-VS $L^{-1} d^{-1}$. Digesters were kept at $39 \pm 2{ }^{\circ} \mathrm{C}$ in incubators and loaded every two days, produced biogas every 4 days and digester pH was measured weekly. The anaerobic digestion (AD) process was allowed 1.5 to 2 HRT to stabilize before adding the VAs. Tests were conducted to compare the effects of VAs on manure nutrients, volatile solid removal, VA degradation, and biogas production. Concentrations of VA added to the manure samples were 263 to $298 \mathrm{mg} / \mathrm{L}$ of CTC, and 88 to $263 \mathrm{mg} / \mathrm{L}$ of Tylosin, respectively. Analysis of VA concentrations before and after the AD process was conducted to determine the VA degradation. Additional tests were also conducted to confirm the degradation of both VAs dissolved in water under room temperature and digester temperature. Some fluctuations of biogas production and operating variables were observed because of the VA addition. All CTC was found degraded even only after 6 days of storage in water solution; thus, there was no baseline to estimate the effects of AD. As for Tylosin, 100\% degradation was observed due to the AD (removal was 100\%, compared with 24-40\% degradation observed in the 12-day water solution storage). Besides, complete Tylosin degradation was also observed in the digestate samples treated with a mixture of the two VAs. Lastly, amplicon sequencing was performed on each group by using the 50 most variable operational taxonomic units (OTUs)s, and perfect discriminations were detected between groups. The effect of administration period and dosage of VAs on Phyla Firmicutes Proteobacteria, Synergistetes, and Phylum Bacteroides was investigated. These biomarkers' abundance can be employed to predict the sample's treatment group. 


\section{Introduction}

Nowadays, a wide variety of antibiotics are being used in animal farms to cure, prevent, and also improve the growth of animals, accounting for more than $52 \%$ of total antibiotics consumption in the world [1-3]. Due to the rapid effect of antibiotics and low cost of them, daily use of it rocketed during the last two decades) [4]. Although in 2017, attempts to restrict using antibiotics took place, from 2009 to 2016 use of several veterinary antibiotics (VAs) was raised by $36.8 \%$ on average [4]. Many of these compounds have weak absorption within the animal gut and intestine during digestion, resulting in the excretion of potent parent and daughter products [5]. A high percentage of the antibiotics (60-90\%) is excreted without metabolism in urine and feces, leading to potential human and ecological health risks for soil and water [6-9]. Moreover, based on a study by Alexy et al. [10], most of the antibiotics being used are not biodegradable, with degradation extents varying between 4 and $27 \%$.

Since a vast volume of manure is being produced each year due to concentrated animal feeding operations (CAFOs) and is mostly being applied to solid materials as a fertilizer, the long-term presence of such antibiotics in manure with even trace concentrations (i.e., ng/L) could lead to the formation of antibiotic resistance genes (ARGs) [11]. The microbacterial resistance will result in higher medical costs, longer treatment periods, and increased mortality [12,13]. Animal farms typically utilize simple treatment systems, which are mainly AD, stockpiling, composting, wetlands, or lagoons $([3,14])$. These simple treatments might not be sufficient to prevent the appearance of ARGs [15]. There are new approaches to remove or reduce antibiotics, including activated carbon adsorption, membrane filtration, advanced 
oxidation processes ([14,16-19]), however, they require advanced technical supervision as well as extreme expenses. Furthermore, the VAs could pollute the soil and water, then the human food chain through crops and animal-derived foods [20-24]. Moreover, the residue of VAs in the $\mathrm{AD}$ process could sustain microbes under the minimum inhibitory concentration (MIC), fostering the selection for ARGs by microbes $[25,26]$.

Anaerobic digesters can produce biogas as well as removing VAs and ARGs [27-29]. In contrast, composting [30] requires less monitoring, has a more stable working system and a generally higher removal rate for certain VAs, but consumes energy and occasionally has less capability to remove ARGs than AD. Xie et al. [31] concluded that thermophilic composting of cow manure would result in ARG mitigation, lowering $16 \mathrm{~S}$ rRNA with tetracycline, sulfonamide, and fluoroquinolone resistance genes, however, not effective with aadA, aadA2, qacED1, tetL, cintI1, intI1, and tnpA04. A similar study of dairy manure composts showed satisfactory treatment of antibiotic-resistant E. coli and Salmonella, yet some antibioticresistant Enterobacter spp. and multidrug-resistant Pseudomonas spp. population raised after application of these composts to rangeland soils in Texas [29]. Prado et al. [32] aimed to use an aerobic reactor with activated sludge to track the fate of tetracycline (TC) and Tylosin as antibiotics. Both TC and Tylosin were not biodegradable in this type of reactor. Research also determined that the biosorption of both antibiotics appeared to be most favorable for TC.

Joy et al. [33] investigated the behavior of three antibiotics (bacitracin, chlortetracycline, and tylosin) and two classes of ARGs (Tet and Erm), which were monitored in swine manure slurry under anaerobic conditions. First-order decay rates were determined for each antibiotic 
with half-lives ranging from 1 day (chlortetracycline) to 10 days (tylosin). Angenent and Wrenn [34] examined the effects of an anaerobic sequencing batch reactor (ASBR) on the removal of antibiotic tylosin. They observed no inhibitory effect on biogas production, but some macrolide-lincosamide- streptogramin B (MLSB)-resistant bacteria appeared. Shi et al. [35], discovered that a certain dosage of tetracycline (TC) and sulfamethoxydiazine (SMD) could reduce biogas production. They also noticed the rapid disappearance of antibiotics (more than $50 \%$ ) in the first 12 hours. However, they were not sure about whether it was being degraded or just absorbed into solid materials. A similar study was conducted by Beneragama et al. [36], who confirmed the efficiency of $\mathrm{AD}$ of antibiotics in dairy manure. They also utilized thermophilic microorganisms (working in $55{ }^{\circ} \mathrm{C}$ ). Results showed no inhibition in gas production and the efficiency of the reactor.

Approximately $80 \%$ of the 16,000 metric tons of antibiotics sold annually in the U.S. are used in animal husbandry [37]. These antibiotics can be transported to run-off water, groundwater, soil, and finally, plants [38-43]. In 2030, antibiotic resistance would cost $\$ 3.4$ trillion due to subsequent mortality and substitute treatment [44]. Therefore, according to this extensive use of antibiotics and their stability in the environment, seeking an efficient and financially feasible method is vital. Besides, limited findings are available about the threshold concentrations of different classes of antibiotics in manure that can be removed during the $\mathrm{AD}$ process and the interaction between anaerobic digesters and antibiotics.

The objectives of this study were to evaluate i) anaerobic digestion efficiency on the removal of chlortetracycline (CTC) and Tylosin, ii) inhibitory behavior of VAs on the reactors, 
and iii) the effect of these antibiotics on microbial dynamics in anaerobic digesters with swine manure. The novelty of this research is the imitation of on-farm mesophilic anaerobic digesters that were loaded frequently with manure from a commercial pig farm while operating over several months. The research focused on widely used antibiotics and emphasized proper concentration and duration at which the antibiotics were administered (following manufacturer's recommendation and average pig weights), and amount of antibiotics excreted by the animals based on a literature review. Critical operating variables of the digesters, including $\mathrm{pH}$ and biogas productions, were monitored closely, similar to what most on-farm $\mathrm{AD}$ technicians are employing to monitor $\mathrm{AD}$ performance, which requires no sophisticated analytical expertise. The bench-scale anaerobic digesters were relatively larger and semicontinuously loaded for over several months, while many of the previous studies only focused on inhibition effect and usually using batch reactors, which are different from actual on-farm AD conditions.

\section{Methods}

The current study focuses on utilizing an AD process to assist in removing VAs and finding the efficiency and practicality of the reactors. Antibiotics are chosen to be spiked meticulously, based on their importance, usage in feedstock, and their danger to the environment. Besides, the dosage of antibiotics was close to concentrations administrated for animals, absorbed, and then excreted, to imitate the real condition. Our reactors are fed with swine manure, which has been tested for background concentration of VAs, to diminish the chance of interference. CTC was injected into anaerobic sequencing batch reactors (ASBR) with 
doses of 263,280 , and $298 \mathrm{mg} / \mathrm{L}$ for each spike and a total of three injections every two days while Tylosin doses were 88,175 , and $263 \mathrm{mg} / \mathrm{L}$ for each injection and a total of 5 injections every two days.

Several factors are contributing to reactor performance and biogas production. Temperature is one of them. Different types of bacteria work on various temperature ranges and some of them are highly susceptible to temperature fluctuation. Besides, the $\mathrm{pH}$ and alkalinity of the environment in which bacteria are growing should be near neutral and consistent. Therefore, the temperature was kept at around $39^{\circ} \mathrm{C}\left(102{ }^{\circ} \mathrm{F}\right)$. Also, we were recording incubator temperature and humidity for tracking the performance of our incubator. The methane-forming bacteria are very sensitive to slight changes in organic loading, $\mathrm{pH}$, and temperature (a temperature change greater than 2 degrees of Fahrenheit per day will affect the methane formers).

\subsection{Feedstock for Anaerobic Digestion}

Manure samples were collected from a mid-central Missouri commercial swine farm. The farm was VA-free for the finishing pigs, located in Versailles, Missouri, USA. Furthermore, to make sure that no antibiotics existed in the solid manure used, it was analyzed to eradicate any interference or error. Because the farm has shallow pits, the manure would be less than one month old. After collecting manure, buckets full of manure were kept frozen at $-20^{\circ} \mathrm{C}\left(-4{ }^{\circ} \mathrm{F}\right)$ until they were used as feedstock for the reactors. Once manure was needed, one of these big buckets was thawed down and separated into a small bucket (usually 4 liters (L) in volume). Just one of these small buckets was in the refrigerator for feeding; the rest were kept in a freezer 
to keep it unchanged as much as possible. Total and volatile solids (TS and VS) of each big bucket were tested to evaluate the proper feeding ratio. The total solid (TS) of the solid manure was $25.89 \%$, and the volatile solid (VS) was $82.02 \%$ of the TS. There was no test conducted to verify the potential effect of the freezing, although there were few observed changes in biogas production between refrigerated and frozen manure in the last year of AD tests.

The inoculum was collected from semi-continuous AD jars of previous tests (Wang et al., [45]), which were steadily producing biogas for over three months, and the feedstock was swine manure with an organic loading rate (OLR) of $1 \mathrm{~g}^{-V S ~ L^{-1}} \mathrm{~d}^{-1}$ only. The total solid (TS) of inoculum was $2.20 \%$, and the volatile solid (VS) was $64.92 \%$ of TS.

\subsection{Experimental Design}

Tests were carried out with laboratory size jars as reactors (adjusted for AD). Antibiotics were added to reactors with different concentrations of CTC and Tylosin to monitor antibiotic removal and gas production variations in those mesophilic reactors. Nine laboratory-scale jars as anaerobic bioreactors with the working volume of $1.375 \mathrm{~L}$ were kept at $39 \pm 2{ }^{\circ} \mathrm{C}\left(102{ }^{\circ} \mathrm{F}\right.$ to $105^{\circ} \mathrm{F}$ ) in the incubator. The jars are being fed with VA-free swine manure at 1g-VS per L-day, with 21 days hydraulic retention time (HRT). The volume of the feed given every two days is measured based on HRT and our reactor volume. Because our HRT is 21 days and the reactor volume is $1.375 \mathrm{~L}$, so $0.131 \mathrm{~L}$ of our reactor liquid was removed and replace by feedstock (the digesters were fed every two days) [46]. 
Each jar was connected to 10-L Tedlar bags to collect produced biogas, and the volume was measured every four days [47]. A custom-built device was used to help distribute the biogas evenly in the bag, so the height of the bag could be measured more accurately. By utilizing a predetermined model, the volume of each bag was then estimated by bag height. Besides, to prevent any leakage of the Tedlar bags, each time two of the bags were randomly tested for possible leakage before emptying. Additionally, tubes, caps, and any connective parts were tested for leakage. After biogas measurements, bags were emptied safely and burned.

The experiment consisted of nine jars; three of them were spiked with CTC, three with Tylosin, and the last three with both CTC and Tylosin, to observe the combined effect or any interaction between two types of antibiotics (Figure 1). Furthermore, to investigate the efficiency of the AD process, we added six more jars, filled with distilled water and the headspace with $\mathrm{N}_{2}$. Three of these jars were being kept in the incubator at the same temperature of the digester jars $\left(39^{\circ} \mathrm{C}\right)$, the rest were being kept in the room temperature to monitor the effect of the temperature. The same pattern of antibiotics concentration was conducted for control jars, two groups of three jars. Retention time and sampling procedures were identical. 


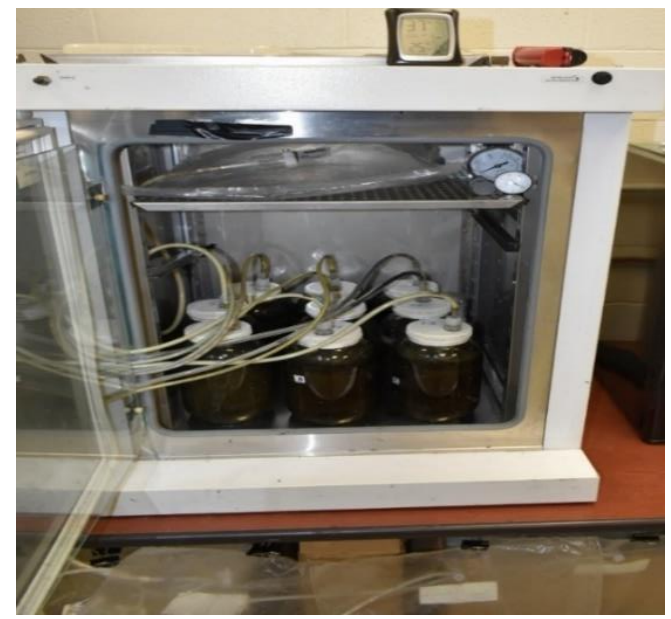

Figure 1. The scheme of the reactors, tubes transferring biogas and the incubator.

\subsection{Antibiotics}

The two most widely used antibiotics were selected based on consumption rate and market share of different antibiotic classes in the United States [4]. Antibiotics used in this experiment were CTC as chlortetracycline $\mathrm{HCI}$ and tylosin as tylosin tartrate. Commercial grade CTC was bought from "PharmGate Animal Health; Omaha, Nebraska" with the brand of "Pennchlor 64". Commercial grade tylosin used was from "Elanco Animal Health; Indianapolis, Indiana" with the brand of "Elanco". Moreover, to prepare standard samples for LCMS/MS, both antibiotics were ordered as the analytical grade from "Sigma-Aldrich", St. Louis, Missouri. Chlortetracycline hydrochloride, VETRANAL ${ }^{\mathrm{TM}}$, analytical standard, with CAS number of 64-72-2 and tylosin, United States Pharmacopeia (USP) Reference Standard, with CAS number of 1401-69-0, were used for standard solutions.

We followed the prescription on the labels to imitate the real condition in a barn. Consequently, the recommended dosage for tylosin was $66 \mathrm{ppm}$ in drinking water. For Swine Dysentery, adding tylosin to drinking water should be continued for 3 to 10 days, depending 
upon the severity of the infection. For CTC, the recommended dosage was $22 \mathrm{mg} / \mathrm{kg}$ body weights per day. The duration of treatment is 3 to 5 days depending on the infection. Pigs are generating 4.28 liters of manure per day on average. Additionally, it is assumed that the average body weight of a pig is around $68 \mathrm{~kg}$ (finishing pigs weigh around $45-113 \mathrm{~kg}$ ). These assumptions would help us estimate the concentration we should inject into our reactors, by considering the excretion rate and metabolism percentage.

The stabilization time for the reactors and the microbial community was expected to be one to three months, until the biogas production, digestate $\mathrm{pH}$, and alkalinity trend became flat. For the current research, the digester was fed for eight weeks or 2.5 times the retention time. Important operating variables, including organic loading rate based on total volatile solids (TVS), solid content, temperature, mixing (swirling the jar daily), and foaming (if any) were recorded. Digester alkalinity and $\mathrm{pH}$ were monitored weekly by measuring the digestate.

For Lower range concentration, the lowest factor in each section was used. For instance, to calculate the lower band of tylosin, $11.35 \mathrm{~L}$ per day as pig's drinking volume, $50 \%$ excretion level applied, and 4.28-liter excretion per day was selected. For upper range concentration, the highest factor in each section was used. For instance, to calculate the upper band of tylosin, 18.93 liters per day as pig's drinking volume, $90 \%$ excretion level, and 4.28-L excretion per day were selected. The average concentration is the average of the lower and upper concentrations. Recalling that jars were loaded every two days with a mixture of solid manure and water, VAs added with feed had a concentration of day 1 plus day 2 . 
Since antibiotics are being added to the water part of the feeding (not to the solid part), therefore solubility of the VAs should be checked. Table 1 is a summary of the solubility of CTC and tylosin in the water at $20^{\circ} \mathrm{C}$ :

Table 1. Chlortetracycline (CTC) and tylosin water solubility.

\begin{tabular}{ccc}
\hline Reference & CTC & Tylosin \\
\hline Manufacture Info. & $264 \mathrm{mg} / \mathrm{L}$ & $528 \mathrm{mg} / \mathrm{L}$ \\
\hline Merck Index & $500 \mathrm{mg} / \mathrm{L}$ & $6000 \mathrm{mg} / \mathrm{L}$ \\
\hline Sigma & $8.6 \mathrm{mg} / \mathrm{mL}$ & $50 \mathrm{mg} / \mathrm{mL}$ \\
\hline
\end{tabular}

Considering the solubility of CTC and tylosin in the water at $20^{\circ} \mathrm{C}$, there was no problem with CTC and tylosin solving limit individually. However, one set of three jars was used, which we decided to use to test the combined effect of antibiotics, so we had to mix two antibiotics in the same volume of water $(0.103 \mathrm{~L})$. There is always a chance of interference between two types of chemicals, especially when they are being added near their solubility limit. Thus, the decision was made to add CTC directly to the water, transfer it to the reactor and then add tylosin powder separately to the reactor. Other solvents such as methanol or ACN were dismissed because of their adverse effect and interference with the reactor's performance (an independent test was conducted to evaluate the impact of adding methanol onto AD performance; details are not included in this paper). Table 2 summarizes the recommended VA concentrations based on the manufacturer's recommendation and corresponding dosages considering the ranges of dosage, water consumption, and excretion rate. 
Table 2. Summary of antibiotics' prescription and concentrations added every two days.

\begin{tabular}{|c|c|c|c|c|c|c|c|c|}
\hline Antibiotic & $\begin{array}{c}\text { Dosag } \\
\text { e } \\
\text { (day) }\end{array}$ & $\begin{array}{c}\text { Manure } \\
\text { (L/d) }\end{array}$ & Consumption & $\begin{array}{l}\text { Treatment } \\
\text { Duration }\end{array}$ & $\begin{array}{c}\text { Excretion } \\
\text { Level }\end{array}$ & $\begin{array}{l}\text { Conc. } \\
\text { (Low) } \\
\text { (mg/L) }\end{array}$ & $\begin{array}{l}\text { Conc. } \\
\text { (High) } \\
\text { (mg/L) }\end{array}$ & $\begin{array}{l}\text { Conc. } \\
\text { (Med) } \\
\text { (mg/L) }\end{array}$ \\
\hline Tylosin & $\begin{array}{c}66 \\
\mathrm{mg} / \mathrm{L}\end{array}$ & 4.28 & $\begin{array}{c}\text { Drinking } \\
\text { 11.35-18.93 } \\
\text { liters/day }\end{array}$ & 3-10 days & $\begin{array}{l}50 \text { to } \\
90 \%\end{array}$ & 87.67 & 263 & 175.34 \\
\hline CTC & $\begin{array}{c}22 \\
\mathrm{mg} / \mathrm{kg} . \\
\text { - body } \\
\text { weight }\end{array}$ & 4.28 & $\begin{array}{c}\text { Average Pig } \\
\text { weight }=68 \mathrm{~kg}\end{array}$ & 3-5 days & $75 \%$ & 263 & 298 & 280.54 \\
\hline
\end{tabular}

As previously mentioned, we recorded biogas production for at least two HRTs, before and after introducing the antibiotics. Table 3 illustrates the added VAs concentration in each reactor. As shown below, the first group is being administrated only with CTC, the second group with both CTC and tylosin, and the last, with only tylosin.

Table 3. Veterinary antibiotics (VAs) concentration spiked in each reactor

\begin{tabular}{ccc}
\hline Jar \# & CTC concentration (ppm) & Tylosin Concentration (ppm) \\
\hline $\mathbf{1}$ & 263 & 0 \\
\hline $\mathbf{2}$ & 280.54 & 0 \\
\hline $\mathbf{3}$ & 298 & 87.67 \\
\hline $\mathbf{4}$ & 263 & 175.34 \\
\hline $\mathbf{5}$ & 280.54 & 263 \\
\hline $\mathbf{6}$ & 298 & 87.67 \\
\hline $\mathbf{7}$ & 0 & 175.34 \\
\hline $\mathbf{8}$ & 0 & 263 \\
\hline $\mathbf{9}$ & 0 & \\
\hline
\end{tabular}


The $\mathrm{pH}$ of the digestate was measured every two days while adding antibiotic, with a pH meter (PINPOINT, American Marine Inc, Ridgefield, CT). Using pH data, the microbial activity of the digester and the reactor performance is projected. However, $\mathrm{pH}$ can also be affected by alkalinity. For quality assurance, alkalinity tests were also carried out.

The $\mathrm{CO}_{2}$ concentration of the biogas was measured with a standard combustion analyzer (Bacharach Fyrite Classic Combustion Analyzer, USA) every eight days. The concentration of $\mathrm{CO}_{2}$ was measured every four days during the antibiotic addition period. Comparative tests with a gas spectrometry device were done to check how accurate our measurements were. Below is a comparative table that illustrates accuracy control values (Table 4). The gas chromatograph device was (GC-2014, Shimadzu, US) with a thermal conductivity detector (TCD) using a ShinCarbon ST 80/100 Column (Restek, US) [48].

Table 4. Comparative table of methane content between data collected by Bacharach Fyrite Classic Combustion Analyzers and gas chromatography.

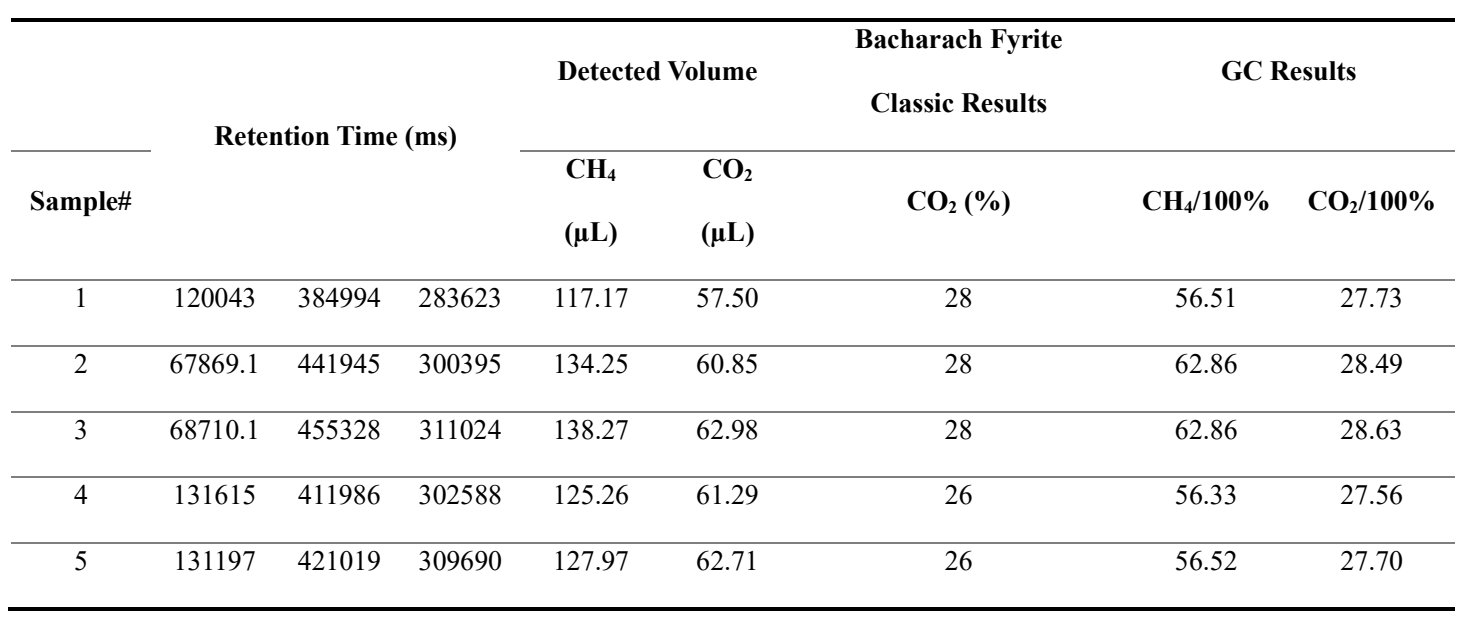

Because the administration times for CTC and tylosin were different ( 6 days for CTC and 10 days for tylosin), jars with CTC spikes were sampled at the end of day 6, while tylosinspiked jars were sampled at day 10. For jars with the combined CTC and tylosin, samples were 
taken on both day 6 and day 10. Since VAs were added every two days with feed, the sampling would occur two days after the last spike. Samples were frozen at $-20{ }^{\circ} \mathrm{C}$ immediately. Gas production, $\mathrm{pH}$, and $\mathrm{CO}_{2}$ level were considered the vital data, which were recorded before, during, and past spikes.

\subsection{Extraction and Chemical Analysis}

\subsubsection{Sample Preparation}

Two grams of the sample were transferred to 50-ml "Corning ${ }^{\mathrm{TM}}$ PP Centrifuge Tubes (polypropylene) and $5 \mathrm{~mL}$ of phosphate buffer $(0.14 \mathrm{M})$ was added. Following the $\mathrm{pH}$ adjustment, $200 \mu \mathrm{L}$ of internal standard (Sulfamethazine phenyl-13C6) was fortified and the antibiotics were extracted with $25 \mathrm{~mL}$ of acetonitrile (ACN) with sonication for an hour. Following the sonication, the samples were centrifuged for 15 minutes in $4000 \mathrm{rpm}$, at $4{ }^{\circ} \mathrm{C}(39.2$ $\left.{ }^{\circ} \mathrm{F}\right)$ with a Sorvall LYNX 6000 Superspeed Centrifuge (Thermo Scientific ${ }^{\mathrm{TM}}$ ), and the supernatant was collected. The same extraction process was repeated with $15 \mathrm{~mL}$ ACN; both supernatants were combined. Twenty milliliters of the extract were transferred to the test tube, and the solvent was further evaporated to $2 \mathrm{~mL}$ under a stream of nitrogen gas. The extract was diluted with $18 \mathrm{ml}$ of DI water before solid-phase extraction (SPE).

\subsubsection{Solid-Phase Extraction}

The antibiotics were extracted by a Waters Oasis-HLB SPE cartridge (Oasis HLB 12 cc Vac Cartridge, 500 mg Sorbent per Cartridge, $60 \mu \mathrm{m}$ Particle Size). The solid-phase extraction cartridges were preconditioned in an order with $10 \mathrm{~mL} \mathrm{ACN}, 10 \mathrm{~mL}$ DI water all with the rate 
of $(2 \mathrm{~mL} / \mathrm{min})$. The sample was subsequently introduced to the cartridge at a flow rate of 2 $\mathrm{mL} / \mathrm{min}$. The impurity in the cartridge was washed by using $10 \mathrm{~mL}$ DI water for $5 \mathrm{~min}$ of vacuum drying. The antibiotics retained on the cartridges were eluted with $8 \mathrm{~mL}$ of methanol followed by $8 \mathrm{~mL}$ of $\mathrm{ACN}$ with a flow rate of $2 \mathrm{~mL} / \mathrm{min}$. The eluate was evaporated by a gentle stream of nitrogen at $15 \mathrm{~L} / \mathrm{min}$ in a water bath at $35^{\circ} \mathrm{C}$ and concentrated to $10-20 \mu \mathrm{L}$. The extract was further filtered via a $0.22-\mu \mathrm{m}$ Anotop inorganic filter (Sigma Aldrich) and was ready for antibiotic analysis [49].

\subsubsection{LC-MS/MS Analysis}

The concentrations of antibiotics were determined by a Waters Alliance 2695 HighPerformance Liquid Chromatography (LC-MS/MS) system coupled with Waters Acquity TQ triple quadrupole mass spectrometer (MS/MS). The analytes were separated by a Phenomenex (Torrance, CA) Kinetex C18 (100 mm × $4.6 \mathrm{~mm} ; 2.6 \mu \mathrm{m}$ particle size) reverse-phase column. The mobile phase consisted of $10 \mathrm{mM}$ ammonium acetate and $0.1 \%$ formic acid in water (A) and $100 \%$ acetonitrile (B). The gradient conditions were $0-0.5 \mathrm{~min}, 2 \% \mathrm{~B} ; 0.5-7 \mathrm{~min}, 2-80 \% \mathrm{~B} ; 7.0-$ $9.0 \mathrm{~min}, 80-98 \% \mathrm{~B} ; 9.0-10.0 \mathrm{~min}, 2 \% \mathrm{~B} ; 10.0-15.0 \mathrm{~min}, 2 \% \mathrm{~B}$ at a flow rate of $0.5 \mathrm{~mL} / \mathrm{min}$. The ion source in the MS/MS system was electrospray ionization (EI) operated in either positive (ES+) mode with a capillary voltage of $1.5 \mathrm{kV}$. The ionization sources were programmed at 150 ${ }^{\circ} \mathrm{C}$ and the desolvation temperature was programmed at $450{ }^{\circ} \mathrm{C}$. The MS/MS system was in the multi-reaction monitoring (MRM) mode with the optimized collision energy. The ionization energy, MRM transition ions (precursor and product ions; Table 5), capillary and cone voltage, desolvation gas flow, and collision energy were optimized by the Waters IntelliStart ${ }^{\mathrm{TM}}$ 
optimization software package [50]. The retention time, calibration equations, and limits of the detection for the analyses of metabolites are summarized in Table 5.

Table 5. The ionization mode, retention times, and optimized precursor/product ions for analysis of the VAs by the developed LC-MS/MS method.

\begin{tabular}{lcccc}
\hline & Chemical & Ionization Mode & Retention Time & Precursor / Product Ions \\
\hline $\mathbf{1}$ & Ceftiofur (Excenel) & ESI + & 7.04 & $523.8 / 210$ \\
\hline $\mathbf{2}$ & Penicillin G Potassium salt & ESI + & 7.32 & $335 / 160$ \\
\hline $\mathbf{3}$ & Carbodox & ESI + & 6.27 & $263 / 90$ \\
\hline $\mathbf{4}$ & Chlortetracycline hydrochloride & ESI + & $479 / 444$ \\
\hline $\mathbf{5}$ & Tiamulin (Denaguard) & ESI + & 7.57 & $494.3 / 192.1$ \\
\hline & & & 8.64 & $917 / 174$ \\
\hline $\mathbf{6}$ & Tylosin & ESI + & 8.63 & $917 / 772$ \\
\cline { 2 - 5 } & & ESI + & 8.63 & 365 \\
\hline $\mathbf{7}$ & Enrofloxacin-d5 & ESI + & 6.98 & \\
\hline
\end{tabular}

\subsection{Statistical Analysis}

The statistical analyses were carried out using a two-sample t-test with unequal variances from the statistical analysis (R Core Team, 2013) to compare biogas inhibition between groups and between different VAs concentrations. Significance was accepted at probabilities $p \leq 0.05$ for all analyses. Besides, for amplicon sequencing, Bray-Curtis similarities and Jaccard similarities methods are used for this comparison. The Bray-Curtis dissimilarity is a method used to measure the structural variation between two different groups, based on counts at each group. Mathematically, the index of dissimilarity is:

$$
B C i j=1-\frac{2 C i j}{(S i+S j)}
$$


where $\mathrm{Cij}$ is the sum of the lesser values for only those species on the intersection of two sets. $\mathrm{Si}$ and $\mathrm{Sj}$ are the total numbers of specimens at both sites. The range is between 0 and 1 [51].

The Jaccard similarity index compares members for two sets of data to quantify the resemblance between them, with a range from 0 to 1 . The closer the number is to 1 , the more similar the two populations are.

$$
J(A, B)=\frac{|A \cap B|}{|A \cup B|}
$$

2.6. Sampling and DNA isolation

Raw and digested manure samples have been analyzed by the MU Metagenomics Center for the microbial/taxonomy analysis using the 16S rRNA library sequencing methodology. The results show that over $60 \mathrm{k}$ sequences were identified, confirming that the taxonomy analysis of manure samples can be analyzed using the specific method.

In total, twelve samples were collected into 50-mL sterile centrifuge plastic tubes. The first three samples were taken from CTC-added jars, with low, medium, and high concentrations, sampled 6 days after the first addition of VAs. The next three were sampled from jars with the addition of a mixture of CTC and tylosin on day 6 and day 10. The last group, including samples 9 to 12 were taken from jars administrated only with tylosin and were sampled on day 10 of VAs addition. Prior to sampling, each jar was mixed thoroughly with a hand mixer for 1 minute. During the time after sampling and before starting the amplicon sequencing, samples were frozen to prevent any interference with oxygen. According to the 
TissueLyser II (Qiagen, Venlo, Netherlands), samples were incubated at $70{ }^{\circ} \mathrm{C}$ for 20 minutes with intervallic vortexing. Then, samples were centrifuged at 5000× $\mathrm{g}$ for five minutes at room temperature, and the supernatant was conveyed to a 1.5-mL Eppendorf tube. Next, ammonium acetate was added, mixed, incubated on ice, and centrifuged. The supernatant was then blended completely with a unit volume of chilled isopropanol and for 30 minutes incubated on ice. Products were then centrifuged at $16000 \times \mathrm{g}$ for 15 minutes at $4{ }^{\circ} \mathrm{C}$. The supernatant was evaporated and removed; the DNA pellet was cleaned several times with $70 \%$ ethanol and resolved in $150 \mu \mathrm{L}$ of Tris-EDTA. The rest of the method was performed, according to Ericsson et al. [52,53].

\section{7. $16 S$ rRNA Library Preparation and Sequencing}

The DNA of extracted samples was tested at the University of Missouri DNA Core Facility. Bacterial $16 \mathrm{~S}$ rDNA amplicons were created with a magnification of the V4 hypervariable region of the $16 \mathrm{~S}$ rDNA gene with universal primers (U515F/806R) formerly established against the V4 region, edged by Illumina standard adapter sequences [54]. A single forward primer and reverse primers with a unique 12-base index were used in all reactions. PCR amplification was completed as follows: $98{ }^{\circ} \mathrm{C}(3: 00)+\left(98{ }^{\circ} \mathrm{C}(0: 15)+50{ }^{\circ} \mathrm{C}(0: 30)+72\right.$ $\left.{ }^{\circ} \mathrm{C}(0: 30)\right) \times 25$ cycles $+72{ }^{\circ} \mathrm{C}(7: 00)[52,53]$. The amplified product from each reaction was mixed entirely; then purified and incubated at room temperature for 15 minutes. Products were washed with $80 \%$ ethanol several times and the dried pellet was resuspended in Qiagen EB Buffer $(32.5 \mu \mathrm{L})$, incubated at room temperature for 2 minutes, and then placed on the magnetic stand for 5 minutes. The final amplicon pool was assessed using the Advanced Analytical 
Fragment Analyzer automated electrophoresis system, quantified with the Qubit fluorometer using the Quant-iT HS dsDNA reagent kit (Invitrogen), and diluted according to Illumina's standard protocol for sequencing on the MiSeq. [52].

\subsection{Informatics Analysis}

Constructing, data binning, and descriptive analysis of DNA sequences was performed at the MU Informatics Research Core Facility. FLASH software [55] was employed to group the contiguous sequences of DNA, and contigs were discarded if they turned out to be less than 31 after trimming for a base quality. Qiime v1.7 [56] software was used to carry out de novo and reference-based chimera detection and exclusion, and other contigs were allocated to operational taxonomic units (OTUs) with a significance of $97 \%$ nucleotide identity. Taxonomy was appointed to selected OTUs using BLAST [57] in comparison to the Greengenes database [58] of 16S rRNA sequences and taxonomy.

\section{Results and Discussion}

\subsection{Biogas production changes}

The presence of VAs in anaerobic digesters could have an inhibitory effect on biogas production $[36,59,60]$ because VAs could disrupt microorganisms' dynamics, especially when the concentration is high. Because AD is not efficient in degrading VAs completely, in the long term, AD reactors can also become a fostering environment for VAs that would help the development of new ARGs [61]. By scrutinizing the figures derived, some abnormalities were visible one week after the last spike, recalling that October 18 was the start date of the spiking 
antibiotics and the final day was October 28 (Figure 2a). This biogas fluctuation started with a decline in samples spiked with tylosin and also a mixture of tylosin and CTC, immediately after the first spike. For CTC samples, this drop was delayed until early November. On November 11, it grew again and then reached its lowest point on November 23.
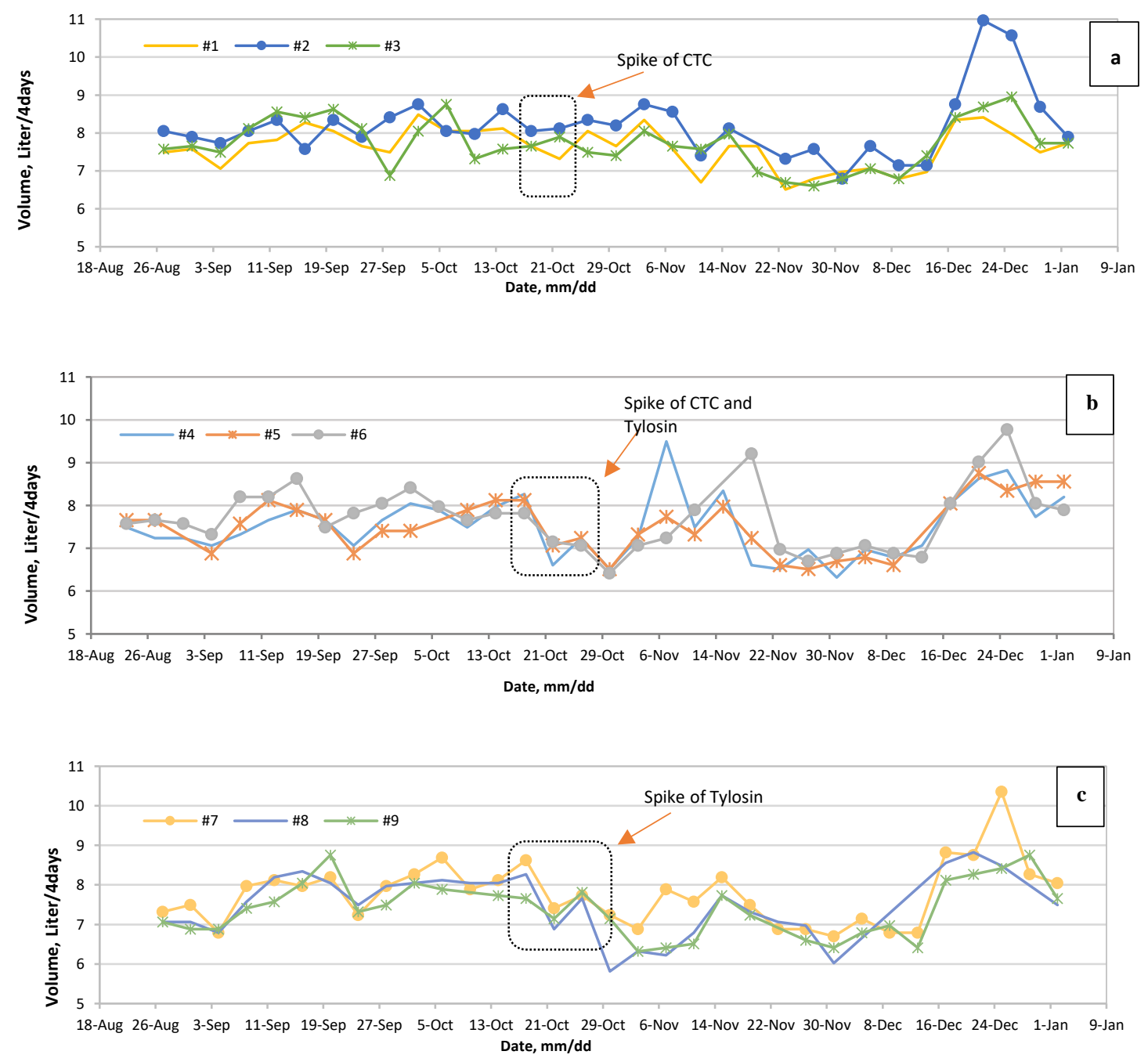

Figure 2. Biogas production in $2017-2018$, a. \#1 low, $\# 2$ medium, and \#3 high concentration, before and after adding CTC, b. \#4 low, \#5 medium and \#6 high concentration, before and after adding both CTC and tylosin, and c. $\# 7 \mathrm{w}, \# 8$ medium, and $\# 9$ high concentration, before and after adding tylosin and the dotted box shows the administration period of the VAs. 
For the CTC plus tylosin, after a drop on October 22, and again on October 30, we witness a surge after that. Reactor \#4 peaks on November 7 and reactor \#6 peaks on November 19. Reactor \#5 climbs steadily during this period. They start to drop in mid-November and reach their low at the end of November. Similarly, Figure $2 \mathrm{~b}$ shows the same behavior, declining after the first spike until the end of October (last spike), followed by an upward trajectory. Likewise, this trend hits its bottom in early December.

Running a T-Test on biogas data implies that AD bacterial activity was immediately inhibited for samples that have tylosin in them (Figure $2 b$ and $2 c)(p$-value $=0.005)$. Still, the bacteria either adapted or the inhibiting compound was removed from the system after a few weeks. Biogas production was untouched for CTC samples, yet for the mixture of CTC and tylosin, and tylosin alone, it was significantly lower, immediately after VA addition. The tylosin concentration in this experiment was $92 \mathrm{mg} / \mathrm{L}$ and less, complying with the findings of Mitchel et al. [62]. They concluded that the bioreactor containing $92 \mathrm{mg} / \mathrm{L}$ tylosin had less biogas for nearly $30 \mathrm{~d}$ until the system recovered. The biogas reduction for samples with tylosin and CTC was close to $14 \%$, and for tylosin, samples were between 8 and 19\%, with no dose-dependent relationship. On the other hand, Chelliapan et al. [63] found no biogas inhibition in an up-flow anaerobic stage reactor (UASR) containing 100-800 mg/L tylosin.

Erythromycin, another macrolide antibiotic caused 6-24\% biogas reduction with 6-100 $\mathrm{mg} / \mathrm{L}$, and no dose-dependent relationship [64]. 
But CTC did not disturb the bacterial activity, substantiate the evidence that CTC antibiotic may present minimal AD biogas inhibition at concentrations less than approximately $70 \mathrm{mg} / \mathrm{L}$ occurring in the current study. Yin et al. [65] observed similar results; for a mesophilic anaerobic digester with the manure and CTC concentrations of $0,20,40$, and $60 \mathrm{mg} / \mathrm{kg}$. TS, no significant inhibition in biogas production occurred. Dreher et al. [66] showed that no inhibition of biogas production happened in an anaerobic sequencing batch reactor with 28 $\mathrm{mg} / \mathrm{L} \mathrm{CTC}$ but that the volumetric composition of methane decreased by about $13-15 \%$. Mixed results of the inhibition in the literature could be due to various reactor types, inoculum/manure ratio, inoculum and manure age and source, reactor size, and batch or continuous operation [67]. In this experiment, CTC concentration was probably lower than its required inhibitory level.

\section{1. $\mathrm{pH}$ and $\mathrm{CO}_{2}$}

$\mathrm{pH}$ value can demonstrate how well Acetogenesis and Methanogenesis bacteria are working. At the beginning of AD performance, Acetogenesis bacteria start to produce volatile acids that cause the $\mathrm{pH}$ to decrease. Subsequently, Methanogenesis bacteria convert the volatile acids to methane and $\mathrm{CO}_{2}$, and cause $\mathrm{pH}$ to increase. At HRTs with more than five days, the methane-forming bacteria begin to consume the volatile acids.

By comparing before and after the addition of VAs, it is evident that reactors are experiencing a fluctuating $\mathrm{pH}$ status (Figure $3 \mathrm{a}-\mathrm{c}$ ). The graph shows that variations immediately after the antibiotic spike have increased intensively, with a rising trend. Following up, in the first week of November, almost all reactors reach their plateau. From then on, the 
gradual decline continued until November 17. Subsequently, reactors seemed to recover themselves with an increase in $\mathrm{pH}$. By the end of November, $\mathrm{pH}$ returns to its average level of around 7.8 .

The T-test on the $\mathrm{pH}$ data shows that $\mathrm{pH}$ values were significantly lower for the samples with tylosin in them $(p$-value $=0.05)$. However, CTC did not affect the $\mathrm{pH}$ significantly. Since fluctuations in $\mathrm{pH}$ level are not sharp, this indicates that VAs did not disturb the bacterial community substantially.
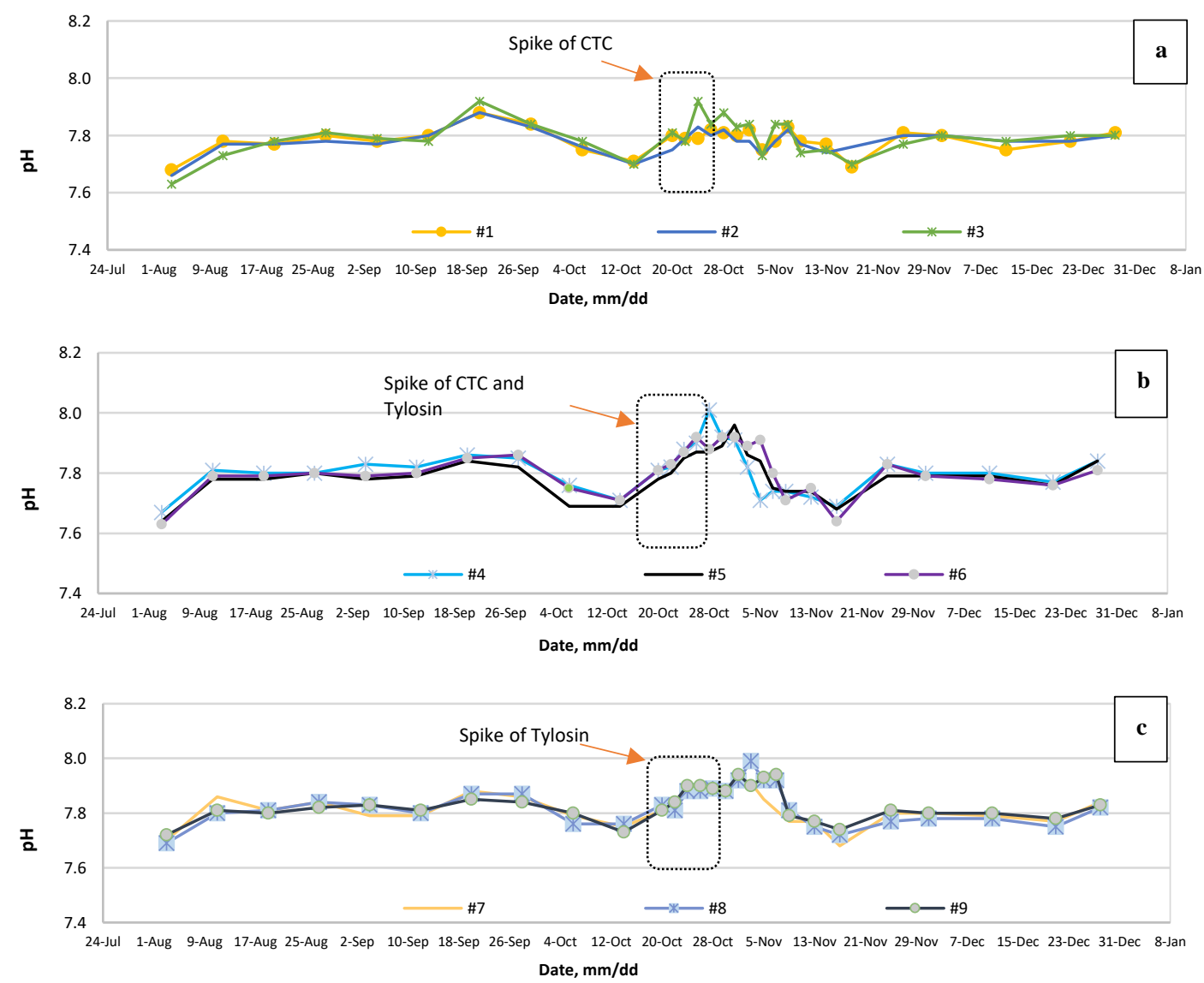

Figure 3. Digestate $\mathrm{pH}$ levels for a. before and after CTC spike, $\mathbf{b}$. before and after CTC plus tylosin spike, and c. before and after tylosin spike and the dotted box shows the administration period of the VAs. 
Nevertheless, none of the reactors became upset or affected intensively by the VA addition. $\mathrm{pH}$ fluctuation was \pm 0.16 maximum and it never dropped under 7.60. Similarly, the $\mathrm{CO}_{2}$ level has detectable alteration around the antibiotic spike date (Figure 4a-c).

Biogas produced is consisting of almost $50-75 \%$ of methane, $25-40 \%$ of carbon dioxide, and other gases, depending on organic material [68]. By comparing $\mathrm{CO}_{2}$ data and performing a T-test, results imply that CTC had a significant effect on the biogas methane content ( $p$-value $=0.05)$. At the same time, samples with tylosin only were not affected considerably. The reason could simply be that the CTC is active primarily against Gram-negative organisms by blending with the A location of the 30 S subunit of bacterial ribosomes. So, they prevent peptide growth and the protein synthesis effect, which finally leads to bacteria death $[65,69]$. Methanogen bacteria are Gram-negative bacteria [70]. Thus, at a certain level of CTC, significant biogas inhibition should be imposed on the bioreactor.
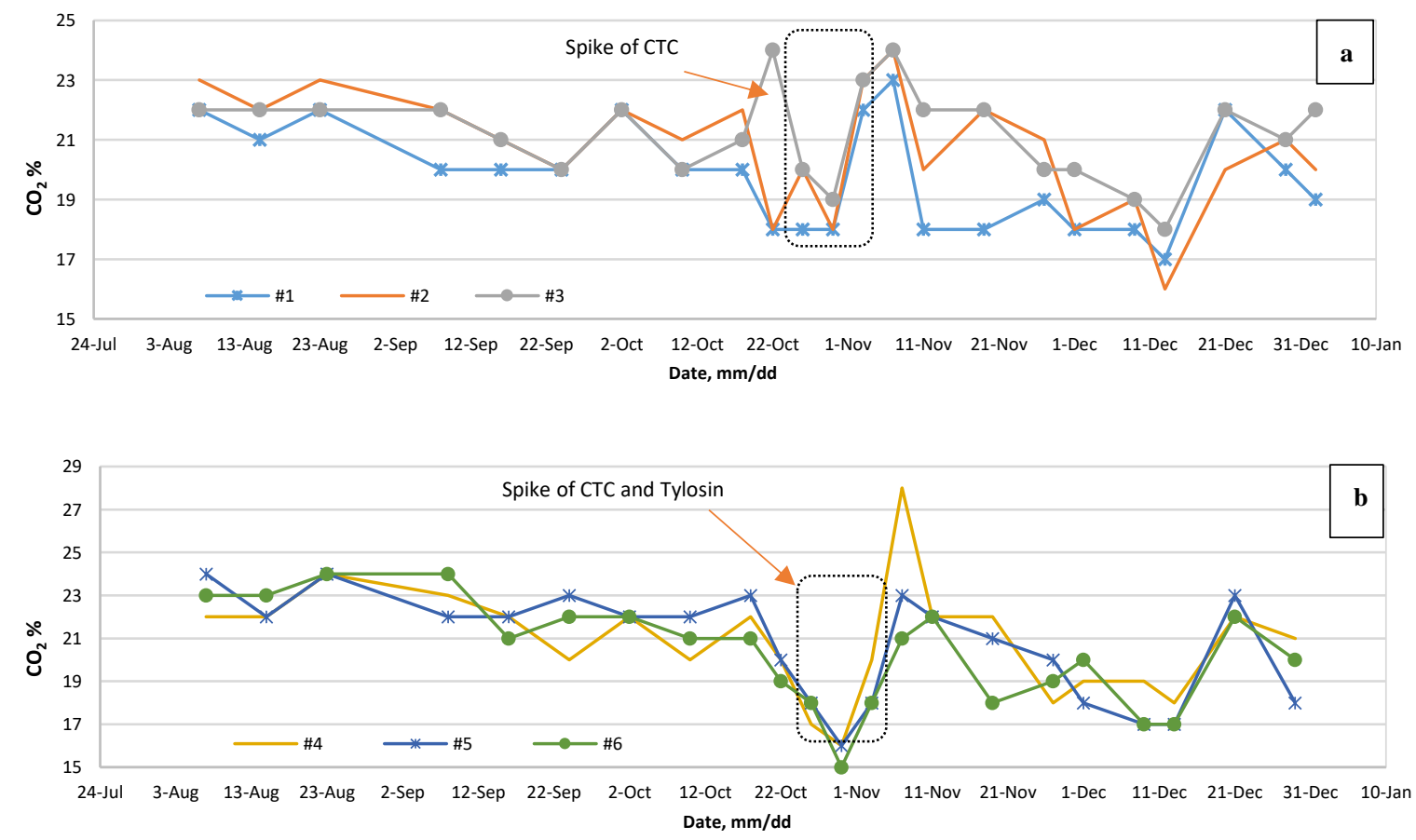


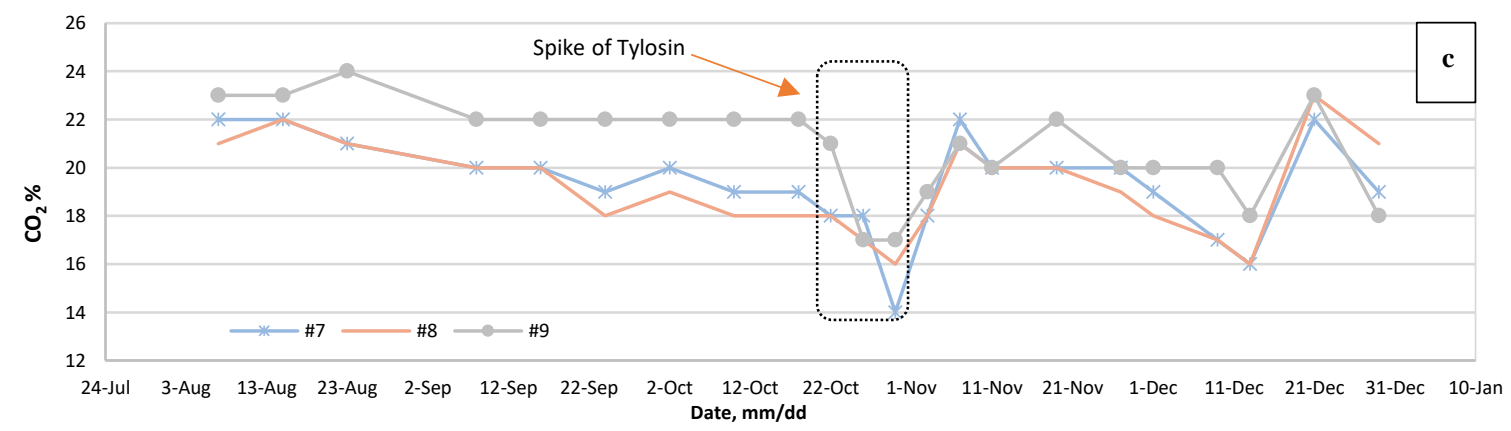

Figure 4. The concentrations of $\mathrm{CO}_{2} \mathbf{a}$. before and after CTC spike, $\mathbf{b}$. before and after CTC

plus tylosin spike, and $\mathbf{c}$. before and after tylosin spike and the dotted box shows the administration period of the VAs.

Values of VS in the digestate before and after VA addition are shown in Figure 5. In general, every treatment sample except for the medium tylosin concentration showed an increase in the VS percentage after VA addition. The VS values agree with the slight fluctuations observed in Figures 2-4, that the microbial communities were slightly affected by the VA addition and the biogas production was not halted. To recall, the initial manure VS loading was $2 \mathrm{~g}$-VS/L/day and the sampling for VS was conducted between 6 and 10 days after the first injection and two days after the last injection of VA. Thus, it complies with a reduction in methane production which was around 13-15\% studied by Dreher et al. [66]. Angenent et al. [34] also reported a temporary decrease in VS removal which recovered quickly. The average VS level before and after VA addition is $0.56 \%$ and $0.64 \%$; and VS removal is $1.44 \%$ and $1.36 \%$, respectively. 


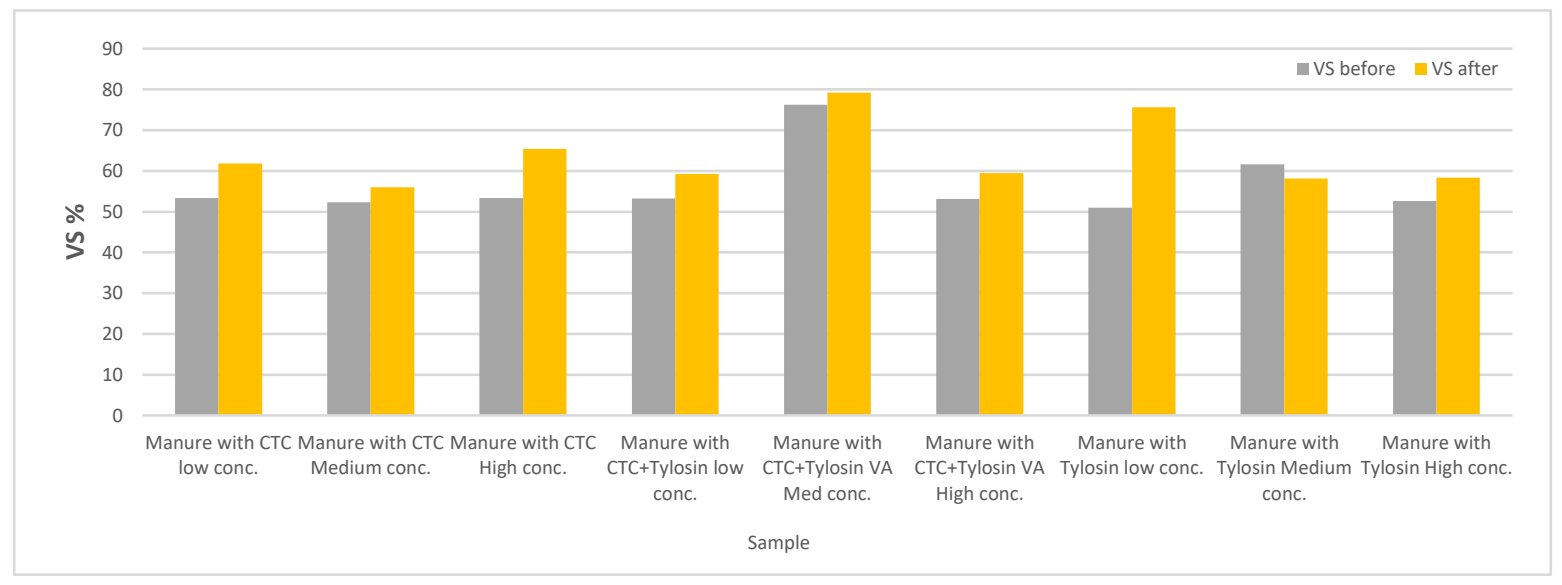

Figure 5. Digestate volatile solid (VS) concentrations before and after VA additions.

\subsection{LC-MS/MS Results and Adjustments}

The plan was to try using the measured Enrofloxacin concentrations to calculate adjustment factors for the other VAs. With these factors, sample concentrations after the dilution and short-term loading in the lab digesters were recalculated, assuming there was no degradation or absorption. Should there be significant differences, these would then be caused by sampling error, degradation due to $\mathrm{AD}$, or the error of the LC-MS/MS measurement, including the SPE. Table 6 shows all of the samples, their added VAs, and a comparison between spiked concentration, detected concentration by LC-MS/MS, and recalculated concentration using adjustment factors. 
Table 6. Samples, their content and comparison between their calculated, detected by LC-MS/MS and adjusted concentrations.

\begin{tabular}{|c|c|c|c|c|c|c|c|c|}
\hline & & & CTC & & Tylosin & & & \\
\hline Sample \# & Sample Type & $\begin{array}{c}\text { Calculated } \\
\text { CTC Conc. } \\
\text { (ppm) }\end{array}$ & $\begin{array}{c}\text { Detected } \\
\text { Conc. } \\
\text { With LC- } \\
\text { MS/MS } \\
\text { (ppm) }\end{array}$ & $\begin{array}{l}\text { Calculated } \\
\text { Tylosin } \\
\text { Conc. (ppm) }\end{array}$ & $\begin{array}{c}\text { Detected } \\
\text { Conc. } \\
\text { With LC- } \\
\text { MS/MS } \\
\text { (ppm) }\end{array}$ & $\begin{array}{c}\text { CTC } \\
\text { Recovery } \\
\text { and Purity } \\
\text { Adj. (ppm) }\end{array}$ & $\begin{array}{c}\text { Tylosin } \\
\text { Recovery } \\
\text { and Purity } \\
\text { Adj. (ppm) }\end{array}$ & $\begin{array}{l}\text { Enrofloxacin } \\
\text { Conc. (ppb) }\end{array}$ \\
\hline 1 & Digestate with CTC low conc. & 61 & 0 & 0 & 0 & -1 & 0 & 226 \\
\hline 2 & Digestate with CTC Medium conc. & 65 & 0 & 0 & 0 & -2 & 0 & 523 \\
\hline 3 & Digestate with CTC High conc. & 69 & 0 & 0 & 0 & -1 & 0 & 1377 \\
\hline 4 & Digestate with Mixture VA low conc. & 61 & 0 & 20 & 1 & 0 & -6 & 1069 \\
\hline 5 & Digestate with Mixture VA Med conc. & 65 & 0 & 40 & 1 & -2 & -5 & 940 \\
\hline 6 & Digestate with Mixture VA High conc. & 69 & 0 & 61 & 1 & -2 & $\overline{-4}$ & 568 \\
\hline 7 & Digestate with Mixture VA low conc. & 50 & 0 & 31 & 1 & -1 & -5 & 1434 \\
\hline 8 & Digestate with Mixture VA Med conc. & 53 & 0 & 61 & 1 & -1 & -4 & 600 \\
\hline 9 & Digestate with Mixture VA High conc. & 56 & 0 & 92 & 2 & -2 & -2 & 834 \\
\hline 10 & Digestate with tylosin low conc. & 0 & 0 & 31 & 1 & -2 & -5 & 881 \\
\hline 11 & Digestate with tylosin Medium conc. & 0 & 0 & 61 & 1 & -2 & -4 & 1186 \\
\hline 12 & Digestate with tylosin High conc. & 0 & 0 & 92 & 2 & -2 & -3 & 891 \\
\hline 13 & VA in water, Heat treated & 69 & 0 & 0 & 1 & -1 & -1 & 236 \\
\hline 14 & VA in water, Heat treated & 56 & 0 & 92 & 106 & -1 & 64 & 3197 \\
\hline 15 & VA in water, Heat treated & 0 & 0 & 92 & 116 & -1 & 70 & 1668 \\
\hline
\end{tabular}




\begin{tabular}{|c|c|c|c|c|c|c|c|c|}
\hline 16 & VA in water, Room Temp. & 69 & 0 & 0 & 2 & -1 & -1 & 1775 \\
\hline 17 & VA in water, Room Temp. & 56 & 0 & 92 & 95 & -1 & 57 & 2809 \\
\hline 18 & VA in water, Room Temp. & 0 & 0 & 92 & 93 & -1 & 55 & 2957 \\
\hline 19 & Diluted Manure without VA & 0 & 0 & 0 & 1 & -2 & -4 & 839 \\
\hline 20 & Diluted Manure without VA & 0 & 0 & 0 & 1 & -2 & -4 & 777 \\
\hline 21 & Diluted Manure without VA & 0 & 0 & 0 & 1 & -2 & -5 & 613 \\
\hline 22 & Diluted Manure with CTC + tylosin & 234 & 15 & 78 & 40 & 131 & 74 & 675 \\
\hline 23 & Diluted Manure with CTC + tylosin & 234 & 36 & 78 & 40 & 319 & 75 & 874 \\
\hline 24 & Diluted Manure with CTC + tylosin & 234 & 29 & 78 & 44 & 251 & 83 & 552 \\
\hline
\end{tabular}




\subsubsection{Relatively High Recovery of Enrofloxacin in the Water-only Samples.}

Although the spiked Enrofloxacin in digestate and manure samples had a very low recovery rate (226 ppb to $1433 \mathrm{ppb}$ vs. $4444 \mathrm{ppb}$ spiked values) (Table 7), all but one water sample detected relatively higher Enrofloxacin concentrations (1667 ppb to $3197 \mathrm{ppb}$, Table 1). The Enrofloxacin concentration in the first water sample (236 ppb, samples \#1) was only a fraction of water samples. The water samples were made with distilled water and VAs, with no solid manure. Relatively higher recovery rates suggest that there is a systematic bias in measuring the Enrofloxacin in the samples that have solids (manure and digestate).

Table 7. Concentrations of VAs were detected in the water samples.

\begin{tabular}{cccccc}
\hline \multirow{2}{*}{ Sample \# } & Sample Type & Compound & $\begin{array}{c}\text { Detected CTC } \\
\text { Conc.(ppb) }\end{array}$ & $\begin{array}{c}\text { Detected } \\
\text { Tylosin Conc. } \\
\text { (ppb) }\end{array}$ & $\begin{array}{c}\text { Enrofloxacin } \\
\text { Conc. }(\mathbf{p p b})\end{array}$ \\
\hline $\mathbf{1 3}$ & VA in water, Heat treated & CTC & 24 & 859 & 236 \\
\hline $\mathbf{1 4}$ & VA in water, Heat treated & CTC + tylosin & 15 & 106,243 & 3197 \\
\hline $\mathbf{1 5}$ & VA in water, Heat treated & Tylosin & 4 & 116,324 & 1668 \\
\hline $\mathbf{1 6}$ & VA in water, Room Temp. & CTC & 17 & 1787 & 1775 \\
\hline $\mathbf{1 7}$ & VA in water, Room Temp. & CTC + tylosin & 9 & 94,837 & 2809 \\
\hline $\mathbf{1 8}$ & VA in water, Room Temp. & Tylosin & 17 & 93,002 & 2957 \\
\hline
\end{tabular}

Therefore, when sample 13 was excluded, the average of the water sample group was 2481 $\mathrm{ppb}$, while the digestate samples averaged $825 \mathrm{ppb}$. On the other hand, if we disregard the Enrofloxacin concentrations as an adjustment factor and just compare the LC-MS/MS values with our calculated concentrations (assuming no degradation), provides a better outcome. In this way, external standards are utilized to evaluate samples with only water and VAs, to monitor whether the removal of VAs is due to AD or not. 


\subsubsection{Very High Recovery of Tylosin in the Water-only Samples.}

As shown in Table 8, concentrations for tylosin are very close to and sometimes higher than what we were expecting (LC-MS/MS measured $106 \mathrm{ppm}$, we expected $92 \mathrm{ppm}$ for sample 2). Furthermore, the water samples that were not spiked with tylosin did yield very low tylosin concentrations (0.86 ppm and 1.79 ppm, samples 13 and 16).

Table 8. Comparison of calculated VAs concentrations and LC-MS/MS detected levels.

\begin{tabular}{|c|c|c|c|c|c|c|}
\hline Sample \# & Sample Type & Compound & $\begin{array}{l}\text { Calculated } \\
\text { CTC Conc. } \\
\text { (ppm) }\end{array}$ & $\begin{array}{l}\text { CTC Detected } \\
\text { Conc. With } \\
\text { LC-MS/MS } \\
\text { (ppm) }\end{array}$ & $\begin{array}{c}\text { Calculated } \\
\text { tylosin Conc. } \\
\text { (ppm) }\end{array}$ & $\begin{array}{c}\text { Tylosin } \\
\text { Detected Conc. } \\
\text { With LC- } \\
\text { MS/MS (ppm) }\end{array}$ \\
\hline 13 & VA in water, Heat treated & CTC & 68.74 & 0.02 & 0.00 & 0.86 \\
\hline 14 & VA in water, Heat treated & CTC + tylosin & 56.27 & 0.01 & 92.07 & 106.24 \\
\hline 15 & VA in water, Heat treated & Tylosin & 0.00 & 0.00 & 92.07 & 116.32 \\
\hline 16 & VA in water, Room Temp. & CTC & 68.74 & 0.02 & 0.00 & 1.79 \\
\hline 17 & VA in water, Room Temp. & CTC + tylosin & 56.27 & 0.01 & 92.07 & 94.84 \\
\hline 18 & VA in water, Room Temp. & Tylosin & 0.00 & 0.02 & 92.07 & 93.00 \\
\hline
\end{tabular}

It is a different case for CTC, yet the reasons for low CTC detection are still unknown. The trend for CTC concentration shows they are disappearing so fast, which may be due to its half-life degradation or anaerobic reactor removal; alternatively, this may simply be because the CTC we used was already degraded, see the discussion below.

\subsubsection{Consistent and Proportional LC-MS/MS Tylosin Results in the Digestate Samples}

Based on the tylosin results being more consistent than CTC and Enrofloxacin results, the LC-MS/MS results of the digestate samples were meticulously scrutinized. Even though the LCMS/MS detected concentration values of tylosin that were lower than expected, they were 
consistently proportional to the concentrations. For example, the expected concentration of tylosin was 20, 40, and $60 \mathrm{ppm}$ for samples 4, 5, and 6, with zero degradation assumption, the LC-MS/MS values were $0.5,0.9$, and $1.2 \mathrm{ppm}$. No significant correlation for CTC was found. Figure 6 shows the LC-MS/MS results (Y-axis, ppm) vs. spiked values (X-axis, ppm). The consistently lower measured concentrations in the digestate samples and the high recovery rates in the water samples suggest that there was significant tylosin degradation due to the AD process.

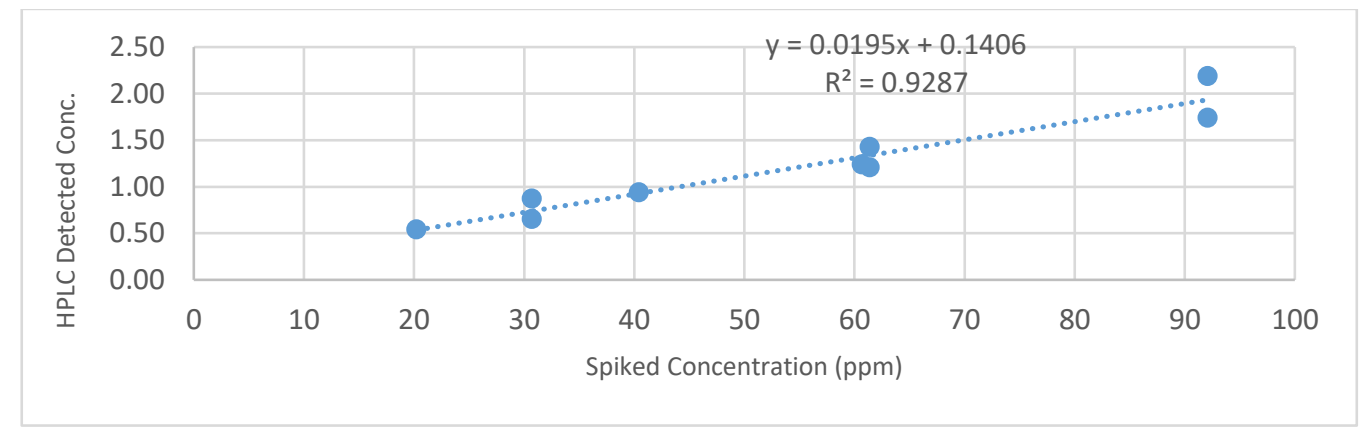

Figure 6. Correlations of LC-MS/MS measured and spiked tylosin concentrations.

\subsubsection{Consistent LC-MS/MS Tylosin Measurements in the Manure External Standards.}

The detected tylosin concentrations of the three external standard samples were similar and had a low deviation, Table 9. For tylosin, the detected levels ranged from 39.8 to $44.3 \mathrm{ppm}$ and averaged $41.5 \mathrm{ppm}$, while the expected concentration was $77.9 \mathrm{ppm}$. For CTC, the measured concentrations were again a small fraction of the expected level. 
Table 9. Concentrations of VAs were detected in the manure external standard samples.

\begin{tabular}{|c|c|c|c|c|c|c|}
\hline Sample \# & Sample Type & Compound & $\begin{array}{l}\text { Calculated } \\
\text { CTC Conc. } \\
\text { (ppm) }\end{array}$ & $\begin{array}{c}\text { CTC } \\
\text { Detected } \\
\text { Conc. } \\
\text { (ppm) }\end{array}$ & $\begin{array}{l}\text { Calculated } \\
\text { tylosin } \\
\text { Conc. } \\
\text { (ppm) }\end{array}$ & $\begin{array}{c}\text { Tylosin } \\
\text { Detected } \\
\text { Conc. } \\
\text { (ppm) }\end{array}$ \\
\hline 1 & Diluted Manure with VAs & CTC + tylosin low Conc. & 233.78 & 14.96 & 77.93 & 39.84 \\
\hline 2 & Diluted Manure with VAs & CTC + tylosin low Conc. & 233.78 & 36.18 & 77.93 & 40.41 \\
\hline 3 & Diluted Manure with VAs & CTC + tylosin low Conc. & 233.78 & 28.52 & 77.93 & 44.32 \\
\hline
\end{tabular}

3.3.5. Relatively Higher Recovery of CTC in the External Standard Samples, and Two Additional CTC Standards

Studying the results of the three external standard samples showed that there was a relatively higher recovery rate for CTC. As an instance, compared with the concentration of 233.78 ppm, LC-MS/MS detected 14.96, 36.16, and $28.52 \mathrm{ppm}$. Compared with previous CTC samples, this group had a much higher recovery rate, which was fresh samples made with diluted manure and VAs. Besides, the external standards were prepared with commercial-grade antibiotics instead of analytical grade.

Table 10 shows results for freshly prepared samples with diluted manure and CTC antibiotic, at concentrations of $4 \mathrm{ppm}$ and $40 \mathrm{ppm}$, and the LC-MS/MS measured concentrations were 1.63 ppm and $11.7 \mathrm{ppm}$, respectively. The recovery rates of CTC were $29 \%$ and $41 \%$. Since the samples were freshly prepared, the probability of degradation due to $\mathrm{AD}$ or half-life degradation was eliminated. Other possibilities are absorption to organic matter, and that inconsistent purity or degradation had already happened before application. For tylosin, LC-MS/MS detected higher concentrations (12 ppm and 67.6 ppm detected for 4 ppm and 40 ppm samples, respectively), which gives a detection rate of $300 \%$ and $169 \%$. 
Table 10. Concentrations of measured calibration standards.

\begin{tabular}{ccc}
\hline \multirow{2}{*}{ Spiked conc. $(\mathbf{p p m})$} & \multicolumn{2}{c}{ LC-MS/MS Detected conc. $(\mathbf{p p m})$} \\
\cline { 2 - 3 } & CTC & Tylosin \\
\hline $\mathbf{0}$ & 0.03 & 1.26 \\
\hline $\mathbf{4}$ & & 12.17 \\
\hline $\mathbf{4 0}$ & 1.63 & 67.62 \\
\hline
\end{tabular}

\subsubsection{Applying External Standard Correction Factors}

Because the internal standards (Enrofloxacin) did not yield consistent measurement, the correction was made based on external standards instead. By applying the external standard adjustment factor, the VA concentrations were corrected accordingly. The adjustment factor was obtained from samples with manure and spiked antibiotics, without retention time for AD. In other words, we just spiked different concentrations of antibiotics in samples made with manure, then prepared those for LC-MS/MS, immediately. In this way, we may be able to track other important factors contributing to our results, such as absorption, ion suppression or enhancement, and recovery rate. Figure 7 presents the measured and corrected VA concentrations.

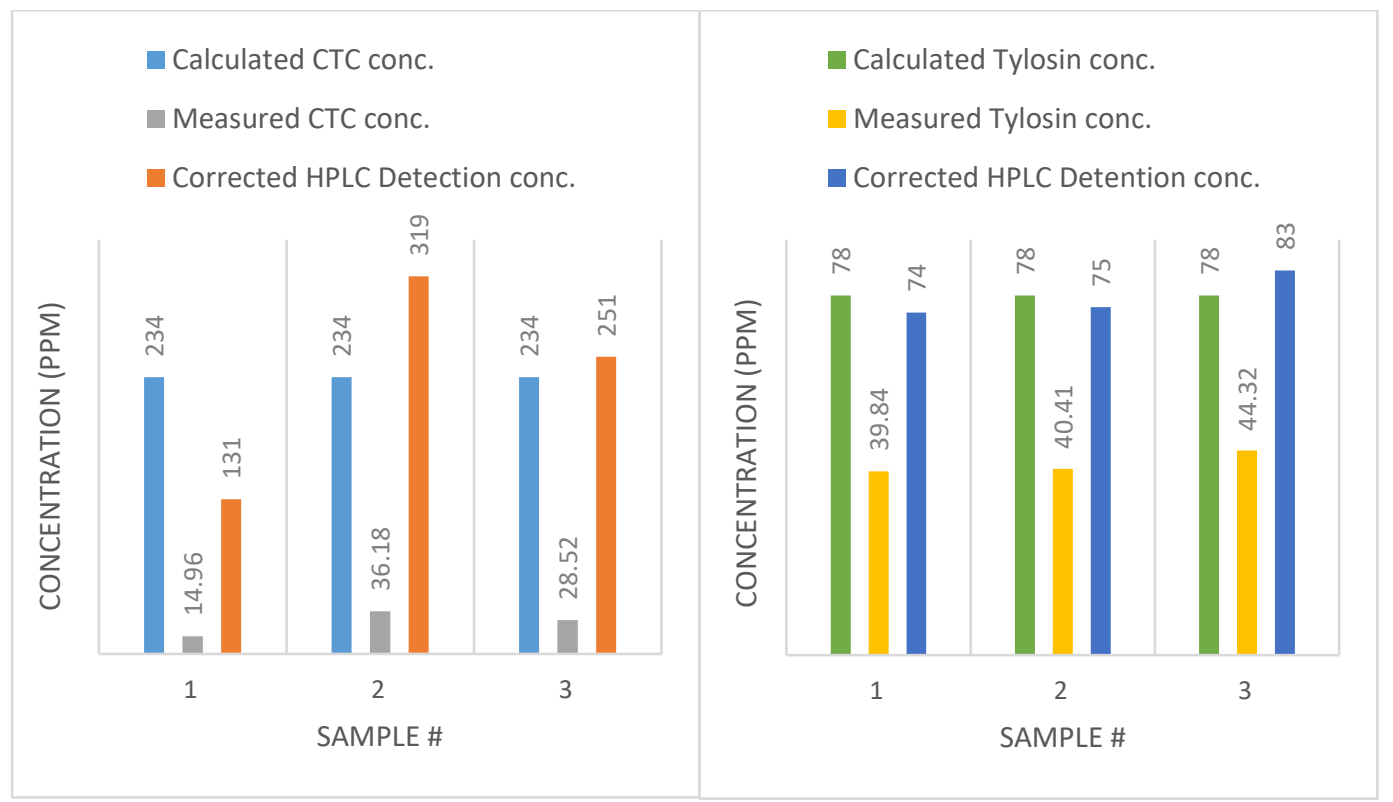


Figure 7. Left: concentrations of CTC, comparing calculated, measured, and corrected concentrations. Right: concentrations of tylosin, comparing calculated, measured, and corrected concentrations.

By using the external standard correction factor instead of the Enrofloxacin correction factor, data are more consistent, especially for tylosin (less than 6\% error). It suggests that Enrofloxacin failed to act as an ideal internal standard. The inconsistency could be due to Enrofloxacin binding to the abundant organic materials or the presence of $\mathrm{Ca}^{2+}, \mathrm{Mg}^{2+}$ Ions.

\subsection{Degradation of CTC}

For CTC, results showed a high degradation rate for both the samples in water and AD (Figure 8). For instance, almost all CTC injections with various concentrations have close to zero concentration. The low concentrations were measured for AD-treated samples, and also for CTC dissolved in water stored at room temperature and $40{ }^{\circ} \mathrm{C}$, the temperature of the AD. The concentrations of the external standards were $234 \mathrm{ppm}$. The results suggest that the CTC degrade much faster than the tylosin, which might be due to the shorter half-life (8 days) as reported by the manufacturer. It is also possible that the CTC powder we used had already degraded. CTC concentration in external standard samples was reduced to 131, 320, and $251 \mathrm{ppm}$ from its original $234 \mathrm{ppm}$. Because the purity correction was already applied and recovery rate adjustment was made, also only low CTC concentration was detected for the water and digestate samples, the CTC probably just degraded itself over a short time. A study by Winckler and Grafe [71] showed that tetracycline in liquid manure was degraded by $50 \%$ in 82 days. Arikan [72] reported a 75\% reduction in CTC concentration with AD after 33 days, with a half-life of 18 days. Cheng et al. [73] reported a high affinity between tetracycline and solid manure during AD. For future research, 
additional testing to examine the possibility of the adsorption by the glass jar used in this study as the $\mathrm{AD}$ reactors should be conducted, since there are very few investigations on this subject.

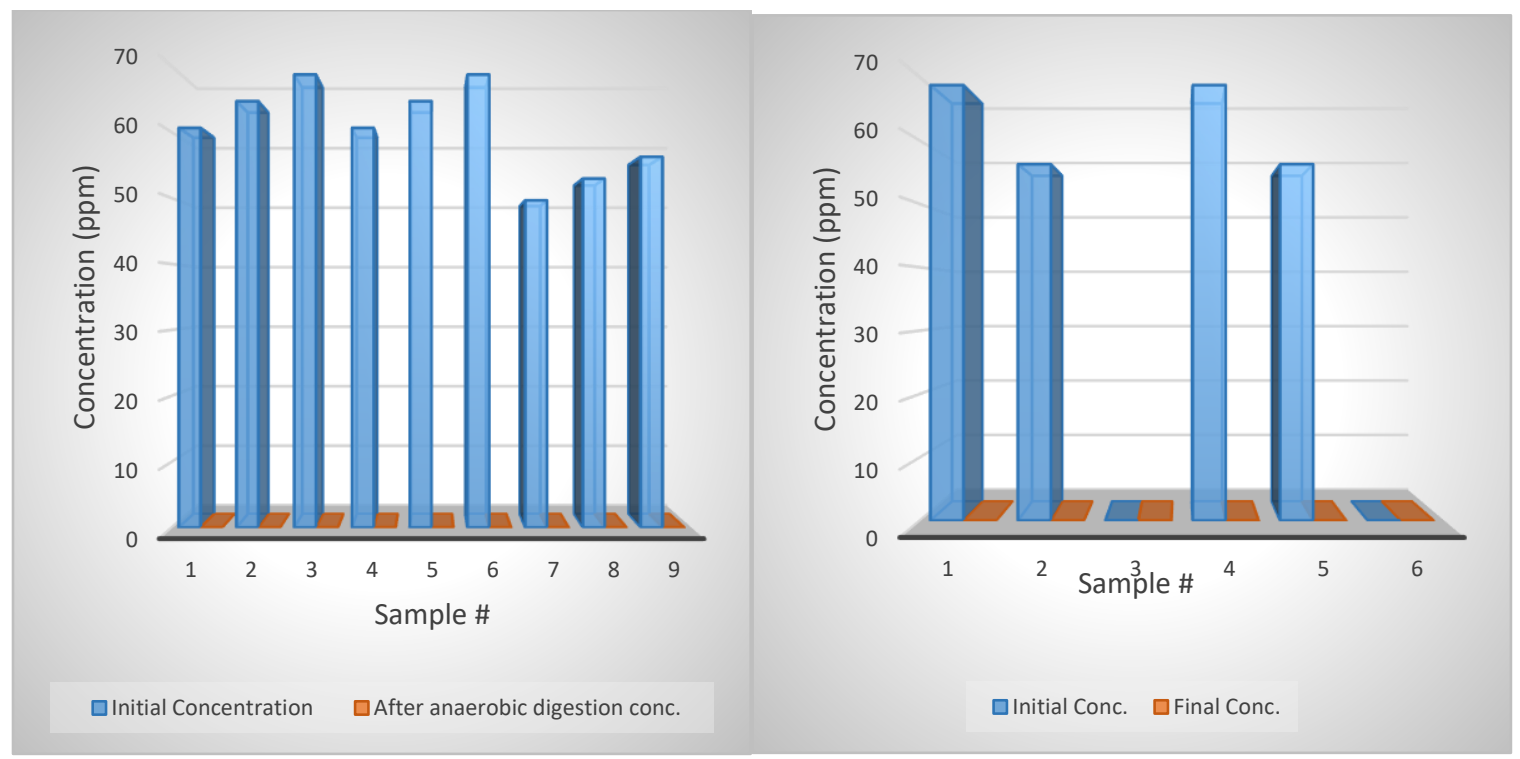

Figure 8. Left: CTC concentration change with anaerobic digestion. Right: CTC concentration change with reactors filled with diluted water.

\subsection{Degradation of Tylosin}

Tylosin degraded very well with the ASBR reactor working at $39^{\circ} \mathrm{C}$ and loading with swine manure every two days. Comparing the degradation rate of tylosin in ASBRs with jars filled only with water shows that $\mathrm{AD}$ is effective in reducing tylosin (Figure 9). The degradation rate of tylosin in water averaged 33.5; however, the degradation was 100 percent with AD. A study by Kolz et al. [74] concluded no effective degradation for tylosin B and D in anaerobic conditions for up to eight months. tylosin A was degraded under aerobic conditions with a half-life of 2 to 40 days [5,75]. Stone et al. [59] also reported no significant degradation for tylosin. 


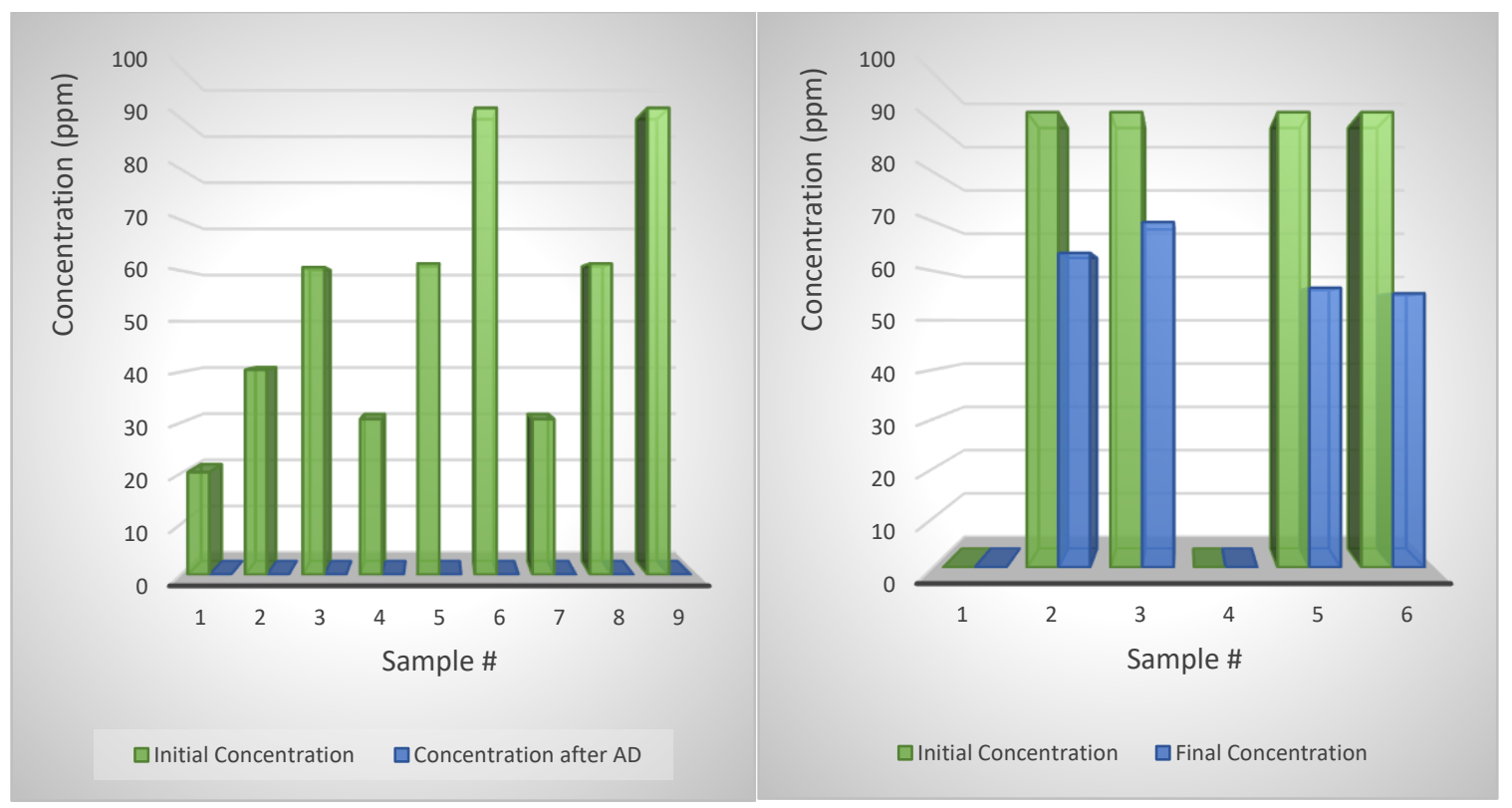

Figure 9. Left: Tylosin concentration changes with anaerobic digestion. Right: Tylosin concentration changes with reactors filled with diluted water.

\subsection{Effects of Having Two Types of VA in the Digestion and Water}

In these experiments, we planned to compare the effect of having two different antibiotics on the reduction efficiency of antibiotics. Identical injections and concentrations were applied in the mixture treatment, except for a series of samples, both antibiotics were spiked.

For tylosin, the results showed that there was little difference between samples. The tylosin removal was similar with or without CTC mixture, suggesting that the CTC addition had no adverse effect on tylosin degradation.

However, because CTC degradation was much faster than tylosin, and because the samples collected for CTC concentration measurements were not resolute enough (shorter time than the five-day sampling), the speed of the CTC degradation and effects of the tylosin addition could not be determined based on this dataset (Table 9). 


\subsection{Contrast Tylosin Reduction in Water and AD Reactors}

Tylosin tartrate showed a relatively higher removal in AD treatment when compared to samples that were dissolved in water. Figure 10 depicts that the tylosin samples treated by AD for twelve days were removed entirely (100\% removal). However, the removal of tylosin tartrate in water (dotted line) was $40 \%$ or less during the same period. The lower degradation in the water samples suggests that $\mathrm{AD}$ is effective in enhancing tylosin degradation in the animal manure and that this could be the essential effect of the AD.

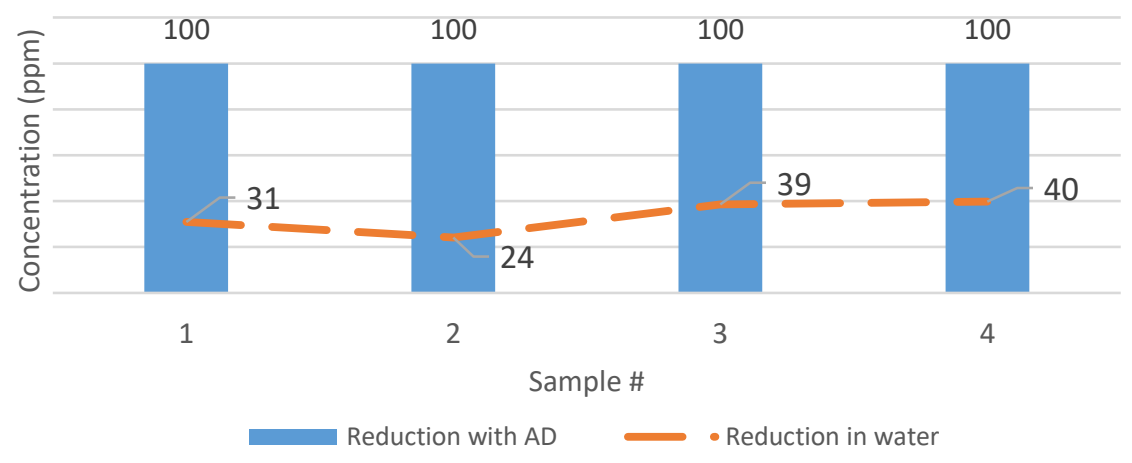

Figure 10. The removal of tylosin in water and the anaerobic digestion (AD) reactor.

\subsection{Bacterial Community Dynamics}

Phyla Firmicutes, Bacteroidetes, Proteobacteria, and Synergistetes were dominant or codominant in bacteria. Different types of Clostridia consisted mostly of the Firmicutes. Methanomicrobia was the dominant Archaea among our samples.

The first group was treated with CTC and showed a slight fluctuation in Archaea abundance, $4.37 \%, 5.19 \%$, and $5.06 \%$ related to low, medium, and high concentrations of CTC, respectively. As shown in Table 11, Firmicutes almost remained constant, and Bacteriodetes increased from 14.03 to $15.30 \%$ and then decreased to $12.50 \%$ for low, medium, and high concentrations of CTC, respectively. The same pattern occurred for Synergistetes, going up from 1.67 to $1.75 \%$ and then 
Table 11. Percentages of different microorganisms with various treatment plans.

\begin{tabular}{|c|c|c|c|c|c|c|c|c|c|c|c|}
\hline & Total & $\begin{array}{l}\text { CTC } \\
\text { Low }\end{array}$ & $\begin{array}{l}\text { CTC } \\
\text { Med }\end{array}$ & $\begin{array}{l}\text { CTC } \\
\text { High }\end{array}$ & $\begin{array}{l}\text { CTC + } \\
\text { Tyl Low }\end{array}$ & $\begin{array}{c}\text { CTC + } \\
\text { Tyl Med }\end{array}$ & $\begin{array}{c}\text { CTC + } \\
\text { Tyl Med }\end{array}$ & $\begin{array}{c}\text { CTC +Tyl } \\
\text { High }\end{array}$ & Tyl Low & $\begin{array}{l}\text { Tyl } \\
\text { Med }\end{array}$ & Tyl High \\
\hline $\begin{array}{c}\text { D_0__Archaea; } \\
\text { D_1_Euryarchaeota }\end{array}$ & $5.90 \%$ & $4.40 \%$ & $5.20 \%$ & $5.10 \%$ & $7.80 \%$ & $7.40 \%$ & $5.20 \%$ & $6.30 \%$ & $4.80 \%$ & $3.70 \%$ & $8.70 \%$ \\
\hline $\begin{array}{c}\text { D_0_Bacteria; } \\
\text { D_1_Actinobacteria }\end{array}$ & $0.10 \%$ & $0.10 \%$ & $0.00 \%$ & $0.10 \%$ & $0.10 \%$ & $0.10 \%$ & $0.10 \%$ & $0.10 \%$ & $0.10 \%$ & $0.10 \%$ & $0.10 \%$ \\
\hline $\begin{array}{c}\text { D_0__Bacteria; } \\
\text { D_1_Atribacteria }\end{array}$ & $1.00 \%$ & $1.00 \%$ & $1.10 \%$ & $1.50 \%$ & $0.90 \%$ & $1.10 \%$ & $0.90 \%$ & $1.30 \%$ & $0.90 \%$ & $0.50 \%$ & $0.70 \%$ \\
\hline $\begin{array}{c}\text { D_0_Bacteria; } \\
\text { D_1_Bacteroidetes }\end{array}$ & $7.70 \%$ & $14.00 \%$ & $15.30 \%$ & $12.50 \%$ & $4.00 \%$ & $5.90 \%$ & $10.20 \%$ & $5.50 \%$ & $2.20 \%$ & $5.30 \%$ & $2.50 \%$ \\
\hline $\begin{array}{l}\text { D_0_Bacteria; } \\
\text { D_1_Chloroflexi }\end{array}$ & $0.40 \%$ & $0.50 \%$ & $.40 \%$ & $0.30 \%$ & $0.40 \%$ & $0.30 \%$ & $0.30 \%$ & $0.70 \%$ & $0.80 \%$ & $0.30 \%$ & $0.50 \%$ \\
\hline $\begin{array}{c}\text { D_0__Bacteria; } \\
\text { D_1_Cloacimonetes }\end{array}$ & $0.10 \%$ & $0.10 \%$ & $0.30 \%$ & $0.10 \%$ & $0.00 \%$ & $0.10 \%$ & $0.20 \%$ & $0.00 \%$ & $0.00 \%$ & $0.10 \%$ & $0.00 \%$ \\
\hline $\begin{array}{l}\text { D_0_Bacteria; } \\
\text { D_1_Firmicutes }\end{array}$ & $74.70 \%$ & $72.80 \%$ & $71.90 \%$ & $75.30 \%$ & $74.90 \%$ & $79.70 \%$ & $77.90 \%$ & $68.10 \%$ & $76.50 \%$ & $82.70 \%$ & $66.70 \%$ \\
\hline $\begin{array}{c}\text { D_0_Bacteria; } \\
\text { D_1_Kiritimatiellaeota }\end{array}$ & $1.00 \%$ & $0.80 \%$ & $0.80 \%$ & $0.50 \%$ & $1.60 \%$ & $0.90 \%$ & $0.70 \%$ & $0.90 \%$ & $1.50 \%$ & $1.00 \%$ & $1.60 \%$ \\
\hline $\begin{array}{c}\text { D_0_Bacteria; } \\
\text { D_1_Planctomycetes }\end{array}$ & $0.30 \%$ & $0.40 \%$ & $0.30 \%$ & $0.30 \%$ & $0.30 \%$ & $0.10 \%$ & $0.20 \%$ & $0.10 \%$ & $0.30 \%$ & $0.20 \%$ & $0.40 \%$ \\
\hline $\begin{array}{c}\text { D_0_Bacteria; } \\
\text { D_1_Proteobacteria }\end{array}$ & $6.00 \%$ & $2.50 \%$ & $1.40 \%$ & $1.90 \%$ & $7.00 \%$ & $1.80 \%$ & $1.90 \%$ & $13.40 \%$ & $10.20 \%$ & $4.00 \%$ & $16.00 \%$ \\
\hline
\end{tabular}




\begin{tabular}{|c|c|c|c|c|c|c|c|c|c|c|c|}
\hline $\begin{array}{c}\text { D_0_Bacteria; } \\
\text { D_1__Synergistetes }\end{array}$ & $2.00 \%$ & $1.70 \%$ & $1.70 \%$ & $1.40 \%$ & $2.60 \%$ & $1.80 \%$ & $1.30 \%$ & $3.40 \%$ & $2.10 \%$ & $1.50 \%$ & $2.60 \%$ \\
\hline No blast hit; Other & $0.60 \%$ & $1.50 \%$ & $1.50 \%$ & $0.80 \%$ & $0.20 \%$ & $0.50 \%$ & $0.90 \%$ & $0.10 \%$ & $0.40 \%$ & $0.40 \%$ & $0.10 \%$ \\
\hline
\end{tabular}


dropping to $1.44 \%$, with the mentioned level of CTC concentrations. However, the reverse happened for Proteobacteria: the abundance level reduced from 2.46 to $1.35 \%$ and then rose to $1.87 \%$.

The second group, consisting of four samples, all are added with the mixture of CTC and tylosin with low, medium, and high concentrations. Two samples were taken from medium range concentration because the administration duration of CTC was 6 days and tylosin was 10 days. Therefore, samples were taken at the end of the administration of each VA, on day 6 and day 10 . There is a reverse relation between Archaea abundance and VAs concentration as well as administration duration. Archaea level is dropping with a higher concentration of VAs and a longer retention time. The effect of the administration period is stronger than the dosage on the Archaea population. Firmicutes, on the other hand, has increased from 74.9 to $79.70 \%$ by increasing the dosage of VAs from low to medium. The trend is not consistent with shifting from medium to high concentration of VA; it would decrease the abundance of Firmicutes. The administration period has the same effect, but not as much as dosage. Phylum Bacteroides population increased with the rise of VAs concentration and doubled with an increase in retention time, from 6 to 10 days with a medium level of VAs. Proteobacteria and Synergistetes abundance both have dropped by increasing dosage for low to medium, but the fall is drastic for Proteobacteria, changing from 7 to $1.8 \%$. By the end of CTC administration, when adding tylosin, their abundance recovered slightly. Surprisingly, in high concentrations of CTC and tylosin, both of these bacteria showed growth in their population. The proteobacteria population is almost doubled by having a high dosage of VAs instead of a low.

The last group, which is being medicated with tylosin only, Archaea, decreased slightly and then almost doubled when moving from low concentration to high. For Bacteroides and Firmicutes, 
it is exactly the reverse, with maximum abundance around medium range concentration and the nearly same number for low and high concentrations. For proteobacteria, results showed a sharp drop with shifting from low to medium concentration, $10.2 \%$ changed to $4.03 \%$. However, by raising the dosage, the abundance of proteobacteria returned to $15.97 \%$.

Bacteroidia is the major class found within the phylum of Bacteroidetes; and is abundant in digesters that use cow manure as feedstock [76]. Firmicutes phylum is mostly syntrophic bacteria that can decompose a variety of fatty acids, and exists in both activated sludge systems and anaerobic digesters [77]. Within the species of Firmicutes, Clostridia is the dominant class. The predominance of Clostridia in the AD sludge was related to the comparably fast hydrolysis and VFA (volatile fatty acids) fermentation happening in the digesters [78].

Fatty acid-oxidizing bacteria, including the Synergistales group which have syntrophs are connecting bonds of the chain between the primary fermenters and methanogens [79], are abundant in thermophilic digesters [80,81]. The presence of Synergistetes (syntrophic acetate oxidizers) might be an indicator of a decent acetotrophic activity in the bioreactor [82].

There are two major categories of methanogens; acetoclastic which consumes acetate to produce methane or hydrogenotrophic that are converting $\mathrm{CO}_{2}$ and $\mathrm{H}_{2}$ to methane.

The acetoclastic methanogenesis is linked with the Methanosarcinales and the hydrogenotrophic methanogenesis is linked with the Methanomicrobiaceae family. In the current study, the hydrogenotrophic pathway with Methanosarcinaceae was dominant. Kim et al. [42], Nogueira et al., [78] and Padmasiri et al. [83] also detected a dominant Methanomicrobiales order on AD. 


\subsection{Statistical Analysis of the Effect of Different Treatments on Samples}

There is a notable difference between the treated and control group, which shows antibiotics had a significant influence on altering the bacterial community in our digesters. Figure 11 shows the samples arranged using the same two similarity measures used to generate the PCoA plots but in the form of a dendrogram. Bray-Curtis similarities and Jaccard similarities methods are used for this comparison.

In both of the methods, the differences between all three treatment groups are modest and likely obscured by the variability introduced by the control samples.
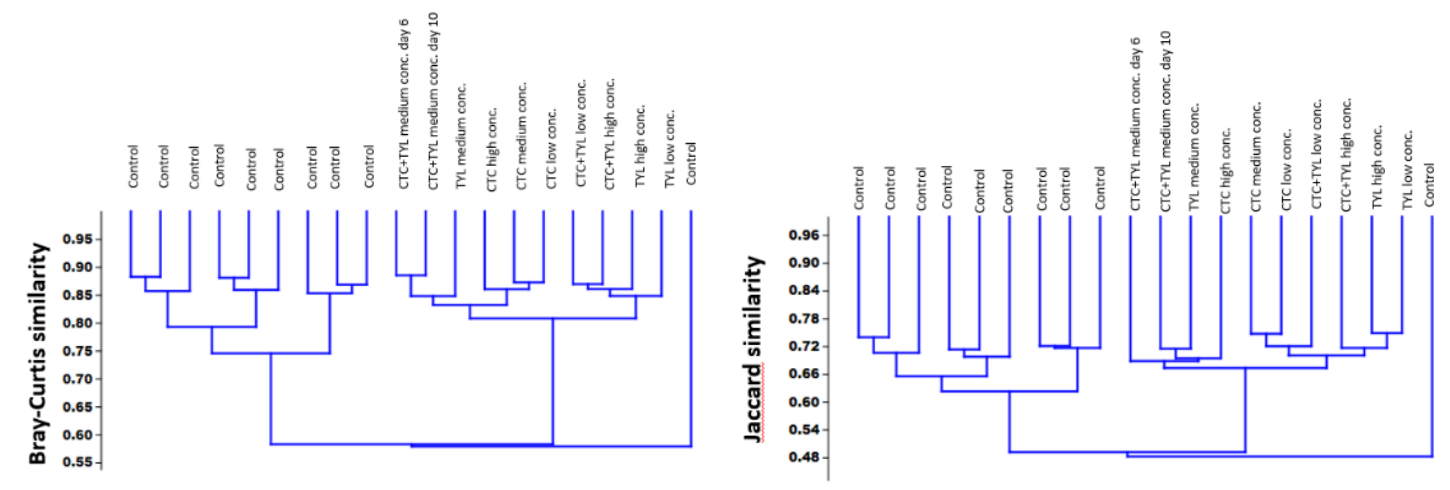

Figure 11. Dendrogram of bacterial community based on Bray-Curtis similarities and Jaccard similarities.

Figure 12 shows a stacked bar chart at the best taxonomic resolution afforded by our primers. Again, the differences between the two datasets are stark, while the differences between treatment groups are more subtle (but present). 


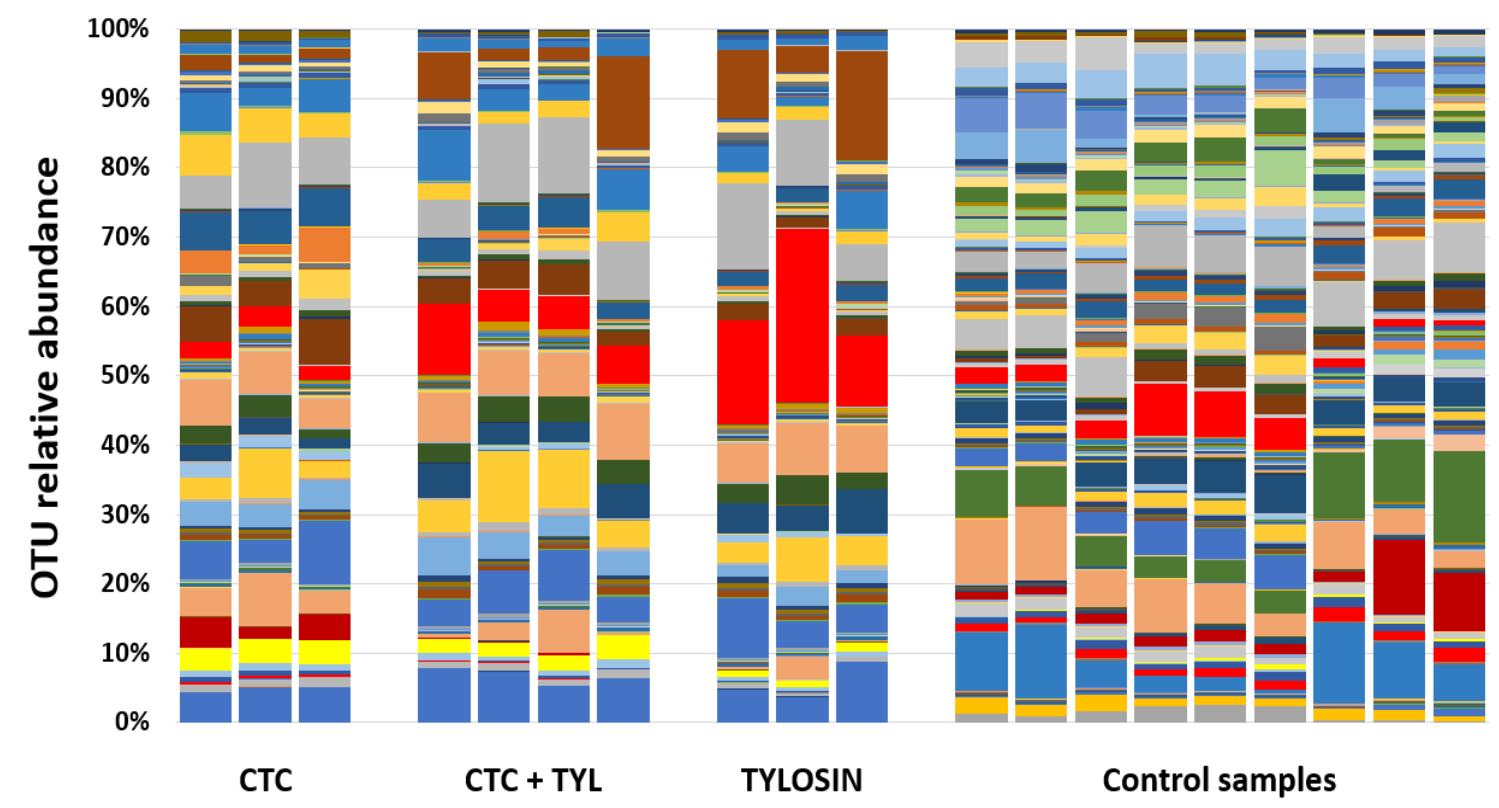

Figure 12. The stacked bar chart at the best taxonomic resolution.

Figure 13 shows a heat map in which samples (columns) are ordered according to similarity using a hierarchical method (UPGMA) based on the 50 OTUs (operational taxonomic unit) (rows) with the lowest $\mathrm{p}$ values following serial ANOVA testing of all 629 OTUs. In short, it shows perfect discrimination between groups when the samples are clustered using only the 50 most variable OTUs. Taxonomic identity of the microbes is listed on the right-hand side of the heat map. 


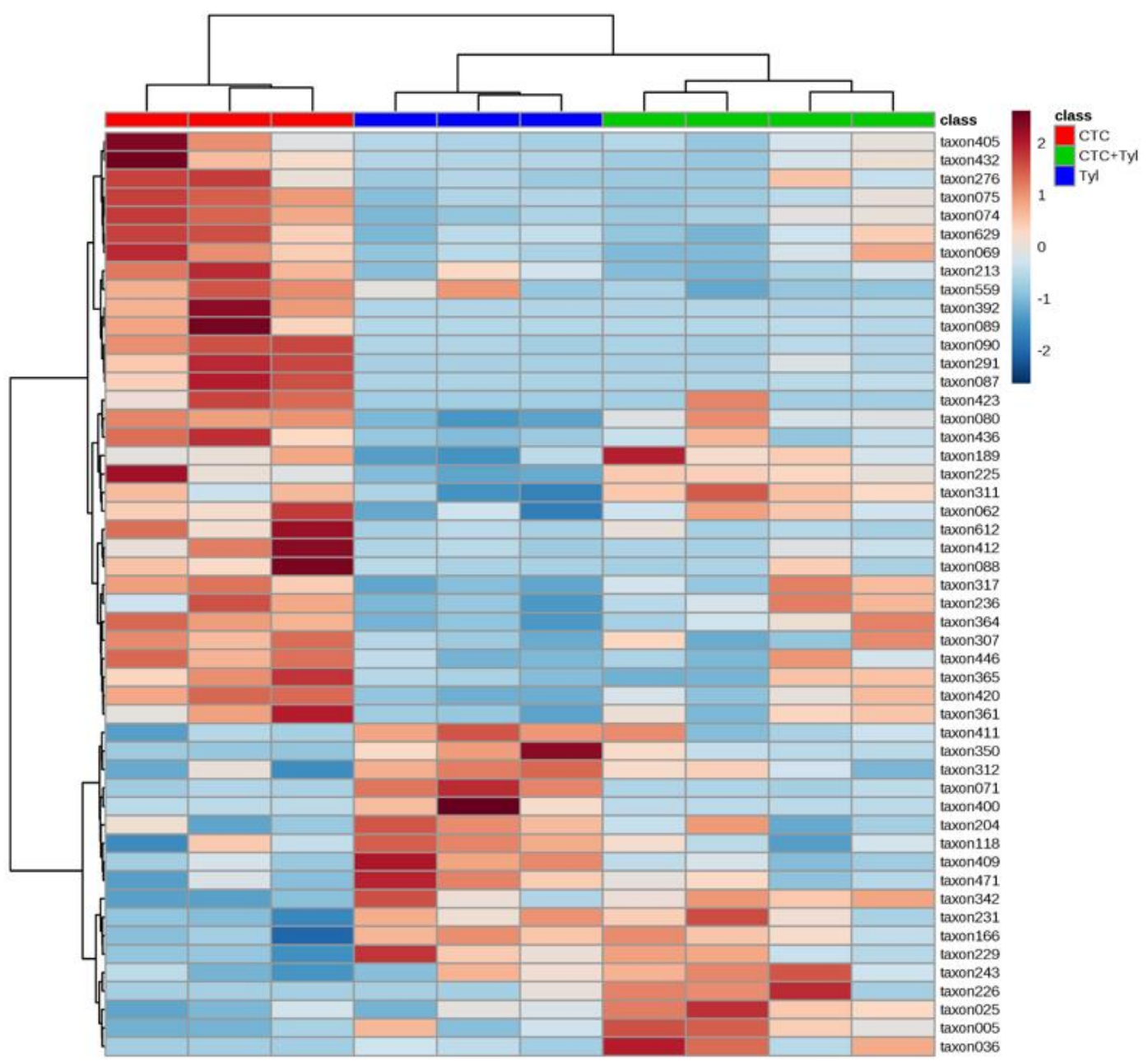

Figure 13. Heat map of treated samples using a hierarchical method (UPGMA) based on the 50 operational taxonomic units (OTUs) (rows) with the lowest p values.

Figure 14 shows box plots representing the relative abundance of eight of the OTUs with the lowest $p$ values. One can easily note the very clear pattern of microbes with sensitivity to one or the other drugs, with Proteiniphilum (lower left) being the anomaly. Some other microbes with low p values mostly had these types of patterns, either down in CTC and CTC + tylosin, or down in tylosin and CTC + tylosin. 

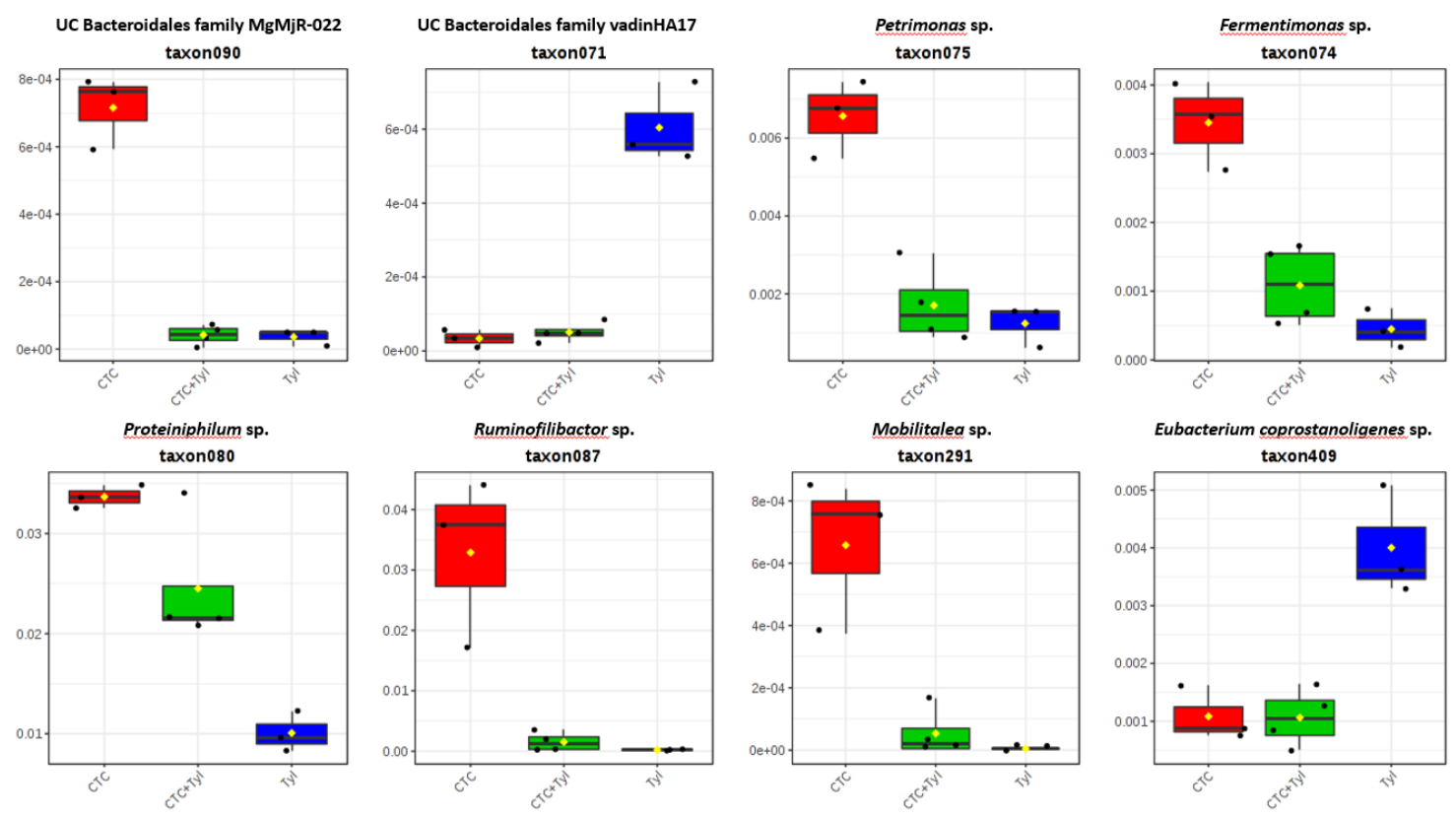

Figure 14. Box plots representing the relative abundance of 8 of the OTUs with the lowest $p$

values.

Finally, Figure 15 is a random forest analysis looking for "biomarkers" of each treatment group. The greater the "MeanDecreaseAccuracy", the better that OTU is as a biomarker of the rankings shown to the right of the Figure. For example, Methanoculleus is apparently an excellent predictor of these groups by having a high relative abundance in the CTC samples and low abundance in the CTC + tylosin samples. Likewise, the Anaerorhabdus furcosa group and Flexilinea sp. can be found more on samples with high tylosin concentration and low CTC. Ruminiclostridium sp. can be abundant in conditions with high CTC levels and low tylosin. 


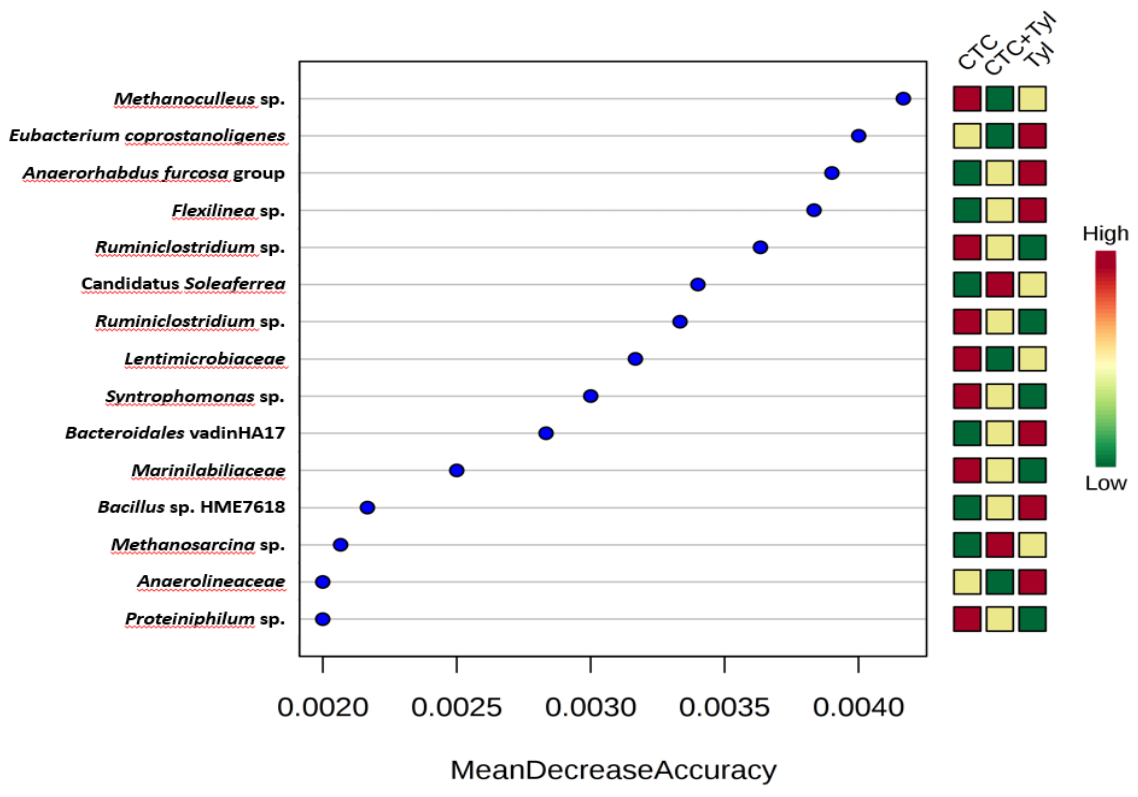

Figure 15. Random forest analysis of biomarkers based on MeanDecreaseAccuracy.

\section{Conclusions}

The results show that for both CTC and tylosin with maximum concentration added of 298 and 263 ppm, respectively, a negligible inhibitory effect on ASBR performance was observed. No harmful effect on the microbial community, $\mathrm{pH}$ or alkalinity was observed; however, microbial diversity was decreased. Efficient tylosin removal with AD occurred (removal was 100\%, while removal in distilled water-filled reactors was around $40 \%$ or less), though, it cannot be proven for CTC. In addition, no difference was detected for using a mixture of tylosin and CTC, compared to the solo use of each. More research must be carried out on testing different VAs to discover the efficiency of $\mathrm{AD}$ reactors for VA removal. Besides, amplicon sequencing was performed on each group by using the 50 most variable operational taxonomic units (OTUs)s, and perfect discriminations were detected between groups. The effect of administration period and dosage of VAs on Phyla Firmicutes Proteobacteria, Synergistetes, and Phylum Bacteroides was investigated. 
OTU's alteration is used to detect biomarkers. These biomarkers' abundance can be employed to predict the sample's contamination with these antibiotics. 


\section{References}

1. $\quad$ Barton, M.D. Antibiotic use in animal feed and its impact on human health. Nutr. Res. Rev. 2000, 13, 279299, doi:10.1079/095442200108729106.

2. Zhang, Q.-Q.; Ying, G.-G.; Pan, C.-G.; Liu, Y.-S.; Zhao, J.-L. Comprehensive evaluation of antibiotics emission and fate in the river basins of China: Source analysis, multimedia modeling, and linkage to bacterial resistance. Environ. Sci. Technol. 2015, 49, 6772-6782, doi:10.1021/acs.est.5b00729.

3. Wang, J.; Wang, S. Preparation, modification and environmental application of biochar: A review. J. Clean. Prod. 2019, 227, 1002-1022, doi:10.1016/j.jclepro.2019.04.282.

4. 2016 Summary report on antimicrobials sold or distributed for use in food-producing animals. Available online: https://www.fda.gov/files/about\%20fda/published/2016-Summary-Report-on-AntimicrobialsSold-or-Distributed-for-Use-in-Food-Producing-Animals.pdf (accessed on June 01, 2018).

5. Teeter, J.S.; Meyerhoff, R.D. Aerobic degradation of tylosin in cattle, chicken, and swine excreta. Environ. Res. 2003, 93, 45-51, doi:10.1016/s0013-9351(02)00086-5.

6. Kuppusamy, S.; Kakarla, D.; Venkateswarlu, K.; Megharaj, M.; Yoon, Y.-E.; Lee, Y.B. Veterinary antibiotics (VAs) contamination as a global agro-ecological issue: A critical view. Agric. Ecosyst. Environ. 2018, 257, 47-59, doi:10.1016/j.agee.2018.01.026.

7. Chen, J.; Yu, Z.; Michel, F.; Wittum, T.; Morrison, M. Development and application of real-time PCR assays for quantification of erm genes conferring resistance to macrolides-lincosamides-streptogramin B in livestock manure and manure management systems. Appl. Environ. Microbiol. 2007, 73, 4407-4416, doi:10.1128/aem.02799-06.

8. Lienert, J.; Bürki, T.; Escher, B. Reducing micropollutants with source control: Substance flow analysis of 212 pharmaceuticals in faeces and urine. Water Sci. Technol. 2007, 56, 87-96, doi:10.2166/wst.2007.560.

9. Kumar, K.; Gupta, S.C.; Baidoo, S.K.; Chander, Y.; Rosen, C.J. Antibiotic uptake by plants from soil fertilized with animal manure. J. Environ. Qual. 2005, 34, 2082-2085, doi:10.2134/jeq2005.0026.

10. Alexy, R.; Kümpel, T.; Kümmerer, K. Assessment of degradation of 18 antibiotics in the Closed Bottle Test. Chemosphere 2004, 57, 505-512, doi:10.1016/j.chemosphere.2004.06.024. 
11. Adeel, M.; Song, X.; Wang, Y.; Francis, D.; Yang, Y. Environmental impact of estrogens on human, animal and plant life: A critical review. Environ. Int. 2017, 99, 107-119, doi:10.1016/j.envint.2016.12.010.

12. Brown, E.D.; Wright, G.D. Antibacterial drug discovery in the resistance era. Nat. Cell Biol. 2016, 529, 336-343, doi:10.1038/nature17042.

13. Liu, Y.; Liu, Y.; Li, H.; Fu, X.; Guo, H.; Meng, R.; Lu, W.; Zhao, M.; Wang, H. Health risk impacts analysis of fugitive aromatic compounds emissions from the working face of a municipal solid waste landfill in China. Environ. Int. 2016, 97, 15-27, doi:10.1016/j.envint.2016.10.010.

14. Liu, P.; Zhang, H.; Feng, Y.; Yang, F.; Zhang, J. Removal of trace antibiotics from wastewater: A systematic study of nanofiltration combined with ozone-based advanced oxidation processes. Chem. Eng. J. 2014, 240, 211-220, doi:10.1016/j.cej.2013.11.057.

15. Qiao, M.; Ying, G.-G.; Singer, A.C.; Zhu, Y.-G. Review of antibiotic resistance in China and its environment. Environ. Int. 2018, 110, 160-172, doi:10.1016/j.envint.2017.10.016.

16. Zhao, W.; Sui, Q.; Mei, X.; Cheng, X. Efficient elimination of sulfonamides by an anaerobic/anoxic/oxicmembrane bioreactor process: Performance and influence of redox condition. Sci. Total. Environ. 2018, 633, 668-676, doi:10.1016/j.scitotenv.2018.03.207.

17. Yu, F.; Li, Y.; Han, S.; Ma, J.; Han, S. Adsorptive removal of antibiotics from aqueous solution using carbon materials. Chemosphere 2016, 153, 365-385, doi:10.1016/j.chemosphere.2016.03.083.

18. Wang, J.; Zhuan, R.; Chu, L. The occurrence, distribution and degradation of antibiotics by ionizing radiation: An overview. Sci. Total. Environ. 2019, 646, 1385-1397, doi:10.1016/j.scitotenv.2018.07.415.

19. Homem, V.; Santos, L. Degradation and removal methods of antibiotics from aqueous matrices-A review. J. Environ. Manag. 2011, 92, 2304-2347, doi:10.1016/j.jenvman.2011.05.023.

20. Menkem, Z.E.; Ngangom, B.L.; Tamunjoh, S.S.A.; Boyom, F.F. Antibiotic residues in food animals: Public health concern. Acta Ecol. Sin. 2019, 39, 411-415, doi:10.1016/j.chnaes.2018.10.004.

21. Phillips, I.; Casewell, M.; Cox, T.; De Groot, B.; Friis, C.; Jones, R.; Nightingale, C.; Preston, R.; Waddell, J. Does the use of antibiotics in food animals pose a risk to human health? A critical review of published data. J. Antimicrob. Chemother. 2003, 53, 28-52, doi:10.1093/jac/dkg483. 
22. Sivagami, K.; Vignesh, V.J.; Srinivasan, R.; Divyapriya, G.; Nambi, I. Antibiotic usage, residues and resistance genes from food animals to human and environment: An Indian scenario. J. Environ. Chem. Eng. 2020, 8, 102221, doi:10.1016/j.jece.2018.02.029.

23. Tasho, R.P.; Cho, J.Y. Veterinary antibiotics in animal waste, its distribution in soil and uptake by plants: A review. Sci. Total. Environ. 2016, 563, 366-376, doi:10.1016/j.scitotenv.2016.04.140.

24. Chung, H.S.; Lee, Y.-J.; Rahman, M.; El-Aty, A.A.; Lee, H.S.; Kabir, H.; Kim, S.W.; Park, B.-J.; Kim, J.-E.; Hacımüftüoğlu, F.; et al. Uptake of the veterinary antibiotics chlortetracycline, enrofloxacin, and sulphathiazole from soil by radish. Sci. Total. Environ. 2017, 605, 322-331, doi:10.1016/j.scitotenv.2017.06.231.

25. Yang, L.; Zhang, S.; Chen, Z.; Wen, Q.; Wang, Y. Maturity and security assessment of pilot-scale aerobic co-composting of penicillin fermentation dregs (PFDs) with sewage sludge. Bioresour. Technol. 2016, 204, 185-191, doi:10.1016/j.biortech.2016.01.004.

26. Bengtsson-Palme, J.; Larsson, D.G.J. Concentrations of antibiotics predicted to select for resistant bacteria: Proposed limits for environmental regulation. Environ. Int. 2016, 86, 140-149, doi:10.1016/j.envint.2015.10.015.

27. Taleghani, A.H.; Lim, T.T.; Lin, C.-H. Degradation of veterinary antibiotics in swine manure via anaerobic digestion. In Proceedings of the 2018 ASABE International Meeting, Michigan, MI, USA, 29 July-1 August 2018.

28. Miller, C.; Heringa, S.; Kim, J.; Jiang, X. Analyzing indicator microorganisms, antibiotic resistant Escherichia coli, and regrowth potential of foodborne pathogens in various organic fertilizers. Foodborne Pathog. Dis. 2013, 10, 520-527, doi:10.1089/fpd.2012.1403.

29. Edrington, T.S.; Fox, W.E.; Callaway, T.; Anderson, R.C.; Hoffman, D.W.; Nisbet, D.J. Pathogen prevalence and influence of composted dairy manure application on antimicrobial resistance profiles of commensal soil bacteria. Foodborne Pathog. Dis. 2009, 6, 217-224, doi:10.1089/fpd.2008.0184.

30. Dolliver, H.; Gupta, S.C.; Noll, S. Antibiotic degradation during manure composting. J. Environ. Qual. 2008, 37, 1245-1253, doi:10.2134/jeq2007.0399. 
31. Xie, W.-Y.; Yang, X.-P.; Li, Q.; Wu, L.-H.; Shen, Q.-R.; Zhao, F.J. Changes in antibiotic concentrations and antibiotic resistome during commercial composting of animal manures. Environ. Pollut. 2016, 219, 182190, doi:10.1016/j.envpol.2016.10.044.

32. Prado, N.; Ochoa, J.; Amrane, A. Biodegradation and biosorption of tetracycline and tylosin antibiotics in activated sludge system. Process. Biochem. 2009, 44, 1302-1306, doi:10.1016/j.procbio.2009.08.006.

33. Joy, S.R.; Li, X.; Snow, D.; Gilley, J.E.; Woodbury, B.; Bartelt-Hunt, S. Fate of antimicrobials and antimicrobial resistance genes in simulated swine manure storage. Sci. Total. Environ. 2014, 481, 69-74, doi:10.1016/j.scitotenv.2014.02.027.

34. Angenent, L.T.; Mau, M.; George, U.; Zahn, J.A.; Raskin, L. Effect of the presence of the antimicrobial tylosin in swine waste on anaerobic treatment. Water Res. 2008, 42, 2377-2384, doi:10.1016/j.watres.2008.01.005.

35. Shi, J.; Liao, X.; Wu, Y.; Liang, J. Effect of antibiotics on methane arising from anaerobic digestion of pig manure. Anim. Feed. Sci. Technol. 2011, 457-463, doi:10.1016/j.anifeedsci.2011.04.033.

36. Beneragama, N.; Lateef, S.A.; Iwasaki, M.; Yamashiro, T.; Umetsu, K. The combined effect of cefazolin and oxytertracycline on biogas production from thermophilic anaerobic digestion of dairy manure. Bioresour. Technol. 2013, 133, 23-30, doi:10.1016/j.biortech.2013.01.032.

37. 2012 Summary report on antimicrobials sold or distributed for use in food-producing animals. Available online: https://www.fda.gov/media/89630/download (accessed on July 01, 2019).

38. Furtula, V.; Farrell, E.G.; Diarrassouba, F.; Rempel, H.; Pritchard, J.; Diarra, M.S. Veterinary pharmaceuticals and antibiotic resistance of Escherichia coli isolates in poultry litter from commercial farms and controlled feeding trials. Poult. Sci. 2010, 89, 180-188, doi:10.3382/ps.2009-00198.

39. Hu, D.; Coats, J. Aerobic degradation and photolysis of tylosin in water and soil. Environ. Toxicol. Chem. 2007, 26, 884-889, doi:10.1897/06-197r.1.

40. Jia, A.; Xiao, Y.; Hu, J.; Asami, M.; Kunikane, S. Simultaneous determination of tetracyclines and their degradation products in environmental waters by liquid chromatography-electrospray tandem mass spectrometry. J. Chromatogr. A 2009, 1216, 4655-4662, doi:10.1016/j.chroma.2009.03.073. 
41. Kemper, N. Veterinary antibiotics in the aquatic and terrestrial environment. Ecol. Indic. 2008, 8, 1-13, doi:10.1016/j.ecolind.2007.06.002.

42. Kim, M.; Ahn, Y.-H.; Speece, R.E. Comparative process stability and efficiency of anaerobic digestion; mesophilic vs. thermophilic. Water Res. 2002, 36, 4369-4385, doi:10.1016/s0043-1354(02)00147-1.

43. Kümmerer, K. Antibiotics in the aquatic environment-A review-Part I. Chemosphere 2009, 75, 417-434, doi:10.1016/j.chemosphere.2008.11.086.

44. World Bank. Drug-Resistant Infections: A Threat to Our Economic Future. World Bank Rep. 2016, 2 (September), 1-132. https://doi.org/10.1007/s11947-009-0181-3.

45. Wang, H.; Lim, T.T.; Duong, C.; Zhang, W.; Xu, C.; Yan, L.; Mei, Z.; Wang, W.; Wang Long-term mesophilic anaerobic co-digestion of swine manure with corn stover and microbial community analysis. Microorg. 2020, 8, 188, doi:10.3390/microorganisms8020188.

46. Lim, T.-T.; Harvey, B.C.; Zulovich, J.M. Implementation of a Pilot Scale Anaerobic Digester System for Swine Finishing Barn. In Proceedings of ASABE international meeting, Kansas City, MO, USA, 2013.

47. Lim, T.-T. Start-up of a pilot scale anaerobic digestion system for swine finishing barn. In Proceedings of the 18th World Congress of CIGR, International Commission of Agricultural and Biosystems Engineering, Beijing, China, 16-18 September 2013.

48. Lin, C.-H.; Lerch, R.N.; Thurman, E.M.; Garrett, H.E.; George, M.F. Determination of Isoxaflutole (balance) and its metabolites in water using solid phase extraction followed by high-performance liquid chromatography with ultraviolet or mass spectrometry. J. Agric. Food Chem. 2002, 50, 5816-5824, doi:10.1021/jf025622d.

49. Lin, C.-H.; Lerch, R.N.; Garrett, H.E.; George, M.F. Improved GC-MS/MS Method for determination of atrazine and its chlorinated metabolites in forage plants-Laboratory and field experiments. Commun. Soil Sci. Plant. Anal. 2007, 38, 1753-1773, doi:10.1080/00103620701435522.

50. Yang, S.F.; Lin, C.F.; Wu, C.J.; Ng, K.K.; Lin, A.Y.-C.; Andy Hong, P.K. Fate of Sulfonamide Antibiotics in Contact with Activated Sludge-Sorption and Biodegradation. Water Res. 2012, 46 (4), 1301-1308. https://doi.org/10.1016/j.watres.2011.12.035. 
51. Bray, J.R.; Curtis, J.T. An ordination of the upland forest communities of Southern Wisconsin. Ecol. Monogr. 1957, 27, 325-349, doi:10.2307/1942268.

52. Ericsson, A.C.; Turner, G.; Montoya, L.; Wolfe, A.; Meeker, S.; Hsu, C.; Maggio-Price, L.; Franklin, C.L. Isolation of segmented filamentous bacteria from complex gut microbiota. BioTechniques 2015, 59, 94-98, doi:10.2144/000114319.

53. Ericsson, A.C.; Davis, D.J.; Franklin, C.L.; Hagan, C.E. Exoelectrogenic capacity of host microbiota predicts lymphocyte recruitment to the gut. Physiol. Genom. 2015, 47, 243-52, doi:10.1152/physiolgenomics.00010.2015.

54. Walters, W.A.; Caporaso, J.G.; Lauber, C.L.; Berg-Lyons, D.; Fierer, N.; Knight, R. Primer Prospector: De novo design and taxonomic analysis of barcoded polymerase chain reaction primers. Bioinformatics 2011, 27, 1159-1161, doi:10.1093/bioinformatics/btr087.

55. Magoč, T.; Salzberg, S.L. FLASH: Fast length adjustment of short reads to improve genome assemblies. Bioinformatics 2011, 27, 2957-2963, doi:10.1093/bioinformatics/btr507.

56. Kuczynski, J.; Stombaugh, J.; Walters, W.A.; González, A.; Caporaso, J.G.; Knight, R. Using QIIME to analyze 16S rRNA gene sequences from microbial communities. Curr. Protoc. Bioinform. 2011, 36, 10.7.110.7.20, doi:10.1002/0471250953.bi1007s36.

57. Altschul, S.F.; Madden, T.L.; Schäffer, A.A.; Zhang, J.; Zhang, Z.; Miller, W.; Lipman, D.J. Gapped BLAST and PSI-BLAST: A new generation of protein database search programs. Nucleic Acids Res. 1997, 25, 3389_ 3402, doi:10.1093/nar/25.17.3389.

58. DeSantis, T.Z.; Hugenholtz, P.; Larsen, N.; Rojas, M.; Brodie, E.L.; Keller, K.; Huber, T.; Dalevi, D.; Hu, P.; Andersen, G.L. Greengenes, a chimera-checked 16S rRNA gene database and workbench compatible with ARB. Appl. Environ. Microbiol. 2006, 72, 5069-5072, doi:10.1128/aem.03006-05.

59. Stone, J.J.; Clay, S.A.; Zhu, Z.; Wong, K.L.; Porath, L.R.; Spellman, G.M. Effect of antimicrobial compounds tylosin and chlortetracycline during batch anaerobic swine manure digestion. Water Res. 2009, 43, 4740-4750, doi:10.1016/j.watres.2009.08.005. 
60. Huang, B.; Wang, H.; Cui, D.; Zhang, B.; Chen, Z.-B.; Wang, A.-J. Treatment of pharmaceutical wastewater containing $\beta$-lactams antibiotics by a pilot-scale anaerobic membrane bioreactor (AnMBR). Chem. Eng. J. 2018, 341, 238-247, doi:10.1016/j.cej.2018.01.149.

61. Spielmeyer, A.; Breier, B.; Groißmeier, K.; Hamscher, G. Elimination patterns of worldwide used sulfonamides and tetracyclines during anaerobic fermentation. Bioresour. Technol. 2015, 193, 307-314, doi:10.1016/j.biortech.2015.06.081.

62. Mitchell, S.M.; Ullman, J.L.; Teel, A.L.; Watts, R.J.; Frear, C. The effects of the antibiotics ampicillin, florfenicol, sulfamethazine, and tylosin on biogas production and their degradation efficiency during anaerobic digestion. Bioresour. Technol. 2013, 149, 244-252, doi:10.1016/j.biortech.2013.09.048.

63. Chelliapan, S.; Wilby, T.; Sallis, P.; Yuzir, A. Tolerance of the antibiotic Tylosin on treatment performance of an Up-flow Anaerobic Stage Reactor (UASR). Water Sci. Technol. 2011, 63, 1599-1606, doi:10.2166/wst.2011.222.

64. Gartiser, S.; Urich, E.; Alexy, R.; Kümmerer, K. Anaerobic inhibition and biodegradation of antibiotics in ISO test schemes. Chemosphere 2007, 66, 1839-1848, doi:10.1016/j.chemosphere.2006.08.040.

65. Yin, F.; Dong, H.; Ji, C.; Tao, X.; Chen, Y. Effects of anaerobic digestion on chlortetracycline and oxytetracycline degradation efficiency for swine manure. Waste Manag. 2016, 56, 540-546, doi:10.1016/j.wasman.2016.07.020.

66. Dreher, T.M.; Mott, H.V.; Lupo, C.D.; Oswald, A.S.; Clay, S.A.; Stone, J.J. Effects of chlortetracycline amended feed on anaerobic sequencing batch reactor performance of swine manure digestion. Bioresour. Technol. 2012, 125, 65-74, doi:10.1016/j.biortech.2012.08.077.

67. Álvarez, J.; Otero, L.; Lema, J.; Omil, F. The effect and fate of antibiotics during the anaerobic digestion of pig manure. Bioresour. Technol. 2010, 101, 8581-8586, doi:10.1016/j.biortech.2010.06.075.

68. Graaf, D.; Fendler, R. Biogas Production in Germany. Federal Environment Agency: Dessau-Rosslau, Germany, 2010.

69. Stone, J.J.; Oswald, A.S.; Lupo, C.D.; Clay, S.A.; Mott, H.V. Impact of chlortetracycline on sequencing batch reactor performance for swine manure treatment. Bioresour. Technol. 2011, 102, 7807-7814, doi:10.1016/j.biortech.2011.06.038. 
70. Thauer, R.K. Special Biochemistry of methanogenesis: A tribute to Marjory Stephenson. In Proceedings of the 140th Ordinary Meeting of the Society for General Microbiology, Nottingham, UK, 30 March-2 April 1998; pp. 2377-2406.

71. Winckler, C.; Grafe, A. Use of veterinary drugs in intensive animal production. J. Soils Sediments 2001, 1, 66-70, doi:10.1007/bf02987711.

72. Arikan, O. A. Degradation and Metabolization of Chlortetracycline during the Anaerobic Digestion of Manure from Medicated Calves. J. Hazard. Mater. 2008, $158 \quad$ (2-3), 485-490. https://doi.org/10.1016/j.jhazmat.2008.01.096.

73. Cheng, D.; Ngo, H.H.; Guo, W.; Chang, S.W.; Nguyen, D.D.; Liu, Y.; Shan, X.; Nghiem, L.D.; Nguyen, L.N. Removal process of antibiotics during anaerobic treatment of swine wastewater. Bioresour. Technol. 2020, 300, 122707, doi:10.1016/j.biortech.2019.122707.

74. Kolz, A.C.; Moorman, T.B.; Ong, S.K.; Scoggin, K.D.; Douglass, E.A. Degradation and metabolite production of tylosin in anaerobic and aerobic swine-manure lagoons. Water Environ. Res. 2005, 77, 4956, doi:10.2175/106143005x41618.

75. Ingerslev, F.; Toräng, L.; Loke, M.-L.; Halling-Sørensen, B.; Nyholm, N. Primary biodegradation of veterinary antibiotics in aerobic and anaerobic surface water simulation systems. Chemosphere 2001, 44, 865-872, doi:10.1016/s0045-6535(00)00479-3.

76. Wang, H.; Vuorela, M.; Keränen, A.-L.; Lehtinen, T.M.; Lensu, A.; Lehtomäki, A.; Rintala, J. Development of microbial populations in the anaerobic hydrolysis of grass silage for methane production. FEMS Microbiol. Ecol. 2010, 72, 496-506, doi:10.1111/j.1574-6941.2010.00850.x.

77. García-Peña, E.I.; Parameswaran, P.; Kang, D.; Canul-Chan, M.; Krajmalnik-Brown, R. Anaerobic digestion and co-digestion processes of vegetable and fruit residues: Process and microbial ecology. Bioresour. Technol. 2011, 102, 9447-9455, doi:10.1016/j.biortech.2011.07.068.

78. Nogueira, R.G.S.; Lim, T.T.; Wang, H.; Rodrigues, P.H.M. Performance, microbial community analysis and fertilizer value of anaerobic co-digestion of cattle manure with waste kitchen oil. Appl. Eng. Agric. 2019, 35, 239-248, doi:10.13031/aea.13023. 
79. Schink, B. Syntrophic associations in methanogenic degradation. Mol. Basis Symbiosis 2006, 41, 1-19, doi:10.1007/3-540-28221-1_1.

80. Hatamoto, M.; Imachi, H.; Ohashi, A.; Harada, H. Identification and cultivation of anaerobic, syntrophic long-chain fatty acid-degrading microbes from mesophilic and thermophilic methanogenic sludges. Appl. Environ. Microbiol. 2006, 73, 1332-1340, doi:10.1128/aem.02053-06.

81. Hattori, S. Syntrophic acetate-oxidizing microbes in methanogenic environments. Microbes Environ. 2008, 23, 118-127, doi:10.1264/jsme2.23.118.

82. Ito, T.; Yoshiguchi, K.; Ariesyady, H.D.; Okabe, S. Identification and quantification of key microbial trophic groups of methanogenic glucose degradation in an anaerobic digester sludge. Bioresour. Technol. 2012, 123, 599-607, doi:10.1016/j.biortech.2012.07.108.

83. Padmasiri, S.I.; Zhang, J.; Fitch, M.; Norddahl, B.; Morgenroth, E.; Raskin, L. Methanogenic population dynamics and performance of an anaerobic membrane bioreactor (AnMBR) treating swine manure under high shear conditions. Water Res. 2007, 41, 134-144, doi:10.1016/j.watres.2006.09.021.

(C) 2020 by the authors. Submitted for possible open access publication under the terms and conditions of the Creative Commons Attribution (CC BY) license (http://creativecommons.org/licenses/by/4.0/). 


\section{Chapter 3}

Degradation of Sulfamethazine in Swine Manure via Anaerobic

\section{Digestion}


ABSTRACT. Antimicrobial resistance is becoming an imminent danger for human health, in part because of excessive consumption of antibiotics in the animal industry. Laboratory-scale anaerobic digesters (ADs) were utilized to investigate the potential removal of veterinary antibiotics (VA) in swine manure. Nine laboratory ADs were kept at $39 \pm 2^{\circ} \mathrm{C}$ in incubators and were loaded every two days. The digesters had a working volume of $1.38 \mathrm{~L}$ (in a 1.89-L glass jar), with a hydraulic retention time (HRT) of 21 days and a loading rate of $1.0 \mathrm{~g}$-VS/L-day. Carbon dioxide concentration of the biogas and $\mathrm{pH}$ values of the digestate verifying digester performance were measured every four days and every week, respectively. The AD process allowed 2 HRT to stabilize before the addition of the VA, Sulfamethazine. Tests were conducted to compare the effects of Sulfamethazine on manure nutrients, volatile solid destruction, and biogas production. Concentrations of Sulfamethazine added to the manure samples were 1042, 1192 and $1339 \mathrm{mg} / \mathrm{L}$, with three replicates for each of the concentration treatments. Analysis of VA concentrations before and after the AD process was conducted to determine the VA degradation. The process of measuring the relatively low VA concentrations involves using solid-phase extraction and LC-MS-MS methodology. Further tests were performed in water under room temperature and digester temperature to approve the degradation of both VAs. Some fluctuations of biogas production and operating variables were observed because of the Sulfamethazine addition. The literature suggested that a Sulfamethazine concentration below $280 \mathrm{mg} / \mathrm{L}$ has no inhibitory effect, while our tests showed that for concentration levels of 1042, $1192 \mathrm{mg} / \mathrm{L}$, biogas production declined on average by $17 \%$ and $20 \%$, respectively, though no significant change was observed for the $1339 \mathrm{mg} / \mathrm{L}$ level. Amplicon sequencing analysis performed on each group using the 50 most frequent amplicon sequence variants (ASVs) showed significant discriminations between groups. A hierarchical method (UPGMA) was applied to obtain the major alteration in bacterial dynamics between treatments. The effect of SMZ dosage on bacterial dynamics and biogas reduction, with reduction of 
Methanosarcina and Synergistetes, was concluded. Ruminiclostridium, Syntrophomonas, Caldicoprobacter, and Fastidiosipila were dominant phylum. These biomarkers' abundance can be employed to detect SMZ antibiotics contamination.

\section{Introduction and Objectives}

It was projected that increased livestock population at the global scale [31] would increase the consumption rate of therapeutic veterinary antibiotics (VAs) to pass over 100,000 tons by 2030 [2]. Antibiotics are organic compounds synthesized naturally by microorganisms or artificially in labs, preventing or killing certain types of microorganisms [32]. Veterinary antibiotics are often supplemented via animal feed to promote the growth or lower the risk of infection in animal production. However, there have been more regulations in many countries to restrict consumption. Manure production in 27 European Union countries and the US is 1.4 billion tons and 1 billion tons per year, respectively [33]. VAs consumption in China was over 162,000 tons, which was $50 \%$ of the total worldwide VAs consumption in 2013. One potential issue with the use of VAs is that between (60-90\%) of the consumed VAs are excreted, leading to potential health risks [34]. Due to

the low cost and the effectiveness of antibiotics, consumption of VAs was on a sharp rise, for both therapeutic and subtherapeutic purposes. However, in the US, growth promotion sales dropped from 5.7 million kilograms (kg) in 2016 to $0 \mathrm{~kg}$ in 2017 due to new regulations. As a result of implementing the Guideline for Industry \#213 act, over-the-counter sales declined dramatically, from 8 million kilograms in 2016 to 271,280 kg in 2017 [28]. Despite all these restrictions, the US's total annual VAs consumption was 10,900 and 11,500 tons in 2017 and 2018, respectively [29].

Most animal farms in the US are not equipped with wastewater treatment facilities. Most excreted VAs are eventually stored with manure for the long-term, and applied to the land as crop fertilizer. The emergence of VAs in manure and their impact on human health when directly used 
as a fertilizer have been widely discussed in previous studies [5]-[7], [35]-[38]. As a result, antibiotic resistance genes (ARGs) could spread in soil, water, and the whole ecosystem [39]-[41]. On the other hand, the presence of VA residues in the fertilizer could eradicate other kinds of bacteria than ARGs and enhance the conditions for resistant ones [42]. Besides, most of these antibiotics are not highly biodegradable, with a degradation range between $4 \%$ and $27 \%$ [11]. With extensive use of VAs, antimicrobial-resistant microbes have become prevalent and their fast development has become a serious public health concern. Resistance against common antibiotics has been rising swiftly for the last two decades [43]. Dantas group [44] tested 18 antibiotics against hundreds of bacteria isolated from soils; about $70-90 \%$ of them displayed resistance. In 2030, antibiotic resistance will cost $\$ 3.4$ trillion due to subsequent mortality and alternative treatment [9]. VAs could pollute the soil and water, then the human food chain through crops and animalderived foods [45]-[49]. Moreover, the residue of VAs in the AD process could sustain microbes under the minimum inhibitory concentration (MIC), fostering ARGs' selection by microbes [50], [51]. There are several approaches to removing VAs in manure, including composting and anaerobic digestion (AD). Anaerobic digesters can produce biogas as well as remove VAs and ARGs [22]-[24]. In contrast, composting requires less monitoring and has a more stable working system and generally higher removal rates for certain VAs, but also consumes energy and occasionally has less capability to remove ARGs than anaerobic digesters [52].

Sulfamethazine (SMZ), a highly used antibiotic from the sulfas family, is often addressed as the most widely used veterinary sulfonamide [53]-[55]. In 2017, SMZ was ranked the 4th mostconsumed VA, at over $274,000 \mathrm{~kg}$ ( $5 \%$ of the medically important antibiotics), after tetracycline, penicillin, and macrolides [28]. Sulfamethazine with the chemical formula of $\mathrm{C}_{12} \mathrm{H}_{14} \mathrm{~N}_{4} \mathrm{O}_{2} \mathrm{~S}$ and a molecular weight of $278.33 \mathrm{~g} / \mathrm{mol}$ has a water solubility of less than $1.5 \mathrm{mg} / \mathrm{ml}$ at room temperature. SMZ has a half-life of over 50 days, as Feng et al. found [56]. They used an anaerobic digester with 
swine manure and a 40-day retention period, and concluded that sulfadiazine and sulfamethizole showed little or no degradation under both psychrophilic and thermophilic phases.

In several studies, SMZ concentration in dairy manure in the US was among the highest, with a maximum of $430 \mu \mathrm{g} / \mathrm{kg}$ of dry manure [57], [58]. Furthermore, several studies focus on optimizing the $\mathrm{AD}$ reactors, considering temperature, $\mathrm{pH}$, and manure solid content. Two mesophilic temperature conditions $\left(27\right.$ and $\left.37^{\circ} \mathrm{C}\right)$ of $\mathrm{AD}$ and swine manure were compared with a thermophilic $\mathrm{AD}$ condition $\left(55^{\circ} \mathrm{C}\right)$ on $\mathrm{ARG}$ removal [59]. The results showed that mesophilic conditions were more effective in the reduction of ARGs from pig manure. Mitchell et al. investigated the effect of $\mathrm{pH}$ (below $\mathrm{pH} 4$ and above $\mathrm{pH}$ 8) on the hydrolysis of chloramphenicol, florfenicol, spiramycin, and tylosin in acidic and basic buffers and under the temperature of 50$60^{\circ} \mathrm{C}$ [60]. Loftin et al. (2008) and Li N. et al. (2017) also studied the hydrolysis of tylosin and fluoroquinolones at extreme $\mathrm{pH}$ (below 3 and above 11) [4], [61]. Much research has presented no degradation regardless of the concentration of SMZ [55], [62]. However, Oliveira et al. used a horizontal-flow anaerobic immobilized biomass reactor with swine manure and observed an SMZ removal efficiency of $75 \pm 6 \%$, which was achieved with an organic loading rate of $2.7 \pm 0.4 \mathrm{~kg} \mathrm{O} 2$ $\mathrm{m}^{-3} \mathrm{~d}^{-1}$ when the hydraulic retention time was 24 hours [63].

Although SMZ belongs to the sulfonamides family, its biodegradation behavior is dissimilar. For instance, biodegradation of sulfamethoxazole, sulfadiazine, and sulfamerazine was very promising (near-complete removal) [55], [64]-[67]. On the other hand, some studies observed no degradation for SMZ [55], [62]. Spielmeyer et al. reported the removal rate of $48 \%$ of SMZ and sulfadiazine with anaerobic fermentation of cattle manure [66]. Besides, no inhibitory effect of SMZ was detected during biodegradation in anaerobic digestion [62], [66]. 
The purposes of this research were to assess (i) anaerobic digestion's ability to remove SMZ, (ii) the effect of SMZ on the reactor's performance, and (iii) the degree to which SMZ can alter the microbial dynamics in swine manure ADs. This research's uniqueness mimics an on-farm mesophilic AD that was fed regularly with pig manure while operating over several months. This study selected a popular VA, SMZ, and emphasized on-farm conditions in which the antibiotic was administered (according to the manufacturer's recommendation). While many previous studies focused only on the inhibition effect and usually used batch reactors, which are different from actual on-farm $\mathrm{AD}$ conditions, this study used relatively larger $\mathrm{AD}$ reactors that were fed semicontinuously over several months.

\section{Methods}

Nine laboratory-size glass jars were used as AD reactors and heated using incubators. The anaerobic bioreactors had operating volumes of $1.375 \mathrm{~L}$ and were kept at $39 \pm 2{ }^{\circ} \mathrm{C}$. The jars were fed with VA-free swine manure at 1g-VS per L-day, with a 21-day hydraulic retention time (HRT). Many of the procedures used in this research are similar to those of previous work, conducted to characterize degradations of chlortetracycline and tylosin [68]. The volume of the feed given every

two days is calculated based on HRT and the reactor working volume. Because HRT is 21 days and the reactor volume is $1.375 \mathrm{~L}, 0.131 \mathrm{~L}$ of the reactor liquid was replaced by $0.131 \mathrm{~L}$ of feedstock every two days (the digesters were fed every two days) [22], [69].

Each reactor was connected to a 10-L Tedlar bag to collect produced biogas, and the bags were measured every four days [70]. A custom-built device was used to help distribute the biogas evenly in the bag, so the height of the bag could be measured more precisely. The volume of each bag was then estimated by bag height using a model, as described in previous publications [70], [71]. Also, to detect potential leakage of the Tedlar bags, two bags during the volume measurement 
were tested for possible leakage. All other parts - including tubes, caps, and any connective partswere routinely tested for leakage. After biogas measurements, the bags were emptied, and the biogas was burned.

In the current project, the efficacy and usefulness of anaerobic digestion bioreactors in degrading VAs were explored. Several criteria were employed to select the antibiotics, including their importance to human health, their market share and popularity, their half-life, and their danger to the environment. Also, the dosage of antibiotics added to bioreactors was calculated based on the concentrations administrated for animals at the farm, absorbed in the animal guts and intestine, and then excreted out, to imitate the real condition. Bioreactors were fed with swine manure collected from a VA-free farm, which has been tested for any background VA, to eliminate

the chance of interference. Sulfamethazine (SMZ) was injected into anaerobic sequencing batch reactors (ASBR) with concentrations of 5063, 5786, and $6509 \mathrm{mg} / \mathrm{L}$ for the first spike and 3375, 3857, and $4339 \mathrm{mg} / \mathrm{L}$ for the second spike - a total of two injections. The difference in dosages is due to the manufacturer's recommendations for use. The SMZ concentrations after the last injection, assuming there was no biodegradation, were 1042, 1191, and $1340 \mathrm{mg} / \mathrm{L}$, for low, medium, and high concentrations, respectively.

Several elements impact the reactor performance and biogas production. Various types of bacteria work on different temperature ranges and some of them are extremely sensitive to temperature variation. Therefore, the temperature was kept at $39^{\circ} \mathrm{C}$; temperature and humidity were recorded to track our incubator's performance.

\subsection{Feedstock for Anaerobic Digestion}

Swine manure for the AD reactors was collected from a farm located in Versailles, Missouri. The finishing barn is VA-free and has a liquid-solid separation system. Fresh solid manure is 
collected from the solid manure storage. Collected solid manure was kept on ice after sampling and immediately frozen at $-20^{\circ} \mathrm{C}$ to minimize changes, with a small portion kept in a refrigerator for feeding to the AD reactors. Solid manure TS and VS were $25.89 \%$ and $82.02 \%$, respectively. The effect of freezing on the solid manure was not investigated, while no sensible difference was witnessed between refrigerated and fresh solid manure for gas production [22], [68].

The inoculum used was from another semi-continuous $\mathrm{AD}$ jar, with the organic loading rate (OLR) of $1 \mathrm{~g}^{-V S ~ L^{-1}} \mathrm{~d}^{-1}$ feed by the swine solid manure for over three months [71]. Inoculum TS and VS were $2.2 \%$ and $64.92 \%$, respectively.

\section{Experimental Design}

The experiment consisted of nine jars, for the addition of SMZ with low, medium, and high concentrations, with three replicates for each concentration (Figure 1). Also, five extra bioreactors were included for back-up or control purposes, to achieve the biogas reference line for comparison. Six jars were filled with DI water with the same working volume of $1,375 \mathrm{~mL}$ and the remaining space with nitrogen gas. Three of these digesters were kept inside the incubator to imitate the thermal condition of reactors, while three others were kept at room temperature. These reactors were spiked with the same concentrations of SMZ (low, medium, and high) and sampled with the same schedule as SMZ-added digesters. The purpose was to compare the AD efficiency and functionality in degrading SMZ.

Alkalinity measurement was performed by using an Alkalinity Test Kit (HACH, AL-AP MGL, Loveland, CO). Digestate samples were first diluted with distilled water at a 1:40 ratio. Furthermore, ammonia was measured using an Ammonia Test Kit (HACH, NI-SA, Loveland, CO), and the digestate was diluted at the 1:1000 level. 


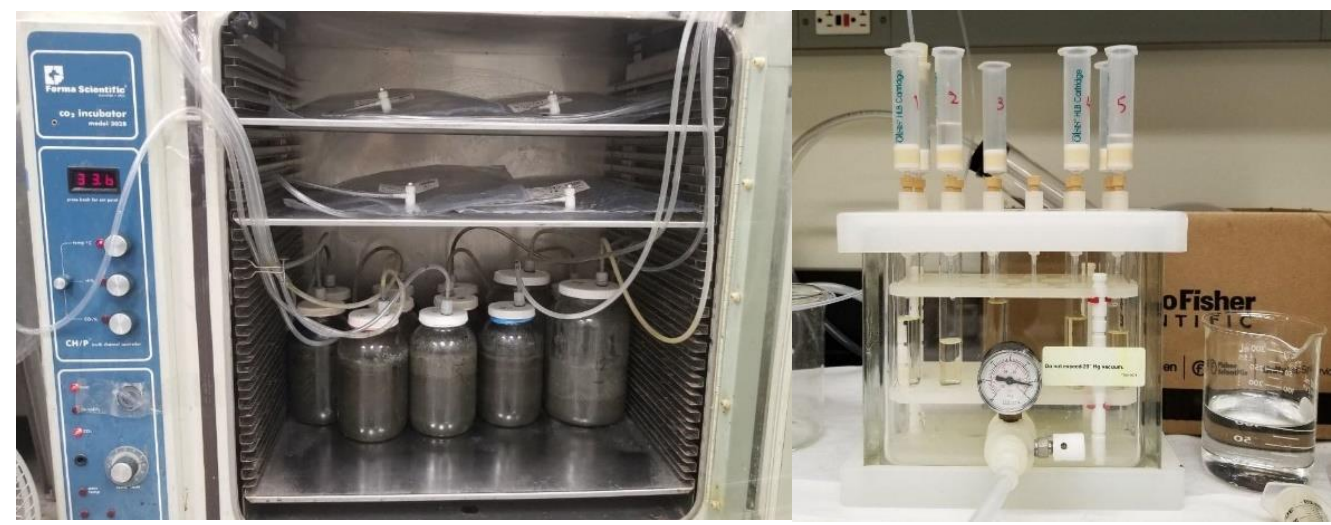

Figure 1. Left) The scheme of the reactors, tubes transferring biogas, and the incubator, Right)

Solid-phase extraction step.

\subsection{Antibiotics Administration}

The concentration of SMZ administered followed the recommendation of "SULMETSulfamethazine sodium powder, for solution, Huvepharma, Inc.". The manufacturer's recommended dosages (per $\mathrm{kg}$ body weight) to be added to drinking water is, $237.6 \mathrm{mg} / \mathrm{kg}$ body weight for the first day and $118.8 \mathrm{mg} / \mathrm{kg}$ body weight for days $2-4$. By assuming the average weight of the finishing pig as $68 \mathrm{kgs}$ and producing 3.36 liters of manure daily, considering the SMZ excretion rate and metabolism percentage of $70 \%$ to $90 \%$, the injection dosage of SMZ to the digesters would be achieved. Because the SMZ injection was conducted along with the feedstock addition every two days, the SMZ concentration was the sum of day one and day two of the dosages for the first injection, and the sum of the day three and day four dosages for the second injection, Table 1. 
Table 1. Recommended dosage of SMZ administration by the manufacturer.

\begin{tabular}{|c|c|c|c|c|c|c|}
\hline Antibiotic & Dosage & $\begin{array}{c}\text { Manure } \\
\text { (liter/day) }\end{array}$ & $\begin{array}{c}\text { Excretion } \\
\text { level }\end{array}$ & $\begin{array}{c}\text { Concentration } \\
\text { (lower band) (mg/l) }\end{array}$ & $\begin{array}{c}\text { Concentration } \\
\text { (upper band) (mg/l) }\end{array}$ & Avg. \\
\hline $\begin{array}{l}\text { Sulfamethazine } \\
\text { first day }\end{array}$ & $\begin{array}{l}237.6 \\
\mathrm{mg} / \mathrm{kg}\end{array}$ & 3.36 & 70 to $90 \%$ & 3375 & 4339 & 3857 \\
\hline $\begin{array}{l}\text { Sulfamethazine } \\
\text { for days 2-4 }\end{array}$ & $\begin{array}{l}118.8 \\
\mathrm{mg} / \mathrm{kg}\end{array}$ & 3.36 & 70 to $90 \%$ & 1688 & 2170 & 1929 \\
\hline
\end{tabular}

Sulfamethazine antibiotic was purchased as Sulfamethazine sodium salt from Sigma-Aldrich with CAS Number 1981-58-4 and Linear Formula $\mathrm{C}_{12} \mathrm{H}_{13} \mathrm{~N}_{4} \mathrm{O}_{2} \mathrm{SNa}$. Because the intention was to add the antibiotic to drinking water (and not administer it via solid feed), the solubility of the VAs was noted and controlled, which, based on manufacturer information, was $50 \mathrm{mg} / \mathrm{ml}$. Table 2 is a summary of the solubility check of the SMZ solution added to the digesters.

Table 2. Low, medium, and high concentrations of SMZ and water solubility check.

\begin{tabular}{|c|c|c|c|c|c|c|c|}
\hline Day & Antibiotic & $\begin{array}{c}\text { Conc. } \\
\text { low } \\
\text { (mg/l) }\end{array}$ & $\begin{array}{l}\text { Conc. } \\
\text { Med } \\
\text { (mg/l) }\end{array}$ & $\begin{array}{l}\text { Conc. } \\
\text { high } \\
(\mathrm{mg} / \mathrm{l})\end{array}$ & $\begin{array}{c}\text { mg in } 107.5 \\
\text { ml feeding } \\
\text { volume }\end{array}$ & $\begin{array}{c}\text { Conc. } \\
(\mathrm{mg} / \mathrm{l}) \mathrm{in} \\
107.5 \mathrm{ml}\end{array}$ & $\begin{array}{c}\text { Water } \\
\text { solubility } \\
\text { (mg/l) }\end{array}$ \\
\hline Day 1 & Sulfamethazine & 3,375 & 3,857 & 4,339 & 568 & 5,288 & 50,000 \\
\hline Days 2-5 & Sulfamethazine & 1,688 & 1,929 & 2,170 & 284 & 2,644 & \\
\hline
\end{tabular}

As presented, all concentrations were below the solubility limit. The use of methanol or Acetonitrile (ACN) as a solvent for SMZ instead of water was dismissed because of their harmful effect on the reactor's performance. (An independent test was conducted to evaluate the effects of adding methanol on AD performance; details were not included in this paper.) 


\subsection{Anaerobic Digester Monitoring}

The essential stabilization time for the reactors and microbial reproduction before the addition of antibiotics was two to three months, until the biogas production, digestate $\mathrm{pH}$, and alkalinity stabilized. The digesters were maintained for eight weeks or 2.5 times the retention time. Organic loading rate based on total volatile solids (TVS), solid content, temperature, mixing (swirling the jar daily), and foaming (if any) were recorded. Digester $\mathrm{pH}$ was measured weekly before feedstock addition.

The $\mathrm{pH}$ of the bioreactors was measured every two days during the antibiotic adding period, with a handheld $\mathrm{pH}$ meter (PINPOINT, American Marine Inc., Ridgefield, CT). Collecting pH data helps determine the microbial activity and how efficiently the reactor is working. However, $\mathrm{pH}$ can also be affected by alkalinity. Ammonia and alkalinity levels were also measured before and after the experiment.

The methane $\left(\mathrm{CH}_{4}\right)$ content of the biogas was measured indirectly by measuring the concentration of carbon dioxide $\left(\mathrm{CO}_{2}\right)$. The $\mathrm{CO}_{2}$ concentration of the biogas was measured with a classic combustion analyzer (Bacharach Fyrite Classic Combustion Analyzer, USA) every eight days. The concentration of $\mathrm{CO}_{2}$ was measured every four days during the antibiotic addition

period. For quality assurance, comparative tests using gas spectrometry were performed on November 15, 2016, to verify the accuracy of the measurements [22]. The gas chromatograph device was (GC-2014, Shimadzu, US) with a thermal conductivity detector (TCD) using a ShinCarbon ST 80/100 Column (Restek, US) [72], [73].

Because the administration period of SMZ is four days, sampling was carried out on day six, which was two days after the last feeding and SMZ addition. The samples were immediately frozen 
at $-20^{\circ} \mathrm{C}$. Gas production, $\mathrm{pH}$, and $\mathrm{CO} 2$ level were recorded before, during, and post VA addition, and until six weeks after the VA addition and sampling.

\subsection{Extraction and Chemical Analysis}

\subsubsection{Sample Preparation}

Similar procedures documented in the previous study were employed to prepare and stabilize the samples [22], including the addition of phosphate buffer $(0.14 \mathrm{M})$, internal standard addition, sonication, centrifuge, evaporation with nitrogen gas, and dilution with DI water. Sulfamethazine phenyl- $-{ }^{13} \mathrm{C}_{6}$ was used as the internal standard. The centrifuge device used was the Sorvall LYNX 6000 Superspeed Centrifuge (Thermo Scientific ${ }^{\mathrm{TM}}$ ).

\subsubsection{Solid-Phase Extraction}

The solid-phase extraction cartridges were Waters Oasis-HLB SPE cartridges (Oasis HLB 12 cc Vac Cartridge, $500 \mathrm{mg}$ Sorbent per Cartridge, $60 \mu \mathrm{m}$ Particle Size). The cartridge was preconditioned with $\mathrm{ACN}$ and DI water; then the sample was added to the cartridge at the rate of $2 \mathrm{~mL} / \mathrm{min}$. The cartridge was washed DI water and vacuum dried. Finally, the retained antibiotic in the cartridge was collected with methanol and ACN [22]. Then nitrogen gas was used to evaporate and concentrate the collected sample. The extract was filtered via a $0.22-\mu \mathrm{m}$ Anotop inorganic filter (Sigma Aldrich) [73].

\subsubsection{LC-MS/MS Analysis}

The Waters Alliance 2695 High-Performance Liquid Chromatography (LC-MS/MS) system, coupled with a Waters Acquity TQ triple quadrupole mass spectrometer (MS/MS), was utilized to measure the SMZ concentration. The column used was a Phenomenex (Torrance, CA) Kinetex C18 
(100 $\mathrm{mm} \times 4.6 \mathrm{~mm} ; 2.6 \mu \mathrm{m}$ particle size) reverse-phase column [22], [73], [74]. Ionization mode, retention times, and optimized precursor/product ions were similar to those of our previous study [22]. The Waters IntelliStart ${ }^{\mathrm{TM}}$ optimization software package [74] was used to optimize the procedure.

\subsection{Statistical Analysis}

To detect changes before and after SMZ addition on biogas production, $\mathrm{pH}$ fluctuation, and methane content, a two-sample T-test with unequal variances was used at the significance level of probabilities $(p \leq 0.05)$ for all analyses [75].

The Bray-Curtis similarities and Jaccard similarities techniques were used to match the amplicon sequencing data. Bray-Curtis dissimilarity is a method used to measure the structural variation between two different groups, based on counts at each group. Mathematically, the index of dissimilarity is:

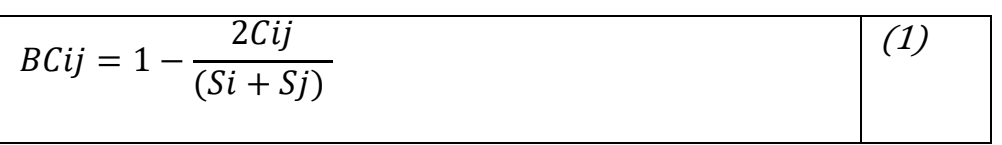

where $\mathrm{Cij}$ is the sum of the lesser values for only those species on the intersection of two sets. Si and $\mathrm{Sj}$ are the total numbers of specimens at both sites. The range is between 0 and 1 [76].

The Jaccard similarity index also ranges from 0 to 1 . The more similar the two populations are, the closer the index gets to 1 [77].

$$
J(A, B)=\frac{|A \cap B|}{|A \cup B|}
$$

\subsection{Sampling and DNA Isolation}

Raw and digested manure samples were analyzed by the University of Missouri Metagenomics Center for the microbial/taxonomy analysis, using the 16S rRNA library sequencing 
methodology. The results show that over 100,000 sequences were identified, confirming that the taxonomy analysis of manure samples can be analyzed using the specific method.

In total, 10 samples were collected in 50-mL sterile centrifuge plastic tubes. A group of the low, medium, and high SMZ concentrations, with two replicate groups and a control sample, was processed. Before sampling, each jar was mixed thoroughly with a hand mixer for 1 minute. Samples were then frozen to prevent any alteration before the amplicon sequencing.

DNA was extracted using “PowerFecal kits (Qiagen) according to the manufacturer's instructions, with the exception that samples were homogenized in the provided bead tubes using a TissueLyser II (Qiagen, Venlo, Netherlands) for three minutes" [78] at 30/sec, "rather than performing the initial homogenization of samples using the vortex adapter described in the protocol, before proceeding according to the protocol and eluting in $100 \mu \mathrm{L}$ of elution buffer (Qiagen). DNA yields were quantified via fluorometry (Qubit 2.0, Invitrogen, Carlsbad, CA) using quant-iT BR dsDNA reagent kits (Invitrogen)" [79] and normalized to a uniform concentration and volume. The rest of the method was performed according to Ericsson et al. [22], [80], [81].

\section{8. $16 \mathrm{~S}$ rRNA Library Preparation and Sequencing}

“Extracted fecal DNA was processed at the University of Missouri DNA Core Facility. Bacterial 16S rRNA amplicons were constructed via amplification of the V4 region of the 16S rRNA gene with universal primers (U515F/806R) previously developed against the V4 region, flanked by Illumina standard adapter sequences" [82] [82]-[84]. "Oligonucleotide sequences are available at proBase [85]. Dual-indexed forward and reverse primers were used in all reactions. PCR was performed in $50 \mu \mathrm{L}$ reactions containing $100 \mathrm{ng}$ metagenomic DNA, primers ( $0.2 \mu \mathrm{M}$ each), dNTPs (200 $\mu \mathrm{M}$ each), and Phusion high-fidelity DNA polymerase (1U, Thermo Fisher)" [82]. Amplification parameters were $98^{\circ} \mathrm{C}(3 \mathrm{~min})+\left[98^{\circ} \mathrm{C}(15 \mathrm{sec})+50^{\circ} \mathrm{C}(30 \mathrm{sec})+72^{\circ} \mathrm{C}(30 \mathrm{sec})\right] \times 25$ 
cycles $+72^{\circ} \mathrm{C}(7 \mathrm{~min})$. "Amplicon pools $(5 \mu \mathrm{L} /$ reaction) were combined, thoroughly mixed, and then purified by addition of Axygen Axyprep MagPCR clean-up beads to an equal volume of 50 $\mu \mathrm{L}$ of amplicons and incubated for 15 minutes at room temperature. Products were then washed multiple times with $80 \%$ ethanol and the dried pellet was resuspended in $32.5 \mu \mathrm{L}$ EB buffer (Qiagen), incubated for two minutes at room temperature, and then placed on the magnetic stand for five minutes. The final amplicon pool was evaluated using the Advanced Analytical Fragment Analyzer automated electrophoresis system, quantified using quant-iT HS dsDNA reagent kits, and diluted according to Illumina's standard protocol for sequencing on the MiSeq instrument" [86].

\subsection{Informatics Analysis}

“DNA sequences were assembled and annotated at the MU Informatics Research Core Facility. Primers were designed to match the 5 ' ends of the forward and reverse reads. Cutadapt [87] (version 2.6; https://github.com/marcelm/cutadapt) was used to remove the primer from the 5' end of the forward read. If found, the reverse complement of the primer to the reverse read was then removed from the forward read as were all bases downstream. Thus, a forward read could be trimmed at both ends if the insert was shorter than the amplicon length. The same approach was used on the reverse read, but with the primers in the opposite roles. Read pairs were rejected if one reads or the other did not match a 5' primer, and an error-rate of 0.1 was allowed. Two passes were made over each reading to ensure the removal of the second primer. A minimal overlap of three bp with the 3' end of the primer sequence was required for removal" [86].

The QIIME2 [88] DADA2 [89] plugin (version 1.10.0) was used to denoise, de-replicate, and count ASVs (amplicon sequence variants), incorporating the following parameters: 1) forward and reverse reads were truncated to 150 bases, 2) forward and reverse reads with a number of expected 
errors higher than 2.0 were discarded, and 3) chimeras were detected using the "consensus" method and removed. $\mathrm{R}$ version 3.5.1 and Biom version 2.1.7 were used in QIIME2. Taxonomies were assigned to final sequences using the Silva.v132 [90] database, employing the classify-sklearn procedure.

\section{Results and Discussion}

\subsection{Biogas Production}

VAs in anaerobic digesters might have a repressive effect on biogas production [91]-[93] because VAs could upset microorganisms' activity, especially when the concentration is over a certain level. Because an anaerobic digester is not always able to degrade the VAs completely, in the long term, $\mathrm{AD}$ reactors can also become a promoting environment for the development of new ARGs [66].

Due to limited space in the first incubator, it was decided to have samples one to six (groups one and two) in the first incubator and samples seven to nine (group three) in a second incubator, with the same temperature setting. Before the VAs were injected, the biogas production of all three groups was compared to a two-tail T-test and no significant difference was found between groups. Figure 2 represents the average biogas productions (measured every four days) for each concentration level (low, medium, and high SMZ concentrations added, and control group with no SMZ added). Some irregularities were noticeable immediately after the first spike, recalling that November 30 was the start date of the spiking antibiotics and the final day was December 2.

Surprisingly, a comparison of the variation of samples of biogas production with the control indicated a decline in the low- and medium-concentration groups, at 1042 and $1191 \mathrm{mg} / \mathrm{L}$ or a decline of $17 \%$ and $20 \%$, respectively. For high SMZ concentration $(1340 \mathrm{mg} / \mathrm{L})$, biogas reduction 
was not significant. Running a T-test on biogas production indicated that AD bacterial activity was immediately inhibited for samples treated with low and medium SMZ concentrations $(p$-value $=$ $0.05)$.

This trend continued and had its lowest biogas production (maximum difference with the control group) eight days after the first SMZ addition. Still, either the bacteria adapted or the inhibiting compound was removed from the system in less than a month after VA addition. Then the trend started to resemble the control group from late December to early January. In a 10-day period after recovery, biogas production of SMZ groups was higher than in the control group. Finally, after 40 days, biogas production for all groups became similar in general. In the current research, biogas reduction was as low as $25 \%$, yet there was no sensible change in methane content percentage.

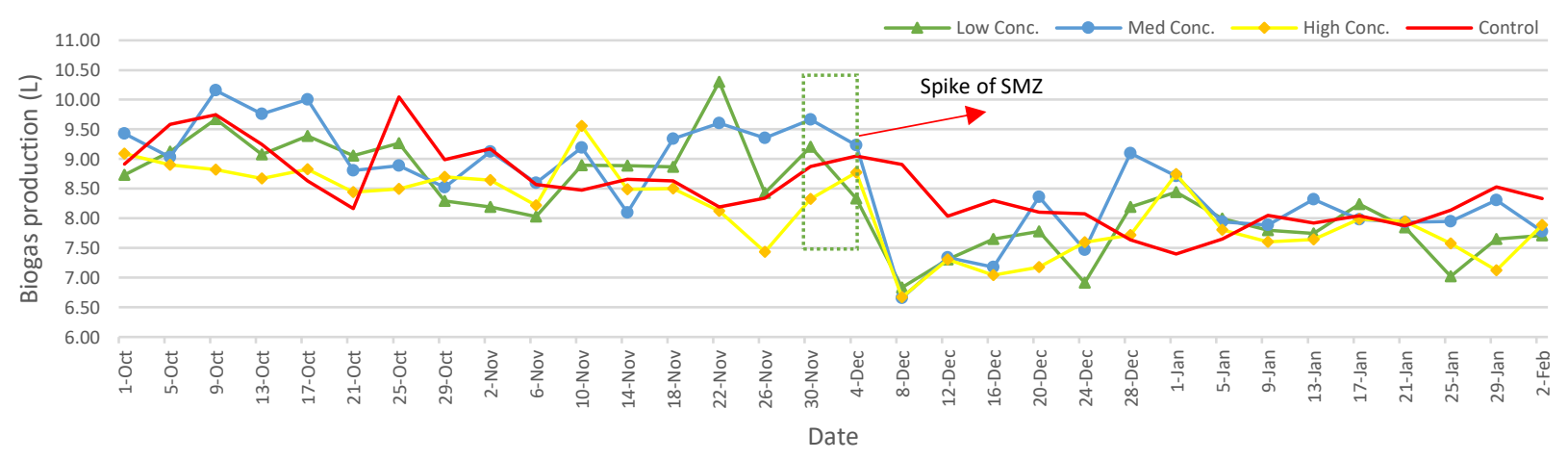

Figure 2. Average biogas production, before and after the addition of SMZ.

The decrease in biogas production due to the SMZ addition was different from the part of the literature. Similar studies reported that SMZ had no effect on either biogas production or methane content [36], [55], [62], [94]. The reason can be ascribed to the SMZ concentration studied, which was less than $280 \mathrm{mg} / \mathrm{L}$ (Table 3). However, Withey et al. concluded a $14 \%$ reduction in methane content, but no effect at the end of the trial [95]. They concluded that SMZ not only 
inhibited methanogens but also reduced the catalytic and metabolic activities of the whole group of microorganisms that exist in an active thermophilic anaerobic digestion process $\left(55^{\circ} \mathrm{C}\right)$.

Table 3. SMZ removal and its effect on biogas production in the literature.

\begin{tabular}{ccccc}
\hline & $\begin{array}{c}\text { Concentration } \\
(\mathbf{m g} / \mathbf{L})\end{array}$ & $\begin{array}{c}\text { Removal of } \\
\text { VA }\end{array}$ & $\begin{array}{c}\text { Effect on } \\
\text { biogas }\end{array}$ & Reactor type \\
\hline Withey et al. (2016) & 20 & $80 \%$ & - & Batch AD \\
\hline Mitchel et al. (2013) & 0.28 to 280 & $<10 \%$ & No & Batch AD \\
\hline Spielmeyer et al. (2015) & 0 to 38 & $48 \%$ & No & Semi-continuous \\
\hline Jin et al. (2017) & 0.01 & $>90 \%$ & No & Semi-continuous \\
\hline Mohring et al. (2009) & 70 & $<10 \%$ & No & Batch AD \\
\hline Spielmeyer et al. (2017) & 5 & $<10 \%$ & - & Batch AD \\
\hline
\end{tabular}

\section{2. $\mathrm{pH}$ and $\mathrm{CO} 2$}

$\mathrm{pH}$ value can reveal the activity of Acetogenesis and Methanogenesis bacteria. At the beginning of the $\mathrm{AD}$ process, Acetogenesis bacteria start to create volatile acids that trigger the $\mathrm{pH}$ to decline. Later, Methanogenesis bacteria convert the volatile acids to methane and $\mathrm{CO}_{2}$ and cause $\mathrm{pH}$ to rise. The methane-forming bacteria begin to consume the volatile acids at HRTs of more than five days. Running a T-test on $\mathrm{pH}$ data revealed a significant change for low, medium, and high SMZ concentration treatments ( $\mathrm{p}$-value $=0.05$ ). Within a week after the first addition, the $\mathrm{pH}$ of all groups with added SMZ showed an increase compared to the control group and returned to normal after almost 20 days. This finding suggests that the Acetogenesis activity is not affected or enhanced by the addition of SMZ, which Hu et al. (2018) observed. Because biogas production decreased without any variation of methane content or $\mathrm{pH}$, it can be explained as SMZ impacting 
Methanogenesis and Acetogenesis activity almost the same. Nevertheless, none of the reactors became upset or affected intensively by the VA addition (Figure 3).

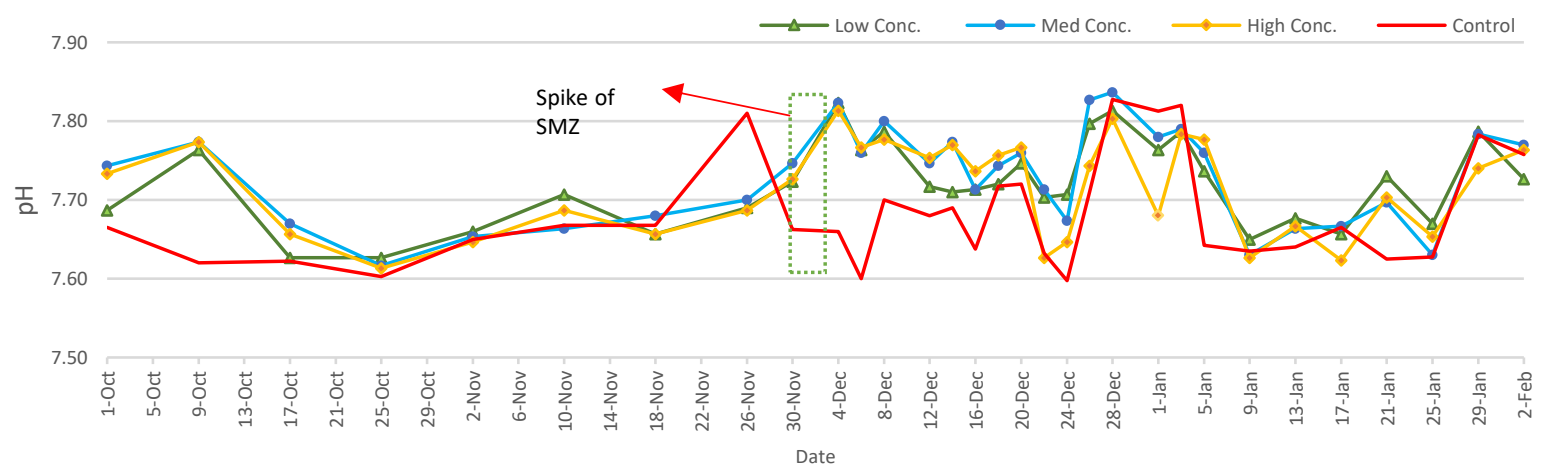

Figure 3. Average $\mathrm{pH}$ of $\mathrm{AD}$ reactors, before and after the addition of SMZ.

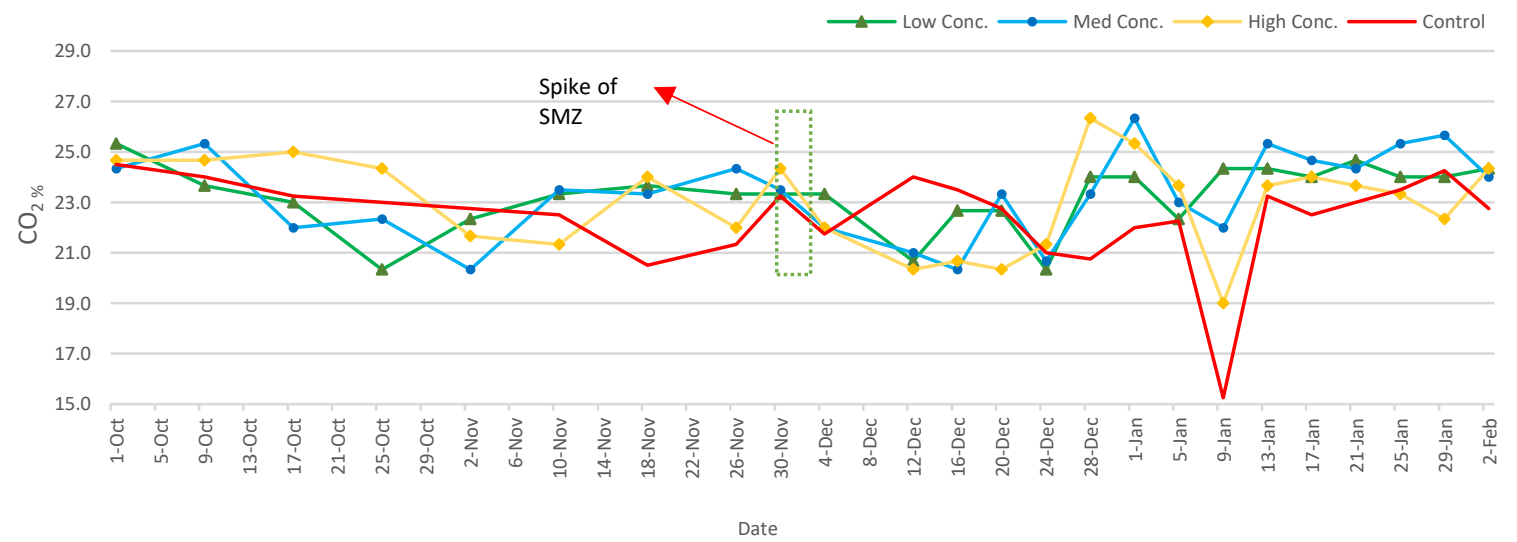

Figure 4. Average CO2 concentrations, before and after the addition of SMZ.

Performing a T-test on the $\mathrm{CO}_{2}$ content of biogas, and comparing the average value for each group with the control group, indicates that there is no significant difference before and after SMZ addition $(p$-value $=0.05)$. On January 9, over 40 days after the SMZ addition, there was a drop in $\mathrm{CO}_{2}$ content; however, this should be due to feedstock variation because the control group also 
followed the same pattern. Jin et al. (2017) and Spielmeyer et al. (2015) also observed no variation in methane content due to SMZ (Figure 4) [66], [94].

\subsection{Antibiotic Removal}

The Sulfamethazine stable isotope concentration was measured to calculate the recovery rate, presuming that there is no degradation or absorption. If there is a significant change, it might be caused by sampling error, degradation due to anaerobic digestion, or an error of the LCMS measurement including the SPE. The protocol average recovery rate for SMZ stable isotope without SMZ VA was $64.7 \%$; thus, we decided to improve it with 10X more dilution. The improved recovery rate increased to an average of $109.4 \%$. Despite the compelling recovery rate, when samples with SMZ antibiotic underwent the LCMS measurement, the recovery rate dropped drastically, to $21 \%$ and $17 \%$ for the manure and water samples, respectively. Moreover, the removal rates of SMZ, calculated using spiked concentrations, detected concentrations by LCMS, and modified concentrations using adjustment factors (internal standard). The removal of SMZ turned out to be negative, which means that not only did no degradation happen, but also there is even more SMZ in our bioreactors than injected. At this point, several potential factors were considered to be the reason. First, there might be a background concentration of SMZ in the manure used. Second, because the recovery rate dropped after the introduction of VA to the system, either the matrix effect or issues related to the SPE cartridge might cause that. Third, the original SMZ concentration added to the bioreactors was not correct.

The first statement cannot be true because control samples have already been tested and showed zero concentration of SMZ. Also, another set of SMZ stable isotope was included to verify the accuracy of the concentration. Table 4 demonstrates that the stable isotope concentration was also impeccable. 
Table 4. Internal standard concentration and recovery rate verification.

\begin{tabular}{|c|c|c|c|}
\hline Sample Type & $\begin{array}{c}\text { Expected Isotope } \\
\text { Concentration (mg/L) }\end{array}$ & $\begin{array}{l}\text { Detected Isotope } \\
(\mathrm{mg} / \mathrm{L})\end{array}$ & Recovery Rate \% \\
\hline Internal Standard, No VA & 10.000 & 10.313 & 103 \\
\hline Internal Standard, No VA & 10.000 & 10.334 & 103 \\
\hline Internal Standard, No VA & 10.000 & 10.452 & 105 \\
\hline
\end{tabular}

To further eliminate the possibility of the matrix effect, 100 times dilution was conducted. In Table 5, both 10X and 100X dilution results are presented.

Table 5. LCMS results of the recovery and removal of 10X and 100X sample dilution.

\begin{tabular}{|c|c|c|c|c|}
\hline \multirow[b]{2}{*}{ Sample Type } & \multicolumn{2}{|c|}{ 10X dilution } & \multicolumn{2}{|c|}{ 100X dilution } \\
\hline & Recovery & Removal & Recovery & Removal \\
\hline & Rate\% & $\%$ & Rate $\%$ & $\%$ \\
\hline Manure with SMZ VA solution, Low conc. & $24 \pm 0.54$ & $-17 \pm 2.47$ & $54 \pm 1.63$ & $-88 \pm 4.01$ \\
\hline Manure with SMZ VA solution, Med conc. & $19 \pm 0.29$ & $-24 \pm 3.67$ & $50 \pm 0.33$ & $-93 \pm 7.54$ \\
\hline Manure with SMZ VA solution, High conc. & $20 \pm 0.86$ & $-19 \pm 4.92$ & $51 \pm 2.92$ & $-87 \pm 9.15$ \\
\hline SMZ VA solution in water, Heat treated & $17 \pm 0.66$ & $-46 \pm 1.76$ & $45 \pm 1.44$ & $-115 \pm 1.33$ \\
\hline SMZ VA solution in water, Room Temp. & $17 \pm 1.00$ & $-48 \pm 1.00$ & $45 \pm 1.74$ & $-117 \pm 3.78$ \\
\hline SMZ VA solution added to Manure filled digestors, Day $1 \& 2$ & 5 & -17 & 20 & -87 \\
\hline SMZ VA solution added to Manure filled digestors, Day $3 \& 4$ & 6 & -37 & 24 & -107 \\
\hline
\end{tabular}

The data indicated that the higher dilution resulted in an improved recovery rate of the stable isotope. For instance, the average recovery rate increased from $20 \%$ for $10 \mathrm{X}$ dilution to $49 \%$ for 100X dilution. Interestingly, the more the concentration of the internal standard increases, the more the recovery rate drops. The possible cause for this issue could be the limited SPE cartridge capacity. Therefore, a modified version of the protocol was prepared to remove the possible errors. The updated protocol has a higher internal standard concentration (10X) and no SPE step. 
The internal standard recovery rate (Figure 5) was $49 \%$ on average, which is comparable with values reported in previous studies. Iglesias et al. [96] reported recovery rates between $73 \%$ and 142\%, while Donato et al. [97] had between 55.8 and 129.3\%, using the Strata-X SPE cartridge. Gao et al. [98] reported 59\% to $131 \%$, Ben et al. [99] 75\% to 121\%, and McClure and Wong [100] 52 to $88 \%$, with the Oasis HLB SPE cartridge.

Negative removal is not logical because no other SMZ sources could be adding to the digesters. One explanation of this condition could be the comparably high concentration of the antibiotic loaded into the SPE cartridge; the cartridge could be saturated and not function properly. For instance, the average SMZ concentration applied to the cartridge was $0.77 \mathrm{mg}$ in the no-dilution sample. The 10X and 100X diluted sample results approve this assumption, as the recovery rate increases with more dilution (less SMZ concentration in the SPE cartridge).

Because the SMZ stable isotope has the same chemical structure and acts similar to SMZ antibiotics, they were competing for adsorption sites inside the SPE polymer cartridge. This could lead to an error. Samples 16 and 17 can be used to confirm that; they were made by applying pure SMZ in water (without any manure) with the concentration of 4.7 and $7.05 \mathrm{mg}$ passing through the SPE cartridge. For these samples, the recovery rate of the internal standard dropped drastically, down to $23.7 \%$ and $19.6 \%$ with $100 \mathrm{X}$ dilution, for samples 16 and 17 , respectively. For the $10 \mathrm{X}$ dilution case, it was even worse, with a recovery of $4 \%$ and $5 \%$ for the 4.7 and $7.05 \mathrm{mg}$ SMZ concentrations, respectively. 


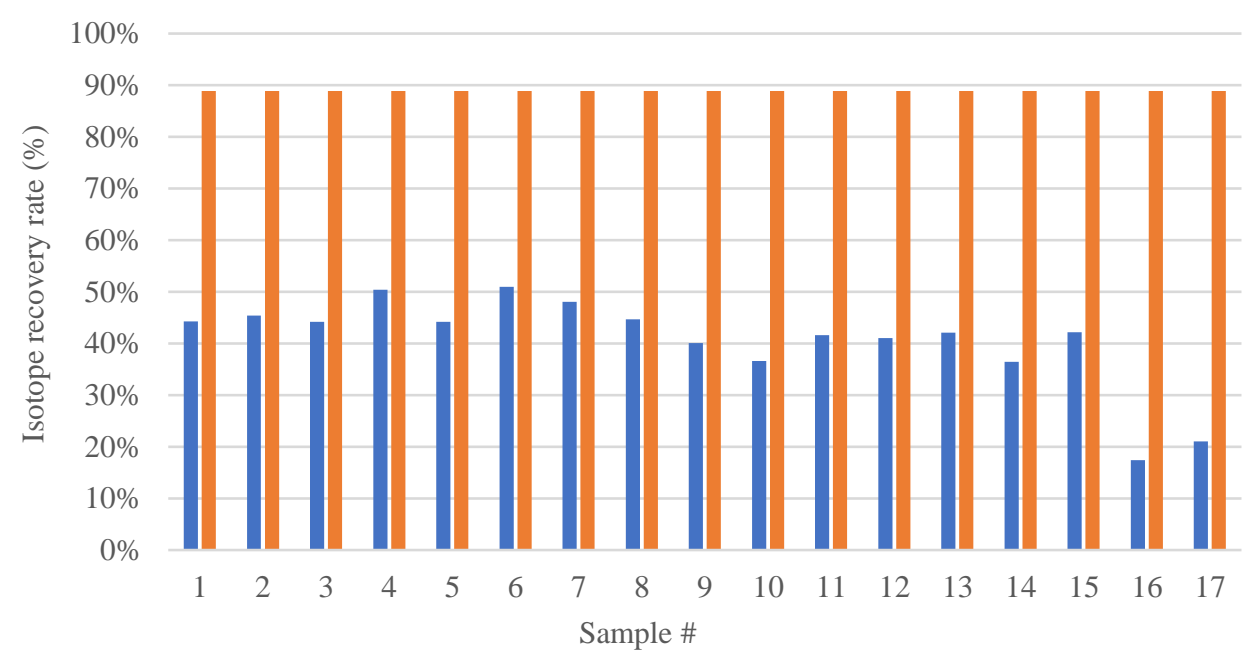

- Isotope Detected Conc. (ppm) —Expected Isotope Concentration (ppm)

Figure 5. Isotope recovery rate in SMZ added samples and control samples with 100X dilution.

Several approaches were used to improve the data, including more sample dilution, changing the SPE cartridge type or bypassing this step, and modifying the detection method and concentrations. The selected revisions were increasing internal standard concentration 10 times, 50 times more sample dilution, and bypassing the SPE step, and proceeding to direct injection for LCMS. Based on these modifications, samples were processed and the results (second analysis round) are presented in Table 6 . The recovery rate, on average, is $68 \%$ and $53 \%$ for manure samples and water samples, respectively. The removal rate is still negative because the detected SMZ concentration is higher than injected. The adjustment factor is calculated based on the concentration of the internal standard injected and detected value. Interestingly, the last five samples, which were SMZ VA solution added to bioreactors and control samples, have values close to what was injected, without the adjustment factor. Also, the recovery rate in water samples was lower than in manure samples. 
Table 6. Second round of data verification with the modified protocol version.

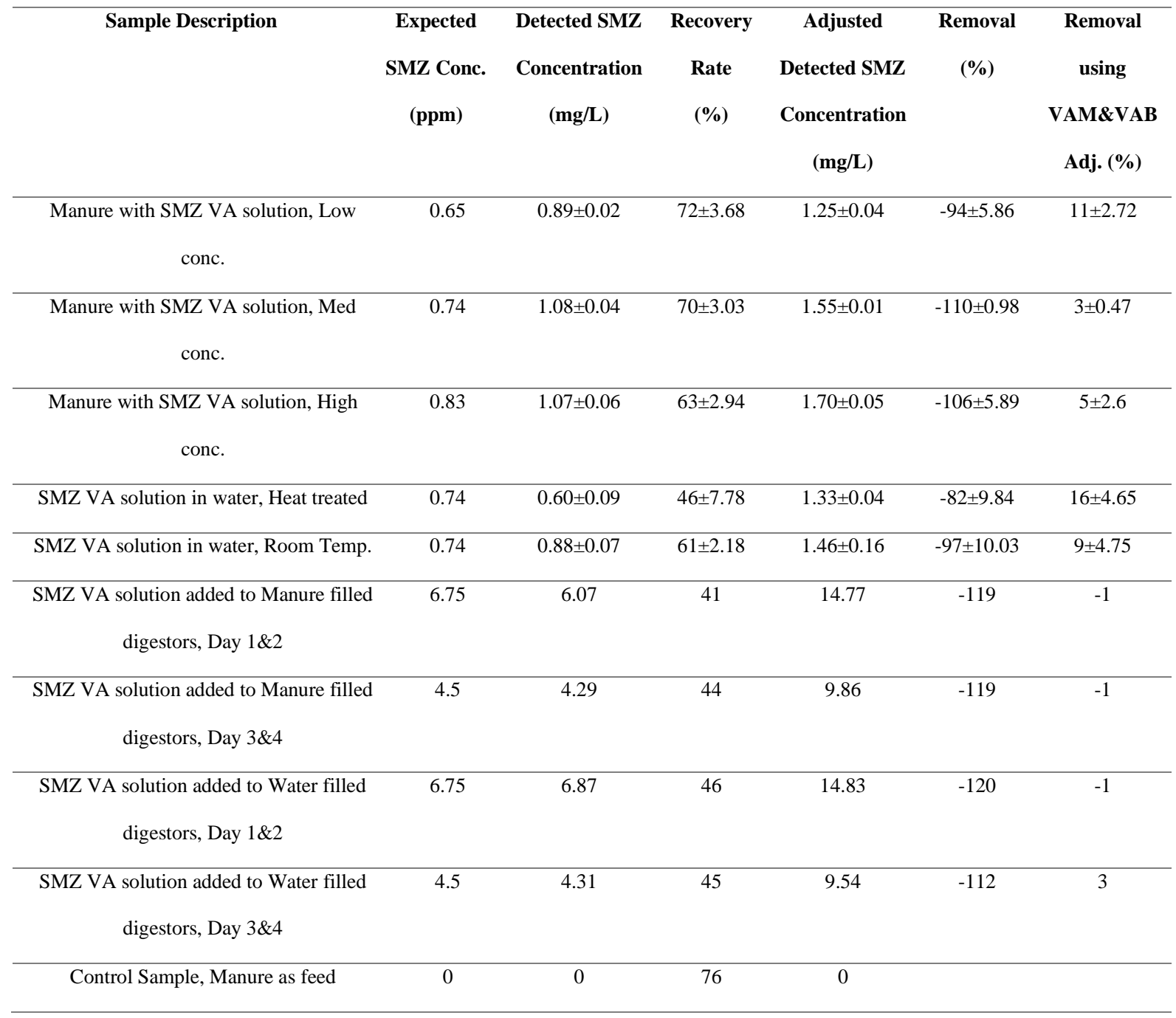

As a result, using the internal standard to adjust the detected values might not be an appealing idea. Further tests should be designed to verify this approach. To evaluate the influence of anaerobic digestion on SMZ removal, another set of samples added to the experiment was carried out as the third round of data verification. These samples were prepared with the same solid manure source and ratio, and the SMZ was injected with the similar concentration range. The only distinction was that there was no anaerobic digestion treatment, and all samples were frozen immediately after VA addition. To determine the effect of SMZ VA and stable isotope competition, 
a set of samples was processed only with a stable isotope in water; no SMZ VAs were added to achieve the recovery rate (Table 7).

As summarized in Table 7, the measured SMZ concentrations without any adjustment are close to the expected values. To illustrate, for injected concentrations of $0.65,0.74$, and $0.83 \mathrm{ppm}$, the measurements were $0.821,0.904$, and $0.989 \mathrm{ppm}$, respectively. The average recovery rate is $69 \%$. Based on all these method verifications and protocol modifications, it was concluded that the use of the Sulfamethazine stable isotope would not be effective. Hence, to measure the effect of anaerobic digestion on SMZ removal, VA added manure samples with AD were compared with the no AD condition (Table 7).

In summary, as shown in Figure 6, the anaerobic digestion process removed less than $10 \%$ of the SMZ added. Also, the removal of SMZ for the current study is not dosage-related. This finding complies with the previous studies including Spielmeyer et al. (2017) [101], Mohring et al. (2009) [55], and Mitchell et al. (2013) [62]. They all reported less than 10\% SMZ removal for the batch reactor. However, Spielmeyer et al. (2015) and Jin et al. (2017) for semi-continuous AD, and Whitey et al. (2016) for batch reactor, achieved $48 \%,>90 \%$, and $80 \%$ removal, respectively [66], [94], [95].

Figure 6 demonstrates that there is no significant difference between the control group and the digestor group. Therefore, anaerobic digestion (biodegradation) is not effective on SMZ with the mesophilic condition and swine manure. 
Table 7. Third round of data verification with the modified protocol version.

\begin{tabular}{|c|c|c|c|c|c|c|c|c|}
\hline Sample Type & $\begin{array}{c}\text { Expected } \\
\text { SMZ } \\
\text { Conc. } \\
\text { (ppm) }\end{array}$ & $\begin{array}{l}\text { Detected } \\
\text { SMZ } \\
\text { Conc. } \\
\text { (mg/L) }\end{array}$ & $\begin{array}{c}\text { Expected } \\
\text { Isotope } \\
\text { Conc. } \\
\text { (mg/L) }\end{array}$ & $\begin{array}{l}\text { Detected } \\
\text { Isotope } \\
\text { (mg/L) }\end{array}$ & $\begin{array}{c}\text { Recover } \\
\text { y Rate } \\
(\%)\end{array}$ & $\begin{array}{c}\text { Adj. } \\
\text { detected } \\
\text { SMZ } \\
\text { conc. } \\
\text { (ppm) }\end{array}$ & $\begin{array}{c}\text { Remov } \\
\text { al } \\
(\%)\end{array}$ & $\begin{array}{c}\text { Adj. } \\
\text { Removal } \\
(\%)\end{array}$ \\
\hline $\begin{array}{c}\text { Manure with } \\
\text { Mixture VA low } \\
\text { conc. No AD }\end{array}$ & 0.65 & 0.821 & 0.009 & 0.006 & 73 & 1.12 & -126 & -172 \\
\hline $\begin{array}{c}\text { Manure with } \\
\text { Mixture VA Med } \\
\text { conc. No AD }\end{array}$ & 0.74 & 0.904 & 0.009 & 0.006 & 69 & 1.31 & -122 & -177 \\
\hline $\begin{array}{c}\text { Manure with } \\
\text { Mixture VA High } \\
\text { conc. No AD }\end{array}$ & 0.83 & 0.989 & 0.009 & 0.006 & 65 & 1.52 & -118 & -182 \\
\hline $\begin{array}{l}\text { Water sample, no } \\
\text { VA and with internal } \\
\text { standard }\end{array}$ & 0.00 & 0.000 & 0.009 & 0.011 & 125 & 0.00 & 0 & \\
\hline $\begin{array}{l}\text { Water sample, no } \\
\text { VA and with internal } \\
\text { standard }\end{array}$ & 0.00 & 0.000 & 0.009 & 0.010 & 117 & 0.00 & 0 & \\
\hline $\begin{array}{l}\text { Water sample, no } \\
\text { VA and with internal } \\
\text { standard }\end{array}$ & 0.00 & 0.000 & 0.009 & 0.009 & 111 & 0.00 & 0 & \\
\hline
\end{tabular}




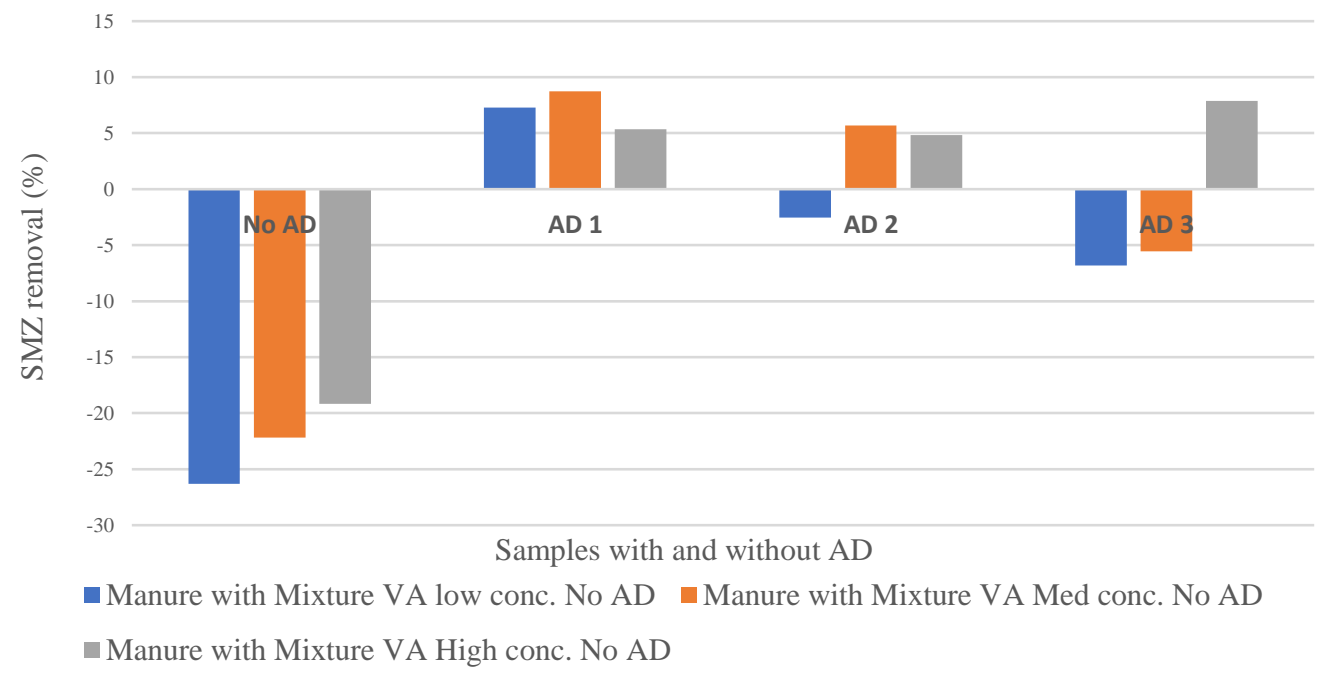

Figure 6. Effect of $\mathrm{AD}$ on $\mathrm{SMZ}$ removal.

Table 8 presents the data for ammonia. Alkalinity, TS and VS, and methane produced was calculated in comparison to the VS destructed. The alkalinity of the control sample is lower than the VA added samples, almost $10 \%$. The control sample has the lowest TS value and the highest VS destruction. It can be inferred that VAs have impacted the bacterial activity in the degradation of solids, which complies with a reduction in biogas production. The total methane production regardless of VS destruction is the highest for the control sample. Surprisingly, biogas and methane production per VS destroyed are higher for VA samples. SMZ could have had a toxic effect on the bacterial group not involved in methane production, which resulted in less energy consumption for the reproduction of non-biogas producer bacteria. 
Table 8. TS/VS, ammonia and alkalinity, biogas, and methane content produced based on VS destroyed results of the SMZ samples and control group.

\begin{tabular}{|c|c|c|c|c|c|c|c|c|c|c|}
\hline & $\mathrm{TS}$ & VS & Ammonia & Alkalinity & $\begin{array}{c}\text { VS } \\
\text { destroyed }\end{array}$ & Biogas & Biogas & $\mathrm{CH}_{4}$ & $\mathrm{CH}_{4}$ & $\mathrm{CH}_{4}$ \\
\hline Treatment / unit & $\mathrm{g} / \mathrm{L}$ & $\mathrm{g} / \mathrm{L}$ & $\mathrm{g} / \mathrm{L}$ & $\mathrm{g} / \mathrm{L}$ & $\mathrm{g} / \mathrm{L}$ & $\mathrm{mL} / \mathrm{d}$ & $\begin{array}{c}\mathrm{mL} / \mathrm{g} \text { VS } \\
\text { des }\end{array}$ & $\%$ & $\mathrm{~mL} / \mathrm{d}$ & $\begin{array}{c}\mathrm{mL} / \mathrm{g} \mathrm{VS} \\
\mathrm{des}\end{array}$ \\
\hline $\begin{array}{l}\text { Manure with SMZ } \\
\text { VA solution, Low }\end{array}$ & $1.43 \pm 0.12$ & $65.50 \pm 0.74$ & $1.80 \pm 0$ & $11.20 \pm 0.38$ & $16.51 \pm 0.74$ & $1980 \pm 65.41$ & $120.77 \pm 7.22$ & $77 \pm 0.27$ & $1518 \pm 52.66$ & $93 \pm 5.81$ \\
\hline $\begin{array}{l}\text { Manure with SMZ } \\
\text { VA solution, Med }\end{array}$ & $1.43 \pm 0.15$ & $66.23 \pm 0.73$ & $1.93 \pm 0.05$ & $10.67 \pm 0.22$ & $15.81 \pm 0.74$ & $2056 \pm 27.82$ & $131.17 \pm 7.97$ & $78 \pm 0.82$ & $1600 \pm 29.31$ & $102 \pm 6.28$ \\
\hline $\begin{array}{l}\text { Manure with SMZ } \\
\text { VA solution, High }\end{array}$ & $1.40 \pm 0.05$ & $66.40 \pm 0.56$ & $1.83 \pm 0.10$ & $10.4 \pm 0.38$ & $15.62 \pm 0.56$ & $1942 \pm 40.82$ & $125.07 \pm 6.9$ & $77 \pm 0.94$ & $1493 \pm 36.72$ & $96 \pm 5.96$ \\
\hline $\begin{array}{l}\text { Manure with SMZ } \\
\text { control }\end{array}$ & 0.8 & 62.4 & 1.8 & 9.6 & 19.61 & 2175 & 110.9 & 78 & 1706 & 87 \\
\hline
\end{tabular}




\subsection{Bacterial Community Dynamics}

Six AD reactors (two sets of a low, medium, and high SMZ treatment) were kept in one incubator and another set of three reactors (low, medium, and high SMZ), and control samples were kept in a second incubator. The temperature for both incubators was set at $39^{\circ} \mathrm{C}$. Interestingly, the two incubator groups showed a sensible discrepancy in bacterial dynamics sequencing. Comparison of the evenness of the samples with two-factor ANOVA (treatment and reactor as factors) found no effect of treatment $(\mathrm{p}=0.935, \mathrm{~F}=0.0693)$, a significant main effect of reactor $(p=$ $0.020, \mathrm{~F}=20.411)$, and no interaction between factors $(p=0.793, \mathrm{~F}=0.251)$ (Figure 7a). Also, twofactor ANOVA of the amplicon sequence variant (ASV) with treatment and reactor as a factor found no effect of treatment $(p=0.123, \mathrm{~F}=4.579)$, a significant main effect of reactor $(p=0.014, \mathrm{~F}=$ $27.261)$, and no interaction between factors $(p=0.414, \mathrm{~F}=1.202)$ (Figure $7 \mathrm{~b})$.

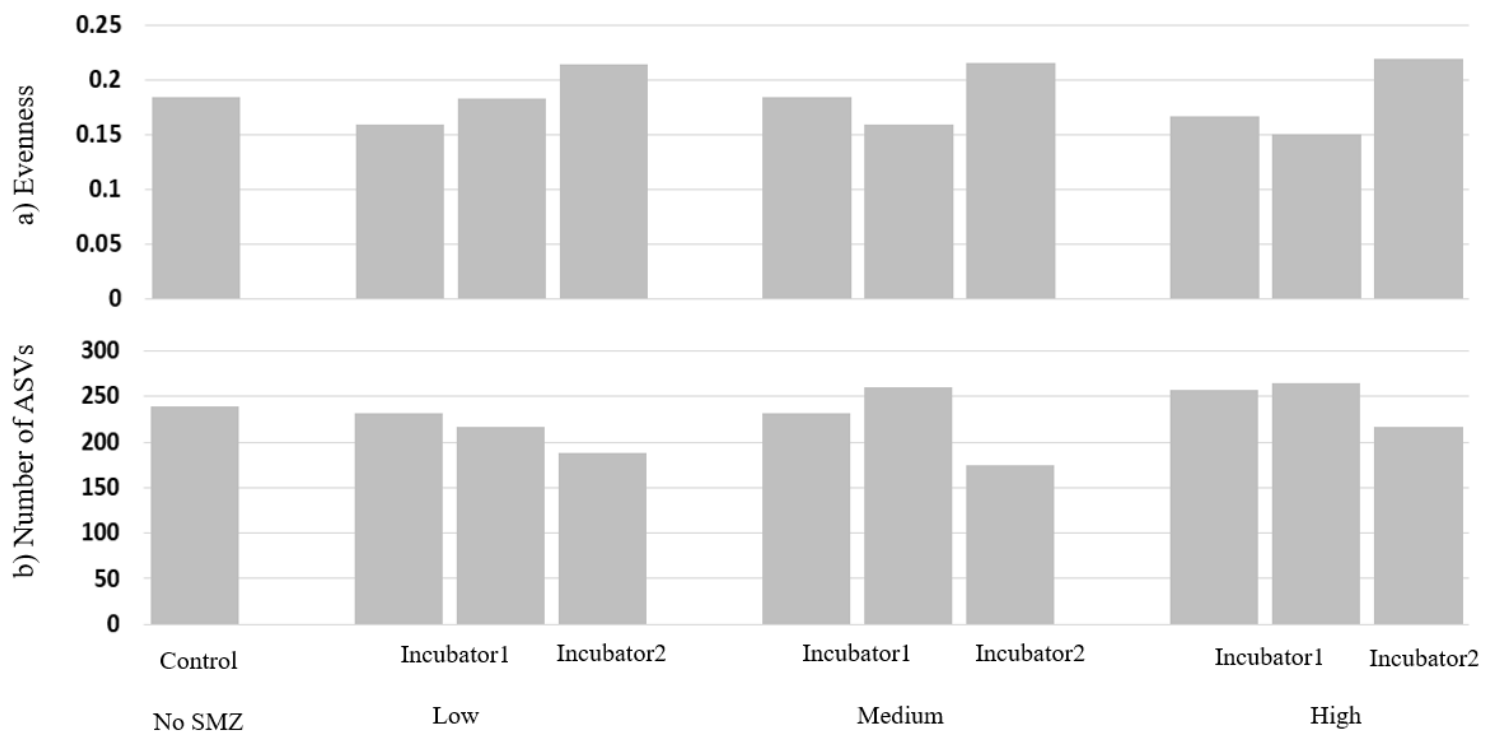

Figure 7. a) Evenness and b) amplicon sequence variant comparison with ANOVA test.

For groups 1 and 2, Phyla firmicutes were the dominant bacteria, following by Bacteroidetes, Proteobacteria, and Synergistetes. For Archaea, Methanosarcina (Euryarchaeota) was dominant. 
With the addition of SMZ, the population of Archaea decreased, and the Firmicutes bacteria population increased. The Proteobacteria, Atribacteria, and Synergistetes population also dropped by over $50 \%$. Within the species of Firmicutes, Clostridia is the dominant class, which indicates relatively fast hydrolysis and VFA (volatile fatty acids) fermentation [102].

Looking deeper into taxonomic levels for groups one and two, Ruminiclostridium, Syntrophomonas, Caldicoprobacter, and Fastidiosipila were dominant groups. Group three showed a completely different behavior. For instance, while other groups have less than $3 \%$ of Ruminiclostridium, two samples in this group have 13\% and 17\% (Figure 8).

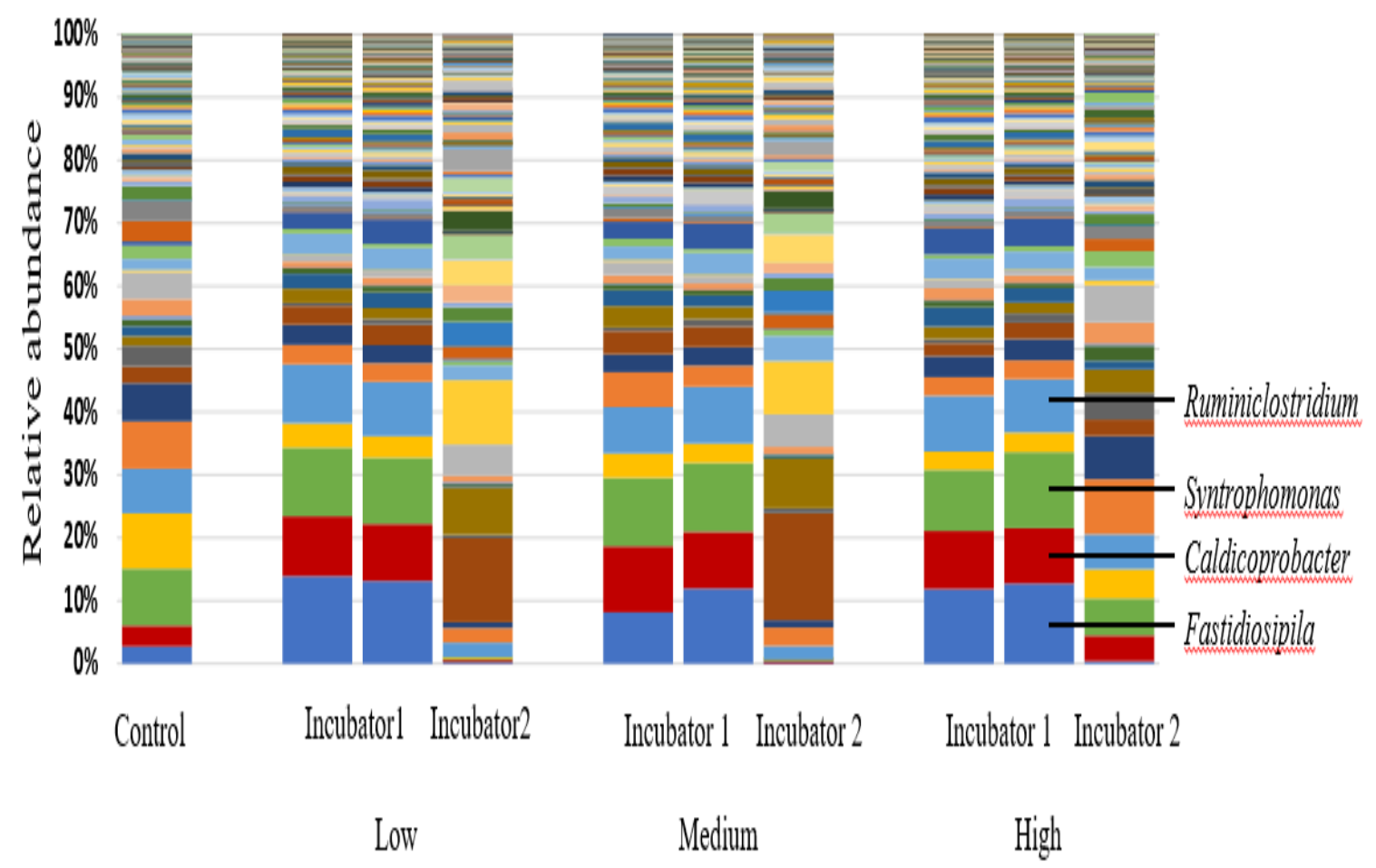

Figure 8. The stacked bar chart at the best taxonomic resolution comparing incubators 1 and 2 .

Figure 9 illustrates principal coordinate analysis (PCoA) plots using Bray-Curtis and Jaccard similarities for incubators one and two. There is a significant difference between incubators one and two. Despite some variations, samples with CTC and tylosin (former study) were showing 
entirely distinct Bray-Curtis values. Because one of the pivotal goals of identifying the bacterial community was to evaluate the source of the pollutant, it is clear that SMZ has a distinctive effect on the dynamics as compared to the CTC and tylosin treatments.

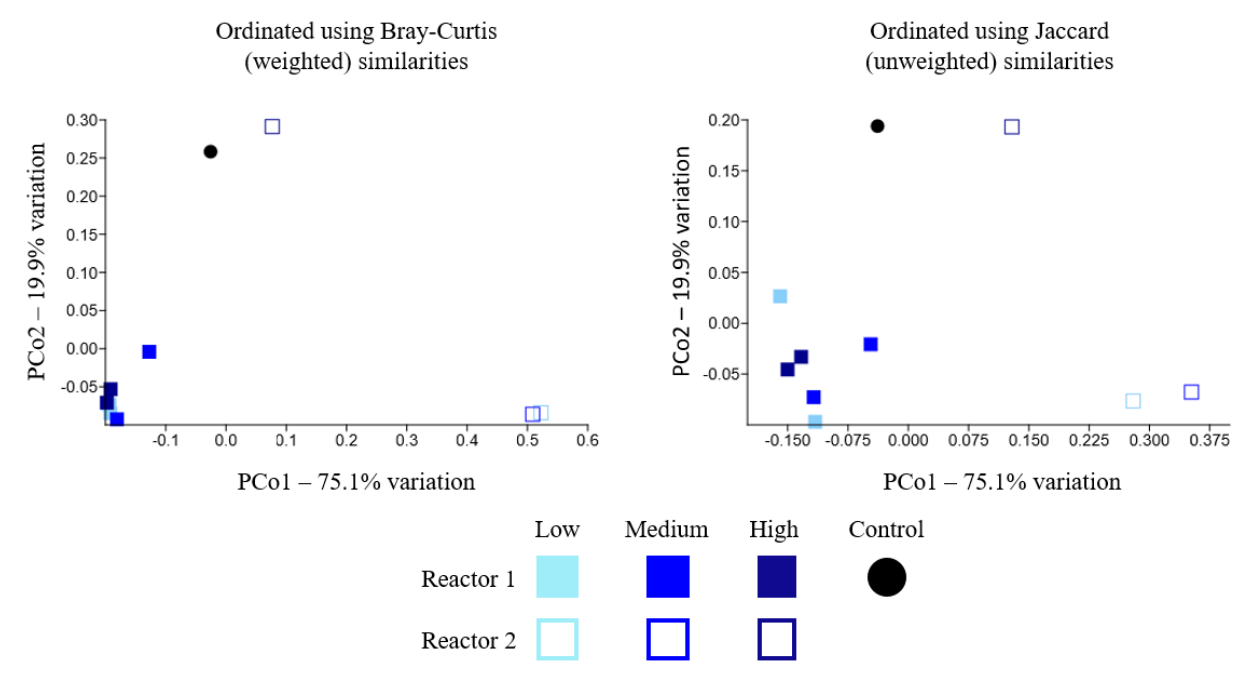

Figure 9. Principal coordinate analysis plots using Bray-Curtis and Jaccard similarities for incubators 1 and 2.

Scrutinizing the ASV abundance in the SMZ experiment, regardless of the last group, revealed that Syntrophomonas and Ruminiclostridium abundance was almost the same. The Fastidiosipila population increased with SMZ addition from $2.7 \%$ to $12 \%$ on average, but no effect was observed with CTC and tylosin treatments. On the other hand, Desulfovibrio, Clostridium sensu stricto, Proteiniphilum, and Methanosarcina populations dropped. Desulfovibrio is a genus of Gram-negative sulfate-reducing bacteria.

Comparing the control sample with the SMZ added samples shows that Methanosarcina dropped from $3.5 \%$ to $1 \%$ on average. The control group was a mixture of 4 back-up bioreactors that were kept and fed with a similar condition to VA added jars. Hence, it can be predicted that 
methane production should also decrease. In this paper, the hydrogenotrophic pathway with Methanosarcinaceae was dominant, as reported by others [103], [69], [104].

The Rikenellaceae RC9 gut group increased almost 6 times, from $0.65 \%$ to over $4 \%$, when compared to the control group. Acetomicrobium decreased from $3.2 \%$ to less than $0.2 \%$ while Syntrophomonas was untouched. Cloacimonadaceae and Synergistaceae have also grown more with SMZ addition and it is dosage related. Synergistetes are significant contributors to the degradation of sludge for the production of biogas in anaerobic digesters producing hydrogen gas. The Syntrophomonadaceae are a family of anaerobic bacteria which consume carboxylic acids as their source of energy [105]. The Synergistetes' (syntrophic acetate oxidizers) emergence might be a sign of modest acetotrophic activity [106]. Caldicoprobacter is a thermophilic anaerobic acetigignens bacteria. Anaerobic digester metagenome declines from $0.5 \%$ to $0.15 \%$.
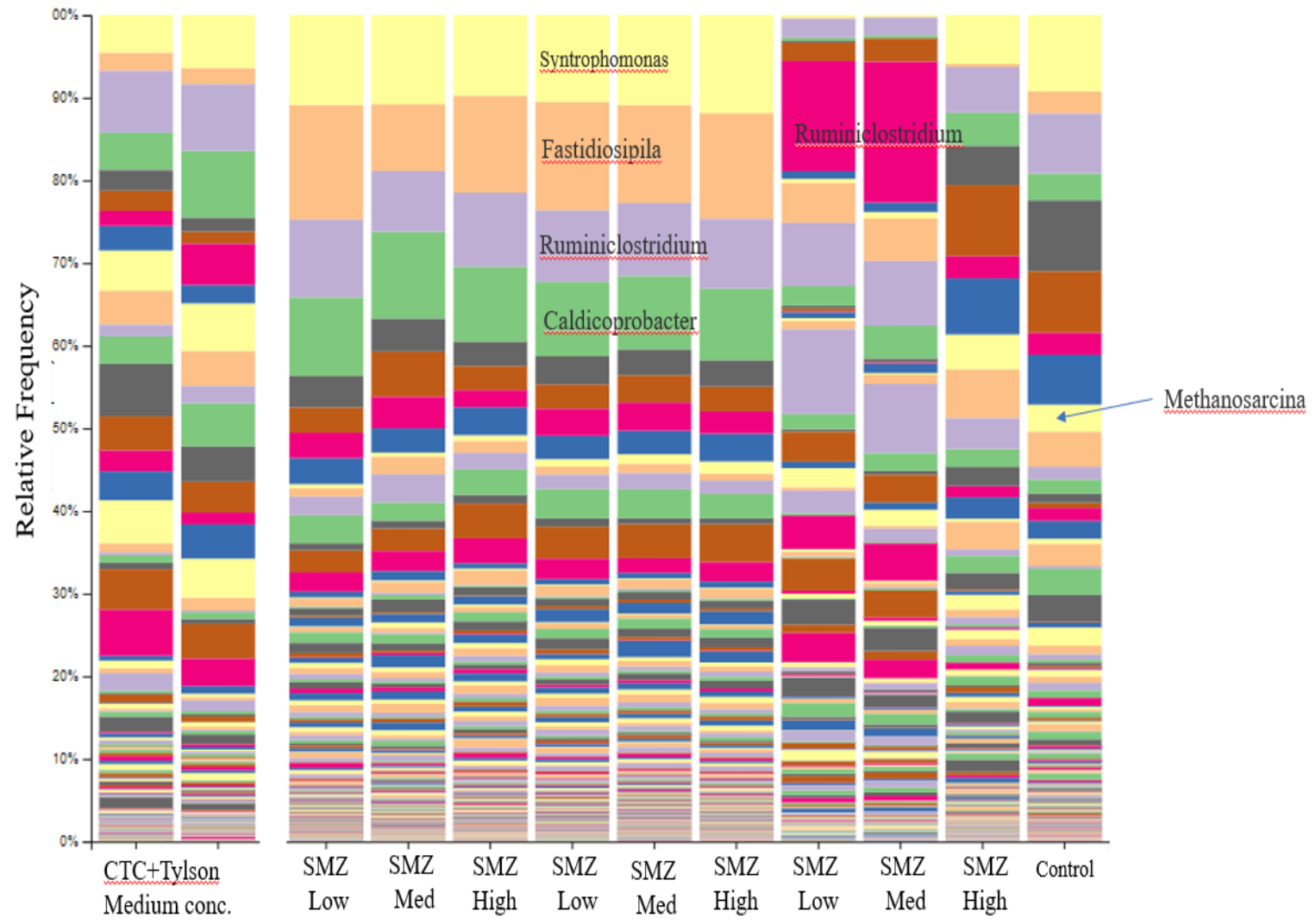
Figure 10. The stacked bar chart at the best taxonomic resolution comparing the effect of different

VAs on bacterial dynamics.

Figure 11 shows a heat map in which samples (columns) are ordered according to similarity using a hierarchical method (UPGMA) based on the 50 ASVs (rows) with the lowest $p$-values following serial ANOVA testing of all ASVs. In short, it shows perfect inequity between groups when the samples are clustered using only the most variable ASVs. The taxonomic identity of the microbes is listed on the right-hand side of the heat map. R1 and R2 are referred to as incubators 1 and 2, respectively.

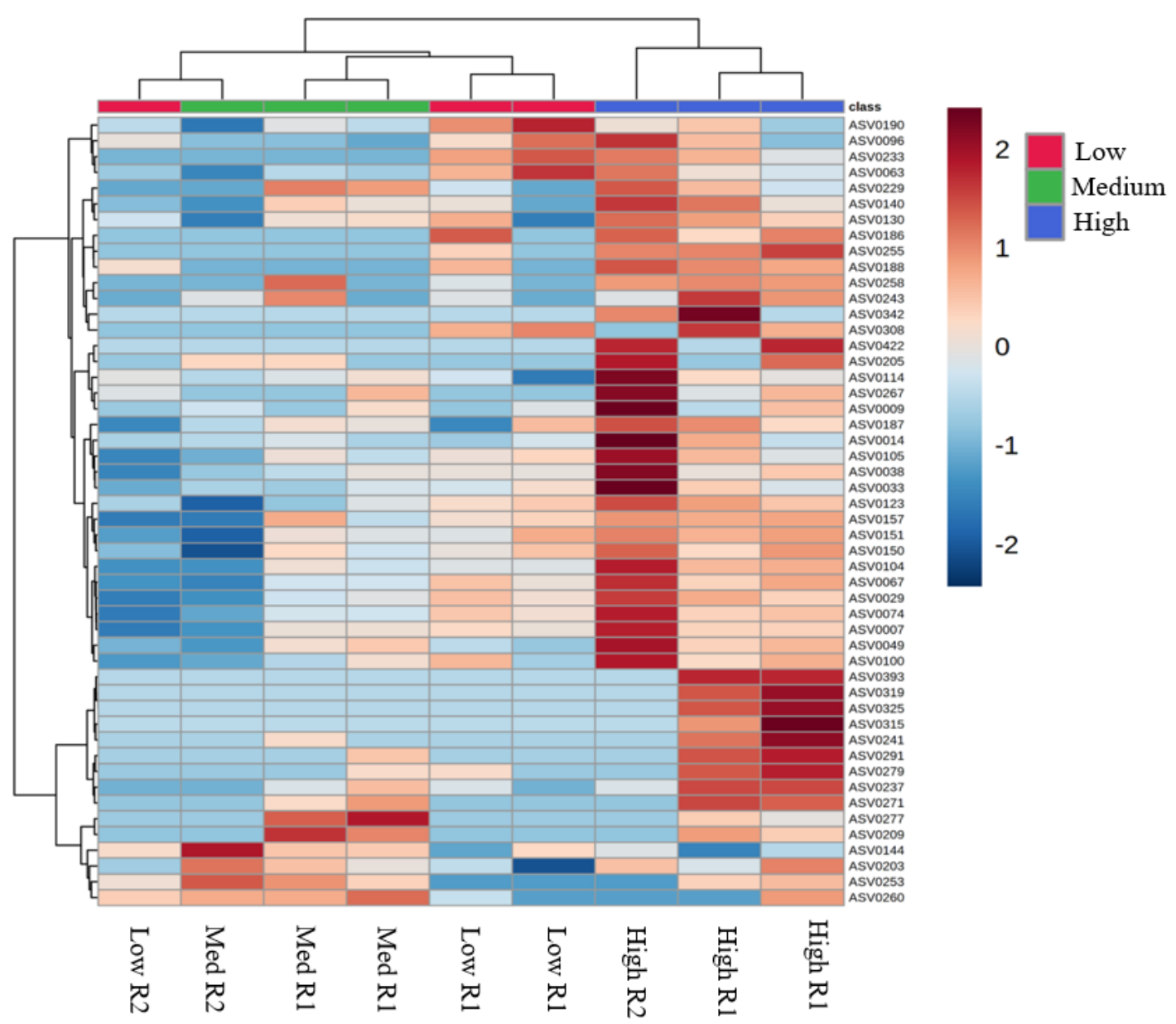

Figure 11. Heat map of treated samples using a hierarchical method (UPGMA) based on the 50 ASVs (rows) with the lowest $\mathrm{p}$ values. R1 and R2 refer to incubators 1 and 2, respectively. 
Again, regardless of incubator 2 data (R2), patterns are visible for different concentrations of SMZ. To illustrate, if the abundance of ASV 277, 209, or 104 is high, it is attributed to the medium concentration of SMZ. Furthermore, if ASV 422, 205, 114, 9, 14, and 33 are abundant, it is related to the high concentration of SMZ in the system.

\section{Conclusion}

Due to the widespread consumption of veterinary antibiotics and their high excretion rate in animal guts and feces, antimicrobial resistance is an imminent risk for the ecosystem. Anaerobic digesters will provide two main factors of temperature and anaerobic condition to foster special bacteria that have shown effective removal of contaminants, including pharmaceuticals. In this study, Sulfamethazine, one of the most consumed veterinary antibiotics which is listed as critically important by the FDA, underwent biodegradation with a mesophilic anaerobic digester. Biogas inhibition due to antibiotic introduction was as high as $25 \%$. The microorganism community could handle the antibiotic, as no drastic fluctuation happened in the $\mathrm{pH}$ or $\mathrm{CO}_{2}$ level. The removal rate of Sulfamethazine was close to zero, which means that current AD bioreactors do not help remove any significant amount of SMZ after a six-day $\mathrm{AD}$ treatment. Besides, amplicon sequencing analysis demonstrated a significant correlation between CTC, tylosin, SMZ, and their concentrations. With the addition of SMZ, the population of Archaea decreased, and the Firmicutes bacteria population increased. The abundance of ASVs can be used to predict the antibiotic type and its concentration. 


\section{Reference}

[1] J. T. Sims and R. O. Maguire, "Manure Management," in Encyclopedia of Soils in the Environment, vol. 4, Elsevier Inc., 2004, pp. 402-410.

[2] T. P. Van Boeckel et al., "Global trends in antimicrobial use in food animals," Proc. Natl. Acad. Sci. U. S. A., vol. 112, no. 18, pp. 5649-5654, 2015, doi: 10.1073/pnas.1503141112.

[3] K. R. Kim, G. Owens, S. I. Kwon, K. H. So, D. B. Lee, and Y. S. Ok, “Occurrence and environmental fate of veterinary antibiotics in the terrestrial environment," Water. Air. Soil Pollut., vol. 214, no. 1-4, pp. 163-174, 2011, doi: 10.1007/s11270-010-0412-2.

[4] A. E. \& I. U. L. and B. I. Service, "European Commission ( DG Environment ) Collection and Analysis of Data for the Control of Emissions from the Spreading of Manure," no. January, 2014.

[5] K. Kumar, S. C. Gupta, Y. Chander, and A. K. Singh, “Antibiotic Use in Agriculture and Its Impact on the Terrestrial Environment," Adv. Agron., vol. 87, no. 05, pp. 1-54, 2005, doi: 10.1016/S00652113(05)87001-4.

[6] The Food and Drug Administration, “2017 Summary report on antimicrobials sold or distributed for use in food-producing animals." 2018, [Online]. Available: https://www.fda.gov/media/119332/download.

[7] The Food and Drug Administration, “2018 Summary report on antimicrobials sold or distributed for use in food-producing animals." 2019, [Online]. Available: https://www.fda.gov/animalveterinary/cvm-updates/fda-releases-annual-summary-report-antimicrobials-sold-or-distributed2018-use-food-producing.

[8] X. Li, C. Liu, Y. Chen, H. Huang, and T. Ren, "Antibiotic residues in liquid manure from swine feedlot and their effects on nearby groundwater in regions of North China," Environ. Sci. Pollut. Res., vol. 25, no. 12, pp. 11565-11575, 2018, doi: 10.1007/s11356-018-1339-1.

[9] D. I. Massé, N. M. C. Saady, and Y. Gilbert, "Potential of biological processes to eliminate antibiotics in livestock manure: An overview," Animals, vol. 4, no. 2, pp. 146-163, 2014, doi: 10.3390/ani4020146.

[10] A. Spielmeyer, "Occurrence and fate of antibiotics in manure during manure treatments: A short review," Sustain. Chem. Pharm., vol. 9, no. March, pp. 76-86, 2018, doi: 10.1016/j.scp.2018.06.004.

[11] N. Udikovic-Kolic, F. Wichmann, N. A. Broderick, and J. Handelsman, “Bloom of resident antibioticresistant bacteria in soil following manure fertilization," Proc. Natl. Acad. Sci. U. S. A., vol. 111, no. 42, pp. 15202-15207, 2014, doi: 10.1073/pnas.1409836111.

[12] F. H. Wang, M. Qiao, Z. Chen, J. Q. Su, and Y. G. Zhu, “Antibiotic resistance genes in manureamended soil and vegetables at harvest," J. Hazard. Mater., vol. 299, pp. 215-221, 2015, doi: 10.1016/j.jhazmat.2015.05.028.

[13] J. Wang, W. Ben, Y. Zhang, M. Yang, and Z. Qiang, "Effects of thermophilic composting on oxytetracycline, sulfamethazine, and their corresponding resistance genes in swine manure," Environ. Sci. Process. Impacts, vol. 17, no. 9, pp. 1654-1660, 2015, doi: 10.1039/c5em00132c.

[14] W. Y. Xie, Q. Shen, and F. J. Zhao, "Antibiotics and antibiotic resistance from animal manures to soil: a review," Eur. J. Soil Sci., vol. 69, no. 1, pp. 181-195, 2018, doi: 10.1111/ejss.12494.

[15] A. Castellanos-Navarrete, P. Tittonell, M. C. Rufino, and K. E. Giller, "Feeding, crop residue and manure management for integrated soil fertility management - A case study from Kenya," Agric. Syst., vol. 134, pp. 24-35, 2015, doi: 10.1016/j.agsy.2014.03.001. 
[16] M. C. Rufino, P. Brandt, M. Herrero, and K. Butterbach-Bahl, "Reducing uncertainty in nitrogen budgets for African livestock systems," Environ. Res. Lett., vol. 9, no. 10, 2014, doi: 10.1088/17489326/9/10/105008.

[17] N. Sanginga and P. L. Woomer, Integrated soil fertility management in Africa: principles, practices, and developmental process. CIAT, 2009.

[18] S. Jechalke, H. Heuer, J. Siemens, W. Amelung, and K. Smalla, "Fate and effects of veterinary antibiotics in soil," Trends Microbiol., vol. 22, no. 9, pp. 536-545, 2014, doi: 10.1016/j.tim.2014.05.005.

[19] R. Alexy, T. Kümpel, and K. Kümmerer, "Assessment of degradation of 18 antibiotics in the Closed Bottle Test," Chemosphere, vol. 57, no. 6, pp. 505-512, 2004, doi: 10.1016/j.chemosphere.2004.06.024.

[20] E. Y. Klein, K. K. Tseng, S. Pant, and R. Laxminarayan, “Tracking global trends in the effectiveness of antibiotic therapy using the Drug Resistance Index," BMJ Glob. Heal., vol. 4, no. 2, pp. 1-7, 2019, doi: 10.1136/bmjgh-2018-001315.

[21] G. Dantas, M. O. A. Sommer, R. D. Oluwasegun, and G. M. Church, “Bacteria subsisting on antibiotics," Science (80-. )., vol. 320, no. 5872, pp. 100-103, Apr. 2008, doi: 10.1126/science.1155157.

[22] World Bank, "Drug-Resistant Infections: A Threat to Our Economic Future.," World Bank Rep., vol. 2, no. September, pp. 1-132, 2016, doi: 10.1007/s11947-009-0181-3.

[23] Z. E. Menkem, B. L. Ngangom, S. S. A. Tamunjoh, and F. F. Boyom, “Antibiotic residues in food animals: Public health concern," Acta Ecol. Sin., vol. 39, no. 5, pp. 411-415, 2019, doi: 10.1016/j.chnaes.2018.10.004.

[24] I. Phillips et al., "Does the use of antibiotics in food animals pose a risk to human health? A critical review of published data," J. Antimicrob. Chemother., vol. 53, no. 1, pp. 28-52, 2004, doi: 10.1093/jac/dkg483.

[25] K. Sivagami, V. J. Vignesh, R. Srinivasan, G. Divyapriya, and I. M. Nambi, “Antibiotic usage, residues and resistance genes from food animals to human and environment: An Indian scenario," $\mathrm{J}$. Environ. Chem. Eng., vol. 8, no. 1, p. 102221, 2020, doi: 10.1016/j.jece.2018.02.029.

[26] R. P. Tasho and J. Y. Cho, "Veterinary antibiotics in animal waste, its distribution in soil and uptake by plants: A review," Sci. Total Environ., vol. 563-564, no. 3, pp. 366-376, 2016, doi: 10.1016/j.scitotenv.2016.04.140.

[27] H. S. Chung et al., "Uptake of the veterinary antibiotics chlortetracycline, enrofloxacin, and sulphathiazole from soil by radish," Sci. Total Environ., vol. 605-606, pp. 322-331, 2017, doi: 10.1016/j.scitotenv.2017.06.231.

[28] L. Yang, S. Zhang, Z. Chen, Q. Wen, and Y. Wang, "Maturity and security assessment of pilot-scale aerobic co-composting of penicillin fermentation dregs (PFDs) with sewage sludge," Bioresour. Technol., vol. 204, pp. 185-191, 2016, doi: 10.1016/j.biortech.2016.01.004.

[29] J. Bengtsson-Palme and D. G. J. Larsson, “Concentrations of antibiotics predicted to select for resistant bacteria: Proposed limits for environmental regulation," Environ. Int., vol. 86, pp. 140-149, 2016, doi: https://doi.org/10.1016/j.envint.2015.10.015.

[30] A. H. Taleghani, T. T. Lim, C. H. Lin, A. C. Ericsson, and P. H. Vo, "Degradation of veterinary antibiotics in swine manure via anaerobic digestion," Bioengineering, vol. 7, no. 4, pp. 1-28, 2020, doi: 10.3390/bioengineering7040123.

[31] C. Miller, S. Heringa, J. Kim, and X. Jiang, “Analyzing indicator microorganisms, antibiotic resistant Escherichia coli, and regrowth potential of foodborne pathogens in various organic fertilizers.," Foodborne Pathog. Dis., vol. 10, no. 6, pp. 520-527, Jun. 2013, doi: 10.1089/fpd.2012.1403. 
[32] T. S. Edrington, W. E. Fox, T. R. Callaway, R. C. Anderson, D. W. Hoffman, and D. J. Nisbet, "Pathogen prevalence and influence of composted dairy manure application on antimicrobial resistance profiles of commensal soil bacteria," Foodborne Pathog. Dis., vol. 6, no. 2, p. 217-224, Mar. 2009, doi: 10.1089/fpd.2008.0184.

[33] W. Y. Xie, X. P. Yang, Q. Li, L. H. Wu, Q. R. Shen, and F. J. Zhao, “Changes in antibiotic concentrations and antibiotic resistome during commercial composting of animal manures," Environ. Pollut., vol. 219, pp. 182-190, 2016, doi: 10.1016/j.envpol.2016.10.044.

[34] W. Baran, E. Adamek, J. Ziemiańska, and A. Sobczak, "Effects of the presence of sulfonamides in the environment and their influence on human health," J. Hazard. Mater., vol. 196, pp. 1-15, 2011, doi: 10.1016/j.jhazmat.2011.08.082.

[35] K. Hruska and M. Franek, "Sulfonamides in the environment: A review and a case report," Veterinarni Medicina, vol. 57, no. 1. Czech Academy of Agricultural Sciences, pp. 1-35, 2012, doi: 10.17221/4969-VETMED.

[36] S. A. I. Mohring, I. Strzysch, M. R. Fernandes, T. K. Kiffmeyer, J. Tuerk, and G. Hamscher, "Degradation and elimination of various sulfonamides during anaerobic fermentation: A promising step on the way to sustainable pharmacy?," Environ. Sci. Technol., vol. 43, no. 7, pp. 2569-2574, 2009, doi: 10.1021/es802042d.

[37] L. Feng, M. E. Casas, L. D. M. Ottosen, H. B. Møller, and K. Bester, “Removal of antibiotics during the anaerobic digestion of pig manure," Sci. Total Environ., vol. 603-604, pp. 219-225, 2017, doi: 10.1016/j.scitotenv.2017.05.280.

[38] N. Watanabe, B. A. Bergamaschi, K. A. Loftin, M. T. Meyer, and T. Harter, “Use and environmental occurrence of antibiotics in freestall dairy farms with manured forage fields," Environ. Sci. Technol., vol. 44, no. 17, pp. 6591-6600, 2010, doi: 10.1021/es100834s.

[39] J. P. Oliver et al., "Invited review: Fate of antibiotic residues, antibiotic-resistant bacteria, and antibiotic resistance genes in US dairy manure management systems," J. Dairy Sci., vol. 103, no. 2, pp. 1051-1071, 2020, doi: 10.3168/jds.2019-16778.

[40] Y. H. Huang et al., "Occurrence and distribution of antibiotics and antibiotic resistant genes in water and sediments of urban rivers with black-odor water in Guangzhou, South China," Sci. Total Environ., vol. 670, pp. 170-180, 2019, doi: 10.1016/j.scitotenv.2019.03.168.

[41] S. M. Mitchell, J. L. Ullman, A. L. Teel, and R. J. Watts, "PH and temperature effects on the hydrolysis of three $\beta$-lactam antibiotics: Ampicillin, cefalotin and cefoxitin," Sci. Total Environ., vol. 466-467, pp. 547-555, 2014, doi: 10.1016/j.scitotenv.2013.06.027.

[42] K. A. Loftin, C. D. Adams, M. T. Meyer, and R. Surampalli, “Effects of Ionic Strength, Temperature, and pH on Degradation of Selected Antibiotics," J. Environ. Qual., vol. 37, no. 2, pp. 378-386, 2008, doi: 10.2134 /jeq2007.0230.

[43] N. Li, H. Liu, Y. Xue, H. Wang, and X. Dai, "Partition and fate analysis of fluoroquinolones in sewage sludge during anaerobic digestion with thermal hydrolysis pretreatment," Sci. Total Environ., vol. 581-582, pp. 715-721, 2017, doi: 10.1016/j.scitotenv.2016.12.188.

[44] S. M. Mitchell, J. L. Ullman, A. L. Teel, R. J. Watts, and C. Frear, “The effects of the antibiotics ampicillin, florfenicol, sulfamethazine, and tylosin on biogas production and their degradation efficiency during anaerobic digestion," Bioresour. Technol., vol. 149, pp. 244-252, 2013, doi: 10.1016/j.biortech.2013.09.048.

[45] G. H. D. Oliveira, A. J. Santos-Neto, and M. Zaiat, "Removal of the veterinary antimicrobial sulfamethazine in a horizontal-flow anaerobic immobilized biomass (HAIB) reactor subjected to 
step changes in the applied organic loading rate," J. Environ. Manage., vol. 204, pp. 674-683, 2017, doi: 10.1016/j.jenvman.2017.09.048.

[46] M. Carballa, F. Omil, T. Ternes, and J. M. Lema, "Fate of pharmaceutical and personal care products (PPCPs) during anaerobic digestion of sewage sludge," Water Res., vol. 41, no. 10, pp. 2139-2150, 2007, doi: 10.1016/j.watres.2007.02.012.

[47] J. Martín, J. L. Santos, I. Aparicio, and E. Alonso, "Pharmaceutically active compounds in sludge stabilization treatments: Anaerobic and aerobic digestion, wastewater stabilization ponds and composting," Sci. Total Environ., vol. 503-504, pp. 97-104, 2015, doi: 10.1016/j.scitotenv.2014.05.089.

[48] A. Spielmeyer, B. Breier, K. Groißmeier, and G. Hamscher, “Elimination patterns of worldwide used sulfonamides and tetracyclines during anaerobic fermentation," Bioresour. Technol., vol. 193, pp. 307314, 2015, doi: 10.1016/j.biortech.2015.06.081.

[49] T. Alvarino, P. Nastold, S. Suarez, F. Omil, P. F. X. Corvini, and H. Bouju, "Role of biotransformation, sorption and mineralization of 14C-labelled sulfamethoxazole under different redox conditions," Sci. Total Environ., vol. 542, pp. 706-715, 2016, doi: 10.1016/j.scitotenv.2015.10.140.

[50] A. Hosseini Taleghani, T. T. Lim, C. Lin, A. C. Ericsson, and P. H. Vo, "Degradation of Sulfamethazine in Swine Manure via Anaerobic Digestion," 2020 ASABE Annual International Virtual Meeting. ASABE, St. Joseph, MI, p. 1, 2020, doi: https://doi.org/10.13031/aim.202000286.

[51] R. G. S. Nogueira, T. T. Lim, H. Wang, and P. H. M. Rodrigues, “Performance, Microbial Community Analysis and Fertilizer Value of Anaerobic Co-digestion of Cattle Manure with Waste Kitchen Oil," Appl. Eng. Agric., vol. 35, no. 2, pp. 239-248, 2019, doi: https://doi.org/10.13031/aea.13023.

[52] T.-T. Lim, B. C. Harvey, and J. M. Zulovich, "Implementation of a Pilot Scale Anaerobic Digester System for Swine Finishing Barn," in 2013 Kansas City, Missouri, July 21-July 24, 2013, 2013, p. 1.

[53] H. Wang et al., "Long-term mesophilic anaerobic co-digestion of swine manure with corn stover and microbial community analysis," Microorganisms, vol. 8, no. 2, 2020, doi: 10.3390/microorganisms8020188.

[54] C. H. Lin, R. N. Lerch, H. E. Garrett, and M. F. George, “Improved GC-MS/MS method for determination of atrazine and its chlorinated metabolites in forage plants - Laboratory and field experiments," Commun. Soil Sci. Plant Anal., vol. 38, no. 13-14, pp. 1753-1773, 2007, doi: 10.1080/00103620701435522.

[55] C. H. Lin, R. N. Lerch, E. M. Thurman, H. E. Garrett, and M. F. George, “Determination of isoxaflutole (balance) and its metabolites in water using solid phase extraction followed by highperformance liquid chromatography with ultraviolet or mass spectrometry," J. Agric. Food Chem., vol. 50, no. 21, pp. 5816-5824, 2002, doi: 10.1021/jf025622d.

[56] S. F. Yang, C. F. Lin, C. J. Wu, K. K. Ng, A. Yu-Chen Lin, and P. K. Andy Hong, "Fate of sulfonamide antibiotics in contact with activated sludge - Sorption and biodegradation," Water Res., vol. 46, no. 4, pp. 1301-1308, 2012, doi: 10.1016/j.watres.2011.12.035.

[57] “Microsoft Excel." Microsoft Corporation, 2018, [Online]. Available: https://office.microsoft.com/excel.

[58] J. R. Bray and J. T. Curtis, “An Ordination of the Upland Forest Communities of Southern Wisconsin,” Ecol. Monogr., vol. 27, no. 4, pp. 325-349, 1957, doi: 10.2307/1942268.

[59] P. Jaccard, "the Distribution of the Flora in the Alpine Zone.," New Phytol., vol. 11, no. 2, pp. 37-50, 1912, doi: 10.1111/j.1469-8137.1912.tb05611.x. 
[60] M. Honarbakhsh et al., "Impact of vitamin A transport and storage on intestinal retinoid homeostasis and functions," J. Lipid Res., p. 100046, 2021, doi: 10.1016/j.jlr.2021.100046.

[61] K. C. Banks, E. A. Giuliano, S. B. Busi, and C. R. Reinero, “Evaluation of Healthy Canine Conjunctival , Periocular Haired Skin , and Nasal Microbiota Compared to Conjunctival Culture," vol. 7, no. August, pp. 1-12, 2020, doi: 10.3389/fvets.2020.00558.

[62] A. C. Ericsson et al., "Isolation of segmented filamentous bacteria from complex gut microbiota," Biotechniques, vol. 59, no. 2, pp. 94-98, 2015, doi: 10.2144/000114319.

[63] A. C. Ericsson, D. J. Davis, C. L. Franklin, and C. E. Hagan, “Exoelectrogenic capacity of host microbiota predicts lymphocyte recruitment to the gut," Physiol. Genomics, vol. 47, no. 7, pp. 243 252, 2015, doi: 10.1152/physiolgenomics.00010.2015.

[64] B. Manpreet, J. Waschek, and A. Ericsson, "The G Protein-Coupled Receptor, VPAC1, is The Principle Driver for VIP De ciency-Induced Alterations of Gut Microbiota in C57BL / 6 Mice .," pp. 1-19.

[65] W. A. Walters, J. G. Caporaso, C. L. Lauber, D. Berg-Lyons, N. Fierer, and R. Knight, "PrimerProspector: De novo design and taxonomic analysis of barcoded polymerase chain reaction primers," Bioinformatics, vol. 27, no. 8, pp. 1159-1161, 2011, doi: 10.1093/bioinformatics/btr087.

[66] J. G. Caporaso et al., "Global patterns of 16S rRNA diversity at a depth of millions of sequences per sample," Proc. Natl. Acad. Sci., vol. 108, no. Supplement 1, pp. 4516-4522, 2011.

[67] A. Loy, F. Maixner, M. Wagner, and M. Horn, "probeBase - an online resource for rRNA-targeted oligonucleotide probes: new features 2007," Nucleic Acids Res., vol. 35, no. suppl_1, pp. D800-D804, 2007.

[68] K. Townsend, A. Lacarrubba, L. Martin, and A. Ericsson, "Exodontia-associated bacteremia in horses characterized by next generation sequencing," pp. 1-16.

[69] M. Martin, “Cutadapt removes adapter sequences from high-throughput sequencing reads," EMBnet. J., vol. 17, no. 1, pp. 10-12, 2011.

[70] E. Bolyen et al., "Reproducible, interactive, scalable and extensible microbiome data science using QIIME 2," Nat. Biotechnol., vol. 37, no. 8, pp. 852-857, 2019.

[71] B. J. Callahan, P. J. McMurdie, M. J. Rosen, A. W. Han, A. J. A. Johnson, and S. P. Holmes, “DADA2: high-resolution sample inference from Illumina amplicon data," Nat. Methods, vol. 13, no. 7, pp. 581583, 2016.

[72] E. Pruesse et al., "SILVA: a comprehensive online resource for quality checked and aligned ribosomal RNA sequence data compatible with ARB," Nucleic Acids Res., vol. 35, no. 21, pp. 71887196, 2007.

[73] N. Beneragama, S. A. Lateef, M. Iwasaki, T. Yamashiro, and K. Umetsu, "The combined effect of cefazolin and oxytertracycline on biogas production from thermophilic anaerobic digestion of dairy manure," Bioresour. Technol., vol. 133, pp. 23-30, 2013, doi: 10.1016/j.biortech.2013.01.032.

[74] J. J. Stone, S. A. Clay, Z. Zhu, K. L. Wong, L. R. Porath, and G. M. Spellman, “Effect of antimicrobial compounds tylosin and chlortetracycline during batch anaerobic swine manure digestion," Water Res., vol. 43, no. 18, pp. 4740-4750, 2009, doi: 10.1016/j.watres.2009.08.005.

[75] B. Huang, H. C. Wang, D. Cui, B. Zhang, Z. B. Chen, and A. J. Wang, "Treatment of pharmaceutical wastewater containing B-lactams antibiotics by a pilot-scale anaerobic membrane bioreactor (AnMBR)," Chem. Eng. J., vol. 341, no. November 2017, pp. 238-247, 2018, doi: 10.1016/j.cej.2018.01.149. 
[76] H. Jin et al., "Distribution of sulfonamides in liquid and solid anaerobic digestates: effects of hydraulic retention time and swine manure to rice straw ratio," Bioprocess Biosyst. Eng., vol. 40, no. 2, pp. 319-330, 2017, doi: 10.1007/s00449-016-1699-1.

[77] J. M. Withey, S. M. Mugo, T. Zhou, P. M. Rosser, and T. Gao, “Depletion of hormones and antimicrobials in cattle manure using thermophilic anaerobic digestion," J. Chem. Technol. Biotechnol., vol. 91, no. 9, pp. 2404-2411, 2016, doi: 10.1002/jctb.4823.

[78] A. Iglesias, C. Nebot, J. M. Miranda, B. I. Vázquez, and A. Cepeda, “Detection and quantitative analysis of 21 veterinary drugs in river water using high-pressure liquid chromatography coupled to tandem mass spectrometry," Environ. Sci. Pollut. Res., vol. 19, no. 8, pp. 3235-3249, 2012, doi: 10.1007/s11356-012-0830-3.

[79] F. F. Donato et al., "Simultaneous determination of pesticide and antibiotic residues at trace levels in water samples by SPE and LC-MS/MS," Brazilian J. Anal. Chem., vol. 2, no. 7, pp. 331-340, 2012.

[80] P. Gao, D. Mao, Y. Luo, L. Wang, B. Xu, and L. Xu, “Occurrence of sulfonamide and tetracyclineresistant bacteria and resistance genes in aquaculture environment," Water Res., vol. 46, no. 7, pp. 2355-2364, 2012, doi: 10.1016/j.watres.2012.02.004.

[81] W. Ben, Z. Qiang, C. Adams, H. Zhang, and L. Chen, "Simultaneous determination of sulfonamides, tetracyclines and tiamulin in swine wastewater by solid-phase extraction and liquid chromatography-mass spectrometry," J. Chromatogr. A, vol. 1202, no. 2, pp. 173-180, 2008.

[82] E. L. McClure and C. S. Wong, "Solid phase microextraction of macrolide, trimethoprim, and sulfonamide antibiotics in wastewaters," J. Chromatogr. A, vol. 1169, no. 1-2, pp. 53-62, 2007, doi: 10.1016/j.chroma.2007.08.062.

[83] A. Spielmeyer, F. Stahl, M. S. Petri, W. Zerr, H. Brunn, and G. Hamscher, "Transformation of Sulfonamides and Tetracyclines during Anaerobic Fermentation of Liquid Manure," J. Environ. Qual., vol. 46, no. 1, pp. 160-168, 2017, doi: 10.2134/jeq2016.04.0152.

[84] R. Galbiatti Sandoval Nogueira, T. Teeh Lim, and H. Wang, “Laboratory Evaluation of Co-digesting Beef Manure and Waste Kitchen Oil," 2016 ASABE Annual International Meeting. ASABE, St. Joseph, MI, p. 1, 2016, doi: https://doi.org/10.13031/aim.20162461767.

[85] M. Kim, Y. H. Ahn, and R. E. Speece, “Comparative process stability and efficiency of anaerobic digestion; mesophilic vs. thermophilic," Water Res., vol. 36, no. 17, pp. 4369-4385, 2002, doi: 10.1016/S0043-1354(02)00147-1.

[86] S. I. Padmasiri, J. Zhang, M. Fitch, B. Norddahl, E. Morgenroth, and L. Raskin, "Methanogenic population dynamics and performance of an anaerobic membrane bioreactor (AnMBR) treating swine manure under high shear conditions," Water Res., vol. 41, no. 1, pp. 134-144, 2007, doi: 10.1016/j.watres.2006.09.021.

[87] M. Sobieraj and D. R. Boone, “Syntrophomonadaceae," The Prokaryotes. Springer, vol. 4, pp. 10411049, 2006.

[88] T. Ito, K. Yoshiguchi, H. D. Ariesyady, and S. Okabe, “Identification and quantification of key microbial trophic groups of methanogenic glucose degradation in an anaerobic digester sludge," Bioresour. Technol., vol. 123, pp. 599-607, 2012, doi: 10.1016/j.biortech.2012.07.108. 


\section{Chapter 4}

Comparison and Conclusion 
In the last two chapters, enhanced degradation of some of the most consumed veterinary antibiotics in the U.S. through anaerobic digestion was investigated. Chlortetracycline, tylosin, and sulfamethazine were selected due to their market shares in the animal industry, different half-lives, and their imminent danger to the environment and humans.

Interestingly, the T-test showed a significant inhibition immediately after the addition of tylosin, but not for CTC. The biogas reduction for samples with a mixture of tylosin and CTC was close to $14 \%$, and for tylosin only was between 8 and 19\%, with no dose-dependent relationship. For the sulfamethazine treatments, biogas productions were decreased for low and medium concentrations by $17 \%$ and $20 \%$, respectively, but the variation was not significant for the high concentration. Also, T-test shows that $\mathrm{pH}$ values were significantly lower for the samples treated with tylosin $(\mathrm{p}$-value $=0.05)$, but no difference in the CTC samples. In contrast, the addition of SMZ resulted in a $\mathrm{pH}$ increase, inferring that contrary to tylosin, $\mathrm{SMZ}$ did not disturb the Acetogenesis activity. However, CTC did not have any biogas inhibition, but it caused the methane content to drop. Since CTC is against gram-negative, that may have affected the Methanogens. There is no significant difference in methane content before and after the addition of SMZ.

Anaerobic digestion with swine manure was able to achieve $100 \%$ removal of tylosin antibiotic. For CTC, removal was also $100 \%$, but no evidence can prove the degradation was because of the AD process. SMZ removal was less than $10 \%$ for all concentrations. The results clearly indicate that not all antibiotics would be degraded through the anaerobic digestion process, especially for the complete-mix digester that not all of the feedstock and antibiotics would be digested for the full HRT. It is possible that a plug-flow digester might degrade antibiotics more effectively than a complete-mix design, because of the flow pattern of the digestate. More research should be conducted to compare the effectiveness of the two different digester designs. 
Although microbial diversity was declined by the addition of VAs, yet no harmful effect on the microbial community, $\mathrm{pH}$, or alkalinity was observed. For all samples, Phyla Firmicutes, Bacteroidetes, Proteobacteria, and Synergistetes were dominant or co-dominant in bacteria. With the addition of SMZ, the population of Archaea decreased, and the Firmicutes bacteria population increased. Amplicon sequencing analysis demonstrated a significant correlation between CTC, tylosin, SMZ, and their concentrations.

Analyzing the microbial dynamics reveals that the Fastidiosipila population increased with SMZ addition from $2.7 \%$ to $12 \%$ on average, but no effect was observed with CTC and tylosin treatments. On the contrary, populations of Desulfovibrio, Clostridium sensu stricto, Proteiniphilum, and Methanosarcina declined.

Recommendation for the future studies:

We were successful to assess the feasibility of the biodegradation of several antibiotics in anaerobic digesters, also their effects on the reactor performance. More antibiotics and their effect on bacterial dynamics are still untested. Furthermore, we need to set-up a pilot system at a commercial farm to detect the shortcomings and propose the pertinent solutions, in order to elaborate standard methods that can be adopted by most farmers. Besides, in a real-condition bioreactor temperature, loading rate and other factors may not be consistent similar to the laboratory. Furthermore, anaerobic digestion will provide biogas that can be easily used as a source of energy, capturing it and storage of biogas in a real-scale project, and biodegradation of VAs simultaneously without disturbing the reactor performance should be investigated. The energy produced can be a great incentive for farmers to adapt and use this system, it is important to investigate methods to reduce the impact of antibiotics in the manure to the on-farm biogas production. Besides, antibiotic's byproducts and their danger to the environment should be noted. 
More studies should be carried out in the analytical part as well, for example, finding/improving an internal standard that is not interfering with the results, evaluating antibiotics absorption by the organic matter or glass container, and improving the method to prevent matrix effect. 


\section{Appendix I}

A Field Test of Acidifying Separated Liquid Manure, Set-up, Troubleshooting, and Recommendations 


\section{Introduction}

\subsection{The role of the fertilizers}

The world population is growing rapidly, and continuous development in the agriculture sector is essential to provide enough quality food. Therefore, strategies to produce cost-effective and environmentally friendly food are vital. The total population is expected to be 9.2 billion by 2050 [1], which is nearly an increase of 1.4 billion comparing to the world's population in 2020 . Food production requires an increase of $70 \%$, and nearly $100 \%$ in developing countries, to handle the population surge in 2050 [2].

Nitrogen $\left(\mathrm{N}_{2}\right)$ is an essential nutrient for the survival of all living organisms. Nitrogen fixation occurs by a group of microbes in the soil, through abiotic processes, or by lightning. The Haber-Bosch process, a revolutionary method to produce synthetic $\mathrm{N}$ fertilizer on an industrial scale, is costly and energy-consuming [3]. The technique acquires $\mathrm{N}$ from the atmosphere and blends $\mathrm{N}_{2}$ with hydrogen gas $\left(\mathrm{H}_{2}\right)$ to create ammonia $\left(\mathrm{NH}_{3}\right)$. The application of synthesized $\mathrm{N}$ fertilizer resulted in more crop yield in the last 60 years[4]. These fertilizers are estimated to be 100 $\operatorname{Tg}_{\text {year }}{ }^{-1}$ (100 Tera-grams per year) used in agricultural fields [5]. After application of $\mathrm{N}$ fertilizer to the soil, microbes release enzymes that reduce the activation energy required to cycle $\mathrm{N}$. The $\mathrm{N}$ cycles consist of urea hydrolysis, nitrification, and denitrification, which are relying on temperature, the water content of the soil, soil organic matter (SOM), and microbial activity [6]. The urease enzyme can be found in the active microbial cell and can remain active even after the death of the cell [7].

However, nitrogen loss through ammonia volatilization is the primary concern for applying urine on the soil in the crop fields, mostly by urease enzyme hydrolysis [8], [9]. Only $17 \%$ of the $100 \mathrm{Tg}$ N produced in 2005 by the Habor-Bosch method was consumed by the crop, farm industries, 
and meat products. [3], [10], [11]. About 75\% of the total US nitrous oxide $\left(\mathrm{N}_{2} \mathrm{O}\right)$ emissions in 2015 were using synthetic $\mathrm{N}$-based fertilizers [12]. On the other hand, the agriculture-related greenhouse gas (GHG) emission has increased by 8\% since 1990 [13], while FAO predicted that $\mathrm{N}_{2} \mathrm{O}$ emissions would increase 35 to $60 \%$ by 2030 [14]. Nitrous oxide is a stratospheric ozone-depleting gas, stable for up to 120 years before being removed by a sink or breakdown [13]. Among GHG emissions, which are mostly consisting of $\mathrm{N}_{2} \mathrm{O}$, carbon dioxide $\left(\mathrm{CO}_{2}\right)$, and methane $\left(\mathrm{CH}_{4}\right), \mathrm{N}_{2} \mathrm{O}$ is of interest because it has a global warming potential 298 times greater than $\mathrm{CO}_{2}$ and 12 times greater than $\mathrm{CH}_{4}$ [15]. Nitrous oxide in the presence of ultraviolet light can be turned into nitric oxide (NO), acting as a catalyst in the breakdown of ozone [5].

\subsection{Urea}

Urea is the primary $\mathrm{N}$ fertilizer source consumed globally, representing $57 \%$ of total $\mathrm{N}$ fertilizer consumption[16], and high N content (460 g kg-1 N) [17]. Relatively high N content (46\%), simplicity of application, and fair price made urea own the highest market share of fertilizer sale [18]. Urea is produced from ammonia and carbon dioxide, making it the only main $\mathrm{N}$ product chemically categorized as an organic compound. Weather condition plays a pivotal role in N loss; heavy rainfalls cause the soil to be saturated and help urea leach laterally and vertically through the soil profile and finally leads to gaseous $\mathrm{N}$ loss due to its solubility [19], [20].

Urease enzyme activity in the soil can be depressed under flooded soil conditions [21], high soil $\mathrm{pH}$ [22], and low soil temperature [23]. The hydrolysis rate depends on the soil's $\mathrm{pH}$, type, buffering capacity, temperature, and moisture content [24], [25]. It has been reported that the $\mathrm{NH}_{3}$ losses varied from $20 \%$ to as high as $80 \%$ [18], [26]-[29]. 


\subsection{Ammonia volatilization and its adverse effect}

In addition to economic loss, $\mathrm{NH}_{3}$ loss would negatively impact air quality [30]-[34]. Nitrogen from livestock wastes becomes available by the breakdown of nitrogen-containing amino acids. Nitrogen in the environment is reduced to ammonia and then to nitrates, elemental $\mathrm{N}_{2}$, and the oxides of nitrogen $\left(\mathrm{NO}, \mathrm{NO}_{2}, \mathrm{~N}_{2} \mathrm{O}\right)$. Nitrogen evaporates into the atmosphere as ammonia or NOx until it returns to soil or water and completes the chain. Microorganisms would metabolize high concentrations of $\mathrm{N}$ in water. Next, along with excess phosphorous, would cause eutrophication of lakes, increase algae bloom, and disturb the balance of the environment. Besides, the metabolism of $\mathrm{N}$ in water requires oxygen, so this reaction consumes soluble oxygen and endangers aquatic animals and plants. Finding out the $\mathrm{N}$ contamination source between animal waste, fertilizer, and human waste is complicated [35].

In the United States, Houlton et al. [36] estimated that about $25 \%$ of the $\mathrm{N}$ used as fertilizer is lost to the atmosphere as $\mathrm{NH}_{3}$, costing farmers around 6 billion USD a ${ }^{-1}$. In addition to economical loss, this makes the agriculture industry the primary source of $\mathrm{NH}_{3}$ emission to the atmosphere considering the consequences for human health, ecosystems, and climate [37], [38].

Storage and anaerobic digestion of liquid manure could lead to the emission of different gases such as $\mathrm{NH}_{3}$, carbon dioxide $\left(\mathrm{CO}_{2}\right)$, methane $\left(\mathrm{CH}_{4}\right)$, and hydrogen sulfide $\left(\mathrm{H}_{2} \mathrm{~S}\right)$. If the depth of stored manure is greater than $3 \mathrm{ft}$, due to the anaerobic state, there might be up to 160 different gasses emitted [39]. Higher concentrations of $\mathrm{NH}_{3}$ are leading to excess arthritis, porcine stress syndrome, muscle lesions, abscesses, and liver ascaris scars [40]. Excess nitrates in drinking water can lead to methemoglobinemia and cancer risk. To be considered toxic, Nitrates must be reduced to nitrites either in the environment or in the GI tract. 
Between 70 to $80 \%$ of $\mathrm{N}$ escapes to the air from the lagoon in the form of ammonia or nitrous oxide. On the other hand, irrigation of liquid manure will cause 30 to $40 \%$ loss of $N$ to the air, in contrast with application to soil and direct injection with $10-25 \%$ and $0-2 \%$ loss, respectively [41], [42]. Ammonia returns to the soil with precipitation and will eventuate in contamination or overgrowth of unwanted species.

To maximize the absorption of nutrients and to reduce malodor, urine has to be stabilized. Stabilization means preventing enzymatic urea hydrolysis. Enzymatic urea hydrolysis can be prevented by acid addition [43], the addition of urease inhibitors [44], or electrochemical treatment [45].

Adverse effects of having excessive $\mathrm{N}$ in the environment are mainly groundwater contamination by nitrate $\left(\mathrm{NO}_{3}\right)$ [46], eutrophication of terrestrial ecosystems, eutrophication of marine ecosystems, endangering the biodiversity, and disturbing the food chain [47]-[50], acidification of land and water resources [51], [52], the emergence of nitrous oxide as a potent GHG [53], air pollution due to $\mathrm{N}$ compounds with severe health effects [54], [55] and crop yield [56], [57], stratospheric ozone depletion due to $\mathrm{N}_{2} \mathrm{O}$ [58], [59], and in general negative consequences on human health. From 2000 to 2050, nitrogen and phosphorus discharges will surge by $180 \%$ and $150 \%$, respectively [11], [60].

Claypan soil, which is prevalent in Missouri, would lead to waterlogged conditions and cause more N loss through denitrification [61]. Missouri has a high potential of N loss with High temperatures and extended periods of saturated soils (Nash P.R. et al., 2015).

Saturated soil would decrease the amount of $\mathrm{NO}_{3}{ }^{-}$leaching, resulting in more significant $\mathrm{N}_{2} \mathrm{O}$ emissions. An estimate of 2 to $4 \%$ loss of applied fertilizer $\mathrm{N}$ as $\mathrm{N}_{2} \mathrm{O}$ gas from a claypan soil was observed by (Nash P.R. et al., 2012). 


\subsection{Previous studies to preserve $N$ ammonia}

Hellström et al. investigated the efficiency of using different acids on urease inhibition and ammonia loss during storage [43]. For this purpose, sulfuric and acetic acid were used with different concentrations and administration periods. They concluded that sulphuric acid is more efficient than acetic acid, which could be related to the lower $\mathrm{pH}$. They also suggested using phosphoric acid or sulphuric acid could be more appropriate since they have additional value as a fertilizer.

Considering the fact that urine is the source of around $70 \%$ of the phosphorus and approximately $90 \%$ of the nitrogen in the domestic wastewater [63], elaborating a system to separate liquid and solid manure at the farm and use urine directly as fertilizer seems attractive. Besides, heavy metals are relatively low in the urine [64].

Studies showed that $\mathrm{N}$ losses are relatively low during collection and storage [64], [65], yet high at the time of application [66]. Moreover, significant loss of $\mathrm{N}$ could happen during the dewatering process of urine due to ammonia evaporation. The hydrolysis of urea is catalyzed by the enzyme urease, an enzyme that many microorganisms possess [67].

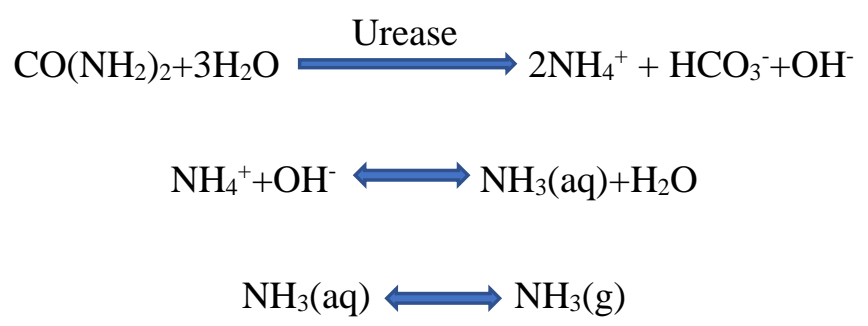

Hanæus et al. [65] concluded that the addition of $26 \mathrm{mmol}$ of sulfuric acid per liter of undiluted urine would prevent urea transform to ammonium. Also, another study [65] has shown a positive relationship between temperature and decomposition rate of urea. 
The optimum $\mathrm{pH}$ for urease activity is 6 to 8 for a silt loam soil, while other surveys on different soil types mentioned no relationship between $\mathrm{pH}$ and urease activity [68], [69]. During the urea hydrolysis, the release of $\mathrm{OH}^{-}$in the soil would lead to the $\mathrm{pH}$ rise. This process fosters the change of $\mathrm{N}$ to $\mathrm{NH}_{3}(\mathrm{~g})$, and as a result, ammonia volatilization happens.

Therefore, soil $\mathrm{pH}$ plays a pivotal role in ammonia volatilization since it determines the ratio and direction of $\mathrm{NH}_{3} / \mathrm{NH}_{4}^{+}$reaction [23]:

$$
\mathrm{NH}_{4}{ }^{+} \Longleftrightarrow \mathrm{NH}_{3}+\mathrm{H}^{+} \quad(\mathrm{pKa}=9.49)
$$

Several studies discovered that an increase in soil $\mathrm{pH}$ would result in higher $\mathrm{NH}_{3}$ volatilization [70], [71]. Fertilizers containing ammonium nitrate develop an acidic environment eventually ( $\mathrm{pH} 4.5$ - 5.5) after being dissolved in the soil and cause lower $\mathrm{NH}_{3}$ loss through volatilization [72].

Nitrification inhibitors (NIs) can be effective in hindering $\mathrm{N}_{2} \mathrm{O}$ emissions. They would restrict the $\mathrm{NH}_{4}{ }^{+}$oxidation into $\mathrm{NO}_{2}{ }^{-}$, and subsequently reduce the $\left(\mathrm{NO}_{3}^{-}\right)$concentration for denitrification [73]-[76]. Naturally, inhibition happens by ammonia monooxygenase, an enzyme produced by Nitrosomonas bacteria.

Considering the rich content of nitrogen and phosphorus in the urea, adverse effects of excessive $\mathrm{N}$ in the environment and economically appealing concept led to urea stabilization and use as fertilizer.

An on-farm liquid manure acidification system was established at a commercial farm. The swine finishing barn had a solid-liquid separation system, so access to fresh liquid manure was much easier compared to more popular flushing or deep-pit barns in the region. The barn was located near Versailles, Missouri, with a capacity of 1200 heads. The acidification equipment was 
installed at the barn, close to the liquid manure collection trough to acidify the urine as fast as possible.

The objectives were to conduct on-farm acid addition for lowering the $\mathrm{pH}$ of manure to 4.5, and to evaluate urea stabilization efficacy during storage, processing, and transport., This report documents the operational issues and improvements made to ensure the $\mathrm{pH}$ manipulation and sampling process. The experiment was carried out using a pilot-scale system for utilizing the existing solid-liquid separating scraper system. After the sampling, the control and acidified liquid manure were shipped to North Carolina State University (NCSU) to reduce the volume of the urine by dewatering and nutrient analysis. This is a project in collaboration with a private company, Waste 2 Green LLC and NCSU, who worked on the low-pressure evaporation concentrating of liquid manure and economics.

\section{Materials and Methods}

\subsection{Solid-Liquid Separation Barn}

The barn in this research project was a swine finishing barn equipped with a solid-liquid separation system. Dimensions of the barn were 80 feet by 132 feet, with an east-west orientation. It has four separate finishing rooms that were connected through a hallway. The capacity of each finishing room was 300 heads, with a total of 1200 heads. In the center of the hallway, there was a

room with monitoring and mechanical devices installed, with stairs leading to the manure collection area. Under each finishing room, there are several automated scrapers, and a conveyor to collect the scraped solid manure, with the automated scraper arms running on schedule. Liquid manure was collected by gravity through slated floors, a V-shaped subfloor under each room, merging the manure as was deposited. The scraper arms were designed to operate when $400 \mathrm{lbs}$ of 
feed were delivered to an individual room. Therefore, they were working 6 times a day on average, powered by a 2-hp motor. The conveyor system was planned to operate circularly between two Vshaped floors; while one scraper was pushing the manure onto the conveyor belt, the other scraper was traveling away from the conveyor belt to be ready for the next cycle. The liquid manure was pouring into a trough, which then drained to the south end of the hallway, to a small reservoir designed for this experiment. After filling up, the excess liquid manure is drained out of the separation barn and to a collection pit placed outside the barn as a temporary storage unit. After the liquid height reaches a certain level, the float switch kicks in and starts pumping the liquid to a lagoon nearby.

Based on previous research conducted at the same finishing barn [77], the approximate periods for different growth stages were as follows: 20 days weaning, 35 days in the nursery, and 140 days in the finishing barn. The estimated mortality rate for pigs during their growth on the farm was $4 \%$ on average.

The small liquid manure reservoir was located on the ground floor of the southeast corner of the hallway, Figure 1. The maximum time for the liquid manure to reach the reservoir was estimated to be 5 minutes. The reservoir capacity was 15 gallons, and the pump was activated by a floating switch when the volume reached 10 gallons. The retention time of the liquid manure in the reservoir depended on the season, day/night, swine age, and population. 


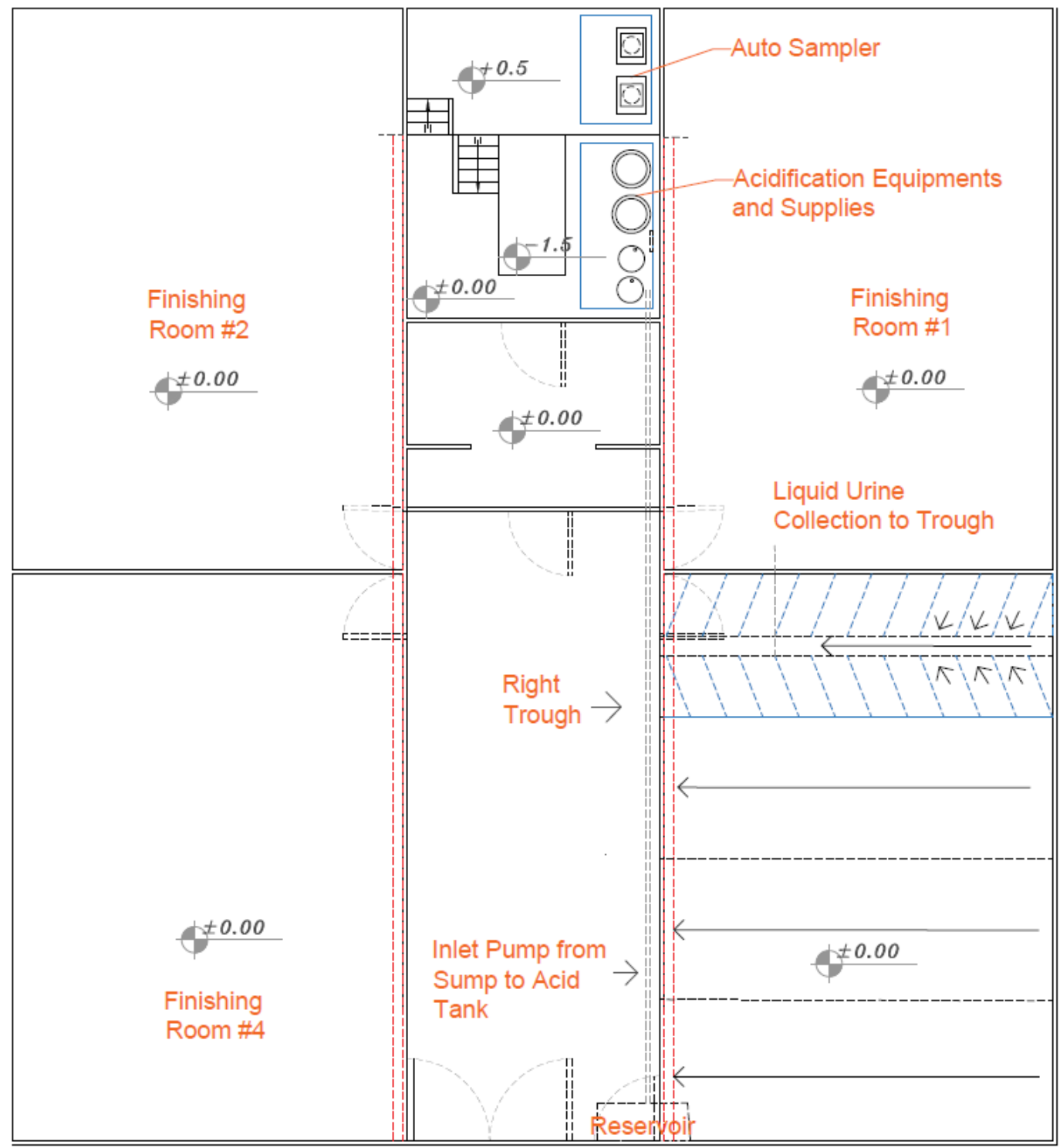

Figure 1. Simplified barn plan, finishing rooms, liquid urine collection system, acidification equipment, February 19 (not to scale)

\subsection{Equipment installation and initial modifications:}

A majority of the pilot set-up was installed by the Waste 2 Green LLC before shipping to the farm. The installation of the reservoir pump and acid pump took place on February 18, 2019 and lasted for about four days. The acid pump was working well, while the controller was maintaining the desired $\mathrm{pH}$. The acid used for this experiment was Citric acid 50\% solution in $555 \mathrm{lbs}$. drum. 
The accuracy of the $\mathrm{pH}$ level was verified by a Bluetooth $\mathrm{pH}$ meter installed in both acid and product tanks and also a portable pH meter (PINPOINT, American Marine Inc, Ridgefield, CT). The next day after the installation was completed (February 21, Figures 2 and 3), the inline flowmeter was not functioning. Due to heavy debris, the inline flowmeter was found to be clogged and causing the acid pump to stop. A switch was then added to better control the pump operation. Two water AutoSamplers (see Liquid Manure Sampling and Handling section) were installed next to the storage tanks to collect the treated liquid manure samples.

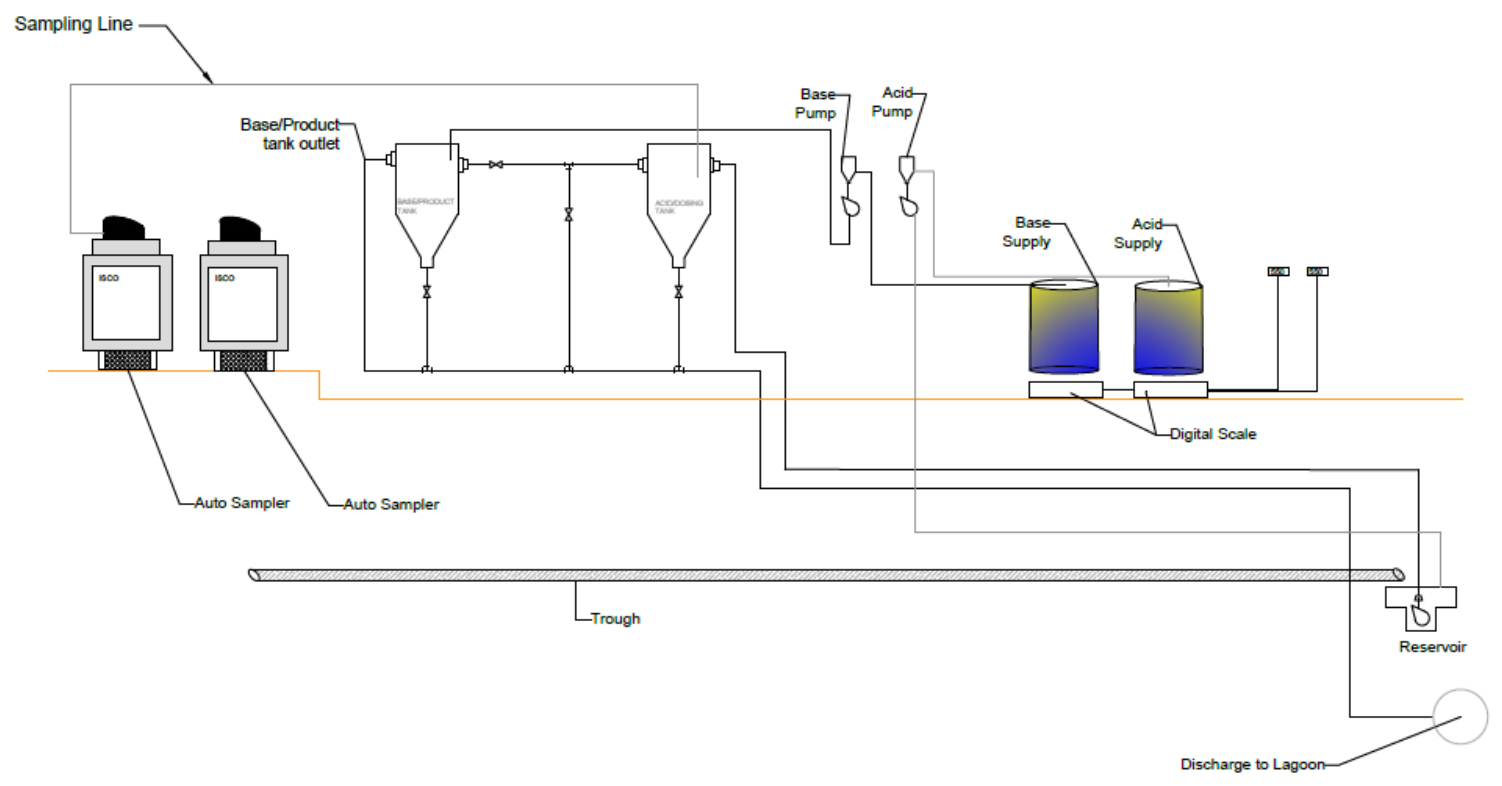

Figure 2. Cross-section plan of acidification pumps, tanks, and autosampler at the barn, February 19 (Not to scale) 


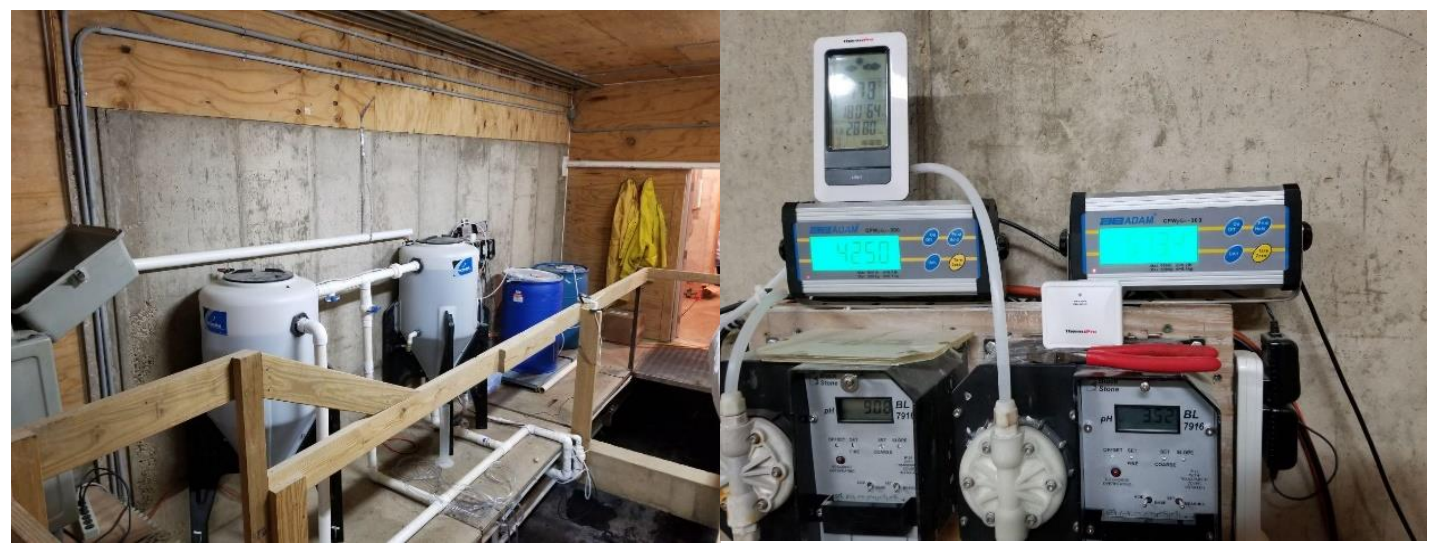

Figure 3. Initial setup of the acid and product tank, acid and base pump, and supplies

The pump used in the reservoir is a $1 \mathrm{HP}$ submersible trash pump (ST2040T Diamond Tool Store, West Palm Beach, Florida). To prevent further issues, the team decided to change the pipe diameter from 1-inch to 2-inch, eliminating the $90^{\circ}$ elbows at the tank and using $45^{\circ}$ transitions to alleviate some of the blockage. To prevent any further clogging, an inline flowmeter was removed. A Doppler-type flowmeter, which mounts externally to the pipe, was ordered to replace the current in-line flowmeter. To remotely monitor the flow sensor, a data logger connected to the laptop at the farm was added, and the TeamViewer software was used so multiple members could closely monitor the operation remotely. Several re-plumbing on the pump was done, the check valve was replaced with a flap-type, and a pipe was plumbed into the tank with a 2-inch line. The pump emptied the reservoir in 20 seconds. The pump was found to need to expel trapped air in the housing occasionally.

\subsection{Flow data collection}

As the previous online flow meter failed to work correctly due to the debris, it was decided to use a doppler flowmeter, outside of the pipe. The replacement flowmeter is a Doppler flow meter (DFM5.1, Greyline Instruments, Largo, FL). Flow data acquisition was conducted by either the 
flowmeter internal memory or USB DAQ and Data Logger System (DI-1100 12-bit, 20,000-40,000 S/s/Ch, DATAQ Instruments, Akron, OH).

The Doppler flowmeter transducer was installed close to the old flowmeter location. The main issue with the flowmeter was the error in detecting flow, which was so high (as high as 250 gals $/ \mathrm{m}$ ) while the pump was off, and the total volume detected in 15 minutes was more than 100 gals. We went through the troubleshooting steps, changed the probe location, added more petroleum gel beneath the probe, added earth ground wire to the clamp, yet no improvement. It was not because of the shaking or vibration of the pipes or ground, either. Besides, the data logger was disconnected to check if it would help. Finally, the cut-off signal percentage of the flowmeter was increased to $5 \%, 10 \%, 15 \%$, and $20 \%$, it was still the same, but with $90 \%$ cut-off, the error was less than half a gallon in a 45 minutes duration, when the pump was off. Several tests were performed while the pump was on and compared the fluid level in the acid tank to verify the calibration. The data collected of the volume pumped had approximately $10 \%$ error. The data logger connected to the flowmeter showed the same flow as the flow meter with a few seconds delay.

Dust was a major issue as well, especially after being accumulated for weeks. A transparent tarp was added to cover the electronic devices and the camera.

\subsection{Acid and base addition set-up and laboratory tests}

Acid was supplied from a 55-gallon citric acid drum, and base supply was made with "Arm \& Hammer" Baking Soda and water at the farm. The mixing ratio and acquired $\mathrm{pH}$ level are shown in the result section. To neutralize the acidified/treated liquid manure in the product tank, a base solution was added before discharging the liquid manure. To prepare the base solution at the farm, three bags of “ARM \& HAMMER ${ }^{\mathrm{TM}}$ Baking Soda Resealable Bag” each 5 lbs. (totally 15 lbs.), was 
added to $460 \mathrm{lbs}$. of well water, and mixed in the base supply barrel. The initial desired $\mathrm{pH}$ for the product tank was 7 . However, reaching this $\mathrm{pH}$ level requires a high intake of the base supply, later it was lowered to $\mathrm{pH}$ 6.5, which sounds fine since the purpose of neutralization was to preserve the concrete of the barn.

During the neutralization, the base supply depleted very fast. To investigate the reason, some lab tests were performed using tap (city) water in the lab, and farm water and liquid manure collected from the farm. The laboratory study aimed to determine the efficiency of baking soda, its optimum concentration solution, and the volume required to neutralize treated liquid manure of 4.5 and $\mathrm{pH}$ 5.5. The details are presented in the result section.

At the beginning of the experiment in February 2019, base supply $\mathrm{pH}$ was measured to be above 13. However, the highest $\mathrm{pH}$ value we achieved later with baking soda was 8.3 at the farm and from replicated tests conducted in the lab. Therefore, the initial $\mathrm{pH}$ was probably an error.

The laboratory tests conducted include:

1. Acidification and neutralization test.

2. Base solution and consumption test.

\subsection{Liquid manure sampling and handling tests}

Autosampler (ISCO model 6700FR refrigerated sampler, Johnston Inc., Lincoln, NE) was used to draw treated samples from the acid tank. It has 24 sampling bottles, 1 liter each, and can be programmed to sample time-based or flow-based automatically. The control and treated liquid manure samples were then shipped to NCSU for further tests. There were some issues with the autosampler, it did not fill all the 24 bottles as programmed. We noticed a problem with the autosampler tube clogging. It could be due to the negative pressure of pump suction and the 
amount of manure solids; the tube was found twisted and clogged. We improved the sampler with a reinforced tube. The manure solids were likely those that were not removed by the scraper system works and bypassed the relatively small settling basin for the liquid fraction.

The delivery method of the samples to North Carolina (NC) was considered, including the temperature, volume of the samples, and mixing condition. There is a trade-off between the cost of shipping and shipping time, plus the sample volume. Therefore, a preliminary test was carried out as follows:

First, collecting a few liters of untreated material from the reservoir directly and distribute it into 4 bottles, then handle them as follows:

I. One bottle was sent to the University of Missouri lab for a full waste analysis and Nanalysis Total Kjeldahl Nitrogen (TKN) and Total Ammoniacal Nitrogen (TAN) without any temperature consideration.

II. One bottle was shipped to NC lab as frozen.

III. One bottle was shipped overnight or 2nd day with dry ice to NC lab.

IV. One bottle was shipped at ambient temperature to the NC lab.

The next step was comparing the analysis results of the three bottles that were shipped to the NCSU lab and the sample analyzed at the University of Missouri. Based on the condition of the material as it arrives and those analyses, we would be able to determine the most economical handling and shipping method without worrying about altering the composition of the sample. We had originally hoped to collect a control sample to be compared with treated samples, but at that point, the second autosampler was not functioning, so there was only one autosampler 
collecting samples from the acid/dosing tank(Figure 4). Liquid manure treatment levels were untreated, $\mathrm{pH} 5.5$ and $\mathrm{pH} 4.5$.

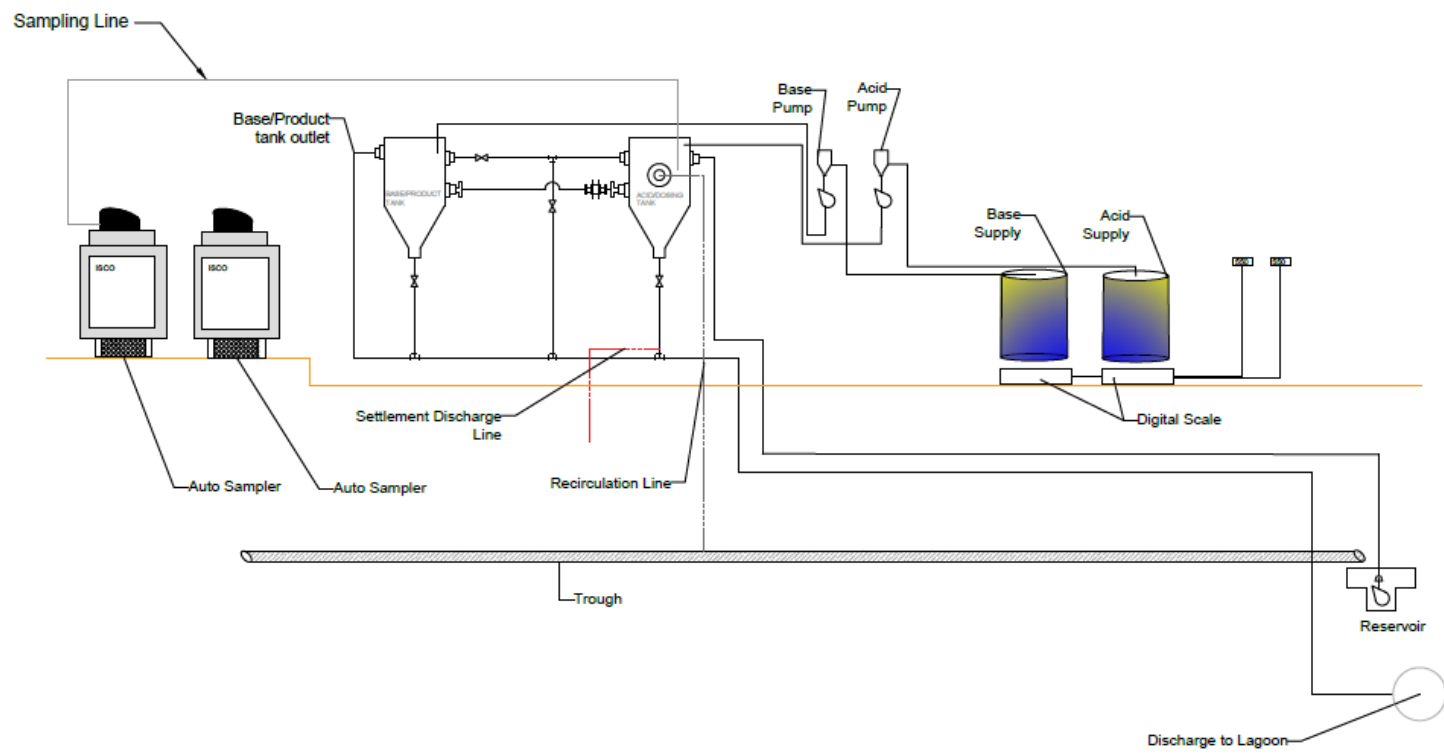

Figure 4. Simplified sketch of the final urine acid treatment system, October 19 (Not to scale).

\subsection{Operating the system and routine sampling}

After all the modifications, the reservoir pump was still struggling to run steadily. Occasionally, it was humming, and it would lead to more foaming and, finally, system failure. In the end, the pump was replaced with a smaller size provided by the farm owner. With the new pump, the system started working steadily, no humming or excessive foaming was observed at the reservoir. Nevertheless, few minor issues happened; for instance, a piece of bone or debris was stuck in the pump and prevented the propeller to work. A metal screen filter around the pump inlet would help prevent such issues.

Routine rounds of sampling were conducted after the system was functioning more steadily. Three distinctive groups of samples were taken with $\mathrm{pH} 4.5, \mathrm{pH} 5.5$, and untreated liquid manure as the control group. Each round of sampling started on Monday as follows: 
Day 1: Clean the reservoir and the system by removing settlements, start the $\mathrm{pH}$ treatment, and set dosing to $\mathrm{pH}$ 5.5. Configure the autosampler to collect samples from 9 am to $1 \mathrm{pm}$ on the next day with $700 \mathrm{~mL}$ each sample every hour, for a total of five samples.

Day 2: Collect the samples, composite them, and grab 3L of treated liquid manure of $\mathrm{pH} 5.5$ and keep them inside the refrigerator. Clean the autosampler bottles, and change the $\mathrm{pH}$ setting from 5.5 to 4.5 ; set the autosampler to collect samples from 9 am to 1 pm on the next day, with 700 mL each sample every hour, for a total of five samples.

Day 3: Collect all pH 4.5 samples, composite them, and grab 3L and keep them inside the autosampler refrigerator. Turn off the acid pump. Wash the autosampler bottles, flush the system, wash the pipes, trough, and reservoir with clean water for 5 minutes. Wait 30 minutes until liquid manure flow in the trough becomes normal and consistent. Then, take the untreated liquid manure samples, directly at the end of the trough before entering the reservoir, every 30 minutes. Collect 3L of untreated samples. Distribute the $\mathrm{pH} 5.5, \mathrm{pH} 4.5$, and untreated samples into three 1-L bottles, put them in the insulated foam package, and add dry ice for cold shipping and deliver to FedEx, for shipping to NCSU.

Sampling time is an essential factor and collecting samples at the same schedule each time would help minimize the variation of the nutrients, especially the nitrogen contents. However, should there be a problem with the autosampler, acid pump, or other general failures of the system, we would lose one day of sampling and need to repeat the treatment and sampling. Since the last day of sending samples to NC was Thursday afternoon in order to ensure delivery on Friday afternoon, sampling untreated urine usually took place the same day of collecting the $\mathrm{pH} 4.5$ samples. A test was conducted to compare $\mathrm{N}$ concentrations over few hours and between the two troughs on the left side and right side of the barn. Figure 5 depicts how the $\mathrm{N}$ concentrations varied 
over time, for both sides of the liquid manure collection troughs. The TKN and TAN levels were relatively consistent from noon to $3 \mathrm{pm}$. Just to recall, the farm had a separate trough on each side of the barn, and our project was performed on the right (east) side.

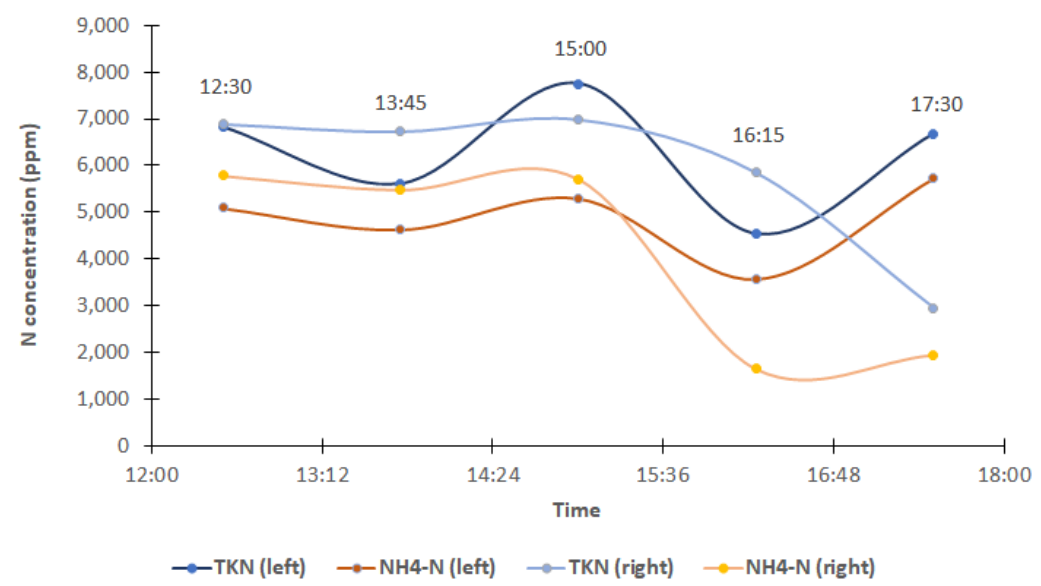

Figure 5. Comparison of the nitrogen concentrations of liquid manure samples collected from left and right-side trough over time (Adopted from A. Deviney et al., NCSU, 2019).

\subsection{Liquid manure production estiamtion}

Inventory data was provided by the farm management, including the date, heads, and the weight of the pigs at the beginning of the finishing growth cycle. Feed delivered to the barn was also provided, but there was not individual feed record for each of the four finishing rooms. So we could not compare the feed consumption and total pig mass for the eastern half barn, where our test and measurement were conducted.

Based on industry standards and previous research [77] Brown et al. conducted at the same farm, a $4 \%$ mortality rate was assumed. Moreover, with the initial inventory and pig weight provided, and average market weight from the previous study, the average pig mass in the two finishing rooms was estimated for each growth cycle. The initial weight of the new group of pigs 
entering the rooms was average $35 \mathrm{lbs}$. each and the final weight as finisher swine was $267 \mathrm{lbs}$. The duration for the pigs to grow from 35 lbs. to 267 lbs., averaged 135 days.

Total feed consumed was the sum of the different feed ingredients (corn, SBM, soy oil ...), which was provided by the farm management. Due to variable feed consumption (larger pigs eat more) and inconsistent delivery, feed consumption rates were more variable, therefore we averaged the feed consumption rate using weekly or biweekly feed consumption, which seems to be a rational idea as presented in the previous study (Brown et al., 2018). To illustrate, Figure 19 shows the weekly and biweekly feed consumption.

The manure production rate was estimated using values provided based on the manure characteristics in MWPS-18 Section 1 [78], where swine manure production can be predicted related to the animal type and weight.

The method Brown et al. used to estimate this ratio is as follows:

"For evaluation of the liquid manure production, the fluid level of the collection pit was continuously monitored by using a liquid pressure data logger (U20L-04, HOBO Water Level, Onset Computer Corporation, Bourne, MA). The fluid level sensor was secured to the bottom of the collection pit. The depth of the liquid manure was monitored by measuring the change in pressure experienced in the pit in two-minute intervals.

With knowledge of the collection pit dimensions and liquid (manure) level variations, estimation of the liquid manure pumped to the lagoon on a daily basis could then be made. Tests to estimate liquid level with the initial logger and the weather station's hourly atmospheric pressure were carried out until the acquisition of a new, dual-sensor data logger (MX2001, Onset Computer Corporation), which utilized a second logger to measure atmospheric pressure simultaneously. 
The amount of solid manure produced was more difficult to monitor. The production rate of the solid manure could not be monitored with a device such as a water level sensor as was the case with the liquid manure. A camera was used to closely monitor the pile height. The camera (BCC100 Construction Time Lapse Camera, Brinno, Taipei City, Taiwan) was set on an hourly timer and was installed on a support beam connected to the East wall. The hourly images were recorded as a video file, which was collected upon each trip to the farm.

Information from the video file was analyzed to determine the solid manure production rate. The removable wall, which served as the background for the images, was constructed out of three levels of concrete blocks, with a uniform height of 24 inches $(0.61 \mathrm{~m})$ each. By a combination of the pile height against the concrete wall, and the shed dimensions, solid manure volume was approximated via pixel measurement. The pile volume was estimated by assuming a flat surface and uniform distribution of the solid manure."

Based on the animal weight, total manure and liquid manure produced can be calculated. And, multiplying it to the number of the swine, total daily liquid manure production in the Eastern half-barn, is estimated. Thus, the estimated population of the pigs belongs to room \#2 and \#4 (east side of the barn), and to simplify the calculation, we assumed there is a similar population of the pigs on the other side (Room \#1 and \#3). Comparison of the total liquid manure produced, biweekly feed consumption, and total animal mass were then conducted to verify the acid consumption, and to confirm their correlations. Therefore, by having the daily total liquid manure produced and extracted for the sampling days, we compared these values with the amount of acid consumed, and also with the lab test results. 


\subsection{Cost-benefit analysis}

By having liquid manure production volume in a year at the farm, calculating the amount of acid required to decrease the $\mathrm{pH}$ to 4.5 and 5.5 is the next step. Nitrogen content data including total kjeldahl nitrogen of acid treated sample and untreated samples data was provided by NCSU team. In actual condition, liquid manure was kept several months before application at the farm, however the untreated samples' N-content level is volatilization within a week. Therefore, two different approaches were employed to calculate the value of the fertilizer produced. First, using the exact data and find the $\mathrm{N}$-content preserved, and second, following the literature to estimate average volatilization ratio and then calculate the $\mathrm{N}$-content preserved (non- conservative method) [79]. Moreover, sulfuric acid price when purchase in bulk was also considered, since it is stronger than citric acid and less expensive. The average TKN were 3940, 5474 and $5556 \mathrm{mg} / \mathrm{L}$ for untreated, $\mathrm{pH} 5.5$ treatment and $\mathrm{pH} 4.5$ treatment, respectively.

Finally, plant-available nitrogen (PAN) and residual nitrogen fertilizer value in manure was calculated according to the MU Guide G9186 [80]. Weather condition, temperature, soil moisture and lots of other factors would influence the amount of nitrogen mineralization and available nitrogen for the plants. Also, type of the animal manure, spreader and nitrogen is important. Energy price, maintenance and machinery expenses were not included in the calculation. 


\section{Results and Discussion:}

\subsection{Laboratory test results}

\subsubsection{Acidification test}

The aim of this test was to measure the amount of acid needed to lower the $\mathrm{pH}$ of the $2 \mathrm{~L}$ of liquid manure samples. The $\mathrm{pH}$ values of three samples after $70 \mathrm{~mL}$ of the acid was added gradually, are presented in Table 1.

Table 1. Amounts of citric acid were added to $2 \mathrm{~L}$ of liquid manure, to reduce the $\mathrm{pH}$ from 7.0 to 4.5 , mimicking the farm condition.

\begin{tabular}{c|ccc}
\hline & Sample 1 & Sample 2 & Sample 3 \\
\hline $\begin{array}{c}\text { Citric Acid } \\
\text { Added }(m L)\end{array}$ & & $\mathrm{pH}$ & \\
0 & 6.94 & 6.95 & 6.96 \\
20 & 5.91 & 6.00 & 6.07 \\
30 & 5.38 & 5.51 & 5.59 \\
40 & 5.05 & 5.16 & 5.20 \\
50 & 4.80 & 4.86 & 4.95 \\
55 & 4.73 & 4.79 & 4.80 \\
60 & 4.63 & 4.69 & 4.71 \\
65 & 4.57 & 4.61 & 4.60 \\
70 & 4.50 & 4.55 & 4.50 \\
\hline
\end{tabular}

The initial $\mathrm{pH}$ of the fresh liquid manure was 6.95. Citric acid was added to each sample until the $\mathrm{pH}$ reached 5.5 and 4.5 , because $\mathrm{pH} 5.5$ and 4.5 were our treatment targets at the farm. The volumes of the acid added to acidify the liquid manure are presented in Figure 6, and the ratios of the acid added (citric acid, $\mathrm{mL}$, added to liquid manure, $\mathrm{mL}$ ) are summarized in Table 2. The amount needed to lower the liquid manure to $\mathrm{pH} 5.5$ ranged from $1.3 \%$ to $1.6 \%$ (acid/liquidmanure, $\mathrm{mL} / \mathrm{mL}$ ), in contrary of 3.5\% (acid/liquid-manure, $\mathrm{mL} / \mathrm{mL}$ ) for $\mathrm{pH} 4.5$ acidification. The results indicate that the amount of citric acid needed to lower the liquid manure to $\mathrm{pH} 4.5$ was about 2.4 times more than it needed to lower to $\mathrm{pH} 5.5$, meaning that the required acid to reduce the $\mathrm{pH}$ values to a lower level does not follow a linear trend. 
Table 2. Volume of citric acid required to reduce $2 \mathrm{~L}$ of the liquid manure $\mathrm{pH}$ to 5.5 and 4.5 .

\begin{tabular}{c|ccc}
\multicolumn{1}{c}{} & Test 1 & Test 2 & Test 3 \\
\hline Total volume required to lower to $\mathrm{pH} 5.5(\mathrm{~mL})$ & 26.77 & 29.52 & 32.2 \\
Ratio \% (acid/liquid-manure, $\mathrm{mL} / \mathrm{mL})$ & 1.34 & 1.48 & 1.61 \\
Total volume required to lower to $\mathrm{pH} 4.5(\mathrm{~mL})$ & 70 & 70 & 70 \\
Ratio \% (acid/liquid-manure, $\mathrm{mL} / \mathrm{mL})$ & 3.50 & 3.65 & 3.50 \\
\hline
\end{tabular}

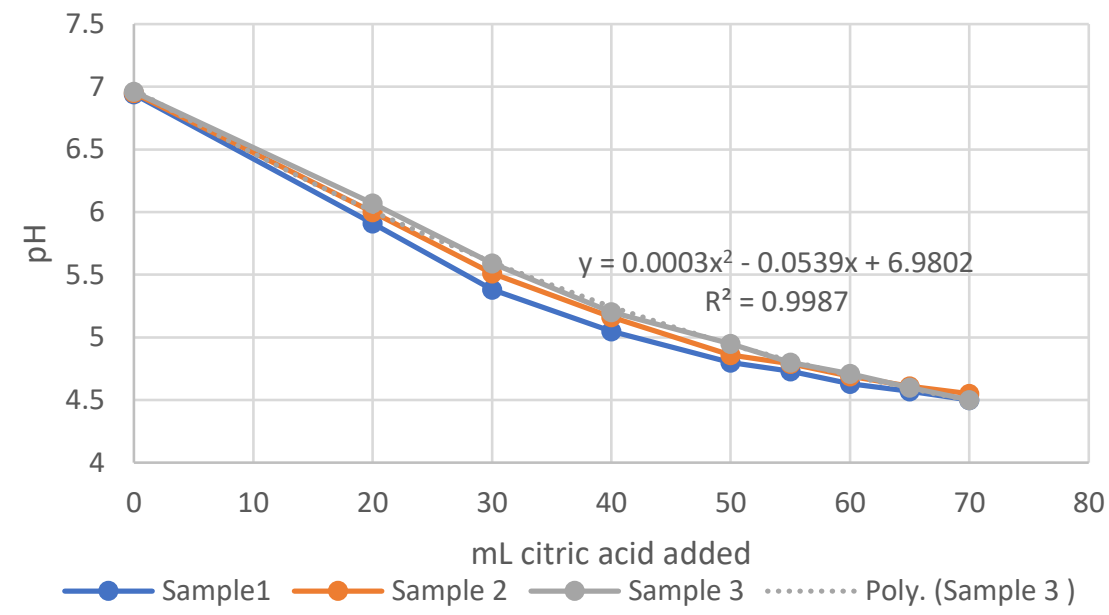

Figure 6. Acid citric addition (ml) to the liquid manure and $\mathrm{pH}$ reduction rate.

\subsubsection{Base solution and consumption test}

Another study was carried out to determine the concentration of baking soda solution and the volume required to neutralize the treated liquid manure at a $\mathrm{pH}$ of 4.5 and $\mathrm{pH}$ of 5.5, Table 3. The water used was tap water from the lab, and well water and liquid manure brought from the farm. Table 4 summarizes the solubility of the baking soda at different temperatures. 
Table 3. Baking soda molarity and achieved $\mathrm{pH}$ with tap and well water.

Chemical Calculations

pH (Tap water $)$

$p H($ Well water $)$

\begin{tabular}{|c|c|c|c|c|c|c|}
\hline $\begin{array}{c}\text { Water added } \\
\qquad(l b)\end{array}$ & $\begin{array}{c}\text { Baking Soda } \\
\text { (lb) }\end{array}$ & Molarity [ $\left.\mathrm{M} \mathrm{OH}^{-}\right]$ & $\begin{array}{c}\text { Rati } \\
\text { o } \\
\end{array}$ & $\begin{array}{c}\text { Day } 1 \\
\text { measurement }\end{array}$ & $\begin{array}{c}\text { Day } 2 \\
\text { measurement }\end{array}$ & $\begin{array}{c}\text { Day } 1 \\
\text { measurement }\end{array}$ \\
\hline 460 & 5 & 0.13 & 0.01 & 8.15 & 9.4 & 8.24 \\
\hline 460 & 10 & 0.26 & 0.02 & 8.10 & 9.27 & 8.22 \\
\hline 460 & 15 & 0.39 & 0.03 & 8.05 & 9.2 & 8.15 \\
\hline 460 & 20 & 0.52 & 0.04 & 8.07 & 9.18 & 8.06 \\
\hline 460 & 25 & 0.65 & 0.05 & 8.07 & 9.14 & 8.03 \\
\hline 460 & 30 & 0.78 & 0.07 & 8.04 & 9.07 & 8.00 \\
\hline 460 & 35 & 0.91 & 0.08 & 7.96 & 9.00 & 7.97 \\
\hline 460 & 40 & 1.04 & 0.09 & 8.04 & 9.07 & 8.02 \\
\hline 460 & 45 & 1.17 & 0.10 & & & \\
\hline 460 & 50 & 1.30 & 0.11 & & & \\
\hline 460 & 55 & 1.42 & 0.12 & & & \\
\hline 460 & 60 & 1.55 & 0.13 & & & \\
\hline
\end{tabular}

Table 4. Baking soda Solubility.

\begin{tabular}{ccc}
\hline Solubility in water & $\square \quad 69 \mathrm{~g} / \mathrm{L}\left(0^{\circ} \mathrm{C}\right)$ \\
& $96 \mathrm{~g} / \mathrm{L}\left(20^{\circ} \mathrm{C}\right)$ \\
& $\square \quad 165 \mathrm{~g} / \mathrm{L}\left(60^{\circ} \mathrm{C}\right)$ \\
\hline
\end{tabular}

Assuming the room temperature to be $20^{\circ} \mathrm{C}$, the maximum (soluble) amount of baking soda that can be added to the water is $43 \mathrm{lbs}$. per $460 \mathrm{lbs}$. of water (in the $55 \mathrm{gal}$ base supply tank), with the ratio of 0.096 .

Note that we repeated the test for two consecutive days, day 1 and day 2. Surprisingly, different results were achieved between the two days, Figure 7. 


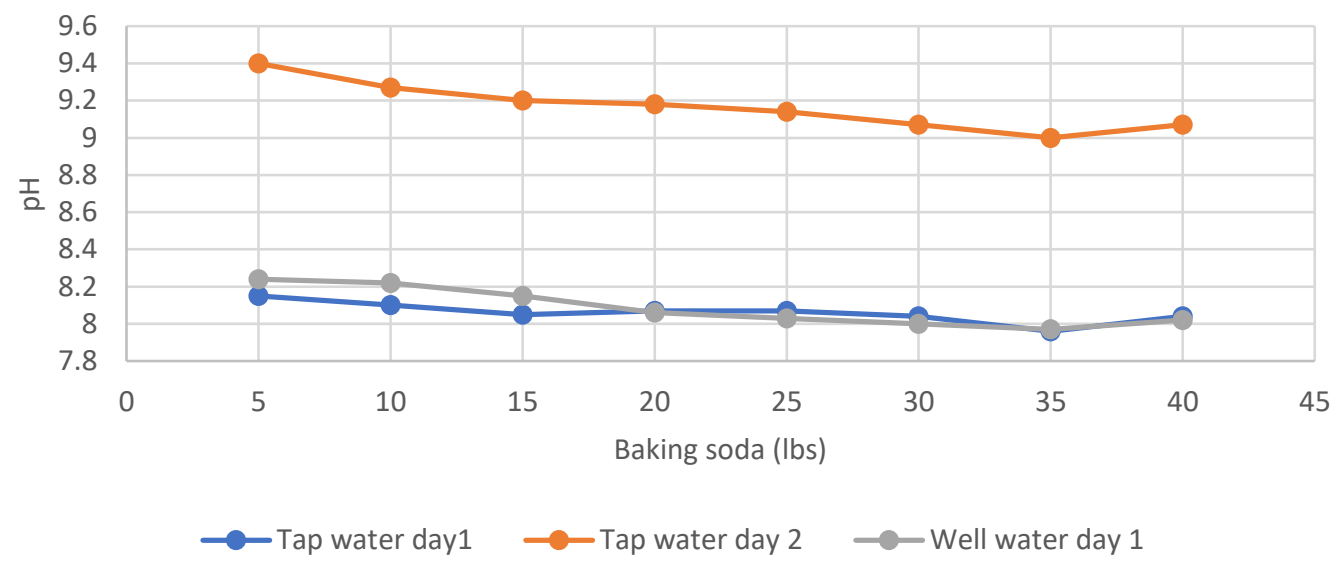

Figure 7. Baking soda addition to the tap water and well water and $\mathrm{pH}$ achieved.

Nevertheless, well water at the farm was our main source of making the base solution; therefore, we use the related data. As shown above, $15 \mathrm{lbs}$. of baking soda in $460 \mathrm{lbs}$. of well water looks optimum mixture to reach $\mathrm{pH}$ around 8.15 . Based on the molarity of the baking soda, a range of $\mathrm{pH}$ variation concerning the amount added is illustrated in Figure 8.

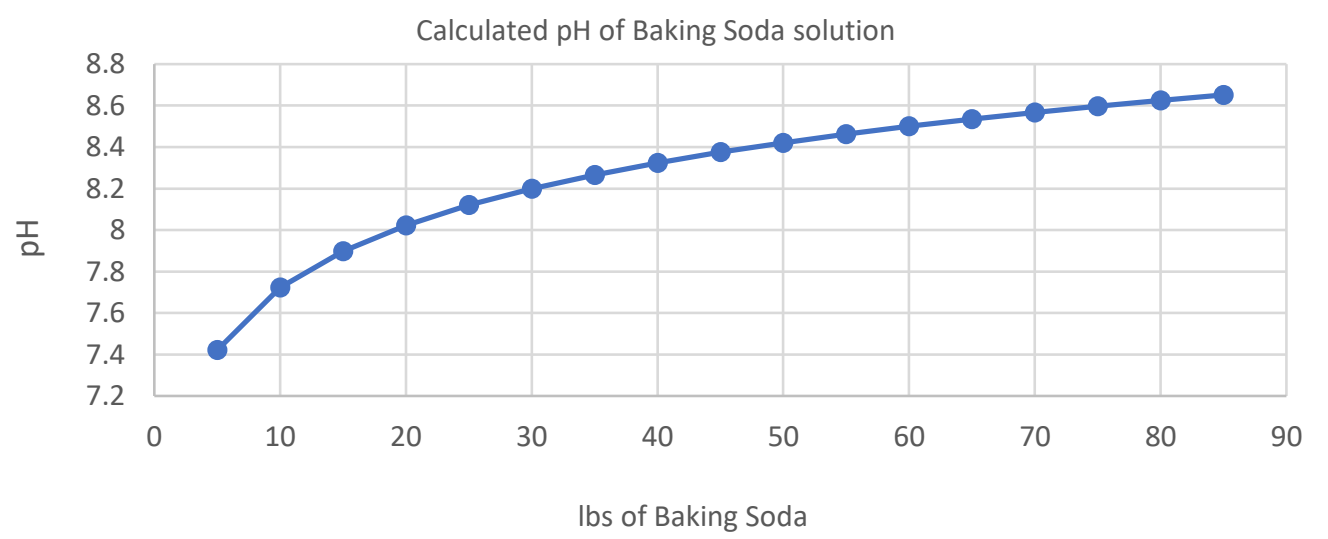

Figure 8. Chemical calculation of baking soda molarity and $\mathrm{pH}$.

Another test was conducted for measuring the volume of base solution (0.39 molarity) required to neutralize the treated liquid manure samples. In summary, for every 1 liter of treated liquid manure at $\mathrm{pH} 4.5$, the base solution volume needed is $1.4 \mathrm{~L}$ to shift the $\mathrm{pH}$ above 6.3. 


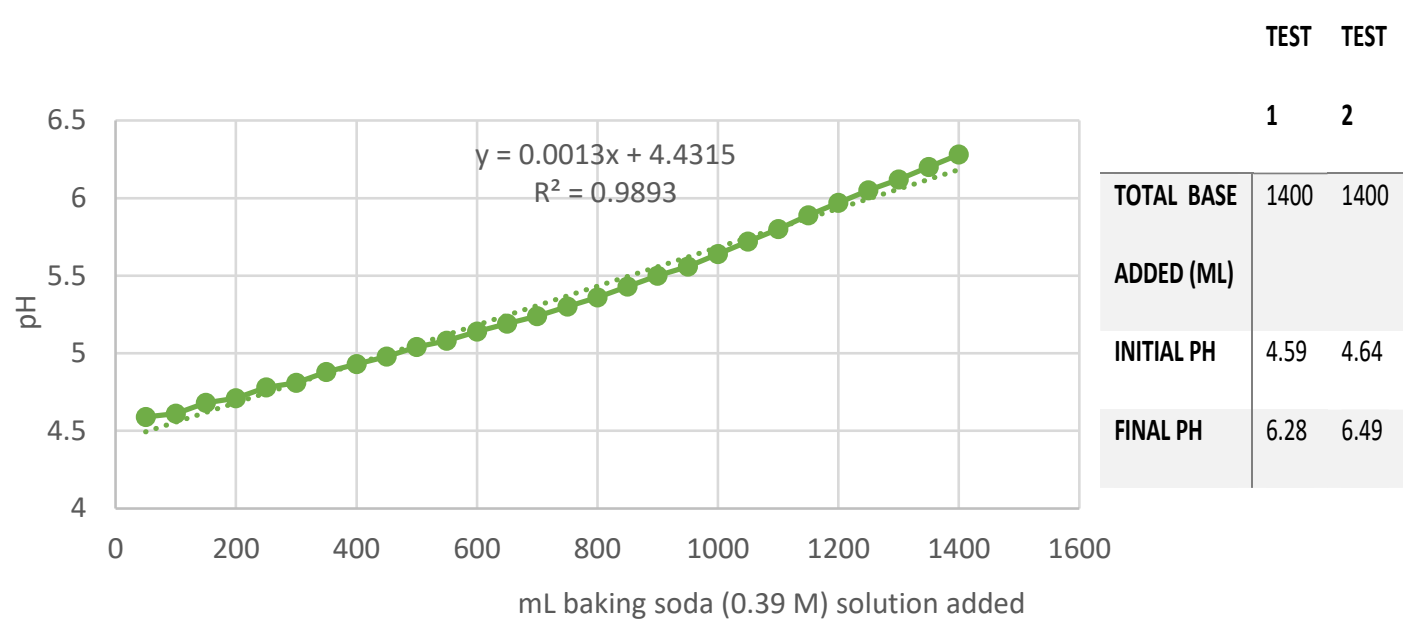

Figure 9. Neutralization of 1 liter of the treated liquid manure with baking soda solution.

In the last sampling process, the required amount of baking soda solution added to acidified samples (lbs.) was approximately 1:1, which was not a significant amount. In conclusion, either because of the solids, baking soda cannot get entirely mixed with the acidified liquid manure, or the insufficient mixing, the addition of baking soda resulted in floating cake form of slurry solid, which prevented effective mixture, and eventually caused clogging or overflow issues.

\subsection{On-Farm Results}

A summary of the important timelines, including installation and modifications made to the on-farm system, was provided in Table 5. The following sections provide more detailed information on the improvements made and observations of the on-farm tests. 
Table 5. Important timeline of the project, installation and modification.

\begin{tabular}{|c|c|}
\hline 2/18/2019 & Project started with equipment and recirculation pipes installed \\
\hline $2 / 22 / 2019$ & Reservoir pump was not working well, it was found \\
\hline $2 / 26 / 2019$ & $\begin{array}{l}\text { Re-plumbing the pump, replacement of the check valve with a flat type and plumbing a } 2 \text { inch pipe into } \\
\text { tank was done, planned to install the baffle inside tank. Pump was still humming }\end{array}$ \\
\hline $2 / 27 / 2019$ & $\begin{array}{l}\text { Flowmeter was the source of the debris collection; new Doppler type flowmeter was ordered. Mel } \\
\text { confirmed the pump was functioning well }\end{array}$ \\
\hline $3 / 16 / 2019$ & Doppler flowmeter installed; calibration completed \\
\hline $3 / 21 / 2019$ & $\begin{array}{l}\text { Pump was running fine, however immediately after running acid pump, it started humming again. } \\
\text { Error in reading flowmeter data, moved the transducer to a horizontal line }\end{array}$ \\
\hline $3 / 25 / 2019$ & Group suggested adding acid while the liquid urine is under pressure (in the pipe) \\
\hline 4/11/2019 & $\begin{array}{l}\text { Group decided to add a flex recirculation line from the acid tank to the trough instead of to the } \\
\text { reservoir }\end{array}$ \\
\hline 4/17/2019 & Added a hose vent near the pump line to trough, to prevent air trap happening \\
\hline $5 / 20 / 2019$ & Recirculation parts delivered \\
\hline $6 / 3 / 2019$ & Recirculation line from acid tank to trough was installed \\
\hline $6 / 10 / 2019$ & $\begin{array}{l}\text { Pump was not stable; debris accumulation was high in acid tank and caused clogging in the connection } \\
\text { line between tanks and also discharge line }\end{array}$ \\
\hline 6/17/2019 & $\begin{array}{l}\text { Base tank discharge line was completely clogged, had to cut the pipe, and use a pressure washer to } \\
\text { unclog, added rubber joint }\end{array}$ \\
\hline 6/30/2019 & Another discharge was added at the bottom of the acid tank to discharge debris from acid tank \\
\hline 7/7/2019 & A second line between acid and base tank was added, below the level of the recirculation line \\
\hline 7/18/2019 & Reservoir pump was replaced with a smaller one and was working better \\
\hline $7 / 25 / 2019$ & Reservoir seems stable, acid pump started and no humming \\
\hline $8 / 1 / 2019$ & Sampling started, pH set at 5.5 and base set to 6.5 \\
\hline 9/5/2019 & New round of sampling, with pH 4.5 and 5.5 and control sample (untreated, directly from the reservoir) \\
\hline 10/8/2019 & Stainless steel screen added around the pump, was clogged in less than a day, and removed \\
\hline $10 / 16 / 2019$ & Added a L-line inside the acid tank to foster mixing in the tank \\
\hline
\end{tabular}

\subsubsection{Acidification improvement, foaming, and pump malfunction}

The liquid manure reservoir's core issues included solids build-up, foaming, inconsistent $\mathrm{pH}$ value, and pump stalling. Due to the limited space and relatively low elevation of the liquid manure trough, the reservoir was limited in size and did not allow for a mixer, and the float switch was not functioning consistently. Increasing the reservoir size might help to improve the float switch operation and reducing the solids and foaming issues. Another challenge was the in-line 
flowmeter, which was catching a lot of solids and giving the inaccurate reading, adding to the challenges of troubleshooting the pump operation. A Doppler type of flowmeter was then installed and calibrated to help with the flow monitoring, Figure 10.

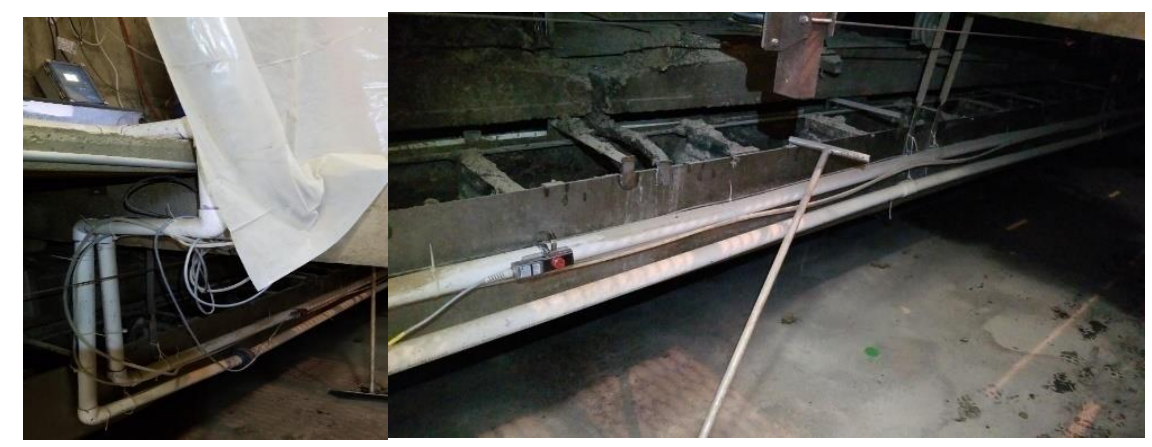

Figure 10. Flow meter probe location and solid manure collection system, March 19.

The reservoir pump was still humming after the acidification started. When acid was added to the reservoir, it would create foam; likewise, pump propeller movement also caused more foaming. The humming noise of the pump is because it cannot pump the foamy liquid manure. Using an anti-foaming agent or adding acid to the liquid manure during pumping (pressurized within the pipe) was among the suggested options. Defoaming agents could be silicone emulsions and compounds, synthetic, non-Silicones, oil-based, and water-based. There is a chance that any air bubbles, including foam, could cause inaccurate readings to the doppler flow sensor. Any high spot in the pipe from the reservoir up to the tank would allow gas to come out of the solution and eventually work its way to the sensor as a bubble. Adding suspension points may help ensure a steady upward gradient in the pipe. Mixing or a small recirculating stream in the reservoir and tank shall be beneficial, provided that the focus is on physically breaking up any bubbles. However, sometimes it can cause more foaming; more controlled tests would be needed to explain the difference. 
In order to improve the acidification and minimize $\mathrm{N}$ loss, a recirculation line (flex line) was added to the preliminary system, Figure 11 . The idea of adding a recirculation line was simply to reduce the chance of $\mathrm{N}$-ammonia volatilization. Due to the animal growth cycle, urine production would be lower with smaller pigs, that it would take longer until the reservoir volume reaches the desired level to kick on the pump. On the other hand, because acidification happens at the acid/dosing tank, liquid manure must reach the acid tank to be acidified. Therefore, to prevent or minimize $\mathrm{N}$ volatilization during retention time in the reservoir, the added recirculation line helps partially acidify the liquid manure sooner, in the trough and the reservoir. Furthermore, it is effective to reduce foaming in the reservoir. The recirculation line design was intended to have a flow rate of 5 gallons per minute.

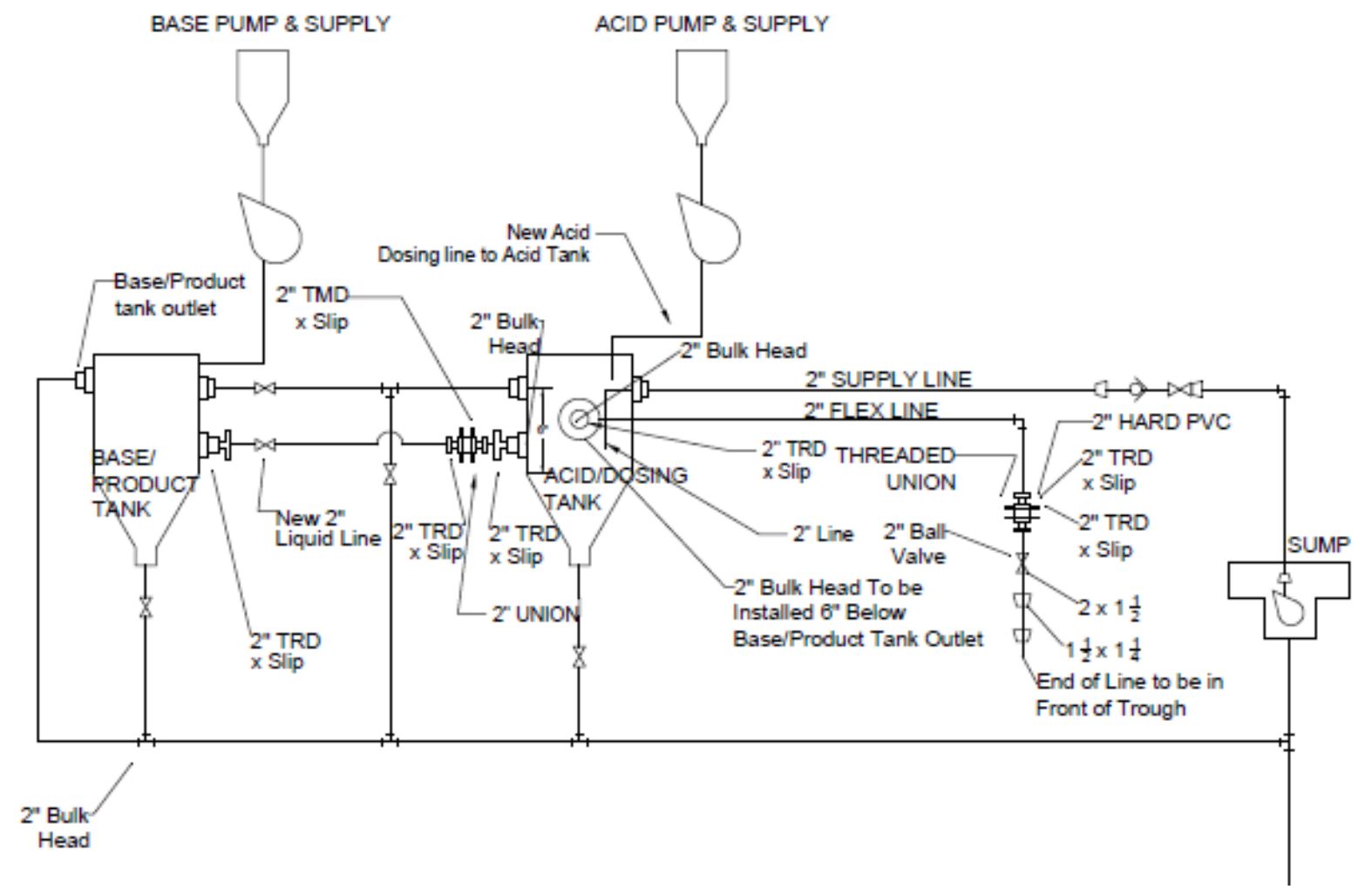

Figure 11. Sketch of the system with added recirculation line and flex line, May 19. 
Figure 12 presents the system after adding a recirculation line, that goes from the acid/dosing tank to the trough. The second line (green line) between the acid and product tank was designed to assist treated liquid transfer from the acid tank to the product tank, considering that the recirculation line-height is lower than the previous connecting line-height (white line).

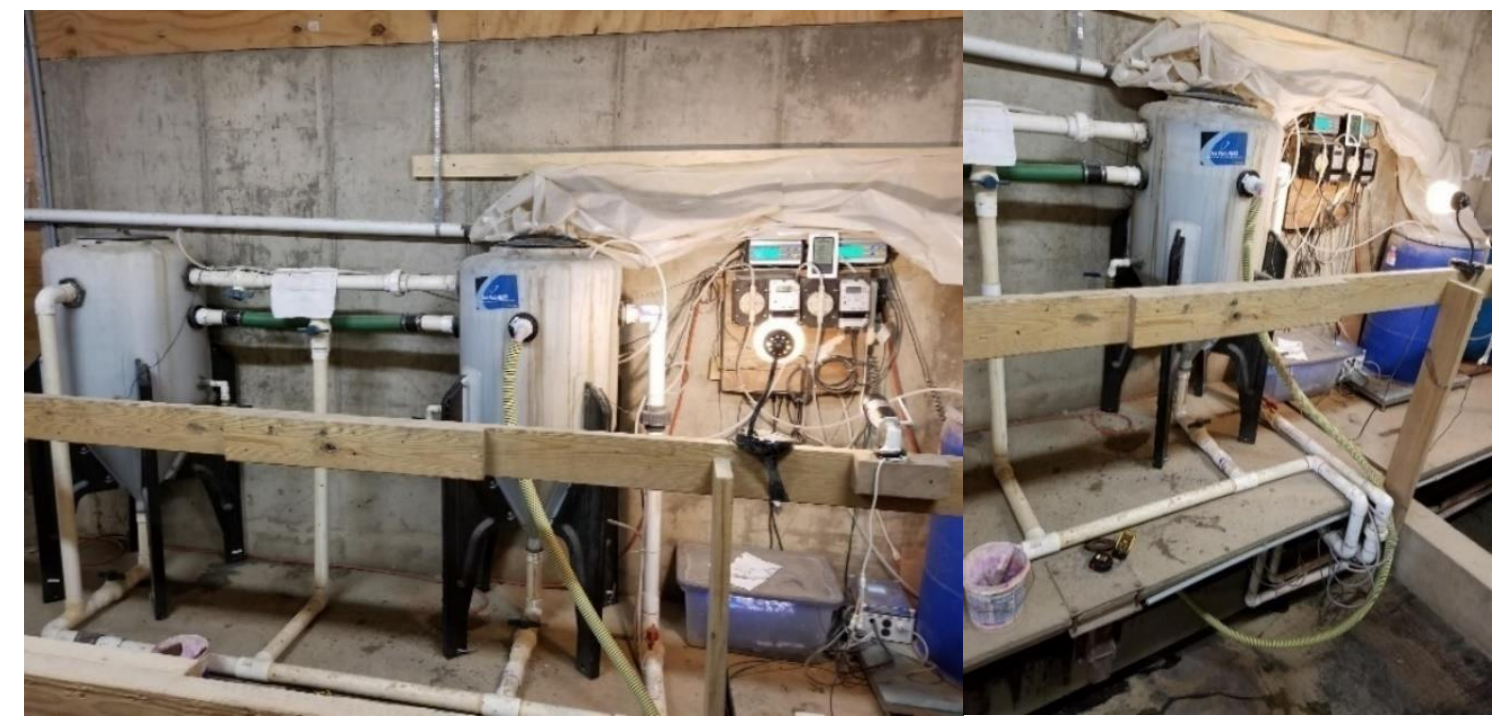

Figure 12. Recirculation line from acid tank to the trough, June 19.

\subsubsection{Reservoir and pipes dimension to prevent debris collection and clogging}

The reservoir dimension is a critical factor in the design of the treatment system. Smaller reservoir size can reduce the liquid manure's retention time in the reservoir. Nevertheless, there would be insufficient space for the debris and solids to settle before reaching the pump. Therefore, more solids would be pumped into the system that eventuates in clogging and system failure. Using a smaller pipe can help with mixing in the tank as well as mixing inside the pipe, since they would increase the flow rate. It would probably reduce the foam and air bubbles in the pipe due to higher pressure and result in more accurate flow readings by the Doppler flowmeter. On the other side, solids and debris can accumulate more quickly and clog the smaller size pipes and connections. 
After pump replacement and addition of the recirculation line, pumping was greatly improved, and foaming was happening mostly inside the acid/dosing tank, Figure 13. Note that the major acidification was occurring in the acid/dosing tank directly, and an acid controller probe was installed inside the acid tank instead of the reservoir.

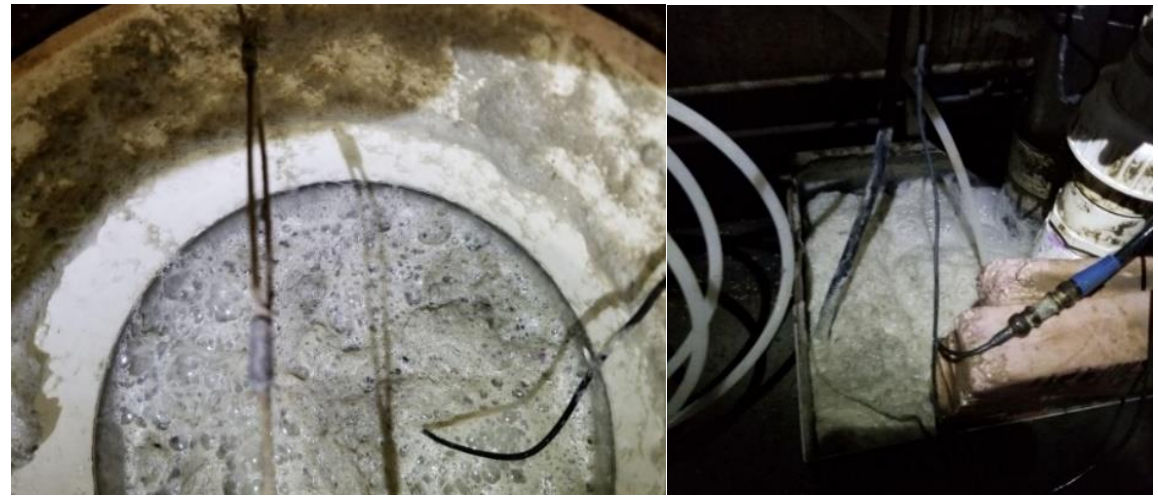

Figure 13. Foaming issue, left foaming happens in the acid tank; right foaming happens in the reservoir.

During the installation of a new line, we noticed that the liquid could not be discharged effectively from the base tank due to clogging. So, we tried to disconnect a union connection to clean the line; used a water hose to remove the clogging. But, it did not work well even with a highpressure washer, probably because we were far from the blockage location in the pipe. Finally, we decided to cut the part of the pipe at the beginning of the product tank to flush the pipe from that point and then reconnect the line to the product tank again. This helped, but the blockage was still not completely removed. Then, using a high-pressure washer, the clogging was removed. 

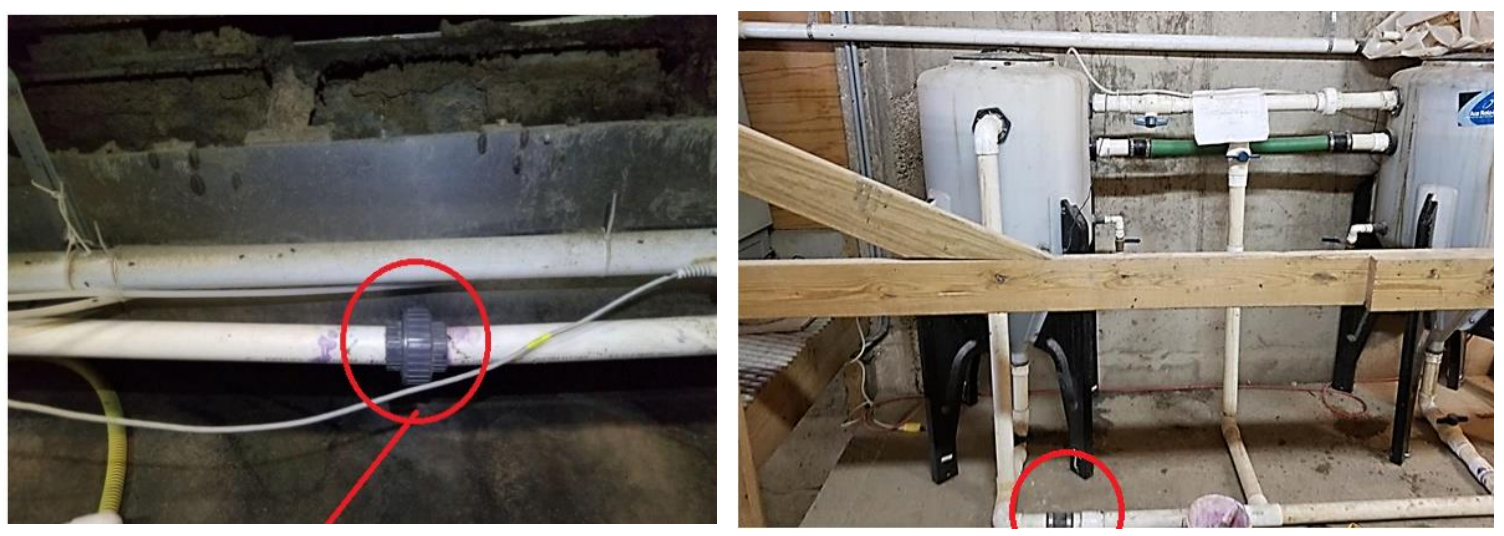

Figure 14. Self-aligning union and rubber couplings added to simply add an access to the system for cleaning.

Installation of a metal mesh screen around the reservoir pump was another approach to prevent debris from getting into the system. Nevertheless, due to the high volume of the debris, the screen's openings were clogged quickly, resulting in a liquid level difference between the float switch and the pump propeller. It caused the float switch to operate the pump, even when there was not enough liquid manure around the pump to be moved into the system. Consequently, it formed excessive foaming without efficient pumping. This happened on September 23 and the total flow recorded was 1,328 gallons, which was lower than previous days. Finally, the screen was removed. 

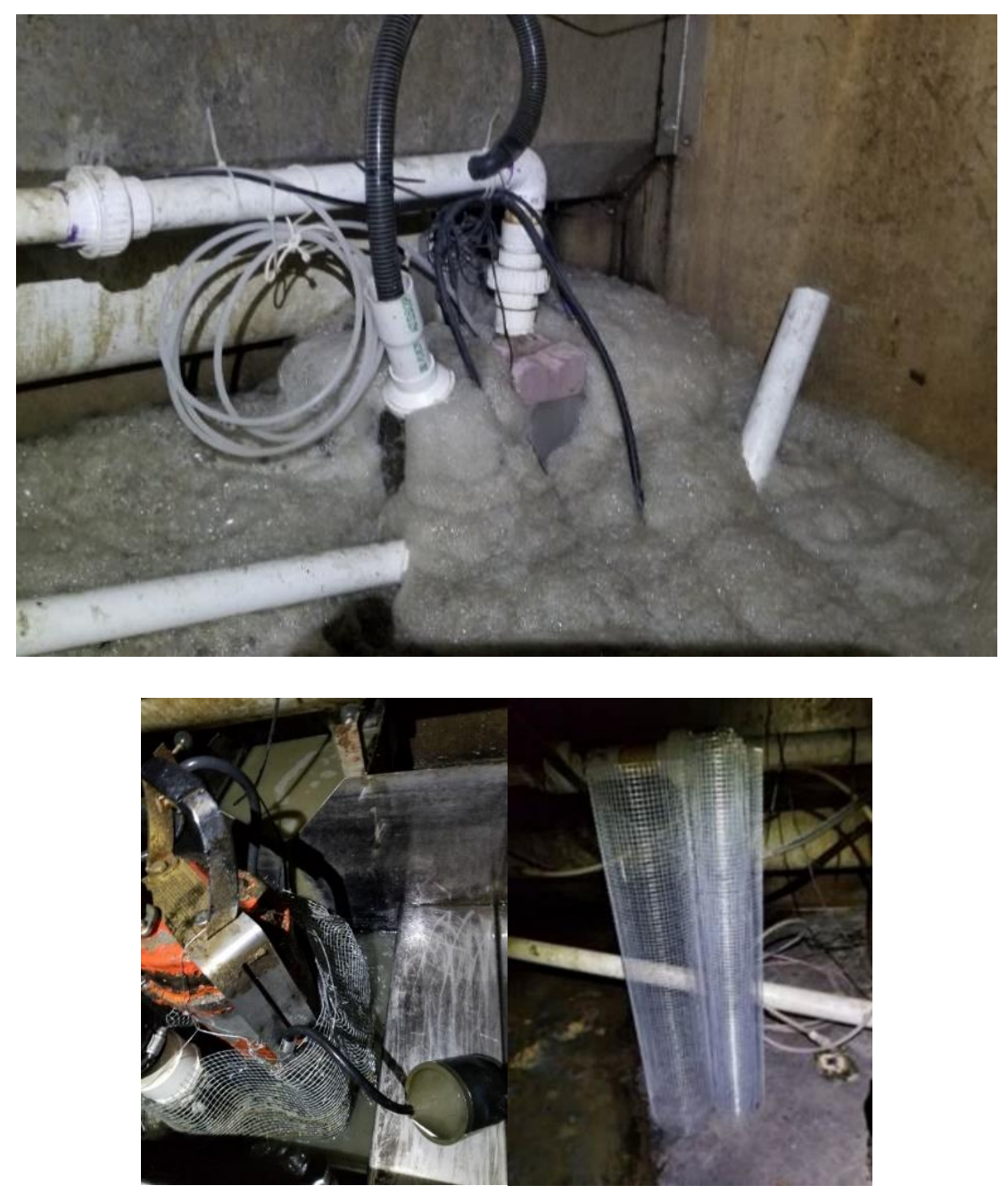

Figure 15. Foaming deactivated the float switch, led to continuous pumping and excessive foaming (July 19), and installation of a filter screen (removed later).

\subsubsection{Autosampler and Doppler flowmeter issues}

Autosamplers used in this experiment were previously used for sampling water. So, sampling liquid manure with a significant amount of debris and solids could be challenging. For instance, once, the autosampler indicated that the pump was jammed. The sampling tube was checked and cleaned, but it was not the issue. Therefore, we tried to put the sampling tube into freshwater and restart the program. It worked after a while, yet for some of the samples, the volume 
was too little, about $50 \mathrm{~mL}$ (it was supposed to be $700 \mathrm{~mL}$ ). Yet, for some others, it was filled 1000 $\mathrm{mL}$ and more.

Next, the calibration of the Doppler flowmeter was performed to ensure proper measurement. Table 6 summarizes the various variables and measured and actual volumes.

Table 6. Doppler flowmeter calibration.

\begin{tabular}{ccccc}
\hline Volume & $\begin{array}{c}\text { Damping=0, } \\
\text { Cut-off=10\% }\end{array}$ & $\begin{array}{c}\text { Damping=0, } \\
\text { Cut-off=30\% }\end{array}$ & $\begin{array}{c}\text { Damping=10, } \\
\text { Cut-off=20\% }\end{array}$ & $\begin{array}{c}\text { Damping=10, } \\
\text { Cut-off=10\% }\end{array}$ \\
\hline Real Volume (USG) & 31 & 34 & 10 & 37 \\
\hline $\begin{array}{c}\text { Flow meter measured } \\
\text { (USG) }\end{array}$ & 64 & 77 & 0 & 40
\end{tabular}

\subsubsection{Additional flexible solid discharge line and final pilot system setup}

As mentioned, one of the major issues was the solid settlements. Because the system was running at least 5 days in each sampling cycle, no cleaning was possible during this period. Subsequently, settlements would eventually build up in both the acid and product tanks. Solids could interfere with acidification and sampling quality and also incapacitate the autosampler. Hence, a Y-adapter with a flexible hose was added below the exit line of the acid tank to discharge settlements manually each day, Figure 16 . The estimated discharge volume was 5 gallons each day. With the average 2000 gallons of liquid manure circulation in the system, 5 gallons is negligible.

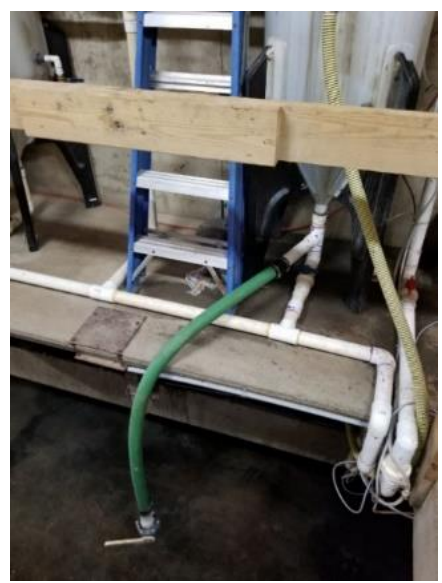

Figure 16. Manual settlement discharge line installed below the acid tank, June 19. 
At the end of July 2019, the system was much more stable, Figure 17. The pump was operating every 90-120 seconds. Yet, the base solution consumption was still high. With every trip to the farm, $\mathrm{pH}$ calibration check, downloading flow data, and $\mathrm{pH}$ data were conducted as routine. Three temperature loggers were installed, one near the acid tank, one near the reservoir, and the last one outside the building under a covered wall with no direct sunlight.

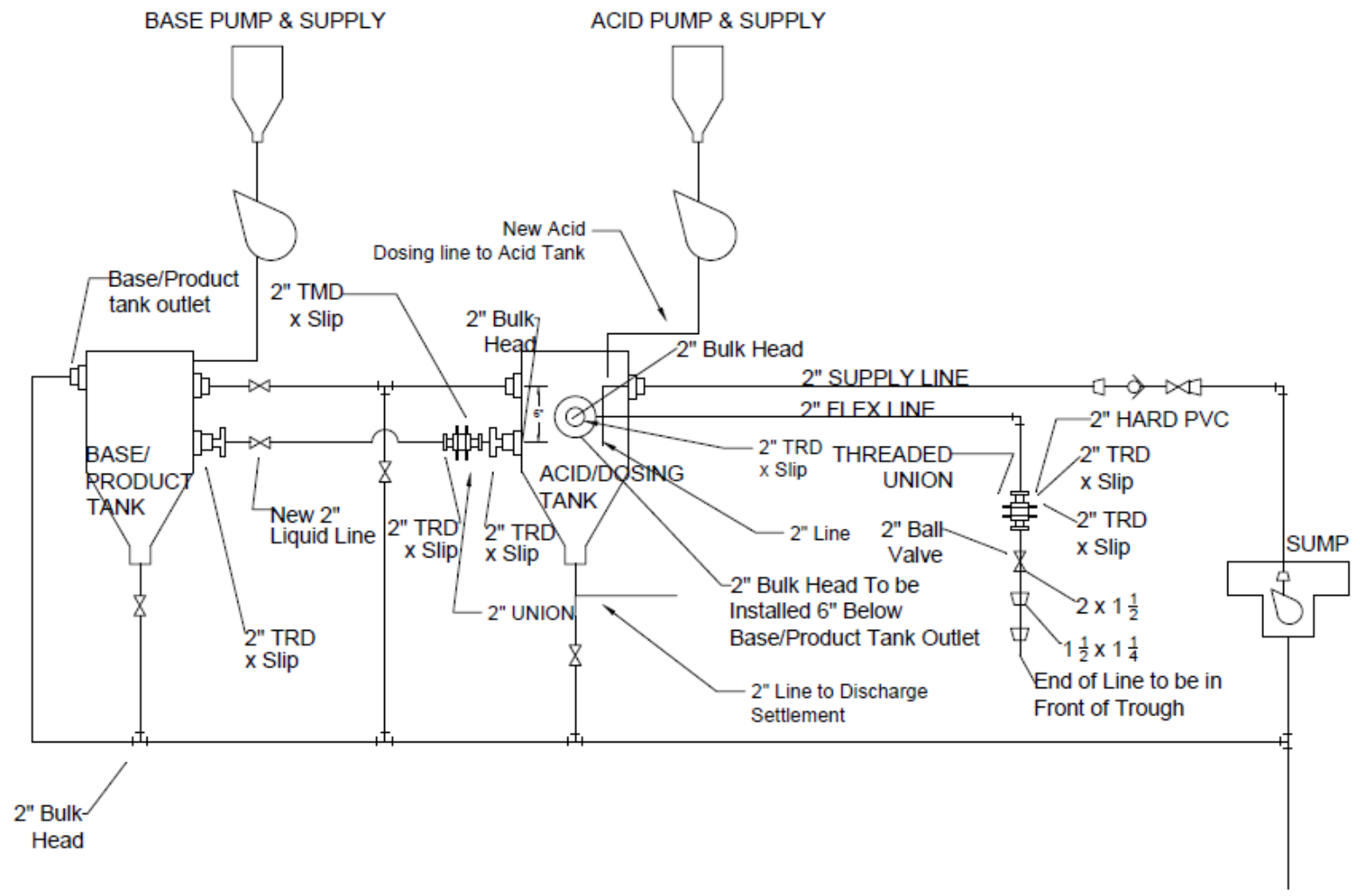

Figure 17. Final outline of the urine treatment system, June 19 (Not to scale).

\subsubsection{Variation of $\mathrm{pH}$ after treatment}

To evaluate the $\mathrm{pH}$ variations of the treated liquid manure during and after treatment by acid, a similar test was performed. The autosampler collected a group of 24 treated samples with $\mathrm{pH}=4.5$. $\mathrm{pH}$ variations of the treated samples, was measured for three weeks (Table 7). The results 
indicated that once the samples were treated with acid and have reached the specified $\mathrm{pH}$ level, they continue to maintain the $\mathrm{pH}$ level at least for three weeks.

Table 7. Acidified samples and $\mathrm{pH}$ change over time.

\begin{tabular}{|c|c|c|c|c|c|c|c|c|c|c|c|c|}
\hline Monday, June 24, 2019 & & & & & & & & & & & & \\
\hline Sample No. & 1 & 2 & 3 & 4 & 5 & 6 & 7 & 8 & 9 & 10 & 11 & 12 \\
\hline$p H$ & 4.80 & 4.96 & 7.98 & 4.46 & 4.85 & 4.48 & 4.39 & 4.44 & 4.39 & 4.58 & 4.80 & 4.80 \\
\hline Sample No. & 13 & 14 & 15 & 16 & 17 & 18 & 19 & 20 & 21 & 22 & 23 & 24 \\
\hline$p H$ & NA. & 4.71 & 4.40 & 4.27 & 4.17 & 4.05 & 4.99 & 4.01 & 4.99 & 4.45 & 4.68 & 4.92 \\
\hline \multicolumn{13}{|l|}{ Friday, July 12, 2019} \\
\hline Sample No. & 1 & 2 & 3 & 4 & 5 & 6 & 7 & 8 & 9 & 10 & 11 & 12 \\
\hline$p H$ & 3.38 & 3.55 & 3.62 & 3.96 & 4.40 & 4.06 & 3.94 & 4.01 & 3.96 & $4.20 *$ & $4.42 *$ & $4.41^{*}$ \\
\hline Sample No. & 13 & 14 & 15 & 16 & 17 & 18 & 19 & 20 & 21 & 22 & 23 & 24 \\
\hline pH & NA. & $4.32 *$ & $4.12 *$ & $4.02 *$ & $3.71^{*}$ & $3.76^{*}$ & $3.73^{*}$ & $3.72 *$ & $3.69^{*}$ & 3.17 & 3.30 & 3.53 \\
\hline \multicolumn{13}{|l|}{ Monday, July 15, 2019} \\
\hline Sample No. & 1 & 2 & 3 & 4 & 5 & 6 & 7 & 8 & 9 & 10 & 11 & 12 \\
\hline$p H$ & 4.25 & 4.44 & 4.48 & 4.86 & 5.15 & 4.86 & 4.74 & 4.80 & 7.75 & 4.93 & 5.08 & 5.12 \\
\hline Sample No. & 13 & 14 & 15 & 16 & 17 & 18 & 19 & 20 & 21 & 22 & 23 & 24 \\
\hline$p H$ & NA. & 5.05 & 4.92 & 4.82 & 4.77 & 4.65 & 4.51 & 4.53 & 4.59 & 4.26 & 4.36 & 4.52 \\
\hline \multicolumn{13}{|l|}{ Thursday, July 18, 2019} \\
\hline Sample No. & 1 & 2 & 3 & 4 & 5 & 6 & 7 & 8 & 9 & 10 & 11 & 12 \\
\hline$p H$ & 4.23 & 4.38 & 4.44 & 4.77 & 5.08 & 4.87 & 4.78 & 7.8 & 4.8 & 4.96 & 5.17 & 5.17 \\
\hline Sample No. & 13 & 14 & 15 & 16 & 17 & 18 & 19 & 20 & 21 & 22 & 23 & 24 \\
\hline$p H$ & NA. & 5.09 & 4.95 & 4.83 & 4.76 & 4.64 & $4 . .63$ & 4.64 & 4.64 & 4.22 & 4.35 & 4.53 \\
\hline
\end{tabular}

* Samples were semi-frozen while being measured for $\mathrm{pH}$

\subsection{Comparisons of estimated liquid manure production and acid consumption}

Following previous study (Brown et al., 2018) and using the MWPS growth curve, the animal weight can be estimated using a polynomial equation and presented in the following figure:

$$
y=9.1127 x^{5}-22.447 x^{4}+17.5 x^{3}-4.1134 x^{2}+0.9545 x-0.0051
$$




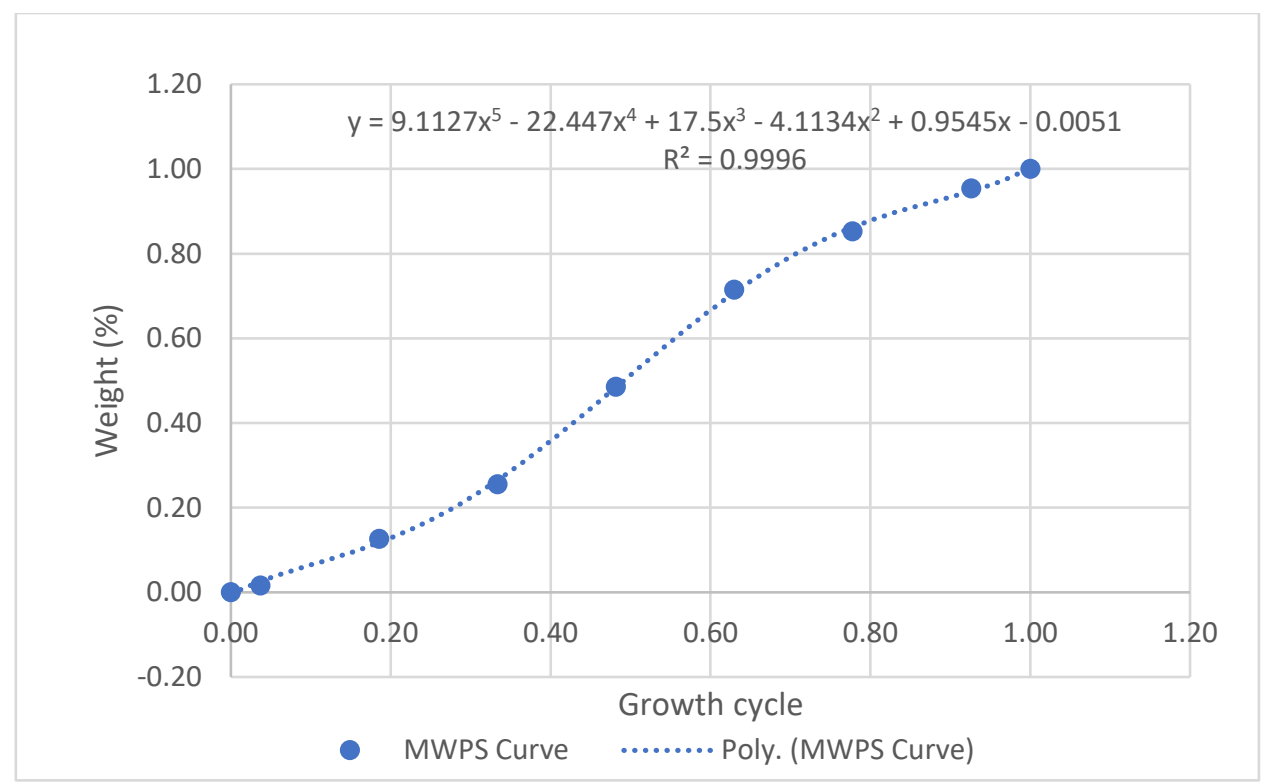

Figure 18. Animal growth curve based on the percentage of nursing and finisher period.

The $\mathrm{X}$-axis is the age of the finishing pigs (days, presented as \% of the time of the growth cycle). For instance, if the growth cycle of a batch of pigs for both weaning and finishing (to reach $267 \mathrm{lbs}$. from the birth) lasted 155 days, the age at the 10th day of the growth cycle was then $x$ $=10 / 155=0.065$ or $6.5 \%$, and the estimated pig weight can be calculated using the equation. Total pig mass is the number of animals (heads) multiplied by the average animal weight (lbs.). Note that the pig inventory is expected to decrease due to mortality over time. Also, the individual room had a different group of pigs that were of various ages and weights.

For swine, size between $25 \mathrm{lbs}$. to $300 \mathrm{lbs}$., manure production, and pig weight were regressed, and the manure produced can be calculated with an equation:

$$
\mathrm{y}=0.0055 \mathrm{x}+0.1012
$$

Where $\mathrm{X}$ is the animal weight (lbs.). 


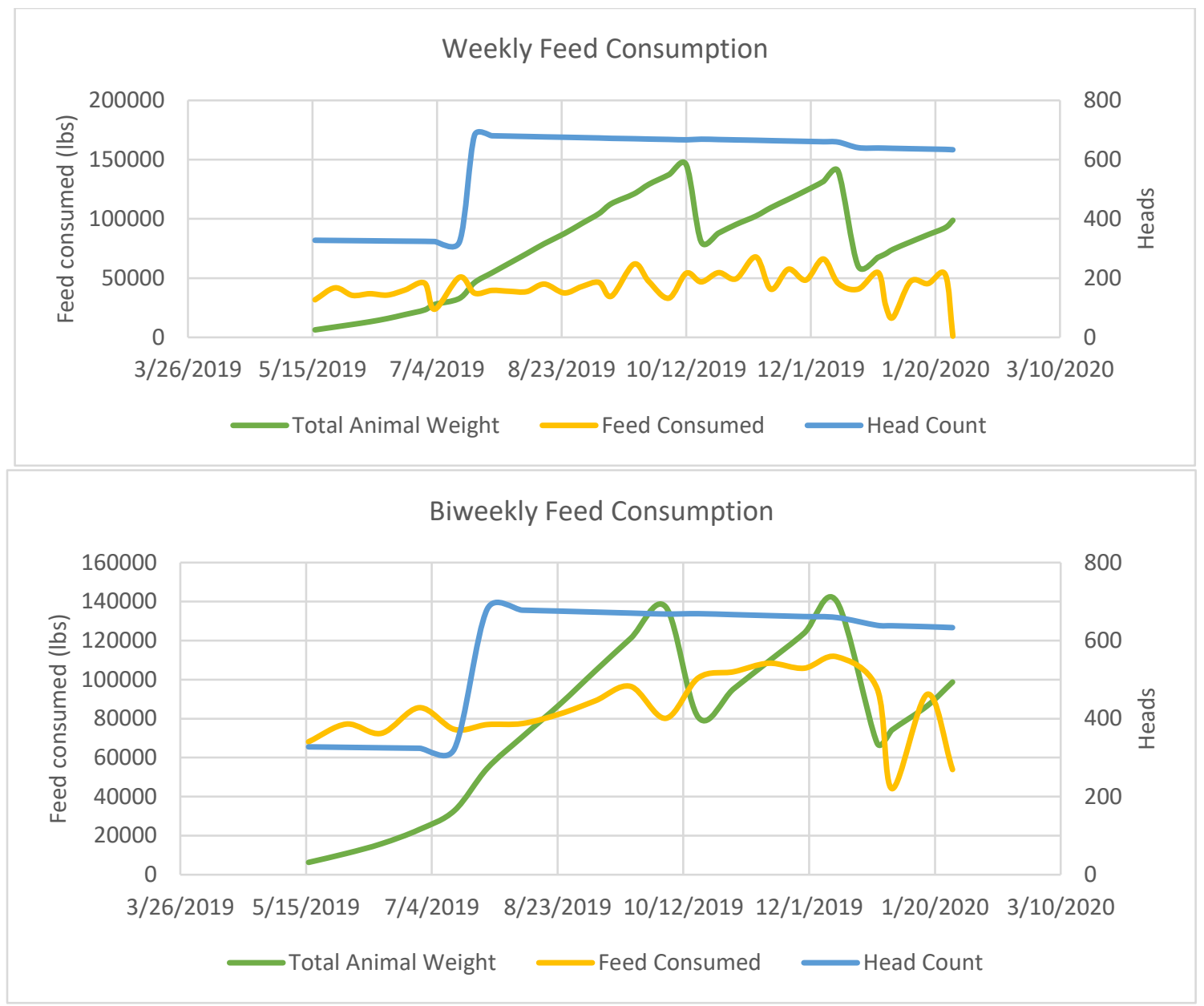

Figure 19. Weekly and biweekly feed consumption.

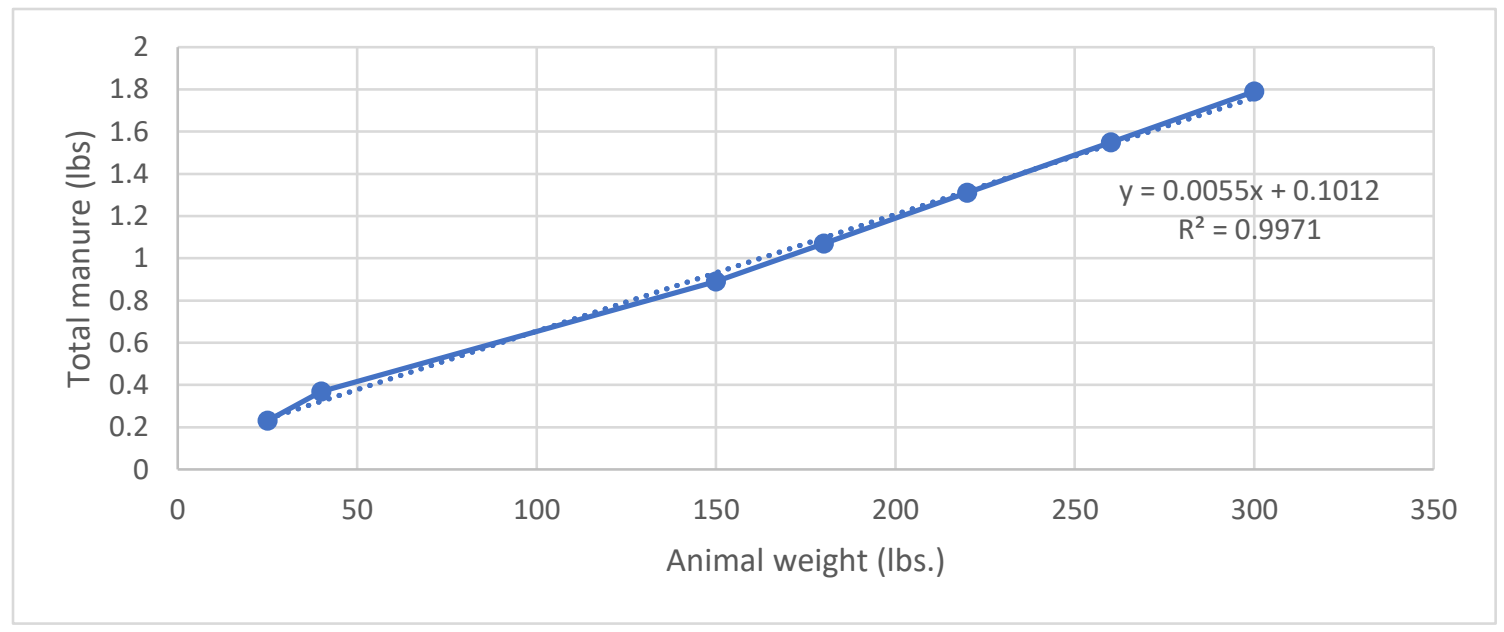

Figure 20. Estimated swine manure production. 
Based on the manure produced, the liquid manure portion could be estimated using a ratio that was suggested by the literature (Brown et al., 2018) [77]. According to the study by Brown et al. (2018), the ratio of the liquid manure to the total manure was $75 \%$. Below, is the average amount of daily solid and liquid manure recorded at this barn.

Table 8. Brown study liquid manure and solid manure estimations.

\begin{tabular}{r|ll}
\multicolumn{2}{c}{ USG/day } & Ratio \\
\hline Liquid Manure & 885 & 0.75 \\
Solid Manure & 299 & 0.25 \\
Total Manure & 1184 & 1
\end{tabular}

Figure 21 depicts the acid added to the liquid manure stream at the farm, which is compared to the total pig mass of the half-barn. Due to system errors, not all of the acidifications were continued over a 24-hour period, we excluded the acid consumption data of days that had less than 21 hours of acidification treatment.

Linear regression was applied to correlate the amount of acid added with the total animal weight (which represents the amount of manure produced), Figure 21. In general, the hourly acid consumptions were proportional to the total animal mass of the rooms, confirming that more acid was needed for higher animal mass, which would produce more liquid manure, as expected. 


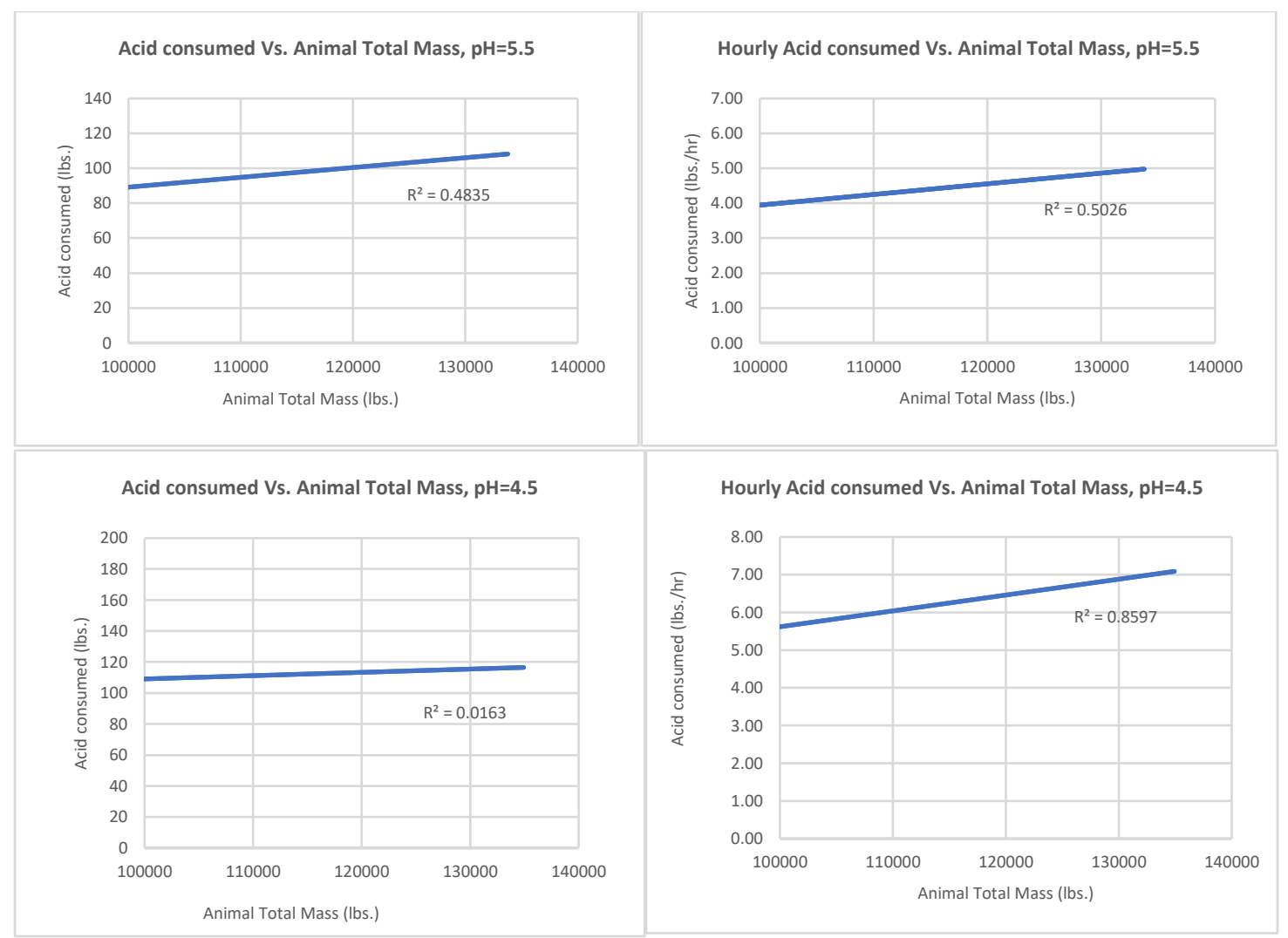

Figure 21. Daily and hourly acid consumption vs. animal total mass.

Figure 22 presents the acid consumptions versus the estimated amount of liquid manure produced at the farm on an hourly basis. Similarly, the hourly acid consumption shows a relatively good correlation with the liquid manure produced.

When comparing the amount of acid needed for the two treatments, the regression for $\mathrm{pH}$ 4.5 did show a steeper slope, indicating more acid was needed to acidify the liquid manure. 


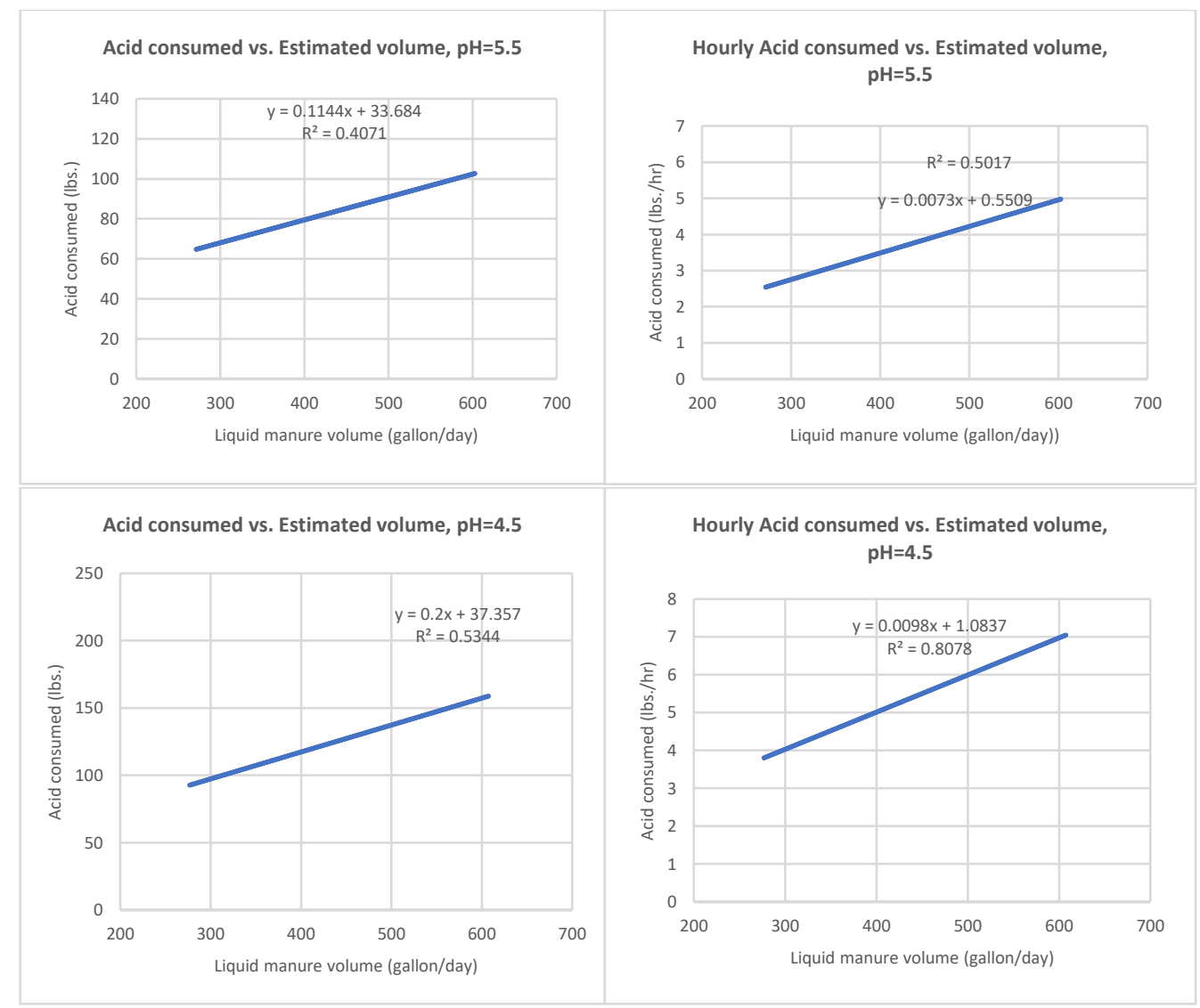

Figure 22. Daily and hourly acid consumption vs. estimated volume.

At the farm, acid consumption was measured by the weight (lbs.) of the citric acid at the end of each sampling day. However, the laboratory test recorded the acid consumptions in volume $(\mathrm{mL})$ per $2 \mathrm{~L}$ of liquid manure treated. Therefore, the acid weight (lbs.) measured at the farm test was then converted to volume (mL) using the density. Knowing the acid solution was $50 \%$ concentration and the density was not indicated on the product details, a density measurement of volume and weight of the acid was conducted in the laboratory, measured as $1.27 \mathrm{Kg} / \mathrm{L}$. This value agrees well with the literature value, which reported a density of aqueous solution of $1.220 \mathrm{Kg} / \mathrm{L}$ for $50 \%$ acid solution ( $\mathrm{O}^{\prime} \mathrm{Neil} \&$ Britain) 
Below is the formula, using the measured acid density, to convert on-farm acid consumption (lbs.) and estimated liquid manure volume treated (gallons), to the ratio $(\mathrm{mL} / \mathrm{mL})$ or percentage values, as reported in the laboratory tests, for comparisons.

(Acid consumed $\left.{ }^{*} 453.592 / 1.27\right) /\left(\right.$ Estimated volume treated $\left.{ }^{*} 3.785^{*} 1000\right){ }^{*} 100$

Note that 453.592 is the conversion factor of $\mathrm{lb}$. to gram, 1.27 is the acid density, and 3.785 is the gallon to liter conversion factor.

The estimated acid consumptions of the on-farm tests, for both $\mathrm{pH} 4.5$ and $\mathrm{pH} 5.5$ treatments are summarized in table 9 .

Table 9. Ratio of acid consumption to the estimated liquid manure volume.

\begin{tabular}{|c|c|c|c|c|c|}
\hline \multicolumn{6}{|c|}{$\mathrm{pH}=5.5$} \\
\hline Date & $\begin{array}{l}\text { Estimated liquid manure } \\
\text { production (USG/day) }\end{array}$ & $\begin{array}{l}\text { Recorded liquid } \\
\text { manure production } \\
\text { (USG/day) }\end{array}$ & $\begin{array}{l}\text { Acid } \\
\text { (lbs.) }\end{array}$ & $\begin{array}{l}\text { Acid consumption/Hour } \\
\text { (lbs./hr.) }\end{array}$ & $\begin{array}{c}\text { Ratio } \\
\%\end{array}$ \\
\hline 9/24/2019 & 565 & 1328 & 108.8 & 4.73 & 1.82 \\
\hline 9/25/2019 & 569 & 5596 & 65.2 & 2.77 & 1.08 \\
\hline $10 / 1 / 2019$ & 598 & 595 & & 5.81 & \\
\hline $10 / 2 / 2019$ & 603 & 5854 & 122 & 5.81 & 1.91 \\
\hline $12 / 16 / 2019$ & 271 & 2434 & 63 & 2.63 & 2.19 \\
\hline $1 / 7 / 2020$ & 366 & 3165 & 81 & 3.38 & 2.09 \\
\hline \multicolumn{6}{|c|}{$\mathrm{pH}=4.5$} \\
\hline Date & $\begin{array}{l}\text { Estimated liquid manure } \\
\text { production (USG/day) }\end{array}$ & $\begin{array}{l}\text { Recorded liquid } \\
\text { manure production } \\
\text { (USG/day) }\end{array}$ & $\begin{array}{l}\text { Acid } \\
\text { (lbs.) }\end{array}$ & Acid consumption/Hour & $\begin{array}{c}\text { Ratio } \\
\%\end{array}$ \\
\hline $9 / 25 / 2019$ & 569 & 5231 & 126.6 & 6.44 & 2.10 \\
\hline 9/26/2019 & 607 & 3441 & 148.2 & 6.74 & 2.30 \\
\hline $10 / 3 / 2019$ & 574 & 7393 & 194.2 & 7.57 & 3.19 \\
\hline $12 / 17 / 2019$ & 277 & 3721 & 105.2 & 4.38 & 3.58 \\
\hline $1 / 8 / 2020$ & 370 & 3988 & 92 & 3.83 & 2.35 \\
\hline
\end{tabular}




\subsection{Comparison of field data with laboratory test data}

The laboratory test results show that the amounts of acid needed to lower the liquid manure to $\mathrm{pH} 5.5$, ranging from $1.34 \%$ to $1.61 \%$, and they were $3.50 \%$ to $3.65 \%$ to lower the liquid manure to $\mathrm{pH}$ 4.5. In contrast, the average acid added to the estimated liquid manure production at the farm tests, ranged from 1.08 to $2.09 \%$, and 2.10 to $3.19 \%$, while the averages were $1.82 \%$ and $2.70 \%$, for $\mathrm{pH} 5.5$ and 4.5, respectively. The calculated acid to liquid manure ratio at the farm, as expected, was more variable than those measured in the laboratory tests.

\subsection{Cost-benefit analysis}

Based on the N-preservation data provided by the NCSU group, we conducted a simple costbenefit analysis for the current nitrogen preserved and acid costs (Table 10). Note that the results shown are basic estimations for comparing the nitrogen preserved vs. acid used. Electric consumption, solid-liquid separation, liquid manure dewatering and the maintenance costs are not included. Comparison is performed only based on the current price of $\mathrm{N}$ preserved as common fertilizer cost (cost of urea was used for calculations and the price during February 2021 is $\$ 457 /$ ton [82], $46 \%$ of $\mathrm{N}$-content), and citric acid price. In this case, the citric acid price is overestimated because it was not purchased in bulk. In addition, the cost of acid would have been significantly lowered if sulfuric acid is to be used in future test or scale-up tests. Sulfuric acid should be a substitute for citric acid, since it is stronger and much less expensive. On the contrary, sulfuric acid when purchased in bulk is $\$ 63 / \mathrm{MT}$ as of March 2021 [83]. Thus, by a simple assumption of the similar strength of citric acid and sulfuric acid to lower the $\mathrm{pH}$, it is estimated that the bulk sulfuric acid, would be $3.15 \%$ of the cost of the citric acid. This research used citric acid for safety reasons. A substantial point that should be noted is that the current cost-benefit analysis is based on ammonia volatilization of the fresh liquid manure measured in a few days of storing, yet on 
commercial farms, liquid manure would typically be kept for several months before application.

Therefore, the current calculation is considered conservative. Finally, if assumed that liquid manure loses $60 \%$ [79] of its $\mathrm{N}$-content in several months due to volatilization, optimistic results would be $\$ 2588$ and $\$ 2656$ in fertilizer savings versus $\$ 282$ and $\$ 432$ sulfuric acid consumed, for acidification at $\mathrm{pH} 5.5$ and $\mathrm{pH} 4.5$ respectively, table 10. Interestingly, the results suggests that decreasing $\mathrm{pH}$ to 4.5 would have substantial difference on $\mathrm{N}$-preservation comparing to $\mathrm{pH} 5.5$.

Table 10. Simple cost-benefit analysis of the acidification of the liquid manure, for 1200 -hd

$$
\text { finishing barn. }
$$

\begin{tabular}{|c|c|c|c|}
\hline & pH 5.5 & pH 4.5 & $\begin{array}{l}\text { Difference } \\
\text { pH 4.5/5.5 }\end{array}$ \\
\hline N preserved (Kg) by acidification (yr.) & 2004 & 2111 & 107 \\
\hline Non-conservative $\mathbf{N}$ preserved (Kg) by acidification (yr.) & 4062 & 4169 & 107 \\
\hline Fertilizer saving $(\$)$ & $\$ 1,991$ & $\$ 2,097$ & $\$ 106$ \\
\hline Non-conservative fertilizer saving $(\$)$ & $\$ 4,036$ & $\$ 4,142$ & $\$ 106$ \\
\hline Non-conservative fertilizer saving, using PAN & $\$ 787$ & $\$ 807$ & $\$ 106$ \\
\hline Citric Acid, Acid consumed (\$) ${ }^{1}$ & $\$ 32,844$ & $\$ 49,267$ & $\$ 16,422$ \\
\hline Sulfuric Acid, Acid Consumed (\$) ${ }^{2}$ & $\$ 1,035$ & $\$ 1,552$ & $\$ 517$ \\
\hline
\end{tabular}

${ }^{1}$ Based on 55-gal citric acid price; ${ }^{2}$ assume quantity discount when purchased in bulk.

Liquid manure available plant nitrogen and total nitrogen conversion were estimated according to MU guide G9186 [80]. Table 11 summarizes the conversion ratio. Note that the rates are based on TKN 3110 and TKN 3192, which are the difference of N-content in pH 5.5 and pH 4.5 to the untreated samples, respectively.

Table 11. Total nitrogen and plant available nitrogen conversion factors based on MU guide G9186

\begin{tabular}{lcc}
\hline & TKN=3110 $\mathbf{~ p m}$ & $\mathbf{T K N = 3 1 9 2} \mathbf{~ p p m}$ \\
\hline Total Nitrogen: & $25.9 \mathrm{lbs} / 1000$ gallons & $26.6 \mathrm{lbs} / 1000$ gallons \\
\hline Organic Nitrogen: & $25.9 \mathrm{lbs} / 1000$ gallons & $26.6 \mathrm{lbs} / 1000$ gallons \\
\hline Ammonium Nitrogen: & $0.0 \mathrm{lbs} / 1000$ gallons & $0.0 \mathrm{lbs} / 1000$ gallons \\
\hline Nitrate Nitrogen: & $0.0 \mathrm{lbs} / 1000$ gallons & $0.0 \mathrm{lbs} / 1000$ gallons \\
\hline Phosphate: & $0.0 \mathrm{lbs} / 1000$ gallons & $0.0 \mathrm{lbs} / 1000$ gallons \\
\hline Potash: & $0.0 \mathrm{lbs} / 1000$ gallons & $0.0 \mathrm{lbs} / 1000$ gallons \\
\hline Plant Available Nitrogen (PAN) & $10.12 \mathrm{lbs} / 1000$ gallons & $10.38 \mathrm{lbs} / 1000$ gallons \\
\hline
\end{tabular}




\section{Issues in brief}

- Frequent clogging in the system, replaced the 1" pipe with 2" pipe, also eliminated the $90^{\circ}$ elbows at the tank, and used $45^{\circ}$ transitions.

- To prevent further clogging, the check valve was replaced with a flap type.

- The inline flowmeter was recognized as the source of debris collection. A Dopplertype flowmeter, which mounts externally to the pipe, was replaced the old flowmeter.

- Doppler flowmeter was mistakenly detecting flow, which was relatively high (as high as $250 \mathrm{gal} / \mathrm{m}$ ) while the pump was off. The location of the ultrasonic probe was changed several times, in vertical and horizontal pipelines, yet no improvement.

- Pump air lock often happened due to a long pumping line and sudden pump shutting down. This was the main reason that the reservoir pump was humming, which was solved by opening the union above the reservoir pump (before 90 degrees- elbow) a little to allow the trapped air release.

- The laptop was shutting down often without obvious reason.

- The lower discharge line (green line) of the product tank was not functioning. After a while, debris and solids accumulated at the bottom of the tank, not enough mixing inside the product tank eventuated in clogging and excess consumption of the baking soda solution.

- When there was a significant $\mathrm{pH}$ difference, acid addition was fast and would cause excess foaming. It occurred during the first hour of acid addition. 
- Using a powerful pump had an adverse effect on the system, creating more air bubbles in the system and more foaming of the acidified liquid manure.

- Debris and solids were pumped directly into the system due to the reservoir dimensions. A larger reservoir would allow the debris to settle before reaching the pump and can be collected and cleaned on a fixed schedule.

- Without appropriate reservoir size, using any type of screens to filter out the debris was unsuccessful, since the openings would have been clogged fast and prevent proper pumping.

- Baking soda solution application to neutralize the treated liquid manure was not effective. Because a large amount of baking soda solution was required to lower the $\mathrm{pH}$ level, it would cause more clogging in the system and product tank. The latter laboratory tests confirmed the inefficiency of the baking soda solution.

- The sampling device was meant for regular water sampling purposes. Thus, wastewater with debris can cause malfunction during sampling and pump failure.

- The acid pump stopped working due to part and connector failure, acid is corrosive to the parts and can cause leakage in the system.

- The recirculation line helped with the foaming reduction and preserved the $\mathrm{N}$ content of liquid manure, by acidifying the liquid manure sooner.

\section{Recommendations}

Farm scraper system could be a part of the problem with significant solids and debris in the liquid manure. Timing, frequency of the operation, and the scraper's efficiency directly impact the 
settlement in the liquid manure. We assume that the commercial farm would maintain the scraper systems and keep the animal health to the best possible.

Recommendation for future on-farm pilot research set-up:

1. A small data logging and programmable logic controller (PLC) system that can log and control some of the critical experimental setup, sends alerts immediately, and sends data files daily. A system that allows for easy remote monitoring of the data and performance of the different equipment.

2. Critical variables to add and monitor closely include flowrate of acid and base applied, flow rate of liquid manure produced (in addition to the current setup, which included flowrate of recirculation, the weight of base storage, $\mathrm{pH}$ of the acidified and base tanks). After replacing the flowmeter with a Doppler flow meter, the flow rate measurements were still not consistent, and we could not distinguish liquid manure produced from the recirculation amount. Both the daily (Figure 23) and multi-day data (Figure 24) indicate some inconsistencies in the flowrates measured. Unfortunately, there was only one flow meter, and it often was difficult to tell if the readings were consistent with the current PLC setup.

3. Add temperature monitoring to the acidified liquid manure and the reservoir.

4. Enlarge the liquid manure reservoir to allow for more solid and liquid manure storage volumes, and to help reduce pump and foaming issues.

5. A small solid retention tank either before or after the reservoir for solid separation, to reduce solids in the liquid manure stream and ended up in the acid/dosing tank. 
6. A corrosion-resistant screen set up around the reservoir pump inlet to prevent debris from getting into the pump and treatment system.

7. An automatic mixing and discharge system (maybe part of the PLC software) to agitate and discharge the settled solids in the acid/dosing and base/product tanks.

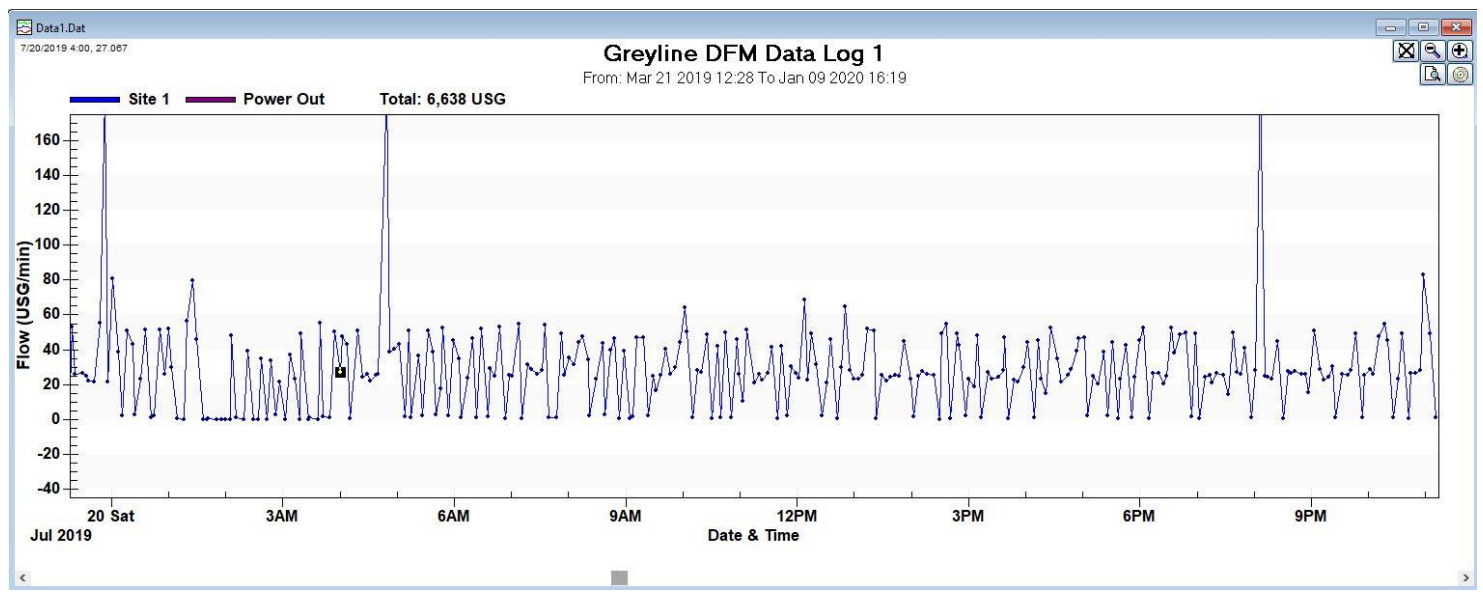

Figure 23. Flow rate measurements of the Doppler flow meter, for one day.

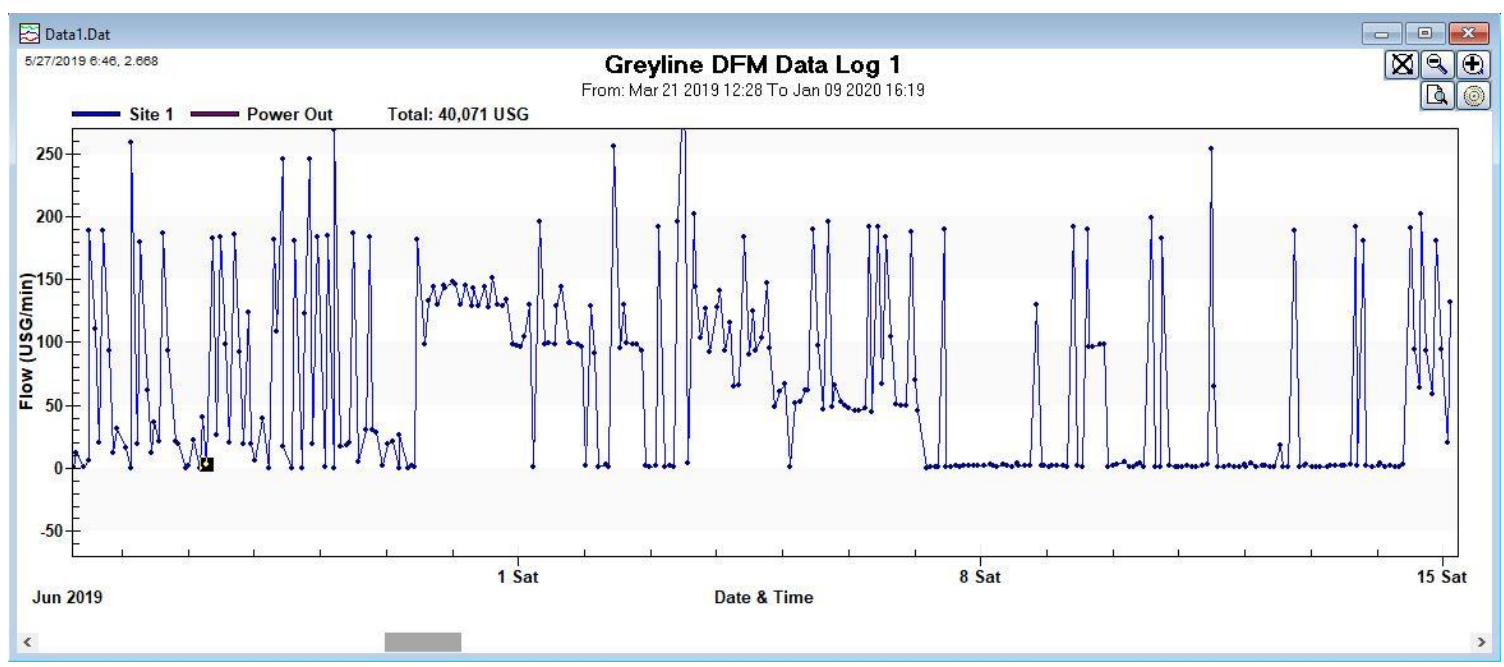

Figure 24. Daily flow rate readings of the Doppler flow meter, for three weeks in May and June 2019. 


\section{Recommendation for future on-farm acidification setup:}

1. Redesign of the solid/liquid separation barn that allows for faster and automatic acid addition based on liquid manure volume produced.

2. Space needed to store the acidification equipment and PLC systems in or near the barn, to protect them from animal and dusty and corrosive environments.

3. On-farm solid separation mechanism (such as a screen or centrifugal separation) to prevent clogging issues.

4. More robust $\mathrm{pH}$ sensors and acid/base addition mechanism.

5. Experiments and economic analysis be designed to determine how critical and effective to acidify the liquid manure in the barn vs. in the collection trough vs. reservoir.

\section{Conclusion}

Preserving $\mathrm{N}$-ammonia in liquid manure or urine and convert it to organic fertilizer is one of the promising practices to minimize the adverse effect of $\mathrm{N}$ emission to the environment and improving energy efficiency. Besides, it would benefit farmers economically to preserve the Ncontent on the land and also provide them with organic conditions. Therefore, on the farms that already have established liquid and solid manure separation systems, considering that liquid manure is the source of around $70 \%$ of the phosphorus and around $90 \%$ of the nitrogen in the wastewater [63] using stabilized urine directly as fertilizer seems attractive. Moreover, heavy metals have been found to be low in the urine [64]. This pilot project can be carried out in farms with solid and liquid separation system, is relatively simple to manage and maintain if the solids 
are separated efficiently. Because the system includes a neutralization tank, concrete deterioration concerns are eradicated at the farm.

Major drawbacks of this pilot study at the farm were 1) effectively monitoring liquid manure production and operational monitoring, and 2) solid/debris accumulation and foaming issues, leading to system failure. Citric acid was efficient in lowering the $\mathrm{pH}$ level, yet the baking soda solution could not neutralize the treated manure without a large amount. We did the best to overcome the issues. In addition, it is critical to acidify the fresh manure as soon as possible to maximize the $\mathrm{N}$-nitrogen preservation. After $\mathrm{N}$ stabilization, cost-effective analysis, and practical volume reduction (dewatering) is the key factor in making this approach financially viable. More investigation should take place to examine the practical land application, nutrient losses over the growing cycles, and effects of acidified liquid on the soil and microorganisms, if used as the fertilizer. If the treated liquid would be further filtered and concentrated, evaluation of adding to existing irrigation system to save application costs and improve nutrient use efficiency, and more timely matching the crop needs, should be considered in future research. 


\section{Reference}

[1] D. Zilberman, B. E. Dale, P. E. Fixen, and J. L. Havlin, “Food, fuel, and plant nutrient use in the future.," Issue Pap. Agric. Sci. Technol., no. 51, 2013.

[2] FAO, “Current world fertilizer trends and outlooks to 2015," p. 41, 2011, [Online]. Available: http://www.fao.org/3/a-av252e.pdf.

[3] J. W. Erisman, M. A. Sutton, J. Galloway, Z. Klimont, and W. Winiwarter, "How a century of ammonia synthesis changed the world," Nat. Geosci., vol. 1, no. 10, pp. 636-639, 2008, doi: 10.1038/ngeo325.

[4] V. Smil, "Nitrogen and food production: proteins for human diets.," Ambio, vol. 31, no. 2, pp. 126131, Mar. 2002, doi: 10.1579/0044-7447-31.2.126.

[5] S. Fields, "Global nitrogen: cycling out of control." National Institue of Environmental Health Sciences, 2004.

[6] W. Shi, B. E. Miller, J. M. Stark, and J. M. Norton, “Microbial nitrogen transformations in response to treated dairy waste in agricultural soils," Soil Sci. Soc. Am. J., vol. 68, no. 6, pp. 1867-1874, 2004.

[7] B. Krajewska, “Ureases I. Functional, catalytic and kinetic properties: A review," J. Mol. Catal. B Enzym., vol. 59, no. 1-3, pp. 9-21, 2009.

[8] S. H. Chien, L. I. Prochnow, and a H. Cantarella, "Recent developments of fertilizer production and use to improve nutrient efficiency and minimize environmental impacts," Adv. Agron., vol. 102, pp. 267-322, 2009.

[9] J. W. Ernst and H. F. Massey, "The effects of several factors on volatilization of ammonia formed from urea in the soil," Soil Sci. Soc. Am. J., vol. 24, no. 2, pp. 87-90, 1960.

[10] UN Environment, “Global Environment Outlook 4 | UNEP - UN Environment Programme," UN Environment Programme. https://www.unep.org/resources/global-environment-outlook-4 (accessed Feb. 19, 2021).

[11] E. Braun, Reactive nitrogen in the environment: too much or too little of a good thing. UNEP/Earthprint, 2007.

[12] D. W. Kweku et al., "Greenhouse effect: greenhouse gases and their impact on global warming," J. Sci. Res. reports, pp. 1-9, 2017.

[13] "Inventory of U.S. Greenhouse Gas Emissions and Sinks: 1990-2015 I Greenhouse Gas (GHG) Emissions I US EPA." https://www.epa.gov/ghgemissions/inventory-us-greenhouse-gas-emissionsand-sinks-1990-2015 (accessed Feb. 19, 2021).

[14] J. Bruinsma, “World Agriculture: towards 2015/2030: Summary Report.,” Food and Agriculture Organization of the United Nations (FAO)., 2002.

[15] P. Forster et al., "Changes in atmospheric constituents and in radiative forcing. Chapter 2," in Climate Change 2007. The Physical Science Basis, 2007.

[16] P. M. Bierman, C. J. Rosen, R. T. Venterea, and J. A. Lamb, “Survey of nitrogen fertilizer use on corn in Minnesota," Agric. Syst., vol. 109, pp. 43-52, 2012.

[17] P. Heffer and M. Prud'homme, “Short-Term Fertilizer Outlook 2011-2012," Int. Fertil. Ind. Assoc. Mimeo, 2011.

[18] A. F. Bouwman, L. J. M. Boumans, and N. H. Batjes, “Estimation of global NH3 volatilization loss 
from synthetic fertilizers and animal manure applied to arable lands and grasslands," Global Biogeochem. Cycles, vol. 16, no. 2, pp. 1-8, 2002.

[19] C. F. Drury, C. S. Tan, W. D. Reynolds, T. W. Welacky, T. O. Oloya, and J. D. Gaynor, "Managing tile drainage, subirrigation, and nitrogen fertilization to enhance crop yields and reduce nitrate loss," $\mathrm{J}$. Environ. Qual., vol. 38, no. 3, pp. 1193-1204, 2009.

[20] P. R. Nash, P. P. Motavalli, and K. A. Nelson, "Nitrous oxide emissions from claypan soils due to nitrogen fertilizer source and tillage/fertilizer placement practices," Soil Sci. Soc. Am. J., vol. 76, no. 3, pp. 983-993, 2012.

[21] P. Wali, V. Kumar, and J. P. Singh, "Effect of soil type, exchangeable sodium percentage, water content, and organic amendments on urea hydrolysis in some tropical Indian soils," Soil Res., vol. 41, no. 6, pp. 1171-1176, 2003.

[22] W. D. Gould, F. D. Cook, and G. R. Webster, "Factors affecting urea hydrolysis in several Alberta soils," Plant Soil, vol. 38, no. 2, pp. 393-401, 1973.

[23] S. G. Sommer, J. K. Schjoerring, and O. T. Denmead, “Ammonia emission from mineral fertilizers and fertilized crops," Adv. Agron., vol. 82, no. 557622, pp. 82004-82008, 2004.

[24] W. L. Hargrove, "Soil, environmental, and management factors influencing ammonia volatilization under field conditions," Ammon. volatilization from urea Fertil. Alabama NFDC, TVA, vol. 2, pp. 17-36, 1988.

[25] G. L. 1979 Terman, "Volatilization losses of nitrogen as ammonia from surface-applied fertilizers, organic amendments, and crop residues," Adv. Agron., vol. 31, pp. 189-223, 1980.

[26] M. Ferm, "Atmospheric ammonia and ammonium transport in Europe and critical loads: a review," Nutr. Cycl. Agroecosystems, vol. 51, no. 1, pp. 5-17, 1998.

[27] H. Cantarella et al., "Ammonia volatilisation from urease inhibitor-treated urea applied to sugarcane trash blankets," Sci. Agric., vol. 65, no. 4, pp. 397-401, 2008.

[28] P. C. O. Trivelin, M. W. de Oliveira, A. C. Vitti, G. J. de C. Gava, and J. A. Bendassolli, “Perdas do nitrogênio da uréia no sistema solo-planta em dois ciclos de cana-de-açúcar," Pesqui. Agropecuária Bras., vol. 37, no. 2, pp. 193-201, 2002.

[29] W. A. R. Cabezas, G. H. Korndorfer, and S. A. Motta, “Volatilização de N-NH3 na cultura de milho:: II. avaliação de fontes sólidas e fluidas em sistema de plantio direto e convencional," Rev. Bras. Ciência do solo, vol. 21, no. 3, pp. 489-496, 1997.

[30] V. P. Aneja et al., “Ammonia Assessment from Agriculture: U.S. Status and Needs,” J. Environ. Qual., vol. 37, no. 2, pp. 515-520, 2008, doi: 10.2134/jeq2007.0002in.

[31] M. Zaman and J. D. Blennerhassett, "Effects of the different rates of urease and nitrification inhibitors on gaseous emissions of ammonia and nitrous oxide, nitrate leaching and pasture production from urine patches in an intensive grazed pasture system," Agric. Ecosyst. Environ., vol. 136, no. 3-4, pp. 236-246, 2010.

[32] EPA, "Reactive Nitrogen in the United States: An Analysis of Inputs, Flows, Consequences, and Management Options. United States Environmental Protection Agency (EPA).," no. August, 2011.

[33] F. Paulot and D. J. Jacob, "Hidden cost of U.S. agricultural exports: Particulate matter from ammonia emissions," Environ. Sci. Technol., vol. 48, no. 2, pp. 903-908, 2014, doi: 10.1021/es4034793.

[34] S. Liu, J. J. Wang, Z. Tian, X. Wang, and S. Harrison, “Ammonia and greenhouse gas emissions from a subtropical wheat field under different nitrogen fertilization strategies," J. Environ. Sci., vol. 57, pp. 
196-210, 2017.

[35] W. M. Alley, Regional ground-water quality. John Wiley \& Sons, 1993.

[36] B. Z. Houlton et al., "Intentional versus unintentional nitrogen use in the United States: trends, efficiency and implications," Biogeochemistry, vol. 114, no. 1, pp. 11-23, 2013.

[37] O. E. Sala et al., "Global biodiversity scenarios for the year 2100.," Science, vol. 287, no. 5459, pp. 1770-1774, Mar. 2000, doi: 10.1126/science.287.5459.1770.

[38] R. W. Pinder, E. A. Davidson, C. L. Goodale, T. L. Greaver, J. D. Herrick, and L. Liu, "Climate change impacts of US reactive nitrogen," Proc. Natl. Acad. Sci., vol. 109, no. 20, pp. 7671-7675, 2012.

[39] R. V O'Neill, A. R. Johnson, and A. W. King, "A hierarchical framework for the analysis of scale," Landsc. Ecol., vol. 3, no. 3, pp. 193-205, 1989.

[40] K. J. Donham, "The concentration of swine production. Effects on swine health, productivity, human health, and the environment.," Vet. Clin. North Am. Food Anim. Pract., vol. 16, no. 3, pp. 559597, 2000, doi: 10.1016/S0749-0720(15)30087-6.

[41] A. da S. Cardoso et al., "Seasonal effects on ammonia, nitrous oxide, and methane emissions for beef cattle excreta and urea fertilizer applied to a tropical pasture," Soil Tillage Res., vol. 194, no. December 2016, p. 104341, 2019, doi: 10.1016/j.still.2019.104341.

[42] E. Mariano, C. R. de Sant Ana Filho, R. Bortoletto-Santos, J. A. Bendassolli, and P. C. O. Trivelin, "Ammonia losses following surface application of enhanced-efficiency nitrogen fertilizers and urea," Atmos. Environ., vol. 203, no. May 2018, pp. 242-251, 2019, doi: 10.1016/j.atmosenv.2019.02.003.

[43] D. Hellström, E. Johansson, and K. Grennberg, "Storage of human urine: acidification as a method to inhibit decomposition of urea," Ecol. Eng., vol. 12, no. 3-4, pp. 253-269, 1999.

[44] N. Adam, J. L. Mitchell, and K. D. Pickering, “Development of low-toxicity urine stabilization for spacecraft water recovery systems," 2012.

[45] M. Ikematsu, K. Kaneda, M. Iseki, and M. Yasuda, "Electrochemical treatment of human urine for its storage and reuse as flush water," Sci. Total Environ., vol. 382, no. 1, pp. 159-164, 2007.

[46] W. De Vries, J. Kros, C. Kroeze, and S. P. Seitzinger, “Assessing planetary and regional nitrogen boundaries related to food security and adverse environmental impacts," Curr. Opin. Environ. Sustain., vol. 5, no. 3-4, pp. 392-402, 2013, doi: 10.1016/j.cosust.2013.07.004.

[47] C. M. Clark and D. Tilman, "Loss of plant species after chronic low-level nitrogen deposition to prairie grasslands," Nature, vol. 451, no. 7179, pp. 712-715, 2008.

[48] R. Bobbink et al., "Global assessment of nitrogen deposition effects on terrestrial plant diversity: a synthesis," Ecol. Appl., vol. 20, no. 1, pp. 30-59, 2010.

[49] S. P. Seitzinger, C. Kroeze, A. F. Bouwman, N. Caraco, F. Dentener, and R. V Styles, "Global patterns of dissolved inorganic and particulate nitrogen inputs to coastal systems: Recent conditions and future projections," Estuaries, vol. 25, no. 4, pp. 640-655, 2002.

[50] R. J. Diaz and R. Rosenberg, "Spreading dead zones and consequences for marine ecosystems," Science (80-. )., vol. 321, no. 5891, pp. 926-929, 2008.

[51] J. H. Guo et al., "Significant acidification in major Chinese croplands," Science (80-. )., vol. 327, no. 5968, pp. 1008-1010, 2010.

[52] G. L. Velthof et al., "Nitrogen as a threat to European soil quality - Chapter 21." pp. 495-510, 2011, 
Accessed: Feb. 19, 2021. [Online]. Available: https://research.wur.nl/en/publications/nitrogen-as-athreat-to-european-soil-quality-chapter-21.

[53] A. Syakila and C. Kroeze, "The global nitrous oxide budget revisited," Greenh. gas Meas. Manag., vol. 1, no. 1, pp. 17-26, 2011.

[54] WHO (World Health Organization), “Global Health Observatory Map Gallery,” 2011, [Online]. Available: https://www.who.int/data/gho/map-gallery.

[55] J. W. Erisman et al., "Consequences of human modification of the global nitrogen cycle," Philos. Trans. R. Soc. B Biol. Sci., vol. 368, no. 1621, p. 20130116, 2013.

[56] R. Van Dingenen, F. J. Dentener, F. Raes, M. C. Krol, L. Emberson, and J. Cofala, “The global impact of ozone on agricultural crop yields under current and future air quality legislation," Atmos. Environ., vol. 43, no. 3, pp. 604-618, 2009.

[57] D. Shindell et al., "Simultaneously mitigating near-term climate change and improving human health and food security," Science (80-. )., vol. 335, no. 6065, pp. 183-189, 2012.

[58] A. R. Ravishankara, J. S. Daniel, and R. W. Portmann, "Nitrous oxide (N2O): the dominant ozonedepleting substance emitted in the 21st century," Science (80-. )., vol. 326, no. 5949, pp. 123-125, 2009.

[59] R. W. Portmann, J. S. Daniel, and A. R. Ravishankara, "Stratospheric ozone depletion due to nitrous oxide: influences of other gases," Philos. Trans. R. Soc. B Biol. Sci., vol. 367, no. 1593, pp. 1256-1264, 2012.

[60] European Environment Agency, European environment - state and outlook 2015: Assessment of global megatrends. 2015.

[61] B. A. Zurweller, P. P. Motavalli, K. A. Nelson, and C. J. Dudenhoeffer, "Short-term soil nitrous oxide emissions as affected by enhanced efficiency nitrogen fertilizers and temporarily waterlogged conditions," J. Agric. Sci., vol. 7, no. 12, p. 1, 2015.

[62] P. R. Nash, K. A. Nelson, and P. P. Motavalli, “Corn response to drainage and fertilizer on a poorly drained, river bottom soil," Agron. J., vol. 107, no. 5, pp. 1801-1808, 2015.

[63] K. Sundberg, “What does household wastewater contain?," 1995. [Online]. Available: https://www.naturvardsverket.se/Documents/publikationer6400/978-91-620-8704-3.pdf?pid=13165.

[64] H. Jönsson, T.-A. Stenström, J. Svensson, and A. Sundin, “Source separated urine-nutrient and heavy metal content, water saving and faecal contamination," Water Sci. Technol., vol. 35, no. 9, pp. 145-152, 1997.

[65] J. Hanæus, D. Hellström, and E. Johansson, “A study of a urine separation system in an ecological village in northern Sweden," Water Sci. Technol., vol. 35, no. 9, pp. 153-160, 1997.

[66] L. Rodhe and S. Johansson, "Ammonia emission and nutrient utilization from urine using different techniques for application," Jordbrukstek. Inst., 1996.

[67] M. Alexander, "Introduction to soil microbiology," Soil Sci., vol. 125, no. 5, p. 331, 1978.

[68] M. I. Zantua, L. C. Dumenil, and J. M. Bremner, “Relationships between soil urease activity and other soil properties," Soil Sci. Soc. Am. J., vol. 41, no. 2, pp. 350-352, 1977.

[69] V. Kumar and R. J. Wagenet, “Urease activity and kinetics of urea transformation in soils," Soil Sci., vol. 137, no. 4, pp. 263-269, 1984.

[70] R. R. Sharpe and L. A. Harper, "Soil, plant and atmospheric conditions as they relate to ammonia volatilization," in Nitrogen Economy in Tropical Soils, Springer, 1995, pp. 149-158. 
[71] S. G. Sommer and A. K. Ersbøll, "Soil tillage effects on ammonia volatilization from surface-applied or injected animal slurry," Wiley Online Library, 1994.

[72] K. Ni, A. Pacholski, and H. Kage, "Ammonia volatilization after application of urea to winter wheat over 3 years affected by novel urease and nitrification inhibitors," Agric. Ecosyst. Environ., vol. 197, pp. 184-194, 2014, doi: 10.1016/j.agee.2014.08.007.

[73] W. Zerulla et al., “3, 4-Dimethylpyrazole phosphate (DMPP)-a new nitrification inhibitor for agriculture and horticulture," Biol. Fertil. soils, vol. 34, no. 2, pp. 79-84, 2001.

[74] D. Abalos, A. Sanz-Cobena, T. Misselbrook, and A. Vallejo, "Effectiveness of urease inhibition on the abatement of ammonia, nitrous oxide and nitric oxide emissions in a non-irrigated Mediterranean barley field," Chemosphere, vol. 89, no. 3, pp. 310-318, 2012.

[75] A. D. Halvorson, C. S. Snyder, A. D. Blaylock, and S. J. Del Grosso, “Enhanced-efficiency nitrogen fertilizers: Potential role in nitrous oxide emission mitigation," Agron. J., vol. 106, no. 2, pp. 715-722, 2014.

[76] L. Yang, S. Zhang, Z. Chen, Q. Wen, and Y. Wang, "Maturity and security assessment of pilot-scale aerobic co-composting of penicillin fermentation dregs (PFDs) with sewage sludge," Bioresour. Technol., vol. 204, pp. 185-191, 2016, doi: 10.1016/j.biortech.2016.01.004.

[77] J. T. Brown, “Evaluation of a solid-liquid manure separation operation.” University of Missouri-Columbia, 2018.

[78] J. Lorimor, W. Powers, and A. Sutton, "Manure Characteristics," Iowa State Univ. MidWest Plan Serv., pp. 1-24, 2004.

[79] S. G. Lupis, N. Embertson, and J. G. Davis, “Best Management Practices for Reducing Ammonia Emissions: Lagoon Covers - 1.631B - Extension," Colorado State University Extension. https:/extension.colostate.edu/topic-areas/agriculture/best-management-practices-for-reducingammonia-emissions-lagoon-covers-1-631b/ (accessed Mar. 24, 2021).

[80] J. A. Lory, G. Davis, D. Steen, B. Li, and C. Fulhage, “Calculating Plant-available Nitrogen and Residual Nitrogen Fertilizer in manure," 2007. Accessed: Mar. 26, 2021. [Online]. Available: https://extension.missouri.edu/publications/g9186.

[81] M. J. O'Neil, “The Merck index : an encyclopedia of chemicals, drugs, and biologicals. - NLM Catalog - NCBI," Royal Society of Chemistry (Great Britain), 2013.

https://www.ncbi.nlm.nih.gov/nlmcatalog/101609748 (accessed Mar. 20, 2021).

[82] R. Quinn, “DTN Retail Fertilizer Trends,” Progressive Farmer, DTN, Feb. 17, 2021. https://www.dtnpf.com/agriculture/web/ag/crops/article/2021/02/17/dap-urea-prices-surge-21-lastmonth (accessed Mar. 22, 2021).

[83] "Sulfuric Acid Price Market Analysis - Echemi," ECHEMI. https://www.echemi.com/productsInformation/pid_Rock19440-sulfuric-acid.html (accessed Mar. 22, 2021). 


\section{VITA}

Ali Taleghani was born in Tehran, Iran. He loves reading books, watching movies, hiking, and biking in his spare time. He also took several dance classes including east and west coast swing and ballroom dances at Mizzou. Besides, he has taken acting classes in his undergrads for two years and played in several plays.

After his basic school, he was accepted in an exam of the National Organization for Development of Exceptional Talents and continued his school there. He graduated from the Iran University of Science and Technology (Top 5 nationwide universities in Iran) in 2009 with a B.Sc. in Civil Engineering. During this time, he was able to cover a wide range of design and construction science, infrastructures, transportation engineering, hydrology and hydraulic systems, environmental engineering, water, and wastewater design at the Department of Civil and Environment within the university. Then, he obtained his PE and worked as a civil engineer for almost four years as a project manager and construction supervisor of more than 14 projects. Later, he started the M.Sc. program in Environmental Engineering at the Sharif University of technology (Leading engineering university in Iran) which was completed in 2014. The main focus of his research during his master was exploring the transport of emerging contaminants in multiphase environments as well as producing activated carbon derived from agricultural residues to remove heavy metals in the industrial wastewater, assisting with the treatment process. Then, sorption isotherm was assessed and the effect of temperature and concentration of pollutants such as metals and organic compounds was evaluated. Besides, he has learned the mathematical modeling of nanofluids via various software. He learned dispersion modeling of contamination in water sources, air pollution, risk management and GIS. To expand his knowledge as an environmental engineer, he joined the lab of Dr. Teng Lim at the University of Missouri to complete his Ph.D. 
During his tenure there, he investigated biological wastewater treatment via bench-scale anaerobic digesters to remove veterinary antibiotics due to the enormous volume of antibiotics used annually in the animal industry in the US. Furthermore, he researched a real-size farm project to preserve ammonia-N content of liquid manure and convert it into organic fertilizer in Versailles, Missouri. 